




\section{UNTERSUCHUNGEN \\ ÜBER}

\section{GASTRULATION UND EMBRYOBILDUNG}

\section{BEI DEN CHORDATEN}

VON

FR. KOPSCH

I. DIE MORPHOLOGISCHE BEDEUTUNG DES KEINHAUTRANDES UND DIE ENBRYOBILDUNG BEF DER FORELLE

MIT 10 LI'THOGRAPHISCHFN TAFELN UND 18 ABBILDUNGEN IM TEX'T

TERLAG TON GEORG THIEME 
Druck ron C. Grumbach in Leipzig. 

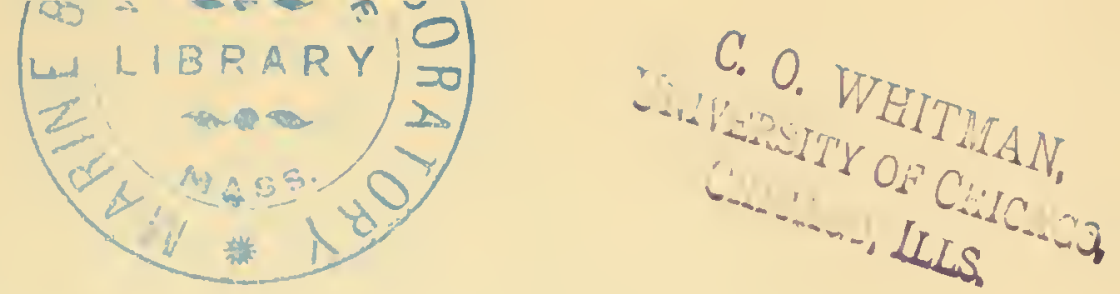

\section{Inhaltsïbersicht.}

I. Vorwort

Seite

II. IIistorischer Teil . . . . . . . . . . . . . . . . . 3

(Die Ansichten über die morphologische Bedeutung des Keimhautrandes und über die Embryobildung bei Knochenfischen und Selachiem von C. Vogt an bis zum Jahre 1898.)

A. Vorbemerkungen . . . . . . . . . . . . . . . . . 3

B. Allgemeine Übersicht . . . . . . . . . . . . . 3

C. Erster Abschnitt (von C. Vogt, 1842, bis W. His, 1874) •. . 4

D. Zweiter Abschnitt (von W. His, 1874, bis 1898) . . . . . 10

E. Zusamucufassung . . . . . . . . . . . . . . . 33

Teleostiel . . . . . . . . . . . . . . . . . 33

Selachier . . . . . . . . . . . . . . . 36

F. Fragestellung . . . . . . . . . . . . . . . . . . 37

III. Material und Methoden . . . . . . . . . . . . . . . . . 38

IV. Deskriptiver 'T'eil . . . . . . . . . . . . . . . . . . . 46

A. Operationen

1. Operationen am Randring bei schon vorhandenem Knnopf

a) Operation nul auf einer Seite

a) auf älterem Stadium

Embryo I . .

$\beta$ ) auf jüngerem Stadium

Operationsstelle $45^{0}$ rom Knopf entfernt

Embryo II . . . . . . . . . . . . . . . . 52

Embryo III . . . . . . . . . . . . . . 56

Embryo IV . . . . . . . . . . . . . . . . . 59

Embryo V . . . . . . . . . . . . . . . 62

Embryo VI . . . . . . . . . . . . . 66

Operationsstelle $90^{\circ}$ vom Knopf entfernt

Embryo VII . . . . . . . . . . . . . . 68

Operationsstelle $180^{\circ}$ vom Knopf entfernt

Embryo VIII . . . . . . . . . . . . . 69

Embryo IX . . . . . . . . . . . . 70

Embrro $\mathrm{X}$. . . . . . . . . . . . . 71

b) Operation an beiden Randringhälften

Embryo XI . . . . . . . . . . . . . . . 72 
c) Operation am Knopf selbst

Seite

Embrro XII . . . . . . . . . . . 73

Embrт̣o XIII . . . . . . . . . . . . . 74

2. Operationen am Randring ror Bildung des Knopfes . . . . . . 75

a) Operation seitlich neben der Mittellinie

Embrтo XIT . . . . . . . . . . . . 76

Embrro XT . . . . . . . . . . . . . . 80

Embrro XVI . . . . . . . . . . . 81

Embrro XYII. . . . . . . . . . . . 83

Embryo XVIII. . . . . . . . . . . . 85

Embryo XIX . . . . . . . . . . . 85

b) Operationen in der Mittellinie

a) rollständiges Fehlen des Embrros

Embrronen XX-XXIT . . . . . . . . . 87

$\beta$ ) Spaltbildungen

Embrтo XXY . . . . . . . . . . . . . . 88

Embryo XXTI . . . . . . . . . . . 90

3. Bildung des Embrjos bei unterbliebener Cmrachsung des Dotters

Embrro XXTí . . . . . . . . . . . 95

B. Tolumenberechnungen . . . . . . . . . . . . . . 9 96

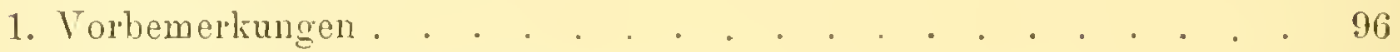

2. Methotik der Untersuchung . . . . . . . . . . . . . 9 98

3. Übersicht der untersuchten Stadien . . . . . . . . . . 102

4. Volumenbestimmungen . . . . . . . . . . . . . . . . 102

a) an Keimscheiben, welche sich im Begim der Ausbreitung befinden und die untere Keimschicht erst an einem kleinen Teil des Randes gebildet haben . . . . . . . . . . . . . . 10:

b) an Kieimscheiben, bei welchen die untere Keimschicht schon an der ganzen Peripherie oder an ihrem grössten Teil rorhanden ist 105

c) an Keimscheiben, welche zwischen den Stadien I und II ron Fr. Kopseh stehen . . . . . . . . . . . 107

d) an Keimscheiben, welche den Stadien $I^{r}, V_{\text {ron }} F r$. Kopsch entsprechen . . . . . . . . . . . . . . . 109

e) an Embryonen bei Dotterlochschluss, welche etwits iilter sind als Stadium X von Fr. Kopseh. . . . . . . . . . . 115

5. Ergebnisse der Yolumenberechnungen . . . . . . . . . . 119

\section{Ergehnisse}

A. Die Ausbreitung des Keims über den Dotter . . . . . . 122

1. Über die Wachstumsrichtung des Embres . . . . . . . . . 124

2. Die Úmwachsung des Dotter's . . . . . . . . . . . . . 124

B. Bildungud Längenwahstum des Embryos. . . . . . 146

VI. Literaturverzeichuis. 


\section{Vorwort.}

Die folgende Arbeit ist der erste Teil einer Untersuchungsreihe, mit welcher ich seit dem Jahre 1893 beschäftigt bin und welche mit der sogenannten Gastrulation des Froscheies beginnend, allmählig immer weitere Ansdehnung gewann, da es sich immer deutlicher herausstellte, dass ohne eine auf eigenen Untersuchungen gegründete Kenntnis von der Entwicklung der bekanntesten und infolge ihrer leichten Zugänglichkeit am häufigsten untersuchten Vertreter der einzelnen Wirbeltierklassen eine kritische Sichtung und richtige Würdigung der besonders auf dem Gebiete der Gastrulation und Embryobildung sich unvermittelt gegeniiberstehenden Meinungen nicht zu erreichen ist.'

Mit den bisher am meisten angewendeten Methoden der Beobachtung des lebenden und des Zerlegens des abgetöteten Materials sind bei unserem Gegenstande zwingende Beweise weder nach der einen noch nach der anderen Seite bisher beigebracht worden; vielmehr hat die Zahl der in grösserem oder geringerem Grade voneinander abweichenden Ansichten sich mit der Zunahme der Arbeiten mehr und mehr vergrössert.

In Ermanglung einer bisher noch nicht untersuchten Spezies, an welcher vielleicht manche der streitigen Punkte hätten erledigt werden können, bleibt es nur übrig, mit neuen Methoden an die Bearbeitung des schon oft untersuchten Materials heranzugehen.

Eine solche ist das Experiment, welches sich in jüngster Zeit bei der Untersuchung von Entwicklungsvorgängen als äusserst wertvolles Rüstzeug erwiesen hat. Es ist für unsere Zwecke am besten geeignet.

Da nun aber viele Zeit notwendig ist, eine geeignete Versuchsanordnung ausfindig zu machen, und neben einer genauen Kenntnis der normalen Entwicklung (aus eigner Anschaung und aus dem Studium der Literatur), eine ausreichende Erfahrung über Beschaffung und Behandlung des Materials erworben werden muss, so wird man es verstehen, warum ich erst jetzt eine zusammenhängende und ins einzelne gehende Darstellung eines Teils meiner Untersuchungen reröffentliche. 
Nachdem nunmehr meine Arbeiten an Amphioxus, Knochenfischen, Selachiern, Amphibien, Vögeln zu einem gewissen Abschluss gebracht sind, glaube ich mit gutem Gewissen die Versuche an Knochenfischeiern und die aus diesen Tersuchen gezogenen Schliisse den Fachgenossen in abgeschlossener Form darbieten zu dïrfen.

In der Darstellung werden die Schilderung der tatsächlichen Verhältnisse und die Deutungen streng auseinauder gehalten werden, erstens um dem Leser und den Nachuntersuchern die Erkenntnis zu erleichtern, was beobachtet und was geschlossen ist, zum anderen, weil die sicher beobachteten Tatsachen in alle Zeit bleiben, die Gesichtspunkte aber, unter denen wir sie betrachten, fortdauernd wechseln. 


\section{Historischer Teil.}

(Die Ansichten über die morphologische Bedeutung des Keimhautrandes und über die Embryobildung bei Knochenfischen und Selachiern von C. Vogt an bis zum Jahre 1898).

\section{A. Vorbemerkungen.}

Die Grundlagen für die morphologische Deutung des Keimhautrandes sind: 1. der histologische Bau, bei welchem das Hauptgewicht auf den Nachweis der beiden primären Keimblätter und des Mesoderms sowie auf die Art ihrer Entstehung zu legen ist, 2. sein Schicksal während der Umwachsung des Dotters, d. h. die Art seiner Verwendung am Aufbau der Embryonalanlage und des Dottersackes.

Da die Aufgabe dieser Arbeit in der Untersuchung des zweiten Punktes besteht, so sollen in dem folgenden historischen Abschnitt nur die in der Literatur iiber die Funktion des Keimhautrandes und die Entstehung, sowie das Wachstụm der Embryonalanlage vorhandenen Meinungen nebst den dafür angeführten Gründen zusammengestellt werden.

Bei dieser Darstellung erwies es sich als zweckmässig, ausser den Teleostiern noch die Selachier in den Kreis der Betrachtung zu ziehen, sowohl mit Rücksicht auf die Konkrescenzlehre, welche durch die bei Selachiern augenfällige Evidenz besonders gestiitzt wurde, als auch, weil die einfacheren Verhältuisse der Selachierentwicklung von jeher zur Erklärung der schwieriger zu deutenden Knochenfischentwicklung benutzt wurden.

\section{B. Allgemeine Übersicht.}

Innerhalb des oben bezeichneten Zeitraumes (1842-1898) können wir zwei Abschnitte unterscheiden: der erste ron 1842-1874, der zweite von $1874-1898$.

Die Forscher des ersten Abschnittes sind im wesentlichen damit beschäftigt, in deskriptiver Weise die rein formalen Verbältnisse bei der Entstehung des Embryos und seiner Organe zu beschreiben. Das Aussehen des zelligen Randringes auf den einzelnen Stadien wird festgestellt und sein Zusammenhang mit der Embryonalanlage wird erkannt. Zellenbewegungen 
und Zellenverschiebungen werden als Ursachen der Massenumlagerungen, welche bei der Embryobildung und der Dotterumwachsung stattfinden, in Auspruch genommen. Das Studium der Missbildungen gewährt wertvolle Aufschlüsse.

Der Übergang zum zweiten Abschnitt wird durch die Arbeiten von $\mathrm{H}$ is gegeben, in denen versucht wird nachzuweisen, dass der Embryo durch Aneinanderlagerung der beiden Randringhälften entsteht. Zum Beweis hierfür werden von anderer Seite (Rauber, Ryder) bestimmte Missbilclungen herangezogen, welche nicht mehr als Curiosa, sondern als von der Natur angestellte Experimente betrachtet werden.

Die epochemachende Bedeutung der $\mathrm{H}$ isschen Auffassung liegt — wie mir scheint - in der ausserordentlich einfachen Weise, in welcher nunmehr die Embryobildung der Wirbeltiere und der Wirbellosen auf dieselben Vorgänge zuriickgeführt werden konnte, nachdem durch die Gastraeatheorie die Homologie der beiden primären Keimblätter und der Gastrula aller Metazoen, wenn auch nicht vollkommen bewiesen, so doch ausserordentlich wahrscheinlich gemacht worden war.

So handelte es sich denn für die späteren Untersucher der Knnochenfischund Selachierentwicklung darum, Stellung zu nehmen zu der neuen Lehre, welche auch ron Gegnern $[R$ abl (72) $]$ als eine der wichtigsten Theorien über den Aufbau des Wirbeltierkörpers bezeichnet worden ist. Eine endgültige Entscheidung wurde aber nicht erreicht. Erst mit den experimentellen Untersuchungen von Kastschenko, Morgan und mir sind einige streitige Punkte erledigt worden, dabei aber neue Probleme aufgetancht, welche noch der Lösung harren.

\section{Erster Abschuitt.}

(Von C. Vogt 1842 bis W. His 1874.)

C. Vogt (94) ist der erste, der - bei Coregonus Palaea - den Zusammenhang vou Fmbryo und Keimhautrand eingehender beschreibt, und die Torgänge bei der Bildung der Embryonalanlage zu ergrïnden sucht. Den verdickten Rand der Keimscheibe hat vor C. Vogt schon K. E. vo n B a er (3) bei Cyprinus blicca und Cyprinus erythrophthalmus gesehen, doch kommt seine Beschreibung hier nicht weiter in Betracht, da er sich über die Bedeutung und die weiteren Schicksale des Keimhautrandes nicht äussert.

C. Vogt beschreibt das hintere Ende eines Embryos mit noch ziemlich grossem Dotterloch und sagt, es hätte den Anschein, als ob die Rückenwïlste (carènes) sich in den Randring fortsetzen (94, S. 47).

Die bei der Bildung der Embryonalanlage in kurzer Zeit stattfindenden Formänderı ngen des Keimes werden aut Zellenbewegungen zurückgeführt, 
ohne dass aber die Möglichkeit ausgeschlossen würde, dass diese Änderungen etwa durch plötzliche Bildung zahlreicher Zellen an einer Stelle und Zugrundegehen an einer anderen hervorgebracht würden; ein Vorgang, der eine Zellenbewegung vortäuschen könnte (S. 42, 43). Dass ihm jedoch am wahrscheinlichsten die Bildung des Embryos durch Umlagerung des Zellenmaterials war, geht hervor aus anderen Stellen (S. 38, 45) z. B. wenn er bei der Beschreibung eines älteren Stadiums sagt, dass die embryonalen Zellen nunmehr sämtlich um die embryonale Achse angesammelt wären.

Die Vorstellung, dass sich die Zellen des Keimes zusammenziehen, wird von A ubert (2) bei der Beschreibung der Hechtentwicklung an einer Stelle klar ausgesprochen (S. 99); an einer anderen bleibt dieser Punkt unentschieden. Als Beweis für die Zellenbewegung wird die Tatsache angeführt, dass die Zellen an dem der Embryonalanlage gegenüberliegenden Abschnitt der Keimscheibe immer dünner und sparsamer werden. Zu einer bestimmten Vorstellung ist dieser Autor aber nicht gelangt, denn „die erste Spur des Embryos" lässt er entstehen entweder durch "eine Zusammenziehung, oder Häufung, oder Wucherung der Keimzellen" (S. 99).

Über das Schicksal des Keimhautrandes, welcher "den Rand des Keimes bildend, wie zwei Arme oder Spangen um den Dotter" läuft und mit dem hinteren Ende der Embryonalanlage zusammenhängt, spricht sich A ubert deutlich aus: Die Spangen ziehen sich gegen den Embryo hin zurück und verschwinden später spurlos; ,sie sind die Reste des Embryo werdenden Keims" (S. 101).

Über den Modis der Dotterumwachsung und die hierbei wirksamen Kräfte erfahren wir nichts näheres; die Ausbreitung des Keimes bei der Umwachsung wird mit dem Zerfliessen einer auf einer Kugel liegenden Masse verglichen.

Eine ganz eigenartige, aber nicht einheitliche, Auffassung über das Verhältnis zwischen Embryonalanlage und Randring wird ron Lereboullet (58-61) entwickelt, der eine andere Verwendung des Randringes bei der Entstehung von Missbildungen annimmt, als es bei der normalen Entwicklung der Fall ist.

Er hat vier Mitteilungen $(1854-1863)$ iiber die Entwicklung von Hecht, Barsch, Forelle veröffentlicht. Die ersten drei handeln von der normalen Entwicklung der genannten Fische; in der letzten werden eine Anzahl verschiedener Missbildungen von Hechtembryonen beschrieben.

Seine Anschaung ist folgende: Die erste Spur der Embryonalanlage entsteht als eine Zellenanhäufung von dreiseitiger Form, welche direkt mit dem Randring zusanmenhängt und von demselben hervorgebracht ist ["produktion" (61, S. 253)]. Diese Zellenanhäufung, welche als "germe embryonnaire" und "poussée du bourrelet" (S. 255, Anm. 1) bezeichnet 
wird, rerlängert sich bei der normalen Entwicklung und bildet den Embryo, während der Randring den Dotter umwächst und die Schwanzanlage enthält. Bei den (später von O ellacher als Mesodidymi, von Rauber als Hemididymi bezeichneten) Spaltbildungen dagegen wächst die erste Spur der Embryonalanlage, der Vorstoss des Randringes, nicht aus zur Bildung des Embryos, sondern bleibt klein und bildet nur das rorderste Ende der Missbildung. Die beiden Rumpfhälften entstehen dann dadurch, dass der Randring selbst zum Sitz der Arbeit wird, welche zur Bildung des Embryos führt, und die linke, sowie die rechte Körperhälfte bildet.

Andere Missbildungen, welche nur aus dem Schwanzabschnitt bestehen, während Kopf und Rumpf fehlen, sollen dadurch entstanden sein, dass der Randring, obwohl kein „germe embryomnaire“ entsteht, doch seine „faculté organisatrice" (61, S. 265) behalten hat und nach der Dotterumwachsung noch den Sehwanz hervorbringt.

Die Worte: „Le bourrelet embryogène doit done êtro considéré comme un amas, une sorte de magasin d'éléments organisateurs, et comme le point de départ de toutes les formations embryonnaires, régulières ou anomales", mit denen Lereboullets letzte Arbeit schliesst, durrfen also nicht so gedeutet werden, wie es ron mancher Seite geschehen ist, als wenn damit gesagt wäre, dass in den beiden Randringhälften die linke und die rechte Seite des Embryos enthalten wären. Eine solche Auslegung dieses Satzes findet in der ganzen Darstellung dieses Autors keine Stiitze; rielmehr wird man mit $\mathrm{R}$ a u ber $(76, \mathrm{Bd} .71 \mathrm{~S} .159)$ sagen muissen, dass nach Lereboullet bei der Entstehung der Hemididymi der Randring für die „zurückbleibende Embryonalanlage vikariierend" eintritt, während bei normaler Entwicklung der ganze Embryo aus der ersten Anlage, dem ,germe embryonnaire" selbständig ohne Beanspruchung des Randringmaterials hervorwächst.

L e r eboullet hat also die Hemididymi nieht angesehen als ron der Natur angestellte Experimente (Hemmungsbildungen), welche zur Erklärung des normalen Geschehens verwendet werden können, - dies haben erst spätere Forscher [R a u b e r (76, Bd. $71 \mathrm{~S} .160), \mathrm{R}$ y $\mathrm{l}$ e r (82)] ausgesprochen -, er ist vielmehr der Ansicht, dass dasselbe Material des Randringes in rerschiedener Weise bei der normalen Entwicklung und bei der Entstehung der Missbildungen rerwendet wird.

Der Vollständigkeit halber müssen wir hier noch Strieker (87) erwähnen, welcher bemerlit, dass die Embryonalanlage ein Teil des Randwulstes ist (87, S. 551) und somit ,die Entwicklnng des Embryos bei den Knochenfisehen" eine "periphere" ist (S. 552) und dass der Randwulst schliesslich nach Tollendung der Unwachsung in das Schwanzende aufgeht.

Fine eingehende, durch Abbildungen erläuterte Darstellung ron den bei der Bildung der Embryonalanlage stattindenden Zellenrerschiebungen, rom 
Längenwachstum des Embryos und der Umwachsung des Dotters durch die Keimhaut gibt $\mathrm{K}$ u p fer (5t).

Die uns hier interessierenden Vorgänge werden untersucht an den Eiern von Gasterosteus aculeatus und Gobius minutus. An beiden sind die bei der Entstchung der Embryonalanlage vorhandenen Zellenverschiebungen gleich deutlich, dagegen sind die Vorgänge beim Längenwachstum des Embryos und der Dotterumwachsung am Gasterostensei viel deutlicher. Hier erscheint die Embryonalanlage schon, wenn der Keimscheibenrand $45^{0}$ vom oberen Eipol entfernt ist; bei Gobius tritt sie erst nach halber Umwachsung auf.

Die Keimhaut umwächst den Dotter in der Weise, dass der Dotterlochschluss am unteren Eipol stattfindet (54 S. 220). Die Embryonalanlage entsteht am "Keimsaum", sie nimmt in kurzer Zeit (eine Stunde bei Gobius) bedeutend an Masse zu, während am entgegengesetzten Umfang die Wulstung des Keimsaumes abnimmt; "die Hauptmasse der Zellen des Saumes zieht sich nach der Stelle hin, wo die neue Bildung ihren Ausgang nimmt" (S. 222).

Das Längenwachstum erfolgt bei Gasterosteus in zweierlei Art, erstens bis der Saum den Äquator erreicht hat), indem sein vorderes Ende nach dem oberen Pol wächst, welcher erreicht ist, wann der Saum an den Äquator des Eies gelangt ist, und zweitens (nach Überschreitung des Äquators) durch gleichmässiges Torriicken des hinteren Endes der Embryonalanlage und des Keimsaumes. Diese Torgänge sind bei Gobius etwas anders, da hier die Embryonalanlage erst auftritt, wenn die Keimscheibe schon mehr als die Hälfte der Dotterkugel bedeckt.

Die Ursachen für die Bildung des Keimsaums und die Ausbreitung der Keimhaut iiber den Dotter findet Kupffer in der Gestaltsveränderung der das Mittelfeld der Keimscheibe bildenden Zellen, welche sich polygonal aneinander legen und sich abplatten, indes die Zellen des Saumes ihre rundliche Form und lockere Lagerung und damit ihre leichte Verschiebbarkeit behalten.

Bei der Bildung der Embryonalanlage findet ausser der "Wanderung“ der Zellen „aus dem ganzen Bereich des Keimsaumes nach der Stelle der neuen Bildung“ auch wahrscheinlich noch „eine rapidere Vermehrung der Zellen in loco" statt. Das "Wandern", die "Verschiebung" spielt aber unzweifelhaft die Hauptrolle, da die „Massenverschiebung“ in äusserst kurzer Zeit, (bei Gobius nicht selten in einer Stunde) stattfindet.

Kupffer benutzt zur Bezeichnung des die Umordnung der Zellen bedingenden Vorganges bald den Ausdruck "Wanderung*;, bald spricht er vou "Verschiebung"; Ausdriicke, welche rerschiedene Auslegungen zulassen, umsomehr, als er die Kräfte nicht näher bezeichnet, welche diese Vorgänge bewirken. Es scheint aber wahrscheinlich, dass er an Massenverschiebungen 
gedacht hat und nicht an ein amöbenartiges Wandern der Keimzellen, in dem Sinne, wie es Rieneck (78) ans Schnittbildern durch Forellenkeim. scheiben erschlossen und Weil (95) an lebenden rom Dotter abgelösten und mit dem anhaftenden Teil des Dotters auf den Objektträger gebrachten Forellenkeimscheiben beobachtet hat, denen sich in gewissem Sinne auch Romiti (79) angeschlossen hat. ${ }^{1}$ )

Gegen eine solche Auffassung wendet sich Goette (15, 16), welcher die bei den Umformungen des Keims stattfindenden Zellenbewegungen nicht als Ausdruck aktiver Bewegungen der einzelnen Zellen auffasst, sondern sie bedingt sein lässt, durch Summierung der vielen kleinen Teilbewegungen, welche bei der Zellteilung durch Formänderung und Tergrösserung der Zellen gesetzt werden.

Goette behandelt nur die Entstehung der sogenannten ersten Embryonalanlage bei der Forelle; über das Iuängenwachstum des Embryos und die Ausbreitung des Keims iiber den Dotter werden keine Beobachtungen mitgeteilt. Die untersuchten Stadien fangen an mit der beginnenden Ausbreitung des Keims und reichen bis zur Ausbildung der schildförmigen Embryonalanlage. Innerhalb dieses Entwicklungsabschnittes bildet eine wichtige Marke die Entstehung der sogenannten unteren Keimschicht.

Am Randwulst der jungen Keimscheibe kann man schon ror der Bildung der unteren, durch Umschlag entstehenden Keimschicht, einen „Embryonalteil" unterscheiden von den ,für den Dottersack bestimmten Keimteil" (16, S. 693). Die Grenzen beider Abschnitte sind auf den jungen Stadien nur annähernd zu bestimmen und erscheinen erst auf dem Stadium der schildförmigen Embryonalanlage deutlicher voneinander gesondert. Der Embryonalteil ist ausgezeichnet durch die stärkere Zellenansammlung (S. 692) welche "aus einer eigentiimlich geregelten Zellenbewegung und -Ansammlung" hervorgeht (S. 698). Diese Bewegung beginnt bei der Ausbreitung des Keims, findet fortwährend statt noch während der Bildung des Umschlages und ist erst beendet zu der Zeit, in welcher die Embryonalanlage ron der ibrigen Keimhaut ganz bestimmt gesondert ist, so dass bis zu dieser Zeit „von keinem Teile des Keims, am wenigsten aber ron einer Stelle des Randwulstes, ausgesagt werden kann, dass er die Elemente jener Anlage vollständig enthalte" (S. 691, 692).

Oellacher (67) dagegen bezeichnet die dickste Stelle des Keims als erste, ,primitive" (S. 19) Embryonalanlage. Diese Stelle enth:̈lt von Anfang an das ganze Material in der späteren Lagerung, doch entsteht aus ihr nicht allein die Embryonalanlage, sondern es wird auch ein grosser 'Teil der in ihr enthaltenen Zellen zur Bildung der Keimböhlendecke verwendet.

1) Zitiert nach II is (29, S. 189. Anm. 4 und S. 218.) 
Aus dem dicken Randwulstabschnitt der „primitiven Embryonalanlage“ geht unter Vergrösserung und Vermehrung der Kellen (infolge beständiger Stoffanfnahme), sowie durch histologische Sonderung die „erste Embryonalanlage" hervor, deren äusseres Konnzeichen das Auftreten des Embryonalschildes ist. Als Beweis hierfür wird u. a. ansgeführt, dass die Durchschnitte durch den Embryonalschild schmaler sind als die durch die primitive Embryonalanlage gelegten. Der äusserste Teil der dicken Stelle der Keimperipherie ist die erste Anlage der Schwanzknospo, aus welcher der eigentliche Körper des Embryos entsteht (S. 19).

Das Längenwachstum des Embryos erfolgt durch „rege Zellenvermehrung“ (S. 49) in der Gegend der Schwanzknospe, woselbst ein "besonderer Herd“ für das "Sinnesblatt" und anch für das mittlere Keimblatt angenommen wird. Dies ergibt sich bei Betrachtung älterer Stadien aus der grösseren Mächtigkeit dieser Organe gegenüber weiter vorn gelegenen Teilen. Die Verlängerung des Embryos findet nach vorn statt, so dass die Schwanzknospe ein punctum fixum darstellt.

Infolgedessen geht die Ausbreitung der Keimhaut iiber den Dotter nicht gleichmässig nach allen Seiten vor sich und der Schluss des Dotterloches konmt nicht an entgegengesetzten Pol zustande, wie es Kupffer bei Gobius und Gasterosteus beschrieben hat, sonderu der Schluss des Dottersackes erfolgt bei der Forelle an derjenigen Stelle, an weIcher die Schwanzknospe bei ihrer ersten Entstehung lag. (Eine schematische Figur, welche ich weiter unten in Textfigur 7 abgebildet habe, erläutert diesen Vorgang).

Die Benutzung des Randringmaterials zum Aufbau der Embryonalanlage, wie es nach Kupffer bei Gobius und Gasterosteus vorkommt, dürfte für das Forellenei "nicht mit Sicherheit" zu bestimmen sein, da es schwer zu entscheiden ist, „ob die Zellen ron den Stellen, an welchen der Ḱeimsaum dünner und schmäler geworden ist, an jene Stellen, an denen er noch gleich dick oder dicker ist als vorher, sich hingeschoben haben, oder ob die Verdïnnung des Saumes bloss durch die fortschreitende Ausbreitung und Ausdehnung desselben und der Keimhaut hervorgebracht sei * denn wenn auch, wie es beim Forellenei scheint, die Ausbreitung des Keims und die Abnahme der Dicke des Saumes nicht gleichen Schritt halten, so kann man auf solche oberflächlichen Schätzungen hin keine Entscheidung mit Sicherheit treffen (S. 36, 37).

Somit hält Oellacher die Umwachsung des Dotter i. e. die Bildung des Dottersackes für die wesentlichste Funktion des Randringes.

Aus dieser Auffassung der normalen Entwicklung wendet er sich in der Arbeit uber die Terata mesodidyma (68) gegen Lereboullets Auffassung von dem vikariierenden Eintreten des Randringes (s. oben S. 6), dessen "angebliche Beobachtung der Entstehungsweise der Mesodidymi" ihm „kaum 
anders als im Lichte einer unhaltbaren Hypothese erscheinen, die auf einer Täuschung in der Beobachtung beruhen mag" (68, S. 320).

Überzeugt ron der Einheitlichkeit der Entwicklungsvorgänge unter normalen und pathologischen Bedingungen sucht Oellacher die Spaltbildungen zu erklären entweder durch eine laesio continui in einem Keimblatt oder auch durch einen anf dasselbe wirkenden Druck oder Widerstand, welcher vom Dotter ausgeht (S. 322). Über die Schwierigkeit, warum denn die Spaltung gerade immer in der Mittellinie stattfindet und nicht anch einmal seitlich davon oder quer, sncht er sich hinwegzuhelfen, indem er sagt, dass der Embryo bei einem auf seine seitlichen Teile wirkenden Druck answeichen wïrde und dass der Widerstand eines Stabes läugs seiner grossen Achse geringer sci als der, den er der kleinen Achse nach leistet.

Diesen Anschaungen Oellachers gegeniiber entscheidet sich van Bambeke (7) auf Grund seiner Beobachtungen an den lebenden kleinen Eiern ron Lenciscus rutilus ohue Beibringung nener Beweise für die von Kupffer ( 54$)$ entwickelte Auffassung, dass die Umwachsung des Dotters eine allseitig gleichmässige ist, und dass Randringmaterial in die Embryonalanlage hineingelangt.

Zum Schluss dieses Abschnittes soll noch die russisch geschriebene Arbeit Kowalerskys (51) iiber Selachier-Entwicklung genannt werden, von deren Inhalt mir nur dasjenige bekannt geworden ist, was R a uber (76, Bd. 71) und was Kowalersky selber (in seiner Arbeit iiber Ascidienentwicklung) zitiert haben. In dieser Arbeit sagt der russische Antor (52, S. 115), er habe bei Plagiostomen und Kuchenfischen den Übergang der verdickten Keimhantränder in die Medullarwiilste gesehen, während Rauber an genannter Stelle angibt, dass nach $\mathrm{K}$ owalersky die Embryonalanlage bei Mustelus und Acanthias wie cine Falte des Keimringes erscheint.

\section{Zweiter Mbschnitt.}

(Von W. His, 1874 bis 1898.)

His (24) formuliert seine Anschaunng ibber die Bildung des Lachsembryos, welche später ron anderen Autoren als Konkrescenztheorie bezeichnet und fïr alle Wirbeltierklassen nachzuweisen versucht wurde, zuerst in einem ror der natmforschenden Gesellschaft zu Leipzig am 5. Juni 1874 gehaltenen Vortrage folgendermassen:

„Die erste Spur des Embryo erscheint in der hinteren Hälfte der Keimscheibe, wenn diese einen Durchmesser ron $3 \mathrm{~mm}$ besitzt. Es ist einc klceblattförmige, rom Randwulst nach rorn abgehende Platte mit breiter lïngsgefurchter Grube, sie umfasst zu der Zeit nur die Anlage des Gchirns mnd der Angenblasen. Rasch entsteht durch seitlichen Schluss der Grube das Gehim mit seiner Gliederung und mit den flach anliegenden Angenblasen. Glcichzeitig wächst der Fmbryo nach riickwïrts durch Zusammen- 
schiebung der an den Embryo anstossenden Strecken des Randwulstes. Dabei werden die an der konvexen Seite des Wulstes liegenden Substanzmassen nach vorheriger Zusammendrängung in der Randknospe zu den Axialgebilden, die an der konkaven Seite liegenden zu den lateralen Gebilden der Rumpfanlage. Die Zusammenschiebung erfolgt unter gleichzeitiger C.mwachsung des Eies durch die Keimscheibe, und mit Vollendung der letzteren ist auch die Anlage des Rumpfes und Schwanzes beisammen."

Dieselbe Anschaunng wird in den Briefen „Unsere Körperform und das physiologische Problem ihrer Entstehung" (25) unter Beibringung von Zeichnungen einzelner Stadien (drei vom Lachs, eine von der Forelle) und Erläuterung des Umwachsungsvorganges mittels schematischer Figuren weiter ausgefiuhrt und durch eine indirekte Beweisfiuhrung zu stiitzen gesucht.

Diese ist gegründet auf die V'ergleichung der vier Stadien, ans welcher sich ergibt, dass die zuerst an der Keimscheibe auftretende Embryonalanlage nur die Anlage des Kopfes darstellt, und dass „der Rumpf sehr rasch und gleich in bestimmter Gliederung hinter dem Kopfe auftritt." Da nun bei der Annahme, dass die Rumpfanlage aus der Kopfanlage hervorgesprosst sein sollte, eine "Rapidität des IVachstums" vorausgesetzt werden müsste, welche ,völlig in Widerspruch wäre mit Allem, was wir sonst auf numerischem Wege ïber den Ablauf dieses Prozesses erfahren", so ist die Anlage des Rumpfes eben an anderer Stelle aufgespeichert, wofuir dann nur der Randring iibrig bleibt. (25, S. 188.)

Somit ist "die Uranlage des Körpers ein platter Ring, dessen Breite und Dicke an einer Stelle, dem zukiinftigen Kopfende, ein Maximum, am gegenüberliegenden, dem Schwanzende ein Minimum besitzt. Successiv legen sich ... die zwei Seitenhälften des Ringes an einander, und vereinigen sich als symmetrische Körperhälften. Dabei bedürfen das Kopfende und das äusserste Schwanzende keiner Verwachsung, weil ihre Seitenhälften ron Anfang an verbunden sind". (25, S. 189.)

Weitere Beweise, und zwar vohmetrischer Art, wurden ein Jahr später beigebracht (26). Es zeigt sich, „dass die Bildung der formellen Körperanlage wesentlich auf Umgruppierung einer bereits vorhandenen materiellen beruht" (S. 22), da das Volumen eines Lachsembryos nach eben vollendeter Umwachsung anf Grund des Rauminhaltes eines bei bestimmter ( 40 -facher) Vergrösserung hergestellten Wachsmodelles zu $0,73 \mathrm{cbmm}$, das - in derselben Weise gewonnene - Volumen einer ganzen Keimscheibe im Beginn der Embryobildung mit 0,78 cbmm bestimmt wird.

Mit einer weit vollkommeneren Methode, welche in der Anwendung planimetrischer Messungen besteht, berechnet His zwei Jahre später $(29,1878)$ die Tolumina von drei älteren Stadien - zwei jüngere werden nach anderen Methoden bestimmt - und schliesst (29, S. 209): "Wührend der ganzen Formungsperiode, d. h. vom Schluss der Furchungszeit bis zur 
rollendeten Aufreilung des Embryos bleibt das Volumen des Keimes dasselbe. Die Bildung des Embryo aus dem Keim beruht in der Umlagerung eines Materiales, welches zum Beginn der Formungsperiode in Gestalt eines flachen Klumpens vollständig beisammen war."

Die Methode besteht in der Ausmessung des Flächeninhaltes aller durch einen Embryo gelegter Schnitte der Serie mittels des Amslerschen Polarplanimeters, woraus bei Kenntnis der Schnittdicke sich das Volumen des Embryos ergibt als das Produkt aus der Summe aller Schnittflächen und der Schnittdicke.

Es wurde berechnet: 1. das Durchschnittsvolumen des Lachskeimes aus den letzten Tagen der Furchungsperiode zu $0,523 \mathrm{cbmm}$ (als Rotationskörper berechnet); 2. das Volumen eines Lachskeimes bei Beginn der Ausbreitung (Durchmesser $1,7 \mathrm{~mm}$ ) zu 0,553 cbmm (berechnet aus der Fläche der Keimscheibe und der Dicke); 3. das Volumen eines Lachskeimes (His Stad. B) ron 2,2 mm Durchmesser, etwas jünger als das Stadium der rautenförmigen Embryonalanlage [Fr. Kopsch (46) Stad. II] zu 0,546 cbmm; 4. das Volumen eines Lachskeimes (His Stadium D) von 3,2 $\mathrm{mm}$ Durchmesser [Stad. IV, V. Fr. Kopsch (46), hufeisenförmige Embryonalanlage] zu $0,548 \mathrm{cbmm} ; 5$. das Volumen eines Lachsembryos bei Dotterlochschluss zusammen mit dem Volumen der Dottersackhülle zu $0,546 \mathrm{cbmm}$.

Aus diesen Berechnungen und daraus, dass das Volumen des Kopfes der Embryonalanlage bei Dotterlochschluss demjenigen des Embryonalschildes (Stad. D. von His) entspricht, folgt, dass der Randwulst mit 0,2 cbmm Volumen „ziemlich genau den Bedarf der Rumpfanlage" deckt.

Hinsichtlich der Ursachen, welche die Keimumformung bedingen meint His im Gegensatz zu Kupffers Anschauungen -, komme man über den Gedanken aktiver Zellbeteiligung nicht hinaus, doch dürfe man dabei nicht an eigentliche "Massenauswanderungen" denken, sondern an Vorgänge mehr lokalisierten Charakters, welche wohl erklärt werden durch das Bestreben der Zellen zu "grösstmöglicher Oberflïchenentfaltung“ infolge eines Respirationsbedürfnisses.

Auch für die Selachier hatte His (27) schon im Juli 1876 auf metrischem Wege zu beweisen gesucht, dass „der Körper durch axiale Verwachsung von zwei, im Randwulste angelegten Hälften" entsteht (S. 108). Bei diesen Tieren sollen die Vorgänge bei der "Aufreihung" des Materials dadurch übersichtlicher sein als beim Lachs, dass sie schon lange vor Beendigung der Dotterumwachsung ihr Ende erreichen. Zugleich liegt ein Unterschied zwischen Selachiern und Knochenfischen darin, dass die Schwanzanlage bei den ersteren jederseits etwas iiber die Mitte der Keimscheibe hinaus d. h. dort liegt, wo der Randwulst in seinen dïnneren Abschnitt ausläuft; as dariiber hinausliegt. wird zum Schlussrande des Dottersackes. 
Als Beweise werden hier angefuihrt: 1. die unmittelbare Evidenz; 2. die grössere Wahrscheinlichkeit; 3, der feinere Bau des Randwulstes.

Uber den ersten Punkt braucht man nicht weiter zu sprechen, denn man kann die Evidenz für und wider die Hissche Anschauung ins Feld führen (Rabl 72, H. Virchow 93).

Der zweite Beweis ist gegründet auf die durch Messungen gewonnene Erkenntnis, dass innerhalb einer bestimmten Entwicklungsperiode ein Längenwachstum des segmentierten Rumpfes gar nicht vorhanden ist. Diese Erkenntnis wird gewonnen durch die Vergleichung entsprechender Stücke eines Embryos von Scyllium catulus mit 4 Ursegmenten und eines Embryos von Pristiurus mit 27 Ursegmenten. Die Länge der vier Ursegmente des Scyllium-Embryos entspricht genau der Länge der vier ersten Ursegmente des Pristiurus-Embryos. Wenn man nun annimmt - wie Balfour -, dass das Längenwachstum des Embryos von dem unsegmentierten Stiick ausgeht, so kommt man zu dem Ergebnis, dass „eine Strecke, die soeben noch im lebhaftesten Wachstum begriffen war, mit einem Male stille steht, sowie sie in den Abgliederungsbereich gelangt" (S, 117). Dies erscheint His als „Unwahrscheinlichkeit", zu welcher noch die Unmöglichkeit kommt, es „zu verstehen, wie der Rumpf aus einem rasch wachsenden und einem verschwindend wenig rasch wachsenden Stück bestehen kann, ohne dass in der Breitenausdehnung ein Unterschied bemerkbar ist". "Ein .... sehr geringes Massenwachstum wird dagegen beansprucht, sowie es sich herausstellt, dass die Substanzanlage des Rumpfes und Schwanzes im verbreiterten Teile des Randwulstes aufgespeichert ist" (S. 117).

Beim dritten Beweise wird an der Hand von Schnitten gezeigt, dass der Randwulst schon lange vor der achsialen Verwachsung denselben Bau zeigt, welcher jeder Hälfte der Embryonalanlage zukommt, und wie sich aus der Verwachsung der beiden Randringhälften die Konfiguration des hinteren Endes der Embryonalanlage mit Leichtigkeit erklärt.

Beinahe gleichzeitig nit His war Rauber (75) durch Studien am Hühnchen zu denselben Anschauungen über die Bildung der Embryonalanlage gekommen. Er suchte dann den Vorgang der achsialen Verwachsung als einen für alle Wirbeltierklassen gelteuden nachzuweiseu, was auch $\mathrm{H}$ is schon in der Arbeit über die Bildung der Haifischembryonen (27) angedeutet und in den Untersuchungen über die Bildung des Hiihnerembryos (28) eingehender ausgeführt hat.

Weiter ergänzen Raubers Darstellungen die von His entwickelten Anschauungen erstens nach der morphologischen Seite hin, indem der Verwachsungsvorgang als Urmundschluss gedeutet wird, zweitens bringen sie einen neuen Beweis, indem die von Lereboullet und Oellacher beschriebenen Hemididymi als Hemmungsbildungen betrachtet und als von der Natur angestellte Experimente zur Erklärung des normalen Geschehens ver- 
wendet werden $(75$, S. 17,18$)$. Drittens werden als Ursachen der bei der Entwicklung stattfindenden Formänderungen vier "Grundfunktionen" der ontogenetischen Entwicklung erkannt (Zellvermehrung, Zellvergrösserung, Zellwanderung, Zelldifferencierung).

Raubers Auffassung von der Entwicklung des Knochenfischembryos und der Dotterumwachsung ist in klarer Weise ausgesprochen in der Arbeit "Formbildung und Formstörung in der Entwicklung der Wirbeltiere" (77), in welcher eine Anzahl Missbildungen - darunter mehrere Hemididymi von Hecht, Lachs, Forelle, Salmling beschrieben werden. Sie ist folgende:

Nach Beendigung der Furchung beginnt allmählich eine Vorschiebung und Ausbreitung der Zellenmassen iiber die Dotterkugel, zugleich bildet sich der Randwulst oder Keimring. Derselbe ist aber von seiner ersten Bildung an nicht überall von gleicher Mächtigkeit, sondern am mächtigsten an der Stelle, an welcher später die "vordere Embryonalanlage" auftritt. Diese ist die Anlage des Kopfes. Die weitere Ausbreitung des Keimes ist eine ungleichmässige (77, Bd. VI, S. 27): „Ein Teil des durchgefurchten Zellenmateriales von excentrischer Lage erleidet die geringste centrifugale Verschiebung durch geringstes Flächenwachstum, während das übrige Zellenmaterial cine grössere ${ }_{w}$ Terschiebung durchzunachen hat, durch stïrkeres Flächenwachstum. Das stärkste Flächenwachstum und die grösste Terschiebung des Zellenmateriales liegt dem Orte der geringsten Verschiebung und des geringsten Flächenwachstums gerade gegeniiber.... Zwischen beiden extremen Stellen folgen nun alle Abstufungen der Bewegung oder der Grösse des Flächenwachstums. Die Stelle der geringsten Flächenbewegung wird zur vorderen Embryonalanlage, die der grössten zur hinteren, die der zwischenliegenden Stufen zur mittleren Fmbryonalanlage. Denn es ist klar, sowie eine Stelle der Keimzellenmasse relativ Ruhe bewahrt, während die iibrigen in allmählicher Abstufung beschleunigte Berregung besitzen, muss ein bilateral-symmetrischer Längsstreifen von Substanz sich ansammeln, welcher mit seiner Achse in einem Meridian liegt."

Unter vorderer Embryonalanlage versteht Rauber die Anlage des Kopfes, die mittlere Embryonalanlage ist die des Rumpfes, die hintere diejenige des Schwanzes.

Während His bisher nur den Rumpf durch achsiale Verwachsung entstehen lässt während der Kopf sowie das äusserste Schwanzende keiner Verwachsung bedürfen, hat Rauber aus der Beobachtung zweier Spaltbildungen (Forelle und Salmling), bei welchen die Tremunng der beiden Körperhälften sich bis in das Gebiet der Augenblasen erstreckt, die Auffassung gewonnen, dass die gesamte vordere Embryonalanlage ihrer Entstchung nach ebenso wie die mittlere und hintere als ein besonders sich differenzierender, morphologisch aber der ïbrigen Embryonalanlage gleichwertiger Keimringteil zu betrachten ist. 
Die Hissche Lehre wurde zunïchst von einigen Forschern mit Freuden begriisst, wolche sich mit der Entwicklung von wirbellosen Tieren beschäftigten (Semper 86, Hatschek 18, 19, C. O. Whitman 98).

Bei vielen Wirbellosen ist die Tatsache, dass am Schluss der Gastrulation eine mediane Verwachsung der Blastoporusränder stattfindet, ganz unzweifelhaft, und der Nachweis eines ähnlichen Vorganges bei den Wirbeltieren konnte nur dazu dienen, die Idee von dem genetischen Zusammenhang der Wirbeltiere und der Wirbellosen nunmehr auch durch den Nachweis der Gleichartigkeit in der Entstehung des Embryos zu unterstützen, zu einer Zeit, in welcher dieser Zusammenhang soeben in der Gastraeatheorie Häckels, sowie in Sempers, von Kowalevskys, Dohrns Arbeiten ausgesprochen war.

Es wird darum nicht wunderbar erscheinen, dass alle Eorscher, welche sich seither mit frühen Entwicklungszustïnden der Fische beschäftigten, Stellung nahmen zu der Hisschen Lehre, so dass es nicht zu viel gesagt ist, wenn wir von der epochemachenden Bedeutung derselben sprechen. In diesem Sinne hat sich ein hervorragender Gegner der Hisschen Lehre noch kürzlich ausgesprochen, indem er sie bezeichnet als eine der wichtigsten Theorien über den Aufbau des Wirbeltierkörpers, welche, solange es überhaupt eine Entwicklungsgeschichte gibt, aufgestellt worden sind. (Rabl 72, S. XII).

Überblickt man nun die Literatur und gruppiert man die Autoren, welche aus eigener Anschaumg iiber die Embryobildung von Knochenfischen und Selachiern urteilen, so sieht man, dass die Zahl der Gegner der $\mathrm{H}$ isschen Lehre ïberwiegt, was $\mathrm{H}$ is auf der Anatomischen Versammlung zu München selber ausgesprochen hat (30, S. 74).

Im Folgenden wird erstens eine Gegenüberstellung der Autoren gegeben, welche in dieser Frage sich nach der einen oder anderen Seite entschieden haben. Eine zweite Gruppe enthält diejenigen Forscher, welche nicht Partei ergriffen haben.

I.

Für Konkrescenz.

W. His.

Kupffer.

Rauber.

Balfour.

Agassiz u. Whitman.

C. K. Hoffmann.

Ryder.

Kollmann.

H. E. Ziegler.

Cunningham.

Goronowitsch.

Rückert.

Fed. Raffaele.

Miecz. v. Kowalewski.

Edw. E. Prince.

Locy.

Henneguy.

Kastschenko.

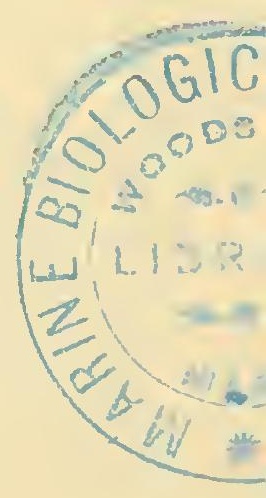


Eigenmann.

Eycleshymer.
C. Rabl.

Wilson.

Sedgwick.

Morgan.

H. Tirchow.

Fed. Raffacle.

H. K. Corning.

Fr. Kopsch.

J. Jablonowski.

II.

Perenyi.

K. F. Wenckebach.

Schwarz.

Clapp.

Koehler und Bataillon.

Eine solche Gegeniiberstellung könnte unnötig erscheinen mit Riicksicht darauf, dass es (vgl. H. Virchow 93, S. 632) nicht darauf ankommt Stimmen zu zählen, sondern die beigebrachten Griinde zu prüfen; sie ist aber trotzdem sehr lehrreich und es regt zu eigenartigen Betrachtungen an, wenn man sieht, dass die Hälfte der Hisschen Anhänger Amerikaner sind, und dass unter den Gegnern eine Anzahl hervorragender Embryologen rertreten sind.

Indem wir nunmehr zu unserem Thema zuriickkehren, sollen zuerst die Anschauungen, welche sich bei den Gegnern der Hisschen Theorie über die Embryobildung und die Umwachsung des Dotters finden, dargestellt werden, wobei auch die Angaben derjenigen Forseher gewïrdigt werden, welche zwar nicht selber Partei ergriffen haben, deren Beobachtungen aber gegen die Konkrescenzlehre sprechen, während die dieser Lehre giinstigen Beobachtungen von Perenyi und Clapp bei der Schilderung der Konkrescenz-Anhänger ihren Platz finden.

Kupffer (55) sieht gegeniiber der Hisschen Anschauung ,gar keinen Grund", seine 1868 geäusserte Meinung zu ändern; er hat an lebenden Heringseiern, welche infolge ihrer gegenseitigen Lagerung fixiert waren, das Torschreiten des Randringes beobachtet und ausserdem ron einem fixierten Stichlingsei in Zwischenräumen ron je einer halben Stunde eine Reihe von mikrophotographischen Aufuahmen machen lassen, und dann an den Bildern die Lage des Keimhautrandes zu bestimmten festen Punkten der Eihaut festgestellt.

Aus diesen beiden Beobachtungen hat er sich überzengt, „dass sowohl am Fie des Herings, wie des Stichlings die Umwachsung ron 
Anbeginn bis nach Überschreitung des Äquators in allseitig gleichmässiger Weise ror sich geht". (S. 212.)

Gegen Ende der Umwachsung kann möglicherweise - weil dann die Beobachtung schwieriger ist - eine Abwcichung von den parallelen Torrücken des Randringes stattfinden, crscheint aber nicht wahrscheinlich, da der Embryo bei den beiden untersuchten Formen im "Momente des Abschlusses" der Umwachsung $180^{\circ}$ der Eikugel umspannt. Kupffer gibt zu, dass beim Lachs, dessen Embryo nach His nur etwas mehr wie $90^{\circ}$ bei Dotterlochschluss bedeckt, die Verhältnisse anders liegen können, doch muss erst noch bewiesen werden, dass das Kiopfende des Salmoniden-Embryos einen festen Punkt darstellt, wie es His annimmt. Er kann sich der Konkrescenzlehre "keineswegs" anschliessen, und driickt die Verschiedenheit seiner und der Hisschen Anschaumg aus wie folgt (55, S. 212):

"Ich nehme eine Zellenbewegung innerhalb des Randwulstes an, die gegen die Stelle der Embryonalanlage gerichtet derselben das Material liefert, nach His fände eine solche Verschiebung oder Anziehung der Zellen in der Richtung der Embryonalanlage innerhalb des Wulstes nicht statt, sondern die Hälften des Wulstes bewegten sich in toto gegeneinander. Demnach wïrden sich also Kopf und Hinterende in ganz anderer Weise bilden als der mittlere Teil des Rumpfes. Der Kopfteil wäre schon vorgebildet, das den hinteren Teil des Rumpfes und den Schwanz enthaltende Hinterende wächst erst hervor, nachdem der Randwulst verschwunden ist, der Mittelrumpf allein entstiinde durch Aneinanderlagerung getrennter Hälften. Schon diese Erwägung diirfte geeignet sein, Bedenken einzuflössen. Ferner meine ich, steht und fällt diese Theorie mit dem Gelingen und Misslingen des Nachweises einer ungleichmässigen, resp. durchaus einseitigen Ausbreitung der Keimhant. Dass dieser Nachweis nicht geführt ist, habe ich oben bemerkt, dass im Gegenteil an Eiern, die zu einer präzisern Untersuchung geeigneter sind, als die grossen, sich langsam entwickelnden des Lachses, ein gleichmässiges Vorschreiten des Randwulstes dargetan werden könne. Bewegt sich der Randwulst parallel seiner ursprïnglichen Stellung iiber die Dotterkugel hin, so umspannt derselbe bis zım Äquator des Eies stetig grössere Parallelkreise und es nicht einzusehen, wie sich dabei seine beiden Hälften aneinanderlegen sollten."

"Der anderen Anschaunng, die ich vertreten habe, steht nichts im Wege. Die direkte Beobachtung ergibt an den meisten Eiern (vom Lachsei sehe ich lieber ab) nicht mehr, als dass die Embryonalanlage eingeleitet werde durch eine Verdïnnung des Randwulstes auf der einen und eine Verdickung auf der andern Seite. Ersteres kann bedingt sein durch zwei Vorgänge, nehmlich durch die stetig fortschreitende Ausdehnung der Keimhaut und eine gleichzeitige Bewegung der Zellen in äquatorialer Richtung nach der anderen Hälfte hin; letzteres durch dieselbe Zellenverschiebung und eine 
gesteigerte Zellenvermehrung in loco. Wahrscheinlich findet beides statt, in welchem Masse aber das Eine und das Andere zur Geltung kommt, lässt sich nicht entscheiden. Mit der Annahme einer Zellenbewegung in bestimmter Richtung wird aber gar kein nenes Monent in die Betrachtung eingefiihrt, denu die Ausbreitung des Keims zur Keimhant erfolgt ja anch durch Bewegung der Zellen, ohue dass man einen äussern Zug oder Druck als Ursache zu entdecken vermag." (S. 2 22, 203).

Ein Jahr nach Abschluss dieser Arbeit veröffentlichte Kupffer zusammen mit B en e ck e seine Untersuchungen am Reptilienei, woselbst er die innerhalb der Keimscheibe gelegene Finstïlpung zum ersten Mal eingehend beschrieb und den Torgang ihrer Bildung als Gastrulation deutete. Er war der Meinung, dass das durch die Einstiilpung entstandene Entoderm zum Epithel der'Allantois werde.

Num hatte er schon frïher bei den Knochenfischen nach dem „äusseren Eindruck" die ron den späteren Autoren sogenannte Kupffersche Blase als Allantois bezeichnet und sucht nunmehr zu ermitteln, ob diese Blase etwa auch "durch Einstiilpung von der Oberfläche des Blastoderms entstehe" (56, S. 596).

Diese "Toraussetzung" wird denn auch beim Hecht (56) und beim Stint (57) bestïtigt, bei denen er in kurzer Entfernung vom Keimscheibenrande eine Einstiilpung fand, und ebenso bei der Forelle, wo er die auf dem Stadium der rautenförmigen Embryonalanlage auftretende Grube (57, S. 9) als Gastrula-Einstiilpung erklärt.

Diese Tatsachen mussten in hohem Masse einwirken anf die Auffassung des Randringes und die Deutung der Umwachsung. Letztere kaun nichts mehr mit der Gastrulation zu tun haben, zumal da am Rande des Blastoderms weder der Umschlag des Entoderms noch die Bildung des Mesoderms erfolgt, noch auch das Dotterloch etwa in Beziehung steht zur Bildung des neurenterischen Kanals. Die Ausbreitung des Blastoderms iiber den Dotter ist vielmehr die Blastulabildung. - Dass Kupffer aus diesen Auschauungen heraus die Hissche Lehre noch mehr zuriickweisen muss, als er es schon friiher getan hat, liegt auf der Hand. - Der Randring rollführt nur die Umwachsung des Dotters, die ihn zusammensetzenden Zellen drängen sich bei Dotterlochschluss in die Anlage des Schwanzes zusammen. Die Schwanzknospe Öllacher's ist ein Rudiment, „das vielleicht seine Erklärung in dem Abriicken der Invaginationsöffnung rom Blastodermrande findet und als Homologon der Raphe hinter dem Prostoma der Elasmobranchier anfzufassen wïre" (57, Jahrg. 1884, S. 35).

Gegen diese Beobachtungen und Deutungen wurde alsbald von rerschiedenen Seiten cuergisch Einspruch erhoben (Henneguy [20], Goronowitsch [17], H. E. Ziegler [101]).

Weder Henneguy noch Goronowitsch haben bei Petrachtung der Oberflächenbilder und Schnittserien ron der Forelle, in keinem Stadium, von dem Erscheinen der Embryonalanlage an bis zum Schluss des Dotterlochs 
etwas ron eincl Invagination, wie sie Kupffer beschreibt, gesehen und meinen, dass die dafür gehaltenc Grube dic erste Anlage der Medullarrinne darstellt. Der beim Hecht und Stint gesehene Kanal, welcher in die Kupffersche Blase führt, scheint Henneguy nur die Homologie dieser Gegend mit derjenigen des Canalis neurentericus zu beweisen, sodass die Schwanzknospe der Krnochenfische dem Primitivstreifen der höheren Wirbeltiere entspricht. Dieser Auffassung schliessen sich Ziegler und sein Schiiler Schwarz (84) an.

Dagegen wird die frihere bei Gasterosteus, Gobius, Clupea von Kupffer gegebene Schilderung der Embryobildung von einer grossen Zahl Autoren im wesentlichen angenommen. (C. K. Hoffmann, H. E. Ziegler, Goronowitsch, List, Wilson). Fine etwas abweichende Auffassung, eine Kombination der Öllacherschen und der Kr upfferschen Anschaumg vertreten Miecz. von Kowalewski, Henneguy.

Nach C. K. Hoffmanns erstem Teil (35) umspannt der Forellenembryo bei eben vollendeter Dotterumwachsung $180^{\circ}$ der Dotterkugel. Diese Tatsache wird in dem $\mathbf{K}$ upferschen Sinne gegen $\mathrm{H}$ is verwendet. In dem zweiten Teil der Arbeit, welche etwas später erschien, gibt er jedoch zu (35, 1882 S. 4), dass er sich mit den $180^{\circ}$ geirrt habe und dass der Forellenembryo zu der genannten Zeit nur $145^{\circ}$ bis $150^{\circ}$ umspannt. Tatsächliche Beweise für den Kupfferschen Umwachsungsmodus werden aber nicht angefüht, sonderu er wird erschlossen, 1. daraus, dass der Embryo $145^{\circ}$ bis $150^{\circ}$ der Dotterkugel umspannt; 2. dass die Embryonalanlage bei ihrem ersten Auftreten schon mehrere Grade vom oberen Keimpol entfernt ist; 3. dass das Dotterloch gegen Schluss der Umwachsung nicht immer kreisrund ist, sondern auch elliptisch sein kann, was für eine Abweichung von dem parallelen Torwachsen des Keimringes spricht.

H. E. Ziegler (100) kann sich „der Ansicht von His über die Bildung des Embryonalleibes" nicht anschliessen. Die Annahme Öllachers, dass die Schwanzknospe ein Punctum fixum sei, wird als ,ganz willkürlich" verworfen. Dagegen findet $\mathrm{K}$ upffers Anschauung ihre Bestätigung an dem länglichen Ei von Rhodeus amarus, bei welchem die Achse des Dotters imp̣er "unzweifelhaft festgelegt" ist. Bei diesen Eiern liegt die Keimscheibe vor ihrer Ausbreitung iber dem oberen Eipol. Während der ganzen Umwachsung bis gegen das Ende verläuft die Ebene des Keimhautrandes senkrecht zur Längsachse des Dotters. Erst am Schluss der Umwachsung tritt eine Asymmetrie in der Art ein, dass das Dotterloch nicht genau am unteren Pol, sondern etwas von demselben nach der Seite der Embryonalanlage verschoben, sich schliesst. Hieraus folgert Ziegler, "dass die Ausbreitung. der Keimscheibe bei allen Knochenfischen eine allseitige sei, dass sie aber ron einem fiir die einzelnen Spezies verschiedenen Stadium ab im embryonalen und im nicht embryonalen Teil nimmer gleichförmig bleibe." 
Goronowitsch (17) ist der Meinung, dass anch bei den Salmoniden sich bis zum Stadium der hufeisenförmigen Embryonalanlage [Stad. IV Fr. Kopsch (46)] direkte Beobachtungen anstellen lassen, welche die Annahme einer allseitig gleichmässigen Umwachsung rechtfertigen. Dazu benutzt er das gegenseitige Lagerungsverhältnis der verdickten Randteile des Parablasts $(H$. Tirchows Rand-Syncytium) zu dem verdiunten Zentralteil. Er glaubt auf Medianschnitten rerschiedener Stadien nachweisen zu können, dass die Entfernung dieser beiden Parablastabschnitte wïhrend der Ausbreitung des Keims rorne und hinten gleich ist. Da nun das Lagerungsverhältnis des Keimscheibenrandes zu dem Rand-Syncytium ein festes ist und der Zentralteil während der ganzen Lmwachsung dem Zentrum der Keimscheibe entspricht, so ergibt sich mit Notwendigkeit, dass die Ausbreitung der Keimscheibe eine allseitig gleichmässige ist. Dabei entfernt sich auch der Kopf des Embryos immer weiter rom Zentrum der Keimscheibe, sodass die „unmotivierte Ansicht von $\mathrm{His}$, dass das Kopfende des Salmoniden-Embryo bei der Beurtcilung des Ganges der Umwachsung des Dotters als unbeweglich zu betrachten sei" (17, S. 429) nicht stichhaltig ist. Goronowitsch nimmt an, „dass die Schliessung des Dotterloches beim Lachs nicht, wie His meint, weit entfernt rom unteren Pol, sondern in unmittelbarer Nähe desselben stattfindet". Die Verlängerung des Embryos erfolgt durch Zuwachs vom hinteren Ende her, wo „der centrale Teil des hinteren Achsenstranges als ein Termehrungsherd von Zellen aufzufassen ist" (17, S. 392).

Bei Esox und Chondrostoma geschieht der Beginn der Umwachsung in der von Kupffer bei Gobius beschriebenen Weise. Der Gesamtrerlauf der Ausbreitung wird nicht geschildert.

Abweichend jedoch von Kupfers Ansicht ist die Darstellung, welche Goronowitsch gibt ron der Bildung des Embryonalschildes bei Chondrostoma; er betrachtet ihn nicht als sekundären Auswuchs des Randringes, sondern als „eine Anlage, die während des Ganges der Umwachsung sich allmählig ausgebildet hat" (S. 432).

List (62), dessen Arbeit wertrolle Zeit- und 'Temperatur-Angaben iiber die Entwicklnng der untersuchten Labrideneier enthïlt, beobachtet 5 verschicdene Crenilabrus-Arten im lebenden und im konservierten Zustande.

Die Umwachsung erfolgt bis gegen das Ende lin allseitig gleichmässig, so dass das Dotterloch am unteren Eipol liegt. Dann aber wird durch stärkeres Wachstum der Endknospe das wie ein Nadelstich erscheinende Dotterloch vom unteren Dotterpol weggedrüngt, sodass es etwas entfernt ron demselben sich schliesst.

Hinsichtlich der ersten Anlage des Embryos ist eine kleine Verschiedeuheit gegenüber Gobius, Gasterosteus, Clupea vorhauden, indem sie hei Crenilabrus nicht ausscbliesslich vom Keimsclieibenrande ausgeht und gegen den oberen Pol hin auswiichst, sondern auf eimmal rom Keimscheiben- 
rand bis gegen den oberen Dotterpol reichend auftritt, was jedoch auch hier auf Zellenverschiebungen beruht.

Miecz. von Kowalewski (53) vereinigt in gewissem Sinne die Anschauung Oellachers mit der Kupffers und führt damit eine neue, bisher noch nicht vertretene Auffassung von der Umwachsung ein. Er will zwar nicht bestreiten, dass die Umwachsung bei verschiedenen Teleostiern in verschiedener Weise vor sich geht, doch stimmt seine Vorstellung von diesem Prozess, wie er ibn sich nach den Befunden an lebenden und konservierten Goldfischeiern, sowie an, aus Triest stammenden, pelagischen (konservierten) Eiern von ellipsoidischer Form gebildet hat, weder mit der Anschauung von Kupffer, noch der von $\mathrm{His}$, noch der von Oellacher überein. Von dem Triester Material standen ihm drei Stadien zur Verfügung: ein Stadium anscheinend gegen Ende der Furchung, das zweite ungeführ halbe Umwachsung, das dritte mit einem Embryo, welcher schon so lang ist, dass er um das Ei gekrümmt, beinahe den ganzen Umfang desselben einnimmt, also schon weit nach Dotterlochschluss entwickelt ist.

Aus der Vergleichung dieser drei Stadien "scheint" (S. 466) hervorzugehen, dass die Umwachsung nach dem Schema Oellachers vor sich geht, aber mit dem Unterschied, dass „der hintere Blastodermrand nicht vom Anfang an fixiert wird, sondern eine kurze Zeit beweglich bleibt, indem er eine kleine Strecke noch weiter nach hinten rückt, und erst dann in seiner Lage weiterhin festgehalten wird." Derselbe Umwachsungsvorgang soll dann auch bei den Eiern von Carassius auratus vorhanden sein; auch in den Eiern von Makropoden soll er "scheinbar" ebenso vor sich gehen (S.468).

Diesen Angaben gegenüber geht aus den Zeichnungen Wenckebach s (97) der ellipsoidischen Eiern von Engraulis encrassicholus hervor, dass der Kopf in loco liegen bleibt, das Längenwachstum des Embryos nach hinten stattfindet und der Dotterlochschluss nicht genau am unteren Pol, sondern etwas nach der Seite der Embryonalanlage verschoben ist.

In anderer Weise tritt Balfour in seinem Handbuche der vergleichenden Embryologie (6) der Hisschen Anschauung entgegen.

In bezug auf die Selachierentwicklung hatte er schon vorher (5), ohne in weitere Erörterung einzutreten gegenüber den Erklärungen von $\mathrm{His}$, an seinen früheren Beobachtungen und Schlüssen festgehalten, dass die Kaudallappen von Anfang an das Schwanzende des Embryos vorstellen und dass das Längenwachstum des embryonalen Körpers durch Einschiebung neuer Somiten am Hinterende vor sich geht wie bei den Chaetopoden.

In seinem Handbuch sucht er bei Besprechung der Prinzipien des Längenwachstums der Wirbeltierembryonen die Hissche Theorie, welche "wenn richtig, jedenfalls sehr bedeutungsvoll wäre," dadurch ad absurdum zu führen, dass er ihre letzten Konsequenzen vorführt (Bd. II S. 274, 276). 
Er weist hin anf den ventral stattfindenden Dotterlochschluss, woraus folge, dass bei Ammahme der Hisschen dorsalen Längsnaht "die ganzə dorsale, sowie die ganze ventrale Leibeswand des Embryos durch die Verwachsung der Blastoporuslippen gebildet werden müsste, was offenbar eine Reduktio ad absurdu ${ }^{1}$ ) der ganzen Theorie ist."

Den von $H$ is und $R$ auber beigebrachten Beweisen legt er kein grosses Gewicht bei; ja die von His beigebrachten Maasse scheinen ihm nur zu beweisen, dass das Wachstum des Embryos durch Einschiebung neuer Somiten zwischen das letztgebildete Somit und das hintere Körperende vor sich geht. Die Tatsache, dass der verdickte Blastodermrand mit der Medullarfalte zusammenhängt, lässt sich weder für, noch gegen die $\mathrm{H}$ issche Auffassung verwerten, da ja bei der Randständigkeit des Embryos seine Medullarplatte mit dem Blastodermrand zusammenhängen muss. "Überdies diirfte man, wenn die Verwachsungstheoric richtig wäre, erwarten, dass die verwachsenden Blastodelmränder einen spitzen TVinkel miteinander bildeten, was keineswegs zutrifft." Ferner weist Balfour zum ersten Male hin auf die Bedeutung, welche der Bildung des neurenterischen Kanals zukommt bei Betrachtungen iiber das Längenwachstum des Embryos. Sobald nämlich der canalis neurentericus gebildet ist, ,ist es offenbar umöglich geworden, dass irgend eine weitere Längenzunahme durch Verwachsung stattfindet." TVemn nun vor Bildung dieses Kanals der Embryo wirklich durch Verwachsung entstünde, so wiirde der grössere hintere 'Teil desselben durch Ḱnospung entstehen, worin aber eine grosse Schwierigkeit liegt. Auf die vou Rauber aus den Spaltbildungen gezogenen Schlïsse geht Balfour nicht ein.

Die angeführten Betrachtungen beweisen: „erstens, dass die von His und Rauber angezogenen Unstände keineswegs von grossem Gewicht sind und zweitens, dass das Längenwachstum des grösseren Teils des Körpers durch Einschiebung neuer Somiten am Hinterende vor sich geht wie bei den Chatopoden, so dass es im höchsten Grade überraschend wäre, wenn ein kleiner mittlerer Körperabschnitt auf ganz andere Weise wachsen solltc.:

Aus der vergleichenden Entwicklungsgeschichte lassen sich die Zustände bei Amphioxus ins Feld fiihren, dessen Blastoporus anfänglich genau am hinteren Körperende liegt und erst später „noch eben bis an die Dorsalseite" hinaufrückt.

Weiter weist Balfour lin auf Kupffers Beobachtungen bei Gobius, Gasterosteus, Clupea und schliesst: „Je eingehender man die Theorie von His und Rauber im Lichte der vergleichenden Embryologie prift, desto unhaltbarer erweist sie sich; es lässt sich vielmehr als völlig sicheres Ergebnis eines vergleichenden Studiums der Entwicklung der Wirbelticre der Satz aufstellen, dass der Rlastoporus derselben urspriinglich am Hinterende des

1) Bei Balfour kursiv gedruckt. 
Körpers liegt, dass er sich aber infolge der Ausbildung eines grossen Nahrungsdotters in den meisten Fïllen auch ïber einen grösseren oder kleineren Teil der Ventralseite ansdehnt."

Während so Balfour aus der Betrachtung des normalen Längenwachstums und aus den Tatsachen der vergleichenden Entwicklungsgeschichte die Hissche Lehre zuriuckweist, wobei er einen Teil der von $\mathrm{H}$ is beigebrachten Maasse gegen dessen Anschauung ausnutzt, was die betreffenden Messungen zur Entscheidung der Frage des Lüngenwachstums nicht gerade sehr eindeutig erscheinen lässt, gelangt Henneguy (21), dessen Arbeit zu den besten gehört, was iiber Knochenfischentwicklung bis dahin geschrieben ist, bauptsïchlich auf dem von $\mathrm{His}$ eingeschlagenen Wege der Messungen zu eiuer Zurückweisung der Verwachsungslehre.

Henueguys Messungen sind nur metrischer Art; er sucht durch Vergleichung der Längenmaasse einzelner Körperabschnitte jüngerer und älterer Stadien (vor Dotterlochschluss) die Gegend zu bestimmen, an welcher das Längenwachstum des Embryos stattfindet.

Zuerst wird nachgewiesen, dass die Entfermung des ersten Ursegments ron der Kopfspitze bei Embryonen ron 3, 6, 22 Somiten 1,0, 1,0, 1,1 mm betrïgt (S. 587). Daraus folgt, dass das zuerst gebildete Ursegment auch das erste bleibt, wofür auch seine gleichbleibende Lagebeziehung zum Gehörbläschen spricht. Weiter wird nachgewiesen, dass die Länge des Stiickes hinter dem hinteren Rande der Kupfferschen Blase und dem vorderen Ende der Schwanzknospe annähernd dieselbe bleibt. Da nun die einmal abgegliederten Ursegmente keine neuen erzengen und durch direkte Beobachtung die beginnende Abgliedlerung neuer Ursegmente am vorderen Ende des unsegmentierten Stiickes zu erkennen ist, so kann die Ver]ängerung des embryonalen Körpers nur stattfinden in dem zwischen dem letaten abgegliederten Ursegment und der Kupfferschen Blase gelegenen Stück, weil die letztere durch alle Entwicklungsstadien ihre gleichmässige Entfernung vom hinteren Ende des Knopfes behält und sich nicht nach vorn verschiebt, wie es der Fall sein muisste, wenn die Verlüngerung des embryonalen Körpers hinter ihr durch Verwachsen der beiden Randringhälften stattfände. Wenn man nun aber annehmen wollte, dass diese Vereinigung vor der Kupfferschen Blase stattfände, so wäre es schwer zu verstehen, dass sich die eben zur medianen Vereinigung gelangten Schichten des Randringes sofort in so differente Organe wie Medullarrohr, Cliorda, differenzieren sollten, wie sie in dem Gebiete vor der Kupfferschen Blase vorlanden siud. Somit wachsen Medullarrohr und Chorda durch Intussusception, während für die Möglichkeit der Bildung lateraler Teile des Embryos die Beobachtung Ryders an Elacate herangezogen werden könnte. Dass der hintere Teil des Embryos durch Anfügung des Randringes entsteht, ist nicht zu bezweifeln („indiscutable“), das folgt aus der Betrachtung des Dotterlochschlusses, bei welchem die Ränder 
des Dotterloches sich in der Medianlinie zusammenlegen und mit der Schwanzknospe eine einheitliche Masse bilden.

Nachdem nunmehr die Hissche Theorie zurückgewiesen ist, bleiben für Henneguy nur noch die von Oellacher und Kupffer geäusserten Anschauungen über das Wachstum des Embryos und die Umwachsung des Dotters iibrig. Beider Anschauungen sind mit seinen Beobachtungen vereinbar und zwar in der Weise, in welcher es Miecz. V. Kowalewski für die von ihm untersuchten ellipsoidischen Eier versucht hat.

Auch Prince (70) erklärt sich auf Grund von Untersuchungen lebender Eier dafür, dass das Kopfende in loco bleibt, das hintere Ende mit dem Randring vorrïckt und die Verlängerung des Embryos in der Rumpfregion und nicht durch Konkrescenz stattfindet.

Die auf Veranlassung von H. E. Ziegler unternommene Arbeit von Daniel Schwarz (84) iiber das Schwanzende bei Wirbeltier-Embryonen (Torpedo ocellata, Lachs, Hecht, Ente) enthält über die Umwachsung des Dotters keine Angaben. Ebenso wenig wird in derselben Stellung genommen zu den vorhandenen Anschauungen über die Bildung und das Längenwachstum des Embryos, sie liefert aber durch Feststellung der feineren Verhältnisse am hinteren Körperende (des Canalis neurentericus) weitere Beweise für die oben erwähnte Anschauung von Balfour über den Canalis neurentericus, und mag darum hier genannt sein.

Schwarz findet, dass die Oellachersche Schwanzknospe beim Lachs der definitiven Schwanzknospe der Selachier homolog ist und den Canalis neurentericus enthält. Aus dieser Feststellung können wir wohl schliessen, was Schwarz nicht ausgesprochen hat, dass von dem Auftreten der Schwanzknospe an eine Bildung des Embryos durch Konkrescenz der Keimscheibenränder unmöglich ist.

Bei den Selachiern (Scyllium, Raja) ist auch vor der Bildung des Canalis neurentericus nach Sedgwick (85) Konkrescenz ausgeschlossen. Schon auf ganz jungen Stadien sind die links und rechts neben der Incisura neurenterica gelegenen Teile des Randrings die Wachstumszonen ("growing points" 85, S. 566), welche einander parallel nach hinten auswachsen, auf älteren Stadien als Schwanzlappen über den Rand der Keimscheibe hervorragen und später zu den Seitenwiinden des Canalis neurẹtericus werden.

Die Ausbreitung der Keimscheibe geht auf jüngeren Stadien gleichmässig an allen Stellen des Randes vor sich, bis zu der Zeit, in welcher die Schwanzlappen stïker nach hinten hervorragen. Von diesem Zeitpunkt an wachsen die denselben benachbarten Randringteile langsamer als der übrige Teil des Randes.

Rabl (71) unterzieht zwei von His' Beweisen für die Verwachsung des Selachier-Embryos einer Kritik, welche mit derjenigen Balfours übereinstimmt und bringt einen neuen, bisher noch nicht geltend gemachten 
Gegenbeweis in dem Verhalten des hinteren Chordacndes bei PristiurusEmbryonen.

Trotzdem die „unmittelbare Evidenz" der Hisschen Auffassung nicht unginstig ist, haben doch Balfour und Rabl selber eine andere gewonnen. Die Maassrerhältnisse abcr sind kein neuer Bewcis, sondern nur die in Zahlen umgesctzte Evidenz. Ausserdem müsste, wonn die Hissche Anschauung zu Recht bestände, das hintere Chordaende gespalten sein; dies hat Rabl abcr niemals gefunden. Überhaupt spräche auch sonst nichts zu Gunsten einer achsialen Verwachsung der beiden Randwulsthälften (S. 128, 129).

Schon ein Jahr vor Rabl war eine Mitteilung von Kastschenko (38) erschienen, in welcher auf Grund experimenteller Eingriffe an Selachierembryonen nachgewiesen wurde, dass "das Material fuir die Bildung der Axenteile des Embryonalleibes von Anfang an nicht in den Randwülsten, sondern am hinteren Ende der Keimscheibe, d. h. dort, wo in der Tat die Formierung des Embryos vor sich geht, gelegen ist", obwohl der Autor anfangs geneigt war, veranlasst durch die Evidenz, sich für die Hissche Auffassung zu entscheiden.

Da aber auch ihm die von $\mathrm{H}$ is angeführten Beweise „nicht genug überzeugend" schienen, wollte er "sicherere" gewinnen und unternahm eine Reihe operativer Eingriffe am lebenden Embryo, deren Resultate mitgeteilt werden (S. 456).

,a) Werden die Randwïlste bei dem Erscheinen der ersten Begrenzung des Embryo (Stad. VII) neben demselben durchgeschnitten, so entwickelt sich trotzdem ein normaler Embryo, welcher das VIII. Stadium durchlaufen kann; b) wird im VII. Stadium der hintere Rand des Blastoderms zerstört, so entwickelt sich normal die vordere Hälfte des Embryo, aber die hintere Hälfte desselben fehlt (der Hisschen Theorie zufolge miisste man erwarten, dass diese letzte Operation die Entwickelung der vorderen Hälfte des Embryo, nicht aber der hinteren hindern wiirde, weil das Material für die letzte in den unbeschädigten Randwülsten gelegen sein soll) und c) wird der ganze Embryoleib mit Ausnahme des vorderen unpaarigen Höckers im Stadium VII der Länge nach in zwei Seitenhälften geteilt, so entwickelt sich jede Hälfte des Embryos einige Zeit lang unabhängig (meistens bis zum Auftreten der ersten drei Urwirbel)".

Kastschenkos Operationen haben in späteren Veröffentlichungen leider nicht die Berücksichtigung gefunden, welche sie verdienen, was wohl seinen Grund darin hat, dass ausser der kurzen eben citierten Mitteilung, welcher zudem noch Figuren fehlen, in deutscher Sprache keine ausführliche Darstellung erschienen ist.

Während Kastschenko sich so bei Selachierembryonen künstliche Marken schafft, glaubt Wilson (99) bei der Untersuchung der Eier von Serranus atrarius einen festen Punkt, auf welchen er den Embryo orientieren 
kann, in der einzigen Ölkugel zu finden, welche stets den oberen Eipol einnimmt. Ton dieser Toraussetzung ausgehend, sieht er das hintere Ende des Embryos, i. e. den Knopf, für verhältnismässig (,comparatively“) fixiert an; der Embryo wächst nach vorn. Er hat in der Entwicklung ron Serranus keine Tatsachen finden können, welche für Konkrescenz sprächen und die gewöhnlichen Grïnde, welche zu Gunsten dieses Vorgangs angeführt werden, scheinen ihm weit entfernt daron, zwingend zu sein; die einzige Tatsache, welche beachtenswert erscheint, ist die Beobachtung ron Ryder an Elacate. Das einzige Stuick des Embryos, welches durch Konkrescenz gebildet wird, ist das hinterste, hinter der Kupfferschen Blase gelegene Stück.

Während die Hissche Lehre von den Forschern, welche ähnliche Vorgïnge bei Würmern gefunden hatten, bei ihren Erscheinen freudig begrüsst, und zum Ausgangspunkt von Spekulationen über den Zusammenhang der Wirbeltiere und der Wirbellosen gemacht worden war, finden wir erst 10 Jahre später Forscher, welche auf Grund eigener Untersuchungen an Knochenfischen sich fuir die Konkrescenzlehre aussprechen.

Als erste sind zu nennen Agassiz und Whitman (1) von denen der letztere schon 1878 bei seinen Untersuchungen an Clepsine (98) die Hissche Lehre angenommen und verwertet hatte.

Die Arbeit dieser beiden Antoren habe ich in Original nicht eiusehen können und muss mich desshalb darauf beschränken, einen ron Wilson (99) wörtlich ziticrten Passus wiederzugeben, welcher lautet: „It appears quite certain to us that the principle of concrescence underlies the formation of the embryo. The concrescence appears under the disguised form of a migratory movement of the cells, wich acompanies the epibolic growth of the blastoderm".

Zu den energischsten Verfechtern der Konkrescenzlehre gehört R y d e r (82), dessen Befund an Eiern ron Elacate canada mit Unrecht so grosse Bedeutung beigelegt worden ist.

Dieser Beobachtung durfte niemand, welcher die Spaltbildungen Lereboullets und Raubers gesehen. hatte, und das Terhältuis der Kr upferschen Blase zux Chorda kennt, anch nur die geringste Bedentung als Beweismittel zuschreiben.

Ryder hat eine Anzahl ron Eiern des genannten Fisches untersucht, welche ungefähr auf dem Stadium der 23 Umwachsung waren. Der rordere Teil des Embryos ist normal ausgebildet, das hintere Stiick aber bietet einen Befund, welcher sich insofern mit einigen von Lereboullet und Ra u ber beschriebenen Missbildungen deckt, als der das Dotterloch umkreisende Randring eine Strecke weit in Ursegmente geteilt ist. Abweichend ron den bei Lereboullet und $R$ a uber mitgeteilten Fiillen ist 
aber, dass in dem Winkel, welchen die beiden Randringhälften bei ilırer Vereinigung mit dem Embryo bilden, eine Zellennasse liegt, in welcher die geschlängelte Chorda eine Strecke weit differenziert ist und die Kupferersche Blase in Gestalt eines kugehunden Blïschens vor dem hinteren Chordaende und links rou der Mittellinie liegt, so dass also Achsialgebilde des Körpers sich in der Medianlinie nach hinten fortsetzen, die Ursegmente aber im Randring enthalten sind. Das Vorhandensein der mittleren Zellenmasse erscheint ihm selber „a little puzzling" und während der Niederschrift kommen ihm Bedenken, ob das Gebilde, welches er zur Zeit der Untersuchung als Chorda angesprochen hat, sie auch wirklich ist.

Sehr einfach ist die Beweisführung vou Cun ningham (11), welcher Eier von Gadus merlangus, morrhua, aeglephinus, gurnardus und von Clupea harengus untersucht. Er argumentiert so: Der Embryo umspannt nach Dotterlochschluss $180^{\circ}$ der Eiperipherie; während der Umwachsung der Dotterkugel aber verschwindet der Randring allmählich. Da nun kein Grund dafür rorliegt, anzunehmen, dass seine Zellen wieder absorbiert werden, so ist es wahrscheinlicher ("much more probable"), dass der Embryo durch Konkrescenz der Randringhälften entsteht.

Auch Eycleshymer (13), dessen Arbeit unter Whitmans Leitung entstanden ist, lässt bei Amiurus catus und Lophins piscatorius den Embryo durch Verwachsung der Randringhälften entstehen. Grïnde fuir diese Ansicht werden jedoch nicht beigebracht.

Besonders interessant und in gewissem Sinne die Lehre von der Konkrescenz unterstiitzend, ist das Verhalten des Randringes bei Lophins piscatorius. Dasselbe ist :ihulich, wie es bei Batrachus tau ron Miss Clapp (9) beschrieben ist. Bei diesen beiden Fischen kommen lange vor Schluss des Dotterloches die beiden Randringhälften hinter dem Knopf zur medianen Tereinigung, so dass wie bei Selachiern eine Dottersacknaht entsteht und eiu sogenannter Dotterblastoporus gebildet wird. Dieses Verhalten beweist (meines Erachtens) aber noch nicht, dass auch der Embryo in derselben Weise durch Verwachsung der Keimhautränder entsteht, ebensowenig wie bei den Selachiern die Dottersacknaht den Vorgang der Nahtbildung auch für den Embryo beweist. Das Wertvolle an dieser Tatsache scheint mir zu sein, dass bei sehr dotterreichen Knochenfischeiern der Randring sich ähnlich wie bei den Selachiern verhält.

Fiir die Konkrescenz bei Selachiern haben sich Kollmann (43), R ii ckert $(80,81)$ und L o c y (4i3) ausgesprocheu.

K o 11 man n (43) betont mehrfach die Übereinstimmung seiner Ansichten mit den ron $\mathrm{H}$ is und $\mathrm{R}$ a uber geänsserten, bei Schilderung seiner Befunde an Torpedo ocellata und der Forelle. Er unterscheidet am. Raudring der Selachier, welcher als Area opaca bezeichnet wird, einen hinteren Abschnitt, in welchem das Material der Rumpfanlage gelegen ist nud einen 
vorderen, welcher die Umwachsung des Dotters ausführt. Der hintere Abschnitt tritt nach Ablauf der Gastrulation zuerst in Form einer Sichel auf, aus welcher sich durch Konkrescenz die "mittlere" und "hintere" Embryonalanlage bildet, während die „vordere“ Embryonalanlage im Bereich der Keimscheibe selber dicht vor der mittleren auftritt. Das Material zur Rumpfanlage, welches bei den Selachiern im hinteren Teil des Keimscheibenrandes "aufgespeichert" ist, .gelangt dadurch an seinen Ort, dass die Zellmassen an das hintere Ende des Embryos sich heranschieben" (S. 290). Das hintere Ende des Embryos „bleibt wie ein fixer Punkt in der Nähe des Äquators stehen, während der übrige Umw a chsungsbezirk sich über die Dotterkugeln hinwegschiebt und sich am Schwanzende des Embryos bis auf einen kleinen Rest schliesst. Das ist natürlich nur relativ zu nehmen; deun auch er rïckt vor bis zum Äquator, allein sehr langsam und nur minimal im Tergleich zu dem iibrigen Teil des Randwulstes" (S. 290, Anm. 1).

Bei den Teleostiern betrachtet Kollmann den Knopf und den unmittelbar an ihn grenzenden 'Teil des Randwulstes als Primitivstreifen. Im übrigen gilt von der Bildung der „vorderen“, „mittleren“, und "hinteren" Embryonalanlage mutatis mutandis dasselbe, was oben fiur die Selachier auseinandergesetzt ist.

R ückert glaubt annehmen zu müssen, dass bei Torpedo „ein Teil des palingenetischen Urmundrandes nachträglich in die axiale Anlage anfgenommen wird" (80) und „möchte das wenigstens von dem hinteren Abschnitte dieses Randes, in dessen Bereiche Urwirbelanlagen gebildet werden, mit ziemlicher Bestimmtheit behaupten“. Die Erklärung für diesen Vorgang sieht ex in den mechanischen Verbältnissen bei der Ausbreitung des Blastoderms iiber den Dotter, bei welcher der hintere Rand sich nicht allein riickwärts, sondern auch "medianwärts gegen die axiale Anlage des Embryo" verschiebt. Dabei tritt jedoch keine "mediane Nahtbildung" auf, "sondern die beiderseitigen Zellenmassen gehen ohne Angrenzung ineinander iiber". $\mathrm{R}$ ii ckert unterscheidet am Keimscheibenrand embryonales und ausserembryonales Peristom. Beide Abschnitte sind scharf voneinander getrennt und schliessen sich zu verschiedenen Zeiten, und unabhängig voneinander. Der embryonale Abschnitt schliesst sich zuerst und bildet den Canalis neurentericus, der ausserembryonale umwächst den Dotter und kommt gleichfalls auf der Rückseite des Eies zum Verschluss in der Dottersacknaht.

Somit bestätigt $\mathrm{R}$ iickert die $\mathrm{H}$ is sche Anschaung „fuir einen beschränkten (hinteren) Abschnitt des Embryo" (S. 155).

Auf einem anderen Wege beweist Locy (63) unter Beibringung von "geradezu abenteuerlichen" (wie H. Virchow 93, S. 636, mit Recht sagt) Figuren; die Aufuahme des Randringes in die achsiale Anlage des Embryos. Er findet bei jungen Keimscheiben von Acanthias zahlreiche primitive Neuromeren sowohl innerhalb der Embryonalanlage als auch an 
den mit ihr zusammenhïngenden Randringteilen und schliesst daraus auf die Entstehung des Embryos durch Konkrescenz der Keimscheibenränder. In der Zwischenzeit hatte $\mathrm{H}$ is (30) auf der anatomischen Versammlung zu Miuchen 1891 die Konkrescenzlehre auch auf die Amnioten zu iihertragen rersucht. Hierbei nahm er Gelegenheit, seine frïher geäusserten Anschanungen in unveränderter Weise in gedrängter Form vorzutragen und die Beweise hierfiir hintereinander aufzuzählen. Für die Terwachsung bei Selachiern führt er als nenen Beweis die von ilım bei Pristimus-Embryonen beobachtete Spaltung des hinteren Chordaendes auf - eine Tatsache, welche schon fünf Jahre rorher von Perenyi (69) bei Torpedo marmorata beschrieben worden ist.

In der sich an $H$ is Vortrag anschliessenden Diskussion bestreiten $\mathrm{Rabl}$ und $\mathrm{R}$ ï ckert das Vorhandensein einer Gabelung des hinteren Chordaendes. $\quad \mathrm{R}$ ückelt nimmt ausserdem Gelegenheit, sich über die Experimente kastschenkos zu äussern. Er habe ebenfalls, wie dieser Autor, „den Randwulst einer Seite bei Pristiurus abgetrennt, habe aber die operierten Embryonen sich bis zu einem älteren Stadium entwickeln lassen, als der genannte Forscher, und dann in der Tat eine geringere Ausbildung, resp. einen Defekt auf der operierten Seite (bei Oberflächenbetrachtung) gesehen" (81). Darum glaube er anch jetzt noch, „dass Zellenmaterial aus dem Randwulst in die axiale Anlage aufgenommen rerde".

Drei Jahre später veröffentlichte $H$ is eine Reihe von Aufsätzen (31-33), in denen er wieder Bezug nimmt anf die Konkrescenzlehre, ohne aber neue tatsächliche Beweise beizubringen.

Dagegen war anf Veranlassung von Whitman, also aus dem Kreise der Anhänger der Konkrescenztheorie herans, eine Arbeit angefertigt worden deren Ergebnisse - vor allem die auf experimentellem Wege gewonnenen die Verwachsungstheorie schwer erschiitterten.

Morgan $(65,66)$ untersucht die normale Entwicklung ron Ctenolabrus; die Experimente wurden an Funduluseiern angestellt.

In bezug auf die normale Entwicklung deckt seine Auffassung ron der Entstehung der Embryonalanlage und dem Verhalten des Randringes sich mit den von Kupffer bei Gobius, Gasterosteus, Clupea beschriebenen Vorgängen, indem er für die Bildung der Embryonalanlage Zelleıwanderungen in Anspruch nimmt. Bei der Verlängerung des Embryos findet eine achsiale Konzentration des Zellenmaterials und eine. Terschiebung desselben nach riickwärts statt, so dass das hintere Endle pari passu mit dem Keimhautrand fortschreitet. Das Material des zelligen Randringes geht zum Teil in den Embryo ïber, zum Teil wird es benutzt zur Bildung des Dottersackes, indem fortdauernd Zellen an den ausserembryonalen Teil des Blastoderms abgegeben werden. Dies ergibt sich einmal direkt aus der Betrachtung der Flächenbilder, zweitens durch Bestimmung der Zellen- 
zahl des ausserembryonalen Blastodermsabschnittes auf rerschieden weit entwickelten Stadien.

Die Experimente an Funduluseiern zeigen, dass der Kopf, sobald er seine Ausbildung beendet hat, ein punctum fixum darstellt, weil die Operationsstelle, welche zur Zeit der Bildung des zelligen Randringes mit einer heissen Nadel in der Mitte des Blastoderms angelegt wird, immer dicht ror dem Kopf des Embryos liegt. Das Material, aus welchem die Kopfanlage hervorgeht, hat nie am Blastoporusrande gelegen.

Wenn nun der Kopf festliegt, so kann das Längenwachstum des Embryos nur nach hinten erfolgen. Ob nun die Verlängerung durch Konkrescenz der Randringhälften ror sich geht oder nicht, entscheiden die Operationen am Randring. Derselbe wird an juingeren Stadien auf einer Seite des Embryos mit einer heissen Nadel durchgebrannt. Es zeigt sich an den auf späteren Entwicklungsstadien untersuchten operierten Embryonen dass "The embryo cut off from all connection with the germ ring on one side elongates backwards producing an embryo having both right and left sides alike and equal". Daraus folgt, dass der "germ ring takes no important part in the formation of the body of the fish embryo". Diese Anschauung erfährt aber durch Beobachtungen an anderen operierten Embryonen und an Missbildungen, welche durch Einbringen der Eier in verdiinntes Seewasser (Seewasser 50, Süsswasser 25 Teile) erhalten sind, eine Änderung dahin, dass der Randring doch Anteil hat am Aufbau des Embryos, indem das Mesoderm derjenigen Seite, an welcher der Randring rom Embryo getrennt war, schwächer ausgebildet ist, als anf der anderen Seite, während Chorda und Medullarrohr anscheinend normal sind.

Aus diesen 'Tatsachen ergibt sich, dass der Embryo auch ohne Benutzung des Randringes nach hinten auswächst, dass aber aus ihm unter normalen Verhältnissen eine gewisse Nenge ron Zellenmaterial in den Embryo gelangt. Eine Tatsache, welche Morgan schon bei der Betrachtung der normalen Entwicklung erkannt hatte.

H. Virchow (89--93) hat sich in einer Reihe ron Veröffentlichungen iiber das Längenwachstum des Embryos und die Verwendung des Randringes bei T'eleostiern (Salmo fario, irideus) und Selachiern (Raja, Scyllium, Pristiurus) ausgesprochen.

In der ihm eigenen logischen Weise zerlegt er die zusammengesetzten Probleme in die sie zusammensetzenden Einzelfragen, und erwägt bei jeder einzelnen das Fiir und Wider, indem er alle Möglichkeiten aufsucht und Gesichtspunkte aufstellt. Wenn er dabei manchmal nicht zu einer bestimmten Antwort gelangt, so liegt die Schuld an der Unzulänglichkeit des bisher vorhandenen 'J'atsachenmaterials.

A. 'Teleostier. I. Längenwachstum des Embryos. a) Mit der von His und seinen Anhängern herangezogenen Evidenz ist in dieser Frage 
nicht durchzukommen, da auf Grinnd des Tatsachenmaterials manches mit Evidenz fiir Verwachsung, manches dagegenspricht (89, S. 72). b) Messungen der Länge des Embryos und des Randringes an Stadien zwischen halber Umwachsung und Dotterlochschluss haben ihn nicht die Überzengung gewinnen lassen, dass eine ,strenge Gesetzmässigkeit zwischen der Abnahme der Randlänge und Zunahme der Embryonallänge besteht". Ausserdem ist der Randring manchmal diinn, manchmal dick, was zwar an sich nicht gegen die Konkrescenz spricht, den Beweis aber undurchsichtiger gestaltet (92, S. 203). c) Vergleichungen der Längenmaasse der einzelnen Körperregionen jüngerer und ïlterer Stadien ergeben, dass "die Verlängerung der Embryonal-Anlage oder wenigstens die des embryonalen Mesoderms nur durch Zunahme im Bereich der ungeglicderten Region" sich vollziehen kann. Nun könnte man ja daran denken, dass das Material dieser Region von Randring stammt, wenn man es - mit His - für unmöglich hält, dass die neugebildeten Ursegmente ausschliesslich durch Vermehrung der Zellen dieses Körperabschnittes erzengt werden können. „Diese Vorstellung verliert" jedoch "gänzlich ihre Beweiskraft, wenn man bedenkt, dass nach Schluss des Dotterloches im "Schwanzende" ganz dieselben Verhältnisse fortbestehen, $d$. h. cin rerhältnismässig kurzes und an Mitosen nicht sehr reiches Stiick von unsegmentiertem Mesoderm die weiteren Urwirbel zu produzieren hat." (92, S. 204.) Der nach Dotterlochschluss vorhandene, bei 25 Urwirbeln $0,7 \mathrm{~mm}$ lange, unsegmentierte hintere Körperabschnitt hat noch 38 Urwirbel hervorzubringen, ohne dass ein Zuschuss von irgend woher dazu kommen kann, folglich kann doch wohl das unsegmentierte Stiick eines jüngeren Embryos, welches z. B. bei 11 Urwirbeln $0,8 \mathrm{~mm}$ lang ist, dasselbe auch ohne Zuschuss rom Randringe her leisten. Mit diesen Erwägungen ist jedoch, was H. Virchow selber anerkennt, weder fuir noch gegen die Konkrescenz etwas bewiesen.

II. Verwendung des Randringes: Bei dieser Frage kommt neben a) dem möglichen Übergang von Material in die Embryonalanlage in Betracht, die auch von Morgan gewiirdigte Tatsache, dass es b) in die Fläche ausweichen kann, d. h. zur Bildung des Dottersackes verwendet wird. Ferner findet c) wahrscheinlich ein Zerfall ron Randringmaterial gegen Dotterlochschluss statt. Wie viel jedoch dadurch verloren geht, entzieht sich bisher der Bestimmung.

III. Der morphologische Beweis: Dieser ist gestiitzt auf den Nachweis, dass im Randring dieselbe Anordnung der Keimblätter besteht, wie sie in jeder Embryohälfte vorhanden ist, da spezifische Gewebsformen oder embryonale Organe im Randring nicht nachgewiesen sind.

Diese Tatsache ist ohne Zweifel von grundlegender Bedentung, rechtfertigt aber nicht „so weitgehende Schliisse, wie sie in der KonkrescenzLehre gezogen werden". Vielmehr muss ein genauer Nachweis verlangt 
wenden, in welcher Weise Teile des Randes in die Embryonal-Anlage eintreten. Da ein solches Eintreten nur am hinteren Ende des Embryos, wo Randring und Knopf zusammenhängen, vor sich gehen kann, so muss diese Gegend zuerst ins Auge gefasst werden.

Bei dieser Betrachtung rertritt $H$. Tirchow die ron Balfour, Henneguy, H. E. Ziegler und Schwarz vertretene Anschaung, „dass der "Schwanz' bei Salmoniden schon in der Zeit ror dem Dotterlochschluss angelegt ist", indem im Knopf "dieselben Lagerungsverhältnisse ron Canalis neurentericus, Kupfferscher Blase und Endwulst bestehen, wie sie während des ganzen Schwanzwachstums der Salmoniden und Selachier zwischen Canalis neurentericus, postanalem Darm und Mesoderm des Schwanzendes existieren". (92, S. 216).

Damit ist die Konkrescenzlehre in ihrer ursprünglichen Form zurïckgewiesen, wenngleich „auf die Frage, in welcher Art und in relchem Grade bei Salmoniden der Keimhautrand für den Aufbau des Embryos verwendet wird, bisher eine geniigende Antwort noch nicht gefunden" ist.

B. Selachier: Im Anschluss an die Schwanzbildung der Knochenfische werden dieselben Vorgänge bei Selachiern analysiert und wird gezeigt, dass bei ihnen dieselben Beziehungen zwischen Canalis neurentericus, Mesoderm u. s. w. bestehen, wie bei den Salmoniden.

In der Mitteilung über Schwanzbildung bei Selachiern tritt H. Tirchow wesentlich auf den Befund einer ,auf einem oder vielleicht zwei Schnitten hinter dem Vorderrande des Canalis neurentericus" (93, S. 647) gespaltenen Chorda bei einem Raja-Embryo von 20 Urwirbeln, für eine achsiale Konkrescenz ein, welche ihm "wahrscheinlich" und ,zwingend" (91, S. 118) elscheint, schliesst sich jedoch keiner der ,.herrschenden Konkrescenzlehren" an und weist nach, dass die - auf jungen Stadien - Iateralen Teile der Kaudallappen nicht zur achsialen Vereinigung kommen, sondern eine ventrale Naht bilden.

Wit einem bisher noch nicht benutzten Beweise tritt Corning (10) gegen die Konkrescenz bei Salmoniden auf. Seine Beweisführung ist gegründet auf der strengen Abhängigkeit zwischen zelligem und syncytischem Randring, welche H. Virchow ganz besonders betont hat. Corning glaubt unter Voraussetzung dieses Verhältnisses aus den Vorgängen im syncytischen Randring auf gleiche Vorgänge im zelligen Randring schliessen zu können. Im Syncytium sind es vor allem die Kerne, aus deren Lage und Ortsveränderung er Schlüsse zieht auf "Wachstumsvorgänge innerhalb der Keimscheibe, ja innerhalb und in nächster Nähe der Embryonalanlage" (S. 110).

An Flächonpräiparaten älterer und jüngerer Stadien sieht man eine "Einstellung" der syncytischen Kerne auf den Rand, derart, dass die ovalen Kerne, welche unter den vorhandenen Formen die Mehrzahl bilden, „ihre Längsachse senkrecht auf den Umwachsungsrand stellen"(S. 112). Daraus 
folgt nun unter Bezugnahme auf das Abhïngigkeitsverhältnis zwischen den Wachstumvorgüngen des zelligen und des syncytischen Randringes, dass der Keimhautrand "sich durchaus gleichmässig verengert" (S. 124) und dass die Stellung der syncytischen Kerne "geradezu den Gegenbeweis" gegen die Konkrescenztheorie liefert. Bei der Umwachsung des Dotters geht Material vom Randring in den Embryo über, nimmt aber "keinen wesentlichen Anteil an der Bildung der Embryonalanlage: (S. 127), das Längsenwachstum des Embryos findet statt "zwischen der vorderen Wand der Kupfferschen Blase und dem letzten Urwirbel" (S. 130).

Zum Schluss dieser Übersicht seien noch die Ansichten von Raffaele mitgeteilt, welcher anfangs (73) bei den ellipsoidischen Eiern von Engraulis das Längenwachstum des Embryos durch Konkrescenz auf Kosten des Randringes vor sich gehen lässt, da aus der Form des Eies hervorgeht, dass der Kopf in loco liegen bleibt und die Verlängerung des Körpers nach hinten erfolgt. In einer sieben Jahre später erschienenen Arbeit (74) aber ist er auf Grund von Beobachtungen ïber das Verhalten der Deckzellenschicht am Keimhautrande zuriickhaltender, er betont, dass an den ellipsoidischen Eiern von Engraulis durch ihn und durch Wenckebach sicher nachgewiesen sei, dass der Kopf des Embryos ein fester Punkt ist. Er will aber nicht in die Erörterung der Streitfrage ïber Wachstum des Embryos und Umwachsung des Dotters eintreten.

Koehler und Battaillon (42) schliessen sich für Lenciscus jaculus der Anschauung Kupffers an. Als Beweis wird benutzt das gegenseitige Lagerungsverhältnis des Embryos und des Blastodermrandes zu demjenigen Punkt des Dotters, welcher anf jungen Entwicklungsstadien am oberen Pol liegt und an konservierten Eiern, durch seine dunklere Färbung erkannt werden kann.

Das von Fr. Kopsch (44) für den Umwachsungsmodus bei der Forelle entworfene Schema entspricht dem von $\mathrm{His}(29)$ gegebenen Bild.

\section{E. Zusammenfassung.}

Wenn wir die Literatur ïberblicken und die vorhandenen Anschauungen klassifizieren wollen - ein Unternehmen, welches stets an einer gewisseu Gewaltsamkeit leidet -, so finden wir in den jungen Stadien der Teleostierentwicklung, in dem Zeitraum vom ersten Auftreten der Embryonalanlage bis zum Dotterlochschluss, eine Reihe von verschiedenen Anschauungen 1. über das Längenwachstum des Embryos; 2. iiber die Art der Dotterumwachsung; 3. über den Anteil des zelligen Randrings am Aufbau des Embryos und des Dottersacks.

I. Über die Art des Längenwachstums sind zwei entgegengesetzte Anschanungen geäussert worden: 
A) Nach der einen wächst der Embryo von seinem ersten Auftreten bis zur Erreichung der endgültigen Zahl von Segmenten durch Vermehrung der Zellen seines hinteren, noch ungegliederten Körperabschnittes (Kupffer 54, 55).

B) Nach der Anschauung von His und Rauber $(24,29,75)$ entsteht der Rumpf des Embryos durch achsiale Verschmelzung der beiden Randringhälften.

II. Über den Modus der Dotterumwachsung sind vier verschiedene Ansichten geäussert worden:

A) Das Vorrücken der Keimhaut über dem Dotter erfolgt concentrisch d. h. allseitig gleichmässig (Kupffer 54, 55).

B) Das hintere Ende der Embryonalanlage bleibt in loco, die Keimhant breitet sich excentrisch aus, der Verschluss des Dotterloches findet dicht hinter der Stelle statt, an welcher bei Entstehung der ersten Embryonalanlage der Knopf liegt (Oellacher 67).

C) Die Ausbreitung der Keimhaut findet excentrisch statt, das rordere Ende der Embryonalanlage bleibt in loco (His 29).

III. Der zellige Randring findet Verwendung:

A) Für den Embryo (Kupffer 54, 55; His 29).

B) Nur zur Bildung des Dottersacks (Oellacher 67).

C) Für Embryo und Dottersack (H. Virchow 93; Norgan 65, 66).

Von den zahlreichen mittels dieser acht Komponenten möglichen Kombinationen finden sich in der Literatur vier vertreten:

Die älteste Anschauung, welche am meisten Zustimmung gefunden hat, ist die von Kupffer $(1868,1878)$ für die Eier von Gobius, Gasterosteus, Spinachia, Clupea harengus entwickelte, dass der Embryo wächst durch Vermehrung der Zellen seines hinteren Körperendes, während der Randring allseitig gleichmässig vorschreitet und sein Zellenmaterial Anteil nimmt am Aufbau des Embryos.

Diese Anschaung wird (allerdings nur im allgemeinen) vertreten durch: van Bambeke 1876 für Leuciscus rutilus; C. K. Hoffmann 1881 Forelle; Balfour 1881; H. E. Ziegler 1882, Salmo salar, Rhodeus amarus; Goronowitsch 1885 Salmoniden, Esox, Chondrostoma; Prince 1886 Gadiden, Trigla, Clupea harengus; List 1887 Labriden; Raffaele 1897 Exocoetus; Wenckebach 1888 Engraulis; Koehler et Battaillon 1893 Leuciscus jaculus; Morgan 1893, 189 j Ctenolabrus, Serranus, Fundulus; Fr. Kopsch 1894 Salmo fario; Corning 1896 Salmo.

Die genannten Autoren fïgen zu den durch $K u p f f^{\prime}$ beigebrachten Beweisen, welche bestehen in der direkten Beobachtung lebender Eier und in der Serienplnotographie eines fixierten Gasterosteus-Eis noch andere hinzu: So Goronowitsch und Corning das Verhältnis der einzelnen Teile des Dottersackentoblasts zu einander und zum Keim, H. E. Ziegler, Raffaele, 
Wenekebach die Beobachtungen an ellipsoidischen Eiern, Fr. Kopsch die Analyse der Oberflächenbilder, Morgan experimentelle Untersuchungen.

Die Einsehrünkung, dass die genannten Autoren sich im wesentlichen der Kupfferschen Ansicht ansehliessen, soll ausdrücken, dass sie durchaus nicht in allen Punkten mit ihr und untereinander iibereinstimmen. Die Verschiedenheiten beziehen sich meist auf die Stelle, an welcher sich das Dotterloch schliesst und wie weit das vordere Ende des Embryos an den oberen Eipol heranreicht. Sie erklären sich wohl in erster Linie aus dem verschiedenen Material, mit welchem die einzelnen Autoren gearbeitet haben.

Bei den runden kleinen Knochenfischeiern des Meeres bedeckt (nach den Autoren) der Embryo bei Dotterlochschluss meist $180^{\circ}$ der Eiperipherie. Bei den ellipsoidischen Eiern findet eine Abweichung statt, indem der Schluss des Dotterloches nicht genau am unteren Pol, sondern etwas nach der Seite des Embryos hin verschoben ist. Bei den glossen Eiern von Lachs und Forelle endlich bedeckt der Embryo bei Dotterlochschluss nur ungeführ $90^{\circ}$ der Eiperipherie. In allen denjenigen Fällen, in denen der Schluss des Dotterlochs nicht am unteren Eipol stattfindet, müssen aber früher oder später die einzelnen Abschnitte des Keimhautrandes ungleich schnell ïber den Dotter wachsen. Trotzdem aber müssen wir im Interesse der Klassifikation die genannten Autoren in diese Gruppe bringen.

Als nächste Anschaunng finden wir die von Oellacher 1873/74 aufgestellte, nach welcher der Knopf einen festen Punkt darstellt, der Embryo durch Zellvermelirung in der Gegend der Schwanzknospe nach vorn wächst, die Keimhaut nicht gleichmässig, sondern excentrisch sich über den Dotter ausbreitet, und das Randringmaterial nur zur Bildung des Dottersacks dient. Beweise werden von diesem Autor nielıt beigebracht.

Dagegen sieht Wilson (99), der einzige Autor, welcher diese Anschauung ohne wesentlichen Einwand annimmt, eine feste Orientierungsmarke in der einzigen Ölkugel des Serranus-Eies, und kommt bei dieser Voraussetzung zu dem Resultat, dass der Knopf verhältnismässig festliegt.

Die dritte Ansicht, von His (29) und Rauber (75), lässt den Embryo entstehen durch Konkrescenz der Keimscheibenründer. Hierbei wird das ganze Randringmaterial zum Embryo. Das Kopfende bleibt in loco liegen, die Verlängerung des Körper's findet nach hinten statt. Der Dottersack wird gebildet lediglich durch Ausbreitung der (von $\mathrm{His)} \mathrm{sogenannten} \mathrm{Mittel-}$ scheibe, d. h. desjenigen Abschnitts der jungen Keimscheibe, welcher nach Wegnahme des Embryos und des Randringes iibrig bleibt.

Diese Theorie ist, wie schon oben erwähnt wurde, besonders von amerikanischen Forschern aufgenommen worden, so (für Teleostier) von Agassiz und Whitman 1884; Ryder 1882-85 (besonders zu bemerken der Befund au Elacate); Kollmann 1885 Forelle; Cunningham 1886 Gadiden, Trigla, 
Clupea harengus; Raffaele 1888 Engraulis; Eycleshymer 1895 Amiurus catus. Lophius piscatorius.

An Beweisen führt $\mathrm{H}$ is an: 1. die unmittelbare Evidenz; 2. Messungen, a) metrischer, b) volumetrischer Art; 3. die Erwägung der bei der Umwachsung stattfindenden mechanisehen Vorgänge. Dazu fügt Rauber den Beweis aus den Spaltbildungen (Hemididymi), wozu auch Ryders Befund an Elacate zu rechnen ist. Von allen anderen Autoren sind weitere Beweise nicht beigebracht worden. Aus der Entnahme ron Längenmassen bestimmter Körperregionen sind Henneguy und H. Virchow zu einer Ablehnung der Konkrescenztheorie gekommen. Letzterer freilich nicht zu einer unbedingten.

Die vierte durch Miecz. v. Kowalewski aufgestellte Anschamung ist eine Verschmelzung der Ansichten von Kupfer und Oellacher. Als Beweis dienen die Befunde an konservierten ellipsoidisehen Eiern einer unbekannten Fischspezies. Der cinzige Autor, welcher sich Kowalewski angeschlossen hat, ist Henneguy.

Bei der Selachier-Entwicklung liegen die Verhältnisse viel einfacher. Hier kann über die Ausbreitung des Keims wenigstens für die Stadien nach Bildung des Canalis neurentericus gar kein Zweifel bestehen. Die an diesem Material vorhandenen Differenzen betreffen lediglich die Bildung und das Längenwachstum des Embryos.

Nach Balfour 1878, 1881, Kastschenko 1888, Rabl 1889, 1896, Sedgwick 1892, H. Virchow 1895 findet die Verlüngerung statt dureh Vermehrung der Zellen am hinteren ungegliederten Stiick des Embryos, wïhrend $\mathrm{H}$ is die Keimscheibenränder in der Medianlinie zur Bildung des Rumpfes und Schwanzes zusammentreten lässt (1876, 1878, 1891, 1894). Scinel Auffassung haben beigestimmt Rauber 1877-1855, Kollmann 1885, Riickert 1887, 1891, Locy 1894.

$\mathrm{H}$ is nimmt hier als Bew eis ebenfalls die unmittelbare Evidenz in Anspruch, ferner werden Messungen an verschiedenen Embryonen ausgeführt und dazu kommt dann im Jahre 1891 die von Perenyi schon frïher vertretene Ansicht, dass das hintere Ende der Chorda gegabelt sei. Diese Tatsache wird ron Rabl und Riickert in Abrede gestellt, von H. Virchow aber in einem Fall bestätigt. Gegen $\mathrm{H}$ is sprechen besonders die Experimente von Kastschenko; doch haben ähnliche operative Eingriffe Riickerts zu einem der Konkrescenztheorie günstigen Resultat geführt.

Die von mir an Seyllium-Embryonen ansgefuihrten Operationen, iiber welche ich auf der Versammung der Anatomisehen Gesellschaft in liel 1893 berichtet habe (47), erbringen ron der experimentellen Seite her den Beweis fïr die Richtigkeit der Anschanungen von Balfour, Rabl, Kastschenko, H. Virchow.

Von Locys Neuromeren am Keimhautrande der Selachier haben die spïteren Untersucher nichts geschen. 


\section{F. Frigestellung.}

Die vorhandenen Streitfragen bei der Embryobildung und der Dotterumwachsung der Knochenfische sind demnach:

1. Ist der Kopf des Embryos ein fester Punkt; mit anderen Worten: findet die Verlängerung des Embryos mach vorne oder wach hinten statt?

2. In welcher Weise schreitet der Keimhautrand bei der Umwachsung der Dotterkugel vor?

3. Welchen Auteil nimmt der zellige Randring am Aufbau des Embryos oder embryonaler Organe (Dottersack, Mesoderm etc.)?

Dic ersten zwei Fragen sind bei kritischer Verwertung des in der Literatur niedergelegten empirischen Materials mit einiger Sicherheit zu beantworten.

Auf die letzte Frage aber ist die Entscheidung nur durch das Experiment zu finden, wie es Morgan $(65,66)$ und ich (45) getan haben. Dabei finden dann die beiden ersten Fragen gleichfalls ihre Beantwortung, und zwar wesentlich in dem Sinne, wie es die Mehrzahl der Autoren im Anschluss an Kupffers Darstellung (aus den Jahren 1868, 1878) getan hat.

Behuts rationeller Auswahl der Operationen sind folgende Überlegungen anzustellen: 1. Wenn der Embryo in die Länge wächst durch Vermehrung der Zellen seines hinteren Körperendes, so muss a) nach Zerstörung dieses Körperabschnittes das Längenwachstum aufhören, b) nach Zerstörung des vor ihm gelegenen 'Teils rom Embryo doch noch der Rest des Körpers gebildet werden. 2. Wenn im zelligen Randring die Organe des embryonalen Rumpfes und Schwanzes potentia enthalten sind, so müssen sie nach Zerstörung der ihnen entsprechenden Stellen des Randringes fehlen, und zwar: a) bei trotz Operation eingetretener Konkrescenz auf der entsprechenden Seite des embryonalen Körpers, b) wenn durch die Operation die Konkrescenz verhindert ist, innerbalb des sich in situ differenzierenden Randringes.

Die unter 1. aufgeführten Operationen können auf älteren und jüngeren Stadien angestellt werden; die Operationen am Randring gestatten zahlreiche Variationen, da man erstens auf älteren und juingeren Stadien, zweitens nur auf einer Seite des Ḱnopfes in grösserer oder geriugerer Entfernung, drittens aber auf beiden Seiten und zwar ebenfalls näher oder weiter rom Knopf operieren kann. 


\section{Material und Nethoden.}

Die benutzten Eier stammen ron Salmo fario und Salmo irideus. Sie sind bezogen aus der Kaiserlichen Fischzucht-Anstalt bei Hïningen, deren Leiter Herr Kommissionsrat $\mathrm{H}$ a a $\mathrm{k}$, bereitwillig und liebenswiirdig auf meine Wünsche einging, so dass ich ihm grossen Dank schulde.

Da es sich im Lauf der Untersuchung als wiinschenswert erwies, dass die Eier von einem Weibchen stammten, um so die Schwankungen und Ungleichheiten der Ei- und Keimscheibengrösse, sowie der Fntwicklung, wenn möglich, zu vermeiden, sind die letzten sechs Eiersendungen (an acht wurde im ganzen operiert) stets Eier von einem Weibchen gewesen, befruchtet mit Samen ron einem Männchen. Trotzdem ist die Eigrösse oft sehr verschieden und damit auch die Grösse der Keimscheibe; man hat aber doch ein gleichartigeres Material zur Verfügung, wenn man die kleinen Eier ganz unberiicksichtigt lässt. Zugleich hat man auch eine bessere Grundlage für die Vergleichung der operierten und der nichtoperierten Embryonen derselben Sendung.

Die Eier werden in einem Bruttrog gehalten, welcher im Arbeitszimmer in der Nähe der Wasserleitung aufgestellt, mit anhaltendem Zulauf und Abfluss versehen ist. Unter diesen Bedingungen entwickeln sich die Embryonen ganz vorzüglich und bleiben auch ron Pilzen rerschont, wenn man nur täglich die toten Eier herausliest und das Wasser durch eine Glasplatte vor Stanb schützt. Übrigens habe ich dabei, wie auch Keibel (40) die Benerkung gemacht, dass, seitdem in der Anatomic das Formaldehyd angewendet wird, die Gefahr des Verpilzens eine sehr geringe geworden ist.

In demselben Bruttrog hängen noch zwei kleinere $(10: 10: 6 \mathrm{~cm})$ Kïstchen aus Messingdrahtgeflecht (Maschenweite $1 \mathrm{~mm}$ ). Jedes ist durch Querwände in vier Unterabteilungen von je $25 \mathrm{qcm}$ Bodentlïche geteilt, anf welcher bequem 50 Eier Platz haben. Jedes Fach ist numeriert und bestimmt zur Anfnahme der operierten Eier, welche sich so mit den nichtoperierten unter gleichen Bedingungen entwicke!n, wodurch die Tergleichung der opcrierten Embryonen mit den normalen an Sicherheit gewinnt. 
Wie gross die Zahl der von mir operierten Embryonen ist, vermag ich nicht anzugeben, da ich darüber keine genanen Aufzeichnungen besitze. Die Zahl der von mir als Danerprïparate eingelegten beträgt gegen 300 .

Ehe man an die Operationen herantritt, muss man eine genane Kenntnis der normalen Entwicklung erworben haben, sonst ist es nicht möglich, mit Sicherheit bestimmte Stellen der Keimscheibe zu operieren. Denn, wenn es schon äusserst schwierig ist, am konservierten Material auf Stadien vor Auftreten des Knopfes die Stelle der ersten Einstiilpung zu erkennen, so ist es selbst bei grosser Übung oft unmöglich, durch die wenig durchsichtige Schale des Salmoniden-Eies die einzelnen Keimbezirke zu erkennen. Ganz unbrauchbar zur Anstellung der Operationen junger Stadien sind Eier, welche äusserlich wie mit feinem Puder bestrent erscheinen, wegen der geringen Durchsichtigkeit der Schale. Selbst bei durchsichtiger Eischale sind die Keimscheibe und ihre einzelnen Teile nur dann so deutlich, wie es für die Operationen erforderlich ist, wenn man das Ei stark durchleuchtet. Dies geschieht am bequemsten mittels des A b bé schen Beleuchtungsapparates und zwar in folgender Weise:

Man entferne den Tubus eines grösseren Mikroskops vom Stativ, so dass 11 r der Objekttisch nebst Belenchtungsapparat iibrigbleiben. Stelle das Mikroskop so ror sich hin, dass die Säule nach rechts oder links gerichtet ist und sende mittels des Hohlspiegels Tageslicht oder Lampenlicht durch den Kondensor. Die Öffnung im Objekttisch enthält ein Korkstïckchen, in welchem eine Durchbohrung von $3-4 \mathrm{~mm}$ Durchmesser angebracht ist. Dieselbe erweitert sich nach oben hin trichterförmig bis höchstens $5,5 \mathrm{~mm}$ (nicht weiter, da der durchschnittliche Durchmesser des Forelleneies $4,5 \mathrm{~mm}$ beträgt). In diese trichterförmige Erweiterung wird das Ei gelegt und kann in ihr beliebig gedreht werden mittels einer Pincette oder eines Pinsels. Der Lichtkegel des Beleuchtungsapparates durchleuchtet das Ei genügend, sobald das auffallende Licht durch eine vorgestellte Metalloder Pappplatte ausgeschaltet ist. Man erkennt alsdann den Rand der Keimscheibe und die Embryonalanlage oft mit grosser Deutlichkeit. Eier, an denen die einzelnen Teile trotz Durchleuchtung nicht scharf hervortreten, werden nicht benutzt; man findet stets eine geniigende Zahl, welche zur Operation geeignet sind.

Unter besonder's günstigen Terhältnissen gelingt es, bei dieser Anordnung die einzelnen Keimbezirke schon auf Stadien zu erkennen, in welchen der Umschlag eben an einem Teil der Peripherie anfgetreten ist, und die Operation an der gewollten Stelle mit Sicherheit auszuführen. Denjenigen Punkt, an welchem der Umschlag zuerst anfgetreten ist, erkennt man an der grösseren Dunkelheit. Die Medianlinie des späteren Embryos schon auf diesem Stadium mit Sicherheit festzustellen, gelingt auch an besonders durchsichtigen Eiern, wie man sich an Keimscheiben iiberzeugen kann, welche 
wenige Stunden nach der Operation konserviert sind. Überhaupt empfiehlt es sich, zunächst an einer Anzahl operierter Eier nach einigen Stunden nachzusehen, ob die Operation auch die gewollte Stelle getroffen hat. Stellt sich dies an den konservierten Keimscheiben heraus, so wird man wohl annehmen diirfen, dass dies auch bei der Mehrzahl der operierten Eier der Fall sein wird.

Auf etwas älteren Stadien - eben gebildeter Knopf oder rantenförmige Embryonalanlage (Stad. I, II von Fr. Kopseh 46) - ist die Erkennung der Topographie viel leichter, namentlich durch die Anordnung der Ölkngeln in der Gegend der Embryonalanlage und des Keimscheibenrandes.

Ausserordentlich giinstig sind solche Eier, an denen der „innere Ring" (H. Virchows) vorhanden ist. Unter innerem Ring verstehen wir eine Bildung innerhalb des unter der Keimhaut bofindlichen Dotters, welehe durch eigenartige Lagerung der Ölkngeln und des optisehen Verhaltens der oberflächlichen Dotterteile ausgezeichnet ist, wie sie sich sonst $11 u \mathrm{rm}$ Bereich des syncytischen Randriuges findet. Er ist auch an durehgefärbten, in toto eingelegten Keimscheiben noch zu sehen; an Schnitten aber gelingt es nicht, ihn aufufinden. Statt eines Ringes kömnen deren zwei oder drei vorhanden sein (siehe die Textfiguren 12, 13, 14). Ihnen allen ist gemeinsam, dass sie weder zu einander, noch zum Rand der Keimseheibe concentriseh verlaufen. Sie liegen einander am nächsten im Bereich der Embronalanlage und sind am weitesten roneinander entfernt an dem gegenïber der Embryonalanlage befindlichen Teil der Keimhaut. Sie entsprechen meiner Anffassung nach den Stellen, an welchen der Randring sich auf jüngeren Stadien befunden hat. Ihr Wert für die Operationen liegt darin, dass sie im Bereich der Embryonalanlage am dichtesten aneinanderliegen und dass sie auch durch die Eischale hindurch bei Durchlenchtung deutlich genug gesehen werden könneu. Dadureh ist eine genane Bestimmung der Medianlinie des Embryos möglich.

Ton dem Stadium der birnförmigen Embryonalanlage ab [Stad. III, Fr. Kopsch (46)] ist das Erkennen des Embryos und des Randrings meist selır leicht, wenn der letztere nicht gerade ausserordentlich diunn ist. Aber auch in diesem Falle ist dureh die Anordnung der Ölkugehn immer noch ein gewisser Anhalt gegeben.

Was nun die Technik der Operationen anbetrifft, so handelte es sich darum, eine Methode zu finden, welche ohne Durchbrechung der Eischale mit Sicherheit und in jedem Falle die Zellen an der bestimmten Stelle abtötet, oder so verändert, dass sie anf späteren Stadien erkannt werden können. Dabei ist erstens durchaus erforderlich, dass die Fischale unverletzt bleibt, weil nach Anstechen derselben der Dotter bald gerinnt, und zweitens, dass die Verletzmug des Embryos oder des Rand- 
ringes oder irgend einer anderen Stelle der Keimhaut nicht derartig ist, dass der Dotter durch die gesetzte Wunde austliessen kann. Wenn dies geschieht, ist das Ei ebenfalls verloren, da die den Dotter fest umspannende Keimhant den Inhalt gewissermassen herauspresst, eine Eigenschaft des Keims, welche sehr bekannt ist und noch kiirzlich von Uorgan zu Versuchszwecken benutzt wurde. Am grössten ist die Spannung nach Überschreitung des Äquators bis gegen Dotterlochschluss, was ja die Betrachtung der normalen Entwicklung zeigt, indem der noch nicht umwachsene Teil des Dotters oft hernienartig hervortritt. Darum gehen bei Eiern, deren Randring nach Überschreitung des Äquator's operiert wird, entweder gleich nach der Operation oder im Lauf der folgenden Tage vertältnismässig mehr zugrunde als bei den anf jungen Stadien operierten Eiern. Drittens darf der Dotter an der Operationsstelle nicht zur Gerinnung gebracht werden, la dor Fischdotter die unangenehme Eigenschaft hat, dass Gerinnungen, welche an einer Stelle auftreten, sehr leicht den ganzen Dotter in Mitleidenschaft ziehen.

Der elektrische Strom ist am besten geeignet (nach meinen Erfahrungen) die genannten Bedingungen zu erfïllen; 1 . durch die unverletzte Eischale hindurchzuwirken; 2. die Zellen so zu alterieren, dass sie entweder zugrundegehen oder sich in atypischer Weise weiter entwickeln, ohne dass der Dotter an der Operationsstelle ausfliessen kann oder gerinnt.

Die notwendigen Instrumente sind ein Akkumulator, eine Doppelnadel, eine Einschaltungsvorrichtnng.

Der Akkumulator besteht aus drei Zellen, sogenannten Tudorzellen, deren jede eine Spannung von 2 Volt besitzt, so dass im ganzen 6 Volt zur Verfuigung stehen. Die Doppelnadel ist die gewöhnliche zur Elektropunktur verwendete mit Platin-Iridiumspitzen. Als Einschaltevorrichtung; um den Strom beliebig unterbrechen und einschalten zu können, kann schon ein einfacher Druckknopf dienen, wie er bei elektrischen Kilingelleitungen zur Anwendnng kommt. Die Spitzen der Doppelnadel sind durch einen Lacküberzug bis auf die vordersten Punkte isoliert, damit der Strom nu. zwischen den beiden Spitzen übergehen kann. Durch längeres oder kïrzeres Abschneiden der Spitzen mittels einer Scheere kann man die Polenden nach Belieben kleiner oder grösser gestalten, je nachdem man die Operationsstelle gross oder klein wünscht. Dies hängt aber, wie gleich bemerkt werden soll, auch von der Stärke des Stroms, seiner Einwirkungsdaner, und der Stelle der Keimhant ab, an welcher operiert wird. Die Entfernung beider Spitzen voneinander wählt man für gewöhnlich möglichst gering, doch kann sie anch nach Belieben vergrössert werden; man muss dann aber stärkeren Strom anwenden und die Stromschleifen sincl grösser. Dies ist insofern ein Nachteil, als durch dieselben auch andere 'Teile des Keims in Mitleidenschaft gezogen werden können. 
Statt zwei Elektrodenspitzen kann man auch drei oder vier oder mehr wiihlen. Diese Anordnungsweise wird man anwenden z. B., wenn man zu beiden Seiten des Knopfes symmetrische Stellen des Randringes abtöten, oder ein Stiick Embryonalanlage von bestimmter Länge markieren will. Alsdann muss man aber darauf achten, dass die beiden Spitzen, welche Marken hervorbringen sollen, mit dem negativen $\mathrm{P}_{0} \mathrm{l}$ in Verbindung stehen, die dritte mit dem positiven.

Zur Ausfiihrung der Operation bringt man das betreffende Ei auf den durchbohrten Korken in geeignete Lage, benetzt es mit ein paar Tropfen physiologischer Kochsalzlösung, setzt die beiden Nadelspitzen auf die Eischale und driickt sie etwas an, wobei man darauf achtet, dass der negative Pol als der wirksamere auf die Stelle kommt, welche man operieren will. Die Daner der Einwirkung des Stroms beträgt 10 bis 15 Sekunden.

Die Übertragung der Eier aus dem Bruttrog geschicht am schonendsten mittels einer genügend weiten Pipette $(5-6 \mathrm{~mm}$ lichten Durchmesser). Mit dieser überträgt man sie in eine Glasschale und stellt diese dann auf den Arbeitstisch.

Man darf zu gleicher Zeit immer nur wenige Eier in der Glasschale auf dem Tische stehen haben, damit das wärmer werdende Wasser die Eier nicht schädigt, deun die Forelleneier sind beinahe ebenso, wie die erwachsenen Forellen gegen höhere Temperatur und Samerstoffmangel empfindlich.

Aus der Glasschale werden die Eier auf den Objekttisch des Mikroskopes gebracht mittels eines kleinen Löffelchens, welches gerade ein Ei aufzunehmen imstande ist. Innerhalh des erweiterten oberen Teiles des Korkstiickchens werden sie in die richtige Lage gebracht, mit physiologischer Kochsalzlösung benetzt, und dann in der oben beschriebenen Weise operiert.

Das Befenchten mit Kochsalzlösung ist ein wesentlicher und wichtiger Faktor. Es erlaubt mit verhältnismässig schwachen Strömen zu arbeiten, während vor ihrer Anwendung st:irkere Ströme benutzt werden mussten, welche meist zum Gerinnen des Dotters an der Operationsstelle und alsdann des ganzen Eidotters fiihren. Wenn nämlich das Ei in der angegebenen Weise auf dem Operationstisch liegt, so ist seine Oberfläche zwar noch feucht und mit Wasser durchtränkt, leistet aber dem Durchtreten des Stromes erheblichen Widerstand. Ausserdem wird dic Umgebung des positiven Pols schnell trocken und damit der Leitungswiderstand noch grïsser, so dass zu seiner Überwindung ein zu starker Strom gehört, welcher auf das Ei in der genanten Weise schädlich einwirlit. Alle diese Missstände werden durch Anwendung der Kochsalzlösung vermieden. Erstens wird der Iseitungswiderstand geringer, da das Leitungsvermögen mit der 
Zunahme des Kochsalzgehaltes wächst, und ansserdem werden die Pole nicht so leicht trocken. Man kommt daher mit sehr schwachen Strömen aus. Die Kochsalzlösung schädigt bei der geringen Nenge und der kurzen Zeit das Ei nicht; selbst wochenlang zur Probe in 0,7\% Kochsalzlösung gehaltene Eier entwickelten sich normal.

Bei festem Andriicken der Nadelspitzen kann die Eihiille durchbohrt, und das Ei verletzt werden; dadurch geht das Ei natïrlich völlig verloren, weil der Dotter sofort gerinnt und ausläuft.

Nach Beendigung der Operation sieht man an der Stelle, an welcher die Eischale von den Nadelspitzen berïhrt wurde, nur einen helleren Punkt. Am unterliegenden Keim ist noch nichts zu sehen. An ihm tritt erst etliche Stunden später ein grösseres oder kleineres weissliches Fleckchen auf, welches die Operationsstelle bezeichnet. Wenn es sehr kurze Zeit (innerhalb der ersten 10 Minuten nach der Operation auftritt, so ist Verdacht vorhanden, dass der Strom zu stark war oder zu stark eingewirkt hat. In diesem Fall kann man darauf gefasst sein, nur wenige oder gar keine der operierten Eier einige Zeit weiter zn ziichten. Sobald man aber nach den angegebenen Regeln verfährt, ist die Operation leicht und schnell auszuführen und der Erfolg sicher. Übung und Erfahrung sind natürlich notwendig, denu im ersten Winter 1894/95, als ich noch nicht auf die Anwendung der Kochsalzlösung gekommen war und mit zu starken Strömen arbeitete, erhielt ich nur einige wenige Embryonen, welche sich längere Zeit entwickelten. Bei jeder der folgenden Serien aber wurde das Resultat immer besser, so dass bei den letzten, von 50 operierten Eiern, im Laufe des nächsten Tages nicht ein einziges, im Laufe der ganzen folgenden Woche nur acht Stiick abstarben.

Nach der Operation werden die Eier sehr sorgfältig mittels des Löffelchens in eine Schale mit frischem Wasser übertragen und von dort in die oben beschriebenen Drahtkörbe, welche sich in demselben Bruttrog, wie die normalen Eier, befinden. Die einzelnen Eier können zur Verfolgung des Operationsresultates in den folgenden 'Tagen wiederholt herausgenommen und durchlenchtet werden, ohne Schaden zu nehmen, uur muss man Sorge tragen, dass die Betrachtung nicht zu lange dauert.

Dem Anfänger im Operieren ist anzuraten, mit Stadien von $1 / 3$ bis $1 / 2$ Umwachsung anzufangen und zwar mit Operationen am Knopf oder am Randring. Bei jüngeren Stadien ist die Orientierung zu schwierig und ältere gehen leicht zugrunde. Die Ursachen dafiir siud oben entwickelt worden.

Fiihrung eines genauen Protokolls, Konservierung vou normalen Eiern zur Beurteilung der Operationsresultate brauchen wohl nicht angeraten werden; ohne sie schwebt ein Teil der Schlussfolgerungen in der Luft. 
Die Konservierung erfolgt ausuahmslos in der von mir früher (46) geschilderten Nethode ron H. Virchow.

I) ie Betrachtung der Oberflächenbilder erlaubt schon ein gewisses Trteil izber den Ansfall der Operation; viel mehr aber ergeben schwach gefürbte, in Kranadabalsam liegende Objekte. Zu ihrer Anfärbung, welche bei der späteren Zerlegung in Schnittserien nicht entfernt zu werden braucht. dient eine kurz ror dem Gebrauch frisch bereitete Mischung ron Boraxkarmin und salzsäurehaltigem Alkohol. (Alkohol 70\%, 100: HCl. 1.) Hierin bleiben die Embryonen 2 bis $2+$ Stunden. Bei zu starker Färbung kann man nachträglich mit dem Säurealkohol ausziehen, bei zu geringer Fürbung muss man die Menge des Boraxkarmins etwas vergrösseru.

Bei diesem Terfahren wird der Dotter fast garnicht gefïrbt, seine Kerne aber treten deutlich hervor; der Embryo ist mach Aufhellung in Nelkennöl und Einlegen in Kanadabalsam so durchsichtig, dass das Terhalten der embryonalen Organe zueinander dentlich genug erkannt werden kann. Das Einlegen in Kinadabalsam geschieht in kleine, niedrige Glaszellen, welche auf dem Objektträgel festgekittet und mit einem Deckglas bedeckt werden. In ihnen wird der Balsam noch nach Jahren nicht völlig hart, der Embryo wird nicht gedrickt, kann jederzeit herausgenommen, eingebettet und geschnitten werden. Bei grossem Material ist eine solche Art des Einschlusses schon allein der Übersichtlichkeit und des bequemen Aufbewahrens wegen zu empfehlen; sie bietet aber ausserdem noch den Torteil ror dem Aufheben in Spiritus, dass die Fürbefähigkeit der Objekte noch nach Jahren so gut erhalten ist, wie in den ersten Tagen, während sie bei Spiritusmaterial im Lauf der Zeit mehr und mehr abnimmt.

Jeder zur Zerlegung in eine Schnittserie bestimmte Embryo wird rorher bei genau ausgemessenex Vergrösserung entweder photographiert oder gezeichnet, wobei mit Rücksicht anf Keibels Vorschlag (39) darauf zu achten ist, dass die Vergrösserungszahl durch 5 teilbar ist.

Nach Anfertigung der Schnitte wird aus ihrer Zahl und den Maassen der Flächenzeichnung die Paraffinverkiirzung berechnet, um die einzehen Schnitte auf die entsprechenden Stellen des Flächenbildes beziehen zu können. Hier müssen die Worte H. Virchows wiederholt werden: „Man kann über gewisse Einzelfragen ïberhaupt nicht diskutieren mit jemandem, der nicht bereit oder nicht imstande ist, jeden seiner Schnitte sofort auf ein Flächenbild zu beziehen".

Den grossen Wert der Schrumpfungsbestimmung wird man am besten erkennen bei den Volumenberechnungen der Embryonen und der Keimscheiben.

Die Schnitte werden in der ïblichen Weise mit Eiweissglycerin anfgeklebt, mit Hämatoxylin nachgefübt und in Kanadabalsam eingeschlossen. 
Dic Zeichnungen der Schnittbilder sind nach Photographien angefertigt, wodurch erreicht werlen sollte, dass möglichst jeder Kern in seiner richtigen Grösse an seiner Stelle sich befindet. Wenn das vielleicht fiir manche Kerne eines Schnittes nicht genan zutrifft, so liegt es an der Schwicrigkeit bei hundertfacher Tergrösserung, in welcher die meisten Keichnungen der Schnittbilder ansgefiihrt sind, dieser Forderung gerecht zu werden. Bei 150 facher Vergrösserung, in welcher einzehe Figuren ausgefiihrt sind, gelingt es schon besser wie Figg. 10-1t, Taf. I, 67-72, Taf. TI zeigen, doch musste der Raumersparnis wegen mit Rïcksicht anf die zahlieichen Zeichnungen die geringere Tergrössermug gewählt werden. 


\section{Deskriptiver Teil.}

\section{A. Operationen.}

1. Operationen am Randring bei schon vorhandenem Knopf.

a) Operation nur auf einer Seite.

«) auf älterem Stadium.

\section{Embryo I.}

(Figg. 1-8 Taf. I.)

Allgemeines: Dieser Embryo war während des Winters 1894/95 neben zwei anderen die einzige Frucht meiner Bemuihungen, welche darauf gerichtet waren, eine leicht und sicher zu handhabende Operationsmethode fuir Salmoniden-Keimscheiben ausfindig zu machen.

Das Stadium, in welchem die Operation vorgenommen wurde, war ein schon ziemlich weit vorgeschrittenes fungefähr Stad. VII oder VIII von Fr. Kopsch (46)]. Die Operationsstelle (Fig. 2) befindet sich am Randring auf der rechten Seite ungefähr $30-40^{\circ}$ entfernt von der Mittellinie des Embryos. Vier Tage nach der Operation wird das Ei konserviert. An den nicht operierten Eiern ist zu dieser Zeit der Dotter bis auf ein kleines Loch ron der Keimhant umwachsen.

Flächenbild: Der Embryo (Fig. 1) besitzt auf jeder Seite 18 Ursegmente von normaler Gestalt und Grösse. Die beiden vorderen Drittel zeigen keinerlei Abweichungen von dem Anssehen der nicht operierten gleichaltrigen Embryonen. Die Veränderungen, welche durch die Operation gesetzt sind, betreffen das hintere Drittel des Embryos und den zelligen Randring. An ersterem bemerkt man eine s-förmige Krrümmung, deren vorderer Bogen flach ist und mit seiner Konkarität nach der Operationsstelle sieht, während die Konkavität des hinteren, stärker gekriimmteu Bogens nach der linken Seite gerichtet ist. Der Knopf, nebst dem ror ihm gelegenen Teil begrenzen mit ihrer rechten Seite das IDotterloch, was bei normalen Embryonen mur die hintere Fliiche des Knopfes tut. Das kaudalste Stiick des Embryos ist also von der geraden Richtung nach der unverletzten 
Seite hin abgewichen und erscheint - rein deskriptiv ausgedrïckt -- gewissermassen als ein 'Teil des linken Randringabschnittes.

Von dem Verhalten der einzelnen Organe lïsst sich Folgendes feststellen. Das Medullarrohr ist von dem seitlich liegenden Mesoderm dentlich abzugrenzen bis in diejenige Gegend des Knopfes, in welcher bei tieferer Einstellung des Mikroskopes eine hellere Stelle die Kupffersche Blase bezeichnet und das hintere, verbreiterte Chordaende ohne deutliche Grenze iibergeht in die aus auscheinend gleichartigen Zellen zusammengesetzte Zellenmasse, welche hinter der Kupfferschen Blase liegt. An den genannten Organen sind bei Betrachtung des Flächenbildes im Vergleich mit normalen Embryonen keine, Veränderungen zu erkennen. Dagegen macht sich ein bedeutender Grössenunterschied bemerkbar an den ungegliederten Mesodermstreifen. Der rechte, anf der operierten Seite befindliche, wird nach hinten zu immer schmaler, während er hinter dem letzten abgegliederten Ursegment und noch eine Strecke weit von dort aus nach hinten, genau so kräftig entwickelt zu sein scheint, als der linke.

Der Randring hat bedeutende Veränderungen erfahren. Vor allem fällt die eigentiimliche Gestalt und Lage des Dotterloches auf, welches an den gleichaltrigen Embryonen eine kleine, runde Öffnung ist. Hier erscheint es als schmale, in die Länge gezogene Spalte, deren Längsachse einen spitzen Winkel bildet mit der durch die beiden vorderen Drittel des Embryos gezogenen Mittellinie. In der Nähe des vorderen Endes dieser Spalte, in der Höhe der letzten Ursegmente, liegt die Operationsstelle kenntlich durch grössere und dunkler gefürbte Zellen, sowie eine beträchtliche Anhäufung von Dotterkernen, deren langgestreckte Formen wesentlich radiär auf die Mitte der Operationsstelle gerichtet sind. An den einzelnen Abschnitten des Randringes finden sich Unterschiede hinsichtlich der Menge der vorhandenen Zellen. Am diinnsten ist er zwischen der Operationsstelle und dem hinteren Stiick des Embryos, etwas stärker an dem jenseits der Operationsstelle befindlichen Abschnitt, welcher dem erstgenannten gegeniiberliegt. Dagegen ist der an die linke Seite des Embryos sich anschliessende Randringteil ausserordentlich kräftig entwickelt.

Schnittbilder: Die Durchsicht der Serie ergibt fïr das vordere Stiick des Embryos in Übereinstimmung mit dem Befunde am Flächbild keinerlei Abweichungen von dem normalen Verhalten. Die ersten deutlich erkennbaren Veränderungen trifft man in der Nähe der Operationsstelle. Hier befindet sich innerhalb des mit zahlreichen, ungeführ kugeligen Hohlräumeı durchsetzten Dotters eine bedeutende Anhäufung von Dotterkernen, was für die Operationsstellen sämtlicher ron mir untersuchter Embryonen charakteristisch ist. Überhaupt zeigen die Operationsstellen eine Reíhe gemeinsamer Eigenschaften, welche bei jedem Fall bald in stärkerem, bald in schwächerem Grade ausgeprägt sind. 
Man kann an jeder Operationsstelle zwei Abschnitte unterscheiden: 1. einen mittleren Teil, in welchem die Zellen stark geschädigt und entweder im Absterben begriffen oder schon abgestorben sind. In letzterem Falle lösen sie sich ron dem darunter befindlichen Dotter mehr oder weniger los, so dass er frei zu Tage liegt. 2. Einen peripherischen Abschnitt im Tmkreis des punktfömigen mittleren Teiles. Die in ihm befudlichen Zellen haben ihre typische Form und Lagerung sowie ihre feinere Struktur verloren. Sie sind grösser und blasig geworden, enthalten oft zwei oder drei Kerne, welche sich manchmal stärker, manchmal schwächer fürben, als es bei den normalen Ḱernen der Fall ist. Infolge dieser Gestalts- und Grössenveräinderungen der Zellen bildet der peripherische Abschnitt gewissermassen einen Wall um den mittleren Teil. Wenn aber in letzterem die Zellen noch nicht abgestossen sind, so bilden beide Abschnitte zusammen einen kleinen, knopfartig nach oben rorspringenden Höcker.

Der entsprechende Abschnitt des Dottersackentoblasts zeigt dieselben bejden Teile. 1. Einen mittleren, in welchem die Reste zerfallener Dotterkerne durch Fïrbung noch auf späteren Stadien nachgewiesen werden können und 2. um diesen herum eine ausserordentlich reichliche Auhäufung ron Dotterkernen, deren Längsachse meist radiär zu Mitte der Operationsstelle gerichtet ist. Dabei ist besonders bemerkenswert, dass diese Anhäufung an der Peripherie des toten Dottermaterials soweit in die Tiefe reicht, wie letzteres, während die Dotterkerne sonst (unter normalen Verhältnissen) dicht nuter dem zelligen Randring in den oberflächlichen Schichten des Dotters liegen, und nux bei Dotterlochschluss, wohl infolge der dabei stattfundenden Zusammendrängung des Raudringmaterials auch in tieferen Schichten gefunden werden. Ob diese Anhänfung der Dotterkerne an der Operationsstelle das Resultat aktirel Wanderungen ist oder auf andero Weise erklärt werden muss, soll nicht erörtert werden.

Tach diesen Bemerkungen kehren wir zur Beschreibung der Schnittbilder zurick. Fin Schnitt, welcher durch die Mitte der Operationsstelle geht (Fig. 3), zeigt am Embryo keine Abweichung vom normalen Verhalten - ïber das Aussehen der Operationsstelle ist nach der vorhergehenden Schilderung nichts mehr zu sagen - Dicht hinter dem abgebildeten Schnitt macht sich die Ungleichheit der linken und rechten Körperhälfte bemerkbar. Sie ist am deutlichsten zu erkennen an den paarigen Organen (Ursegmenten, Seitenplatten), während sie am Medullarrohr und der Chorda nicht zu bemerken ist. 'Luerst wehmen anf der operierten Seite die Seitenplatten immer mehr an Breite ab, auch die Ursegmente werden kleiner. Schliesslich sind Soitemplatten iberhaupt nicht mehr vorhanden (Fig. 4), und die Menge des Mesolferms auf der operierten Seite ist bedentend geringer wie auf der. anderen Seite. Am Medullarrohe ist eine Ungleichheit der linken und rechten Hälfte kaum zu erkenmen, an der Chorda ist dies iberhaupt nicht 
möglich. Die Kupffersche Blase hat eine asymmetrische Gestalt. Die Zellen ihrer Wand setzen sich nach links fort in ein zweischichtiges Entoderm, welches rom Mesoderm deutlich abgegrenzt ist; nach rechts sind die Zellen der Wand rou dem. Mesodermstreifen nicht abzugrenzen.

In der Zellemmasse hinter der Kupfferschen Blase ist noch eine Strecke weit das Gebiet des Medullarrohrs vom seitlichen Mesoderm abgegrenzt (Fig. 5), etwas weiter kaudal ist das typische Bild des Ḱnopfes rorhanden il der konzentrischen Schichtung der Zellen. Noch weiter uach hiuten (Fig. 7, 8) haben wir den Durchschnitt des Randringes, dessen linker Teil bedentend zellemreicher ist als der rechte. Das Dotterloch ist von der Deckschicht bedeckt, wie es bei Dotterlochschluss in der Regel der Fall ist. Über die Dotterkerne ist weiter nichts Besonderes zu bemerken.

Ergebuisse und Folgerungen: Fassen wir die Ergebnisse dieses Tersuchs zusammen, so zeigt sich: 1. dass die Abtötung eines dem Knopf benachbarten Randringstïckes bei einem Embryo von 1-2 Ursegmenten, das Längenwachstum des Körpers nicht gehiudert hat, denn es sind beiderseits 18 Ursegmente und das hintere ungegliederte Stück bis zum Knopf rorhanden; 2. dass innerhalb eines grossen Teils des uach der Operation gebildeten Rumpfabschnittes (bis zum 18. Ursegment) linke und rechte Seite noch vollkommen symmetrisch ausgebildet sind, dass aber 3. hinter dem 18. Ursegnent die Seitenplatten der operierten Seite immer schmaler werden und schliesslich ganz verschwinden; 4. dass der ungegliederte Mesodermstreifen nach dem Knopf hin immer schwächer wird, う. dass die Operationsstelle das gleichmässige Torwärtsschreiten des betroffenen Randringabschnittes und der benachbarten T'eile gehindert hat; 6. dass der Randring zwischeu Knopf und Operationsstelle ausserordentlich diinn geworden ist: 7 . dass am Medullarrohr nur eine äusserst geringe Ungleichheit beider Hältten, an der Chorda gar keine Veränderungen nachzuweisen sind.

Die Tergleichung der ursprïinglichen und der späteren Lage der Operationsstelle (Fig. 2 und Fig. 1) zeigt, dass der Randringabschnitt, welcher durch die Operation gekennzeichnet ist, bei der Umwachsung des Dotters nicht viel näher an den Embryo gelangt ist. Daraus darf nun weder geschlossen werden, dass der ganze zwischen Ḱnopf und Operationsstelle zur Zeit der Operation gelegene Raudringabschnitt an der Tereinigung mit dem Embryo gehindert worden wäre, noch dass der ron der Operation selbst be. troffene 'Teil nichts mit der Bildung des Embryos oder eines Teils desselben zu tun habe, wenn man sich nicht einer ähulichen Oberflächlichkeit schuldig machen will, wie alle diejenigen Autoren, welche bisher lediglich nach dem Ausfall der Operationen an Froschgastrulis sich für Konkrescenz erklärt haben.

Nur die eingehende Analyse des einzelnen Falls unter Beriicksishtigung der normalen Entwicklung und unter Benutzung rollständiger Schnittserien 
kann durch Anfsuchming und Erörterung der in Betracht kommenden Möglichkeiten die nötige Sicherheit der Beurteilung geben, welche zur Erlaugung einer richtigen Entscheidung notwendig ist.

Der operierte Randringteil hat sich, wie der Augenschein lehrt, bci der Umwachsung des Dotters in meridionaler Richtnng langsamer bewegt als die angrenzenden Teile. Hiernach darf man wohl annehmen, dass auch nach andereu Richtungen hin eine ähnliche Behinderung der Bewegung rorhanden gewesen ist und dass die anmähernd gleiche Entfernung der Operationsstelle rom Knopf bezw. Embryo zur Zeit der Operation sowie am konservierten Embryo auf Rechnung dieser Bewegungshinderung zu setzen ist. Daraus würde dann wieder folgen, dass der zwischen Operationsstelle und Knopf gelegene Ringabschnitt keinen Anteil nimmt am Aufbau des Embryos.

Einem solchen Schluss widerspricht aber die Zellenarmut dieses Randringteils und es muss zunächst untersucht werdeu, wozn sein Zellenmaterial rerbrancht ist.

Zunächst könnte an seine Verwendung znr Bildung des Dottersacks gedacht werden. Dagegen spricht, dass die anderen Randringabschnitte trotz eines teilweise grösseren Weges, welchen sie bei der Lmwachsung des Dotters (d. h. Bildung des Dottersacks) zurückgelegt haben, bedeutend zellenreicher sind.

Wenn wir nun davon absehen, dass das Material ganz oder teilweise zugrunde gegangen ist, wofür sich keinerlei Anhalt aus dem tatsächlichen Befund ergibt, so bleibt nur noch seine Terwendung fiur den Embryo oder die Operationsstelle iibrig. Da um letztere selbst sehr wenig Zellen enthält, so kommen wir per exclusionem zu dem Schluss, dass das Material des Randringabschnittes, welcher zwischen Knopf und Operationsstelle liegt, zum Aufban des Embryos verwendet worden ist.

Hier erhebt sich nun die neue Frage, in welcher Wreise die Terwendung stattgefunden hat: 1. entstehen aus ihm bestimmte Organe des Embryos, 2. wird es den einzelnen Organen mehr oder weniger gleichmässig zugeteilt oder 3. bildet es die ganze Hälfte eines entsprechenden Teils des Embryos, wie es nach der Auschanung von $H$ is der Fall sein miisste.

Betrachten wir zunächst die letzte Möglichkeit: Zur Zeit der Operation ist der ganze Kopf des Embryos schon angelegt, rom Rumpf 1 bis 2 (vielleicht auch mehr) Ursegmente und ein etwa 0,8 mm langes unsegmentiertes Stiick, von welchem man allerdings nicht weiss, wieviel es vom liörper des Embryos darstellt. Da nun aber die Keimscheibe zur Zeit der Operation den Dotter noch nicht einmal halb bedeckt und bei Dotterlochschluss ungeführ 18 bis 28 Ursegmente vorhanden sind, so wird man nach der Hisschen Anschanung wohl erwarten kömnen, dass das Randringmaterial, welches das dem Embryo ron 1--2 Ursegmenten am nächsten liegende Achtel des gesamten Randrings (Viertel der Randringhälfte) ist, das Stïck der rechten Seitenhälfte des Embryos, 
nugeführ entsprechend der Gegend des 10. bis 20. Ursegments enthält. - Die hinter dem 20. Ursegment liegenden Teile der rechten Körperhülfte miissten alsdann aus dem Randringmaterial entstehen, welches jenseits der Operationsstelle liegt.

Bei diesem Embryo müsste also, wenn das Zellonmaterial, welehes zwischen Operationsstelle und Kunopf liegt, zum Embryo gekommen ist, der vordere Teil symmetrisch ansgebildet sein; seinem hinteren Absehnitt aber miisste, da der Ansehluss des jenseits der Operationsstelle liegenden Randmaterials an den Embryo verhindert ist, die rechte Hälfte völlig fehlen.

Beides ist nicht der Fall.

Daraus folgt nun aber noch nicht ohne weiteres, dass die Hissche Anschauung widerlegt ist. Es ist vielmehr noch nötig, zu untersuchen, $a b$ und wie weit etwa Vorgänge regenerativer und umdifferenzierender Art im Knopf, welcher hierfïr allein in Betracht kommt, stattgefunden und dadureh das gesehilderte Resultat hervorgerufen haben kömnten.

In bezug auf die unter Unständen im Knopf einsetzenden Regenerationen und Regulationen ergibt die Untersuehung der Spaltbildungen (s. weiter unten S. 88), dass der Knopfabschnitt jeder der beiden Kürperhälften imstande ist, einzelne Teile der fehlenden Körperhälfte nachzubilden und zwar in Gestalt mehr oder weniger kräftig ausgebildeter Ursegmente, indess aus der Hïlfte der Chorda und dem halben Medullarrohr bilaterale aber nicht symmetrische Organe hervorgehen, von denen die Chorda anseheinend gleiche, das Medullarrohr aber ungleiche Fälften besitzt, so zwar, dass die der fehlenden Seite zugekehrte Hälfte stets zellenärmer ist als die andere, ferner ist bei diesen Missbildungen die Regeneration des Mesoderms der fehlenden Körperhälfte unvollstïndig und zwar 1. der Grösse nach insofern als nur ein ursegmentartiges Gebilde von geringeren Dimensionen gebildet wird, Seiteuplatten, Urnierengang, intermediäre Zellmasse aber fehlen, 2. dass die Nachbildung des Mesoderms zeitlich (und infolgedessen örtlich) verschoben ist, indem sie wie jede Regeneration erst nach V'erlauf einer bestimmten Zeit einsetzt. Dadurch kommt es, dass eine grössere oder geringere vordere Strecke der Hemididymi ohne nachgebildetes Mesoder'm ist.

Betrachten wir nun unter Zugrundeleging dieser Erfahrungen den operierten Embryo und nehmen wir als Ausgangspunkt das Stadium an, in welchem der zwischen Knopf und Operationsstelle befindliche Randringabschnitt verbraucht ist, $1 \mathrm{~m}$ das entsprechende Stiick der rechten Hälfte des Embryos zu bilden. Dann miisste 1. der bis zu dieser Zeit enstandene Kürperabsehnitt des Embryos vollkommen symmetrisch sein und bei weiterer Differenzierung der linken Randringhälfte mïsste der entsprechende Teil der rechten Körperhälfte fehlen, weil ja der jenseits der Operationsstelle liegende Teil der reehten Raudringhälfte sich nicht mit dem linken Randringteil vereinigen kann. Es müsste also ein Stiick des Embryos nur die linke Hälfte 
der Organe der linken Seite enthalten und falls eine Nachbildung ron Mesoderm der fehlenden Körperhälfte eingetreten wäre, so wiirde dieselbe eine Strecke weit fehlen oder rostral schwach begonnen haben und nach dem Knopf zu immer stärker geworden sein. Ferner könnte man allenfalls erwarten, dass der jenseits der Operationsstelle liegende Randringteil sich zu seiner Zeit in die entsprechenden Organe des Embryos differenzierte.

Nichts von alledem ist bei unserem Embryo vorhanden. Am Mesoderm der operierten Seite findet sich geradezu ein entgegengesetztes Verhalten; es wird nach dem Knopf zu immer schwächer. Danach scheint es ausgeschlossen zu sein, dass der Randring den Embryo enthält.

Dagegen könnte das allmählige Schmalerwerden und das Aufhören der seitlichen Teile des Mesoderms in einer gewissen Abhängigkeit ron dem allmähligen Verbranch des zwischen Knopf und Operationsstelle gelegenen Zellenmaterials stehen, und der Randring wïrde alsdann ansser zur Bedeckung des Dotters in erster Linie zum Aufban der Seitenplatten, welche ja anch zur Dottersackwand gehören, und etwa noch anderer Organe rerwendet. Genanere Erkenntnis hieriiber lässt sich jedoch an diesem Fall nicht gewinnen.

Für das Längenwachstum des Embryos und die Art der Dotterumwachsung ergibt sich, dass der Knopf nach hinten auswächst und dass der Randring nicht gleichen Schritt hält mit dem Längenwachstum des Embryos, sondern dass der dem Knopf gegenuiberliegende Punkt den längsten Weg zuriicklegt, während die sich daran anschliessenden Teile einen umso kïrzeren Weg durchmessen, je näher sie dem Knopf sind.

ß) Operation anf juingerem Stadium.

Operationsstelle $45^{\circ}$ vom Knopf entfernt.

\section{Embryo II.}

(Figg. 9-14, Taf. I, Fig. 16, Taf. II).

Allgemeines: Die Operation findet statt am 11. Tige nach der Befruchtung, anf dem Stadinm, in welchem die Embryonalanlage als rantenförmiges Feld erscheint und der Knopf schon gebildet ist (Starl. II Fr. Kopsch 46). Die Operationsstelle befindet sich anf der linken Seite, sic ist $45^{\circ}(1 \mathrm{~mm})$ ron der Medianlinie des Embryos entfernt (Fig. 16). Die Konservierming erfolgt am 1ð. Tage nach der Befruchtung, mithin hat sich der Embryo nach der Operation vier Tage entwickelt. Die gleichaltrigen normalen Embryonen derselben Brut haben 8 bis 10 Ursegmente.

Flächenbild: Der Eimbryo (Fig. 9) besitzt 9 Ursegmente, welche anf beiden Seiten von gleicher Grösse sind. Abgesehen von einer leichten Kriimmung seines Kopfes nach links ist er rollkommen gerade nach hinten 
gewachsen. Das rordere Stück und die Ursegmentregion sind von ganz. normalem Aussehen. Dagegen zeigt sich, wie bei Embryo I, die Wirkung der Operation an dem anf der Operationsseite gelegenen ungegliederten Mesodermstreifen, welcher rou vorn nach hinten immer schmaler wird. Am Medullarrohr und der Chorda sind keine Teräinderungen zu erkennen. Die Operationsstelle, welche zur Zeit der Operation 1 min von der Medianlinie entferut war, liegt jetzt in der Höhe des 7. Jis 9. Ursegmentes $0,3 \mathrm{~mm}$ entfernt ron der Medianlinie, am Grunde einer schmalen Bucht, deren Rand links gebildet wird von dem jenseits der Operationsstelle befindlichen Randringteil, rechts rou dem ungegliederten linken Mesodermstreifen des Embryos.

Die Operationsstelle erhebt sich über die Fläiche der Keimscheibe als kleiner Höcker, dessen Zellen grösser sind als die der benachbarten Teile des Keims. Die Dotterkerne unter ihr sind infolge der dichten Zellenmasse nicht dentlich zu erkennen. Die in der Bucht befindliche Dotteroberfläche enthält Dotterkerne und ist von der Deckschicht bedeckt. Der Terlauf des Randringes ist auf der rechten Seite der Norm entsprechend; anf der linken Seite begrenzt er die Dotterbucht, an deren Spitze die Operationsstelle liegt, und nähert sich an einer. Stelle dem Embryo beinahe bis zur Berihinug (Fig. 13). Dann weicht er aber wieder zuriick und rerläinft in der Richtung welche dem Randring bei noch weitem Dotterloch zukommt.

Schnittbilder: Das gesamte Aussehen der Schnitte durch das vordere Stiick des Embryos bis zum 7. Ursegment entspricht vollkommen demjenigen, welches gleich weit entwickelte, nicht operierte Embryonen zeigen. Wesentlich fiir unsere Betrachtung ist die vollkommene Symmetrie der beiden Seitenhälften dieser Strecke.

Die ersten Zeichen von der Trirkung der Operation finden sich in nächster Nähe der Operationsstelle und zwar am Embryo als unregelmälsige Lagerung der Kellen im Gebiet der linken Seitemplatten und Verschwinden der Grenzen zwischen den Keimblïttern, am Dottersackentoblast und am Dotter als Anhäufung zahlreicher Dotterkerue (Fig. 10). Die Ursegmente sind aber links und rechts noeh gleichgross; die linke Seitemplatte jedoch ist $n$ ein geringes schmaler als die rechte, wie in der Eig. 10, welche durch die Mitte des S. Ursegmentes geht, deutlich zu erkennen ist ${ }^{1}$ ). Je näher man dem Knopf kommt, desto gröfser wird der Unterschied zwischen der rechten und linken Körperhälfte. Dies zeigt

1) An diesem Beispiel ist die Sicherheit in der Orientierung der Schnittbilder auf das Flächenbild, welche dureh die Berechnung der Paraffinverliüzung (Schnittkorrelitur) ermöglicht wird, ausserordentlich klır. Unter Berieksichtigung der Korrektur fällt der Schnitt genau in die Mitte des 8. Ursegmentes, und die Auszählung der Schnitte an der Serie zeigt ebenfalls, dafs der in Fig. 10 abgubildete Schnitt der mittelste der das 8. Ursegment treffenden Schnitte ist. 
sich schon sehr dentlich auf dem nächsten Schnitt, welcher durch die Operationsstelle geht (Fig. 11). Hier fehlt ein grosser Teil der linken Seitenplatten; an ihrer Stelle liegen die durch Einwirkung des elektrischen Stroms veränderten Zellen des urspriinglich $45^{\circ}$ vom Knopf entfernten Randringteils. Jenseits der Operationsstelle befindet sich der nur wenig veränderte Randring, welcher die Dotterbucht begrenzt. Die Mitte der Operationsstelle wird gebildet von locker gefïgten Zellen, deren Kerne und Protoplasma mannigfache Degenerationen zeigen. In dem darunter liegenden Dotter werden Gruppen von Zellen (Fig. 11) angetroffen, von denen man nicht angeben kann, auf welche Weise sie dorthin gelangt sind. Die Anhäufung voll Dotterkernen ist unter der ganzen linken Körperhälfte vorhanden. Der Dotter unter dem jenseits der Operationsstelle gelegenen Randringabschnitt enthält eine dichte Lage stark gefïrbter Körnchen, welche an die bei Dotterlochschluss im Randring gewöhnlich vorhandenen erinnern und dort auf Kernzerfall zurïckgefïhrt werden. Die Anordnung der Zellen in dem darüber befindlichen zelligen Randring ist, wie es die Nühe der Operationsstelle erklärlich macht, keine regelmässige; die Abgrenzung der Keimblätter ist erst auf den folgenden Schnitten möglich (Fig. 12, 13, 14). Der nächste der abgebildeten Schnitte (Fig. 12) zeigt Medullarrohr und Chorda anscheinend normal, das linke Nesoderm aber schwächer als das rechte und ohne Seitenplatten; auch das Entoderm ist nicht so breit als rechts. Am linken freien Rande gehen die drei Keimblätter ohne Grenze ineinander über. Der anf der linken Seite der Dotterbucht liegende Randring ist ziemlich zellenreich mit deutlicher Sonderung der oberen und unteren Schicht. In letzterer und in den darunter gelegenen oberflïchlichen Dotterschichten sind die bei Fig. 11 erwähnten stark fürbbaren Körnchen noch reichlich vorhanden.

Sehr instruktiv ist der Schnitt durch die Mitte der Kupfferschen Blase (Fig. 13), an welchem das bedentende Übergewicht der rechten Mesodermmasse iiber die linke ganz besonders deutlich ist. Die Medianebene des Medullarrohrs liegt etwas nach links geneigt, die Masse seiner linken Hälfte ist wohl nur um ein Geringes kleiner als die der rechten. An der Kupfferschen Blase aber ist von Asymmetrie nichts zu bemerken. Entoderm, Wand der Kupfferschen Blase und Mesorlerm sind in dem rentralen Abschnitt der linken Ǩörperhälfte nicht von einander albugrenzen. Der gegenüberliegende linke Randringteil beriihrt beinahe den Embryo; er ist ausserordentlich dick und zellenreich, was ror allem auf Rechnung der unteren Schicht zu setzen ist. Der Schnitt Fig. 14 geht durch das hintere Fnde des Knopfes. Er zeigt die bekannte konzentrische Anordnung der Kellenkerne. Rechts hängt er mit dem Randring zusammen. Links grenzt er mit abgerundeter Fliiche an die Dotterbucht. Auch hier ist die linke Randringhälfte noch schr zellenreich. 
Ergebnisse und Folgerungen: Die Operationsstelle, welche ursprünglich $1 \mathrm{~mm}$ vom Ḱnopf entfernt war, liegt später in der Seitenplattengegend des 7.-9. Ursegments. Bis zum 7. Ursegment ist der Körper ganz symmetrisch ausgebildet, vom 8. Ursegment an fehlen die seitlichen Teile des Mesoderms und des Entoderms. Das Mesoderm wird nach dem Knopf zu immer zellenärmer, die Kupffersche Blase aber zeigt keine Asymmetrie. Am Medullarrohr ist eine nur geringfügige, an der Chorda ist gar keine Ungleichheit beider Seitenhälften zu bemerken.

Jie Verschiebung des Randringmaterials ist in diesem Falle angenscheiulich gar nicht oder nur in geringem Masse gehindert worden, wie aus der gestreckten Gestalt des Embryos und aus der unmittelbaren Nähe der Operationsstelle am Embryo folgt.

Wenn aber die Zellenverschiebungen am Randring nicht gestört worden sind, so dürfte geschlossen werden, dass die Operationsstelle sich an derjenigen Stelle des Embryos befindet, welche aus dem durch die Operation zerstörten Randringteil bei normaler Entwicklung gebildet wird. Da nun weder das Medullarrohr noch die Chorda, noch die medianen Teile des Mesoderms und des Entoderms irgend etwas mit der Operationsstelle zu tum haben, so folgt, wie bei Embryo I, dass der von der Operation getroffene Randringabschnitt nicht eine bestimmte Strecke der linken Körperhälfte des Embryos enthält. Dasselbe gilt für den jenseits der Operationsstelle befiudlichen Randringteil, denn der Zustand des Mesoderms der operierten Seite im hinteren Teil des Embryos ist ebenso wenig, wie dies an entsprechender Stelle bei Embryo I der Fall war, durch Regeneration oder Umdifferenzierung entstanden.

Dass das Randringmaterial eine Bedeutung für den Aufbau der Seitenplatten hat, folgt aus der Lage der Operationsstelle und aus dem Verhalten der Seitenplatten. Cranial von der Operationsstelle sind die Seitenplatten schmaler als auf der anderen Seite, was wohl auf einen etwas verzögerten Anschluss des der Operationsstelle benachbarten Randringmaterials an den Embryo zu schliessen gestattet. Das durch die Operation zerstörte Material liegt in der Seitenplattemregion, und kaudal von der Operationsstelle sind überhaupt keine Seitenplatten vorhanden.

Auch das Mesoderm der Ursegmente scheint einen gewissen Zuschuss vom Randring zu erhalten, denn die Somiten sind bei gestörtem Anschluss des Randrings (s. Embryo I) schon eine Strecke weit rostral von der Operationsstelle kleiner und nehmen kaudalwärts in der Richtung nach dem Knopf zu immer mehr an Grösse ab.

Die Lage der linken Randringhälfte bestätigt die beim Embryo I gezogenen Schlüsse über die Bewegung des Randringmaterials nach dem Embryo zu, welche fïr den zwischen Operationsstelle und Knopf gelegenen Abschnitt durch diesen Embryo ja direkt bewiesen worden ist. Die Lage des jenseits 
der Operationsstelle liegenden Teils der linken Randringhälfte lässt das Torhandensein zweier verschieden gerichteter Krïfte erschliessen, deren Resultante der Weg ist, welchen jeder cinzelne Teil des Randrings während der Ausbreitung der Keimhaut zuriicligelegt hat. Da die Richtung dieser Resultante durch die Lage der Operationsstelle bekannt ist, so kann auch die Richtung der beiden sie erzeugenden Kräfte bestimmt werden, und da ergibt sich, dass die eine dieser Kräfte das Randringmaterial in der Richtung zum Embryo bewegt, die andere aber den Randring in meridionaler Richtung iiber den Dotter schiebt. Ein Resultat, welches mit dem bei Embryo I gewonnenen iibereinstimmt.

\section{Embryo III.}

\section{(Taf. II, Figg. 15, 16, 18-22.)}

Allgemeines: In bezug auf die allgemeinen Daten gilt für diesen Embryo das bei dem vorhergehenden Gesagten, da beide aus demselben Versuch stammen.

Flächenbild: Das Gehin des Embryos (Fig. 15) weicht der Gestalt nach ron demjenigen des Embryos Fig. 9 ab, ist aber symmetrisch ausgebildet. Die Operationsstelle ist ausserordentlich gross, sie liegt in der Höhe des Hinterhirns und der drei ersten Ursegmente. Der Rumpf ist bogenförmig gekriimmt dadurch, dass der Knopé beim Auswachsen immer mehr nach der rechten Seite von der geraden Richtung abgewichen ist.

Während am Medullarrohr, der Chorda und der Kupferschen Blase keine sichtbaren Veränderungen festgestellt werden liömnen, macht sich die Wirkung der Operation am Mesoderm der linken Körperhälfte viel mehr bemerkbar als beim Embryo II. Es ist schon in der Gegend des Hinterhirns schmaler als anf der rechten Seite und wird umso schwächer, je nïher cs dem Knopfe liegt. Besonder's dentlich tritt dies an den Ursegmenten hervor. Die drei ersten kann man wohl als annähernd gleich gross in Vergleich zu den entsprechenden der rechteu Seite bezeichnen, obwohl das Fehlen der seitlichen Begrenzung eine genane Bestimmung ilnres Querdurchmessers unmöglich macht. Das vierte Ursegment der operierten Seite ist schon kleiner als das entsprechende reclite, und an den folgenden wird der Unterschied immer deutlicher. Ausserdem hat die Abgliederung des nemuten Segments links noch nicht stattgefunden. Am ungegliederten Mesodermstreifen setzt sich die Verjüngung noch eine Strecke weit nach hinten fort, liört aber bald auf, so dass sein hinterstes Ende von ziemlich gleichmässiger Breite ist. Der Knopf springt erheblich nach links und nach hinten vor, so dass er vom zelligen Randring der rechten Seite durch eine Bucht abgesetzt ist.

Die Operationsstelle ist selır gross. (Vergl. Fig. 15 mit Fig. 1, 9.) Der Randring jenseits der Operationsstelle lat das gewöhnliche Aussehen, 
er bildet mit dem Embryo und der Operationsstelle eine Bucht, in deren Spitze wie bei den Embryonen I und II die Operationsstelle liegt.

Schnittbilder: Auf den Schnitten erkeunt man dic Wirkung der Operation, schon vor der Region des Gehörbläschens, an den Veränderungen der Zellen nach Lage und Aussehen. Das Medullarrohr und das dicht an ihm liegende Mesoderm sind nicht verändert, die direkte Wirkung der Operation ist auf seitliche Teile des Embryos beschränkt.

Ein Schnitt durch die Operationsstelle (Fig. 18) zeigt das Medullarrohr vollständig symmetrisch ausgebildet, ebenso die Chorda. Das Mesoderm der operierten Seite ist viel schwïcher als das der andern. Dabei ist jedoch zu bedenken, dass die Schnittrichtung an dieser Stelle nicht genau senkrecht, sonderu schräg zur Medianlinie des Embryos verläuft. Infolgedessen befinden wir uns auf der linken Seite noch in Kopfimesoderm, auf der rechten schon dicht am ersten Ursegment. Da nun das Kopfmesoderm viel schwächer ist als dasjenige der Ursegmentregion, so muss bei einem Schnitt, welcher so verlïuft wie der eben geschilderte, auch bei nicht operierten Embryonen ein scheinbarer Unterschied in der Dicke des Mesoderms beider Seiten sich zeigen. Aus diesem Grunde sind Fig. 18 und Fig. 19 für die Vergleichung der linken und rechten Mesodermmassen nicht gut zu verwerten. Erst die Schnitte Fig. 20-22, deren Ebene senkrecht auf der Embryonalachse steht, erlauben eine Vergleichung.

Unter der Operationsstelle und in ihrer Umgebung (Fig. 18) ist bei diesem Embryo keine erhebliche Anhäufung von Dotterkernen eingetreten, dagegen sind vorhanden die feinen, stark gefärbten Körnchen, welche wir bei Embryo II (Fig. 11 und 12) kenuen gelernt haben. Die Zellen in der Mitte der Operationsstelle sind gelockert und liegen unregelmässig durcheinander. In einer Anzahl derselben sind die Kerne sehr blass, in einem andern Teil dunkler gefärbt; ausserdem ist die Struktur von Kern und Protoplasma verändert. Auch die benachbarten Teile des Embryos und des Randrings zeigen Erscheinungen desselben destruktiven Prozesses, wenn auch in geringerem Maasse. Der Randring ist zellenreicher als es an entsprechender Stelle eines nicht operierten Embryos von neun Ursegmenten der Fall ist.

Der nächste Schnitt liegt etwas hinter der Mitte der Operationsstelle; Embryo und linker Randring sind von einander getrennt durch einen weiten mit Deckschicht iiberzogenen Raum. Soweit letztere reicht, finden sich in den oberflächlichen Schichten des Dutters zahlreiche Kerne (Fig. 19). Am Embryo ist auffallender. Weise die linke Hälfte des Medullarrohrs mächtiger als die rechte. Doch sei auch hier daran erinnert, dass der Schnitt schräg zur Medianlinie verläuft, was an dem Aussehen des Mesoderms der rechten Seite deutlich hervortritt. Dass aber die Masse des linken Mesoderms viel geringer ist als die der rechten Seite, ist sicher. Die Seitenplatten und die seitlichen Teile des Entoderms fehlen anf der linken Seite vollständig. 
Auf den Schnitten durch das hintere Körperstïck (Fig. 20, 21) tritt infolge der veründerten, jetzt genau transversalen Schuittrichtung der Unterschied zwischen linker und rechter Körperhälfte ausserordentlich klar und deutlich hervor. Am bedeutendsten ist der Grössenunterschied beim Mesoderm, welches auf der operierton Seite noch geringer ist als beim Embryo II. Dies wird besonders deutlich bei der Vergleichung der Figg. 13 und 21, welche beide durch die Kupffersche Blasé gehen. Auch die linke Hälfte des Medullarrohrs ist zellenärmer als die rechte, doch ist der Unterschied gegeniiber dem Verhalten des Mesoderms uur als gering zu bezeichnen. Chorda und Kupfersche Blase zeigen keine Asymmetrie. Die linke Wand der letzteren ist durch ihre ventralen Teile mit dem Mesoderm und Entoderm in direkter Verbindung (Fig. .21), wie es auch bei Embryo II der Fall ist.

Die Seitenplatten fchlen in dem ganzen hinter der Operationsstelle gelegenen Körperabschnitt; das Entoderm reicht in der Höhe der vordersten Ursegmente noch bis zum linken Rand des Embryos, wird aber im Gebiet der hinteren Segmente und des ungegliederten Mesodermstreifens immer schmaler (Fig. 20).

Die Deckschicht und mit ihr der Dottersackentoblast überragen den linken Rand des Embryos noch eine Strecke weit. Dies wird nach dem Knopf zu immer geringer, sodass in der Höhe der Kupfferschen Blase (Fig. 21) nichts davon mehr vorhanden ist. Die Dotterkerne erreichen hier nicht einmal mehr die linke Seitenkante des Embryos, sondern bleiben etwas von ihr entfernt (Fig. 21, 22). Thre Zahl unter dem Embryo ist ebenso reichlich wie bei Embryo IT.

Der mittlere Teil des Knopfes zeigt die bekannte koncentrische Anordnung seiner Kerne; nach rechts hängt er mit den Schichten des Randringes zusammen; in seinem linken Teil erlaubt die Stellung der Kerne dic Grenzen des linken Mesodermstreifens einigermassen zu erkennen.

Ergebnisse und Folgerungen: Aus der Analyse dieses Falles ergeben sich dieselben Schlüsse wie bei den beiden vorher beschriebenen Embryollen.

Einige Erläuterung verlangt nur die abweichende Gestalt der linken Randringhälfte und dic Krümmung des Embryos. Aus ihnen geht hervor, dass die Kraft, welche das Randringmaterial in der Richtung zum Embryo bewegt, entweder nur gering gewesen, oder gegen eine in entgegengesetzter Richtung wirkende Kraft nicht zur Geltung geliommen ist. Letztere kann vor Erreichung des Ei-Äquators dadurch vorgetäuscht werden, dass der Randring beim Vorschreiten in meridionaler Richtung sich ïberhaupt nicht dehnt, sondern die vorher besessene Iänge beibehïlt. Alsdam wird ein solches Verhalten wie bei diesem Embryo ausreichend erklärt Sobald aber der Keimhautrand den Äquator des Eies iiberschritten hat, trifft diese 
Erklärung nicht zu. Da nun bei einem Embryo mit neun Ursegmenten die Keimhant mehr als die Hälfte der Dotterkugel bedeckt, wird eine andere Erklärung für den bei diesem Embryo beobachteten Zustand gesucht werden miissen. Diese wird in der Spannung gefunden, welche im Randring vorhanden ist und sich am lebenden $\mathrm{Ei}$ in tiefer Einschnürung des Dotters und bruchsackartigem Herrortreten der noch nicht umwachsenen Teile des Eies äussert.

Wir haben somit am Randring drei zu einander in Wechselwirkung stehende Krï̈fte kennen gelernt: 1. Diejenige, welche bestrebt ist die einzelnen Teile des Randrings in meridionaler Richtung weiter zu schieben, 2. diejenige, welche in latitudinaler Richtung das Randringmaterial zum Knopf bewegt, 3. eine im Randring vorhandene (elastische) Spannung, welche aber durch die an zweiter Stelle genannte Kraft hervorgerufen sein kann.

Durch das Zusammenwirken dieser Kräfte werden die einzelnen Zellen des Randringes bei der Umwachsung an die richtige Stelle gebracht.

\section{Embryo IV.}

(Taf. II, Figg. 17, 23-26).

Allgemeines: Die Embryonen IV, V, VI stammen aus derselben Versuchsreihe; sie sind an demselben Tage und in derselben Entfernung vom Krnopf operiert worden, IV und VI auf der linken Seite, V auf der rechten Seite.

Die Operation wurde ausgefüht am 29. I. 1896, am 11. Tage nach der Befruchtung, auf dem Stadium der biruförmigen Embryonalanlage (Fig. 17). Die Operationsstelle ist $45^{\circ}(1,5 \mathrm{~mm})$ von der Mittellinie des Embryos entfernt. Die Konservierung der drei Embryonen erfolgte am 4. IIT. d. i. am 6. Tage nach der Operation, am 18. Tage nach der Befruchtung, zu einer '/eit, in welcher von den normalen Embryonen dieser Zucht einige den Dotter bis auf einen geringen Teil umwachsen haben (Dotterloch 1,4:1,1 mm) und dann 11-12 Ursegmente besitzen, andere mit 18-20 Somiten sich auf dem Stadium des eben geschlossenen Dotterlochs befinden.

Flächenbild: An dem vorderen Teil des Embryos IV (Fig. 23) ist nichts Besonderes zu bemerken ausser einer geringen Krimmung, deren Konkavität nach links sieht. Die Zahl der Ursegmente beträgt auf der linken, operierten, Seite 11, auf der rechten 12. Nicht weit hinter dem letzten Somit biegt das hintere Stück des Rumpfes unter stumpfem Winkel von der Richtung des vorderen Stiickes nach der rechten Seite ab. An dem hinter dieser Knickung gelegenen Teil des Embryos nimmt das Mesoderm der operierten Seite immer mehr ab, je näher man dem hinteren Körperende kommt und verschwindet in der Gegend des Knnopfes anscheinend vollständig, da hier die Substanz des Medullarrohrs teilnimmt an der Begrenzung des Dotterlochs. Bei tiefer Einstellung aber erkennt man auch hier neben der Chorda 
das Mesoderm. Am Medullarrohr und Chorda sind Veränderungen nicht festzustellen.

Die Operationsstelle zeigt in der Mitte ein helleres Feld, um welehes der uns schon von den früheren Embryonen her bekannte Wall von dunkler gefärbten Zellen sich befindet. Dieser Wall reicht an ciner Stelle bis dicht an das Medullarrohr heran, so dass es scheinen könnte, als ob die Ursegmentzone von der Operation in Mitleidenschaft gezogen ist. Bei Einstellung auf die tieferen Schichten erkennt man jedoch, dass neben dem Nedullarrohr noch Mesoderm vorhanden ist, dessen Zellen nicht das Aussehen der Operationsstelle haben.

An den Knopf schliesst sich, gewissermassen als direkte Fortsetzung des Embryos, nach hinten die rechte Randringhälfte an. Gegenuiber dem hinteren Abschnitt des Embryos und in gleicher Richtung verlaufend liegt die linke Randringhïlfte, welche im allgemeinen zellenreicher ist als die rechte. Beide Hälften umgeben das stark in die Länge gezogene Potterloch, an relchem man zwei Teile unterseheiden kann: einen vorderen schmalen und einen hinteren birnförmigen. Die Grenze beider liegt in der Höhe des Knopfes. Del vordere Abschnitt ist rechts vom Embryo, links vom Randring, vorn ron der Operationsstelle begrenzt, ist von der Deckschicht bedeckt, und entspricht der Bucht der Embryonen II, III. Er stellt ein älteres Stadium dar. Der hinter dem Knopf gelegene Abschnitt entspricht dem Dotterloch normaler Embryonen.

Schnittbilder: Die Wirkung der Operation macht sich sehon in der Höhe des zweiten Ursegments bemerkbar; sie besteht darin, dass die Soitenplatten der linken Seite nicht so breit sind als rechts. Sie laufen seitwärts auch nicht dïnn aus, sondern hören plötzlich mit abgerundeter Kiante auf, während auf der rechten Seite infolge der allmählichen Abnahme und der Verdiunnung die laterale Grenze der Seitenplatten nicht mit Sicherheit anzugeben ist. In der Höhe des dritten und vierten Ursegments wird die seitliche Abrundung der Seitenplatten auf der operierten Seite noch deutlicher. Fig. 24 ist der Mittelschnitt durch das vierte, linke Ursegment. Das Medullarrohr hat eine etwas unregelmässige Gestalt, doch kommt ähnliches auch bei normalen Embryonen vor; ein Unterschied zwischen seiner linken und rechten Hälfte ist nicht zu erkennen. Auch die Ursegmente sind links und rechts gleich gross. Das Aussehen der linken und rechten Seitenplatten aber ist durehans verschieden, wie es oben gesehildert ist. Auch das Entoderm reicht auf der operierten (linken) Seite nicht soweit seitlich wie rechts.

In der Höhe der folgenden Ursegmente werden linke Seitenplatten und linkes Entoderm noeh schmaler und zwar umsomehr, je nïher wir der Operationsstelle kommen. Am kandalen Ende des 7. und am kranialen Eude des 8. Ursegments zeigen sich die ersten direkten Verïnderungen an den Zellen der Seitenplattenregion als unregelmässige Lagerung der 
Zellen und Verschwinden der Keimblättergrenzen, wie wir es ähnlich schon bei den vorher geschilderten Embryonen kennen gelernt haben. In der Höhe des 9. und 10. Ursegments wird die Menge der Zellen immer grösser, was durch den Wall in der Ungebung der Operationsstelle bedingt ist. Im Dotter beginnt die Anhäufung der Kerne in der Höhe des 8. Ursegments. Dabei ist zu bemerken, dass innerhalb des Walles bis zur Höhe des 9. Ursegmentes, Entoderm und Mesoderm noch als gesonderte Lagen deutlich ron einander abzugrenzen sind, und dass beide Keimblätter an der Bildung des Walles beteiligt sind. Mesoderm und Entoderm sind in ihm aber nicht mehr voneinander abzugrenzen.

Was das Verhalten der Ursegmente in der Höhe der Operationsstelle anbetrifft, so ist die epitheliale Anordnung ihrer oberflächlichen Zellen an der dem Medullarrohr zugekehrten Seite vollständig erhalten, desgleichen die dorsale und ventrale Abgrenzung (Fig. 25), die laterale aber ist unvollständig, indem der ventrale laterale Teil des Ursegments mit den Zellen des Walls direkt zusammenhängt. Dorsal und lateral von den Ursegmenten befinden sich zahlreiche Zellen, deren unregelmässige Anordnung zeigt, dass sie durch die Operation in ihrer normalen Funktion gestört sind, an denen aber die Degenerationserscheinungen der von dem elektrischen Strom stark getroffenen Zellen nicht vorhanden sind. Der Schnitt, welcher in Fig. 25 abgebildet ist, liegt dicht vor der Mitte der Operationsstelle und zeigt darum die geschilderten Störungen in stärkstem Masse; weiter nach vorn und nach hinten werden sie immer geringer und sind vor allem auf die lateralen Teile des Embryos beschränkt. Ganz besonder's sei hervorgehoben, dass an Medullarrohr, Chorda und mittlerem Teil des Entoderms nicht die geringsten Veränderungen durch die Operation gesetzt sind. Dass der elektrische Strom in diesem Falle sehr' energisch gewirkt hat, geht aus der beträchtlichen Tiefenwirkung hervor (Fig. 25). Die Dotterkerne sind ausserordentlich in die Länge gestreckt und zu dünnen Fäden ausgezogen.

Die kaudal von der Operationsstelle befindlichen Teile des Embryos zeigen in dem allmählichen Schwächerwerden des Mesoderms nach dem Knopfe zu, in dem Fehlen der Seitenplatten und in der etwas schwächeren Ausbildung der linken Hälfte des Medullarrohrs, dieselben Erscheinungen, welche uns schon bei den vorher geschilderten Embryonen entgegengetreten sind. Als gute Vergleichungsstelle sei auch von diesem Embryo der Schnitt durch die Mitte der Kupfferschen Blase abgebildet (Fig. 26). Auch hier tritt wieder die beinahe vollkommene Symmetrie und die der normalen Ausbildung entsprechende Grösse des Hohlraumes besonders hervor.

Der dem hinteren Körperabschnitt des Embryos gegenüber liegende Teil des Randrings ist sehr dünn; an ihm sind nicht einmal die Keimblätter voneinander deutlich abzugrenzen; von irgend welchen Difterenzierungen embryonaler Organe fehlt jede Spur. Der an den Knopf sich anschliessende 
(rechte) Randring ist eine Strecke weit $(10-12$ Schnitte ì $10 \mu)$ etwas dicker als die iibrigen das Dotterloch begrenzenden Randringabschnitte.

Die Dotterkerne und die Deckschicht sind am rechten Randringteil etwas weiter vorgeschritten als der zellige Randring, links bleiben dagegen die Dotterkerne hinter dem freien Rande etwas zurück, zeigen also das typische Verhalten. Die Bucht zwischen dem hinteren Stiick des Embryos und dem linken Randringteil ist ron der Deckschicht iiberzogen; der von ihr bedeckte Dotter enthält auch eimige Kierue.

Ergebuisse und Folgerungen: Bei diesem Embryo ist ron Bedeutung die grosse Übereinstimmung in wesentlichen Punkten mit dem Embryo II, was dadurch ron grossem Wert ist, dass die Embryonen aus verschiedenen Bruten stammen.

Die ïbereinstimmenden Punkte sind: Die Operation hat den zwischen Knopf und Operationsstelle liegenden Randringteil nicht am Anschluss an den Embryo gehindert; die Operationsstelle befindet sich in der Seitenplattenregion des Embryos, Medullarrohr und Chorda sind nicht in Mitleidenschaft gezogen; dem Mesoderm der Ursegmente und dem Entoderm fehlen nur laterale Teile; die Verminderung der Breite der Seitenplatten macht sich schon weit rostralwärts bemerkbar und wird nach der Operationsstelle hin immer erheblicher. Kaudal von der Operationsstelle fehlen Seitenplatten und intermediäre Zellmasse völlig, die Ursegmente bezw. das unsegmentierte Mesoderm der operierten Seite werden nach dem Kinopf zu immer schwächer.

Verschieden ist die Lage der Operationsstelle. Dieselbe liegt bei Embryo II in der Höhe des 7.-9., bei diesem Embryo in der Höhe des 8.-10. Ursegments. Dabei ist aber zu bedenlien, dass der Embryo II auf einem etwas juingeren Stadium operiert worden ist als der vorliegende.

Somit gelten auch für diesen Embryo die vorher für das Längenwachstum des Körpers und für das Fortschreiten des Randrings bei Embryo II gezogenen Schliisse.

\section{Embryo V.}

(Taf. II, Fig. 17; Taf. IIT, Figg. 27-31.)

Allgemeines: Über die allgemeinen Daten siehe Embryo IT.

Die Operation fand auf der rechten Seite statt, $45^{0}(1, \check{\mathrm{mm}})$ entfernt ron der Mittellinie des Embryos.

Flächenbild: Der Embryo (Fig. 27) ist gerade, verliinft aber nicht in radiürer Richtung zur Nitte der Keimscheibe, sondern ist nach links abgewichen; er lrat jederseits siebzehn Ursegmente. Die sehr ausgedehnte Operationsstelle liegt in der Höhe der ersten Ursegmente. Sie zeigt nicht die an den Fmbryonen II und IV vorhandene Wucherung. Die Verschiebung, welche sie im Lauf der Entwicklung erfahren hat, ist deutlich erkenmbar durch das Torhandensein ron zahlreichen stark gefübten kleinen Körnchen in den oberflächlichen 
Dotterschichten. Die Entfernung der Operationsstelle rom Embryo ist etwa ein Drittel kleiner geworden, als sie zur Zeit der Ausfiihrung der Operation war. Zwischen der Operationsstelle und dem Embryo ist die Keimhant viel durchsichtiger als auf' den entsprechenden Stellen der linken Seite und zwar wird die Verdünung der Schichten, welche die grössere Durchsichtigkeit bedingt, in der Nähe der Operationsstelle immer bedeutender. Jenseits der Operationsstelle schliesst sich der Randring an, welcher eine Strecke weit zum Embryo parallel rerläuft, dann aber unter annähernd rechtem Winkel in denjenigen Teil des Randringes umbiegt, welcher den Rand der Keimscheibe bildet. Letztere bedeckt erst ungefïhr zwei Drittel der Dotterkugel, obwohl man nach der Zahl der Ursegmente (17) und nach dem Verhalten der normalen Embryonen aus derselben Zucht eine beinahe rollständige Umwachsung erwarten sollte. An der Umbiegungsstelle des rechten Randringabschnittes ist eine etwas stärkere Anhäufung von Zellen vorhanden. (Fig. 27.)

Am rorderen 'Teil des Embryos sind bis zur Höhe des dritten Ursegments keine Abweichungen rom typischen Verhalten zu vermerken. Zwar erscheint die linke Seite des Kopfes schmaler als die rechte, doch findet sich ähnliches anch bei nicht operierten Embryoneu und braucht nicht durch eine schwächere Ausbildung dieser Seite bedingt zu sein, sondern kann durch das nach links umgelegte Medullarrohr vorgetäuscht werden. Die rordersten Ursegmente sind links und rechts annähernd gleich gross. Tom vierten an zeigt es sich aber ganz dentlich, dass nach hinten zu die Grösse der rechten Ursegmente immer geringer wird. Seitenplatten sind auf der operierten Seite an allen siebzehn Ursegmenten rorhanden; ihre Breite nimmt nach dem Knopf zu allmählich ab. Der Knopf springt stark wach rechts ror. Die grosse Bucht zwischen Embryo, Operationsstelle und rechtem Randringteil ist ron der Deckschicht hedeckt, unter welcher zahlreiche Dotterkerne von runder oder ovaler Form liegen (langgestreckte Dotterkerne werden in dieser Gegend nicht beobachtet). Der Dottersackentoblast iiberragt anch den Knopf und den sich daran anschliessenden Teil der linken Randringhälfte ein wenig. Ob die Deckschicht an dieser Stelle ebensoweit reicht wie der Dottersackentoblast, kann am Flächenbild nicht sicher festgestellt werden.

Schnittbilder: Die Wirkmng der Operation am Randring ist um geringfügig, die Teränderungen der Zellen in der Umgebung der am stärksten betroffenen Stelle sind nur unbedeutend, betreffen aber ein grösseres Gebiet, wie auch das Flächenbild zeigt. Namentlich erstreckt sich die Ansammlung ron Dotterkernen, welche bisher an jeder Operationsstelle gefunden wurde, iiber eine grössere Fläche.

Am Embryo zeigt sich der Einfluss der Operation schon am Mesoderm der Perikardialhöhle, welche auf der operierten Seite weniger weit seitwärts 
reicht wie auf der anderen Seite. Der Unterschied beider Seiten ist aber nur unbedentend. Deutlich wird die schwächere Ausbildung des rechten Mesoderms erst in der Region des ersten Ursegments; sie betrifft Ursegment und Seitemplatten. Von hier an wird die Grössenabnahme beider Organe immer erheblicher. Dabei zeigt sich, was in dieser Klarheit bei keinem der bisher beschriebenen Embryonen beobachtet wurde, die interessante Erscheinung, dass die Seitenplatten in der Höhe des 9. Ursegments, der Unierengang in der Höhe des 11., die intermediäre Zellmasse mit dem 16. Ursegment aufhört, während nur derjenige Teil des Mesoderms, welcher im weiteren Terlauf der Entwicklung die folgenden Ursegmente geliefert haben würde, sich allmählich immer mehr an Volmmen abnehmend, bis in den Knopf erstreckt. Die mesodermalen Organe hören also umso weiter voru, mit anderen Worten umso friiher auf, je mehr lateral sie liegen.

Während die Grösse der Lrsegmente allmählich abnimmt, werden die Seitemplatten immer schmaler (Fig. 28, 29) und sind schliesslich am 10. Ursegment gar nicht mehr rorhanden.

Der Urnierengang, welcher rom $\check{5}$. Ursegment an als besonders abgegrenzter Teil am medialen Rand der Seitemplatten zu erkennen und im Bereich des 7. und 9. Ursegments (Fig. 28, 29) ein scharf begrenzter, rundlicher Strang ist, kann im Bereich des 11. Ursegments nicht mehr erkannt werden, wïhrend er anf der nicht operierten Seite noch weiter zu verfolgen ist.

Die intermediäre Zellmasse hört am 16. Ursegment auf, so dass ron hier aus auf der operierten Seite nur das Ursegment-Mesoderm rorhanden ist (Fig. 30, Schnitt durch das 17. Ur'segment).

Das Entoderm reicht auf der operierten Seite ebensoweit lateral; wie die Seitenplatten, in der Höhe des 9. Ursegmentes reicht es weiter lateral (Fig. 29) und im Bereich des 17. Ursegmentes iiberragt es den lateralen Rand des Mesoderms um eine Breite von vier bis fünf Zellen.

An Medullarohr und Chorda sind auch bei diesem Embryo die Wirkungen der Operation nicht zu bemerken. Erst in der Gegend der Kupfferschen Blase (Fig. 31) ist die rechte Hülfte des Medullarrohres etwas schwächer als die linke.

Der Zusimmenhang des embryonalen Ectoderms mit der Deckschicht, welche einen Teil der Dotterbucht bedeckt, wird auch am Schnittbild erkannt.

Der rom Terhalten des Dottersackes md der Dotterkerne beim Flächenbild gegebenen Beschreibung ist auch nateh I Jurhsicht der Schnitte nichts hinznznfügen .

Frgehnisse und Folgerungen: Bei diesen Embryo hat sich die Operationsstrlle nur wenig weiter bewegt, was bei der geringen Wirkmng 
des elektrischen Stroms in die Tiefe merkwürdig ist. Die Bewegung in meridionaler Richtung ist nur sehr gering gewesen, die Annäherung in der Richtung zum Knopf betrïgt nur ein Drittel $(0,5 \mathrm{~mm})$ der ursprünglichen Entfernung. Das zwischen Operationsstelle und Knopf befindliche Randringmaterial ist jedoch fuir den Embryo verwendet worden, wie die ausserordentliche Dünne dieses Randringabschnittes beim konservierten Embryo beweist (Begriindung siehe bei Embryo I, S. 49-52.).

Die geradegestreckte Gestalt des Embryos und der Verlauf des jenseits der Operationsstelle liegenden Teils der rechten Randringhälfte zeigen, dass in diesem Fall die Spannung im Randring kleiner gewesen ist, als die Kraft, welche das Zellenmaterial zum Knopf bewegt. Die in meridionaler Richtung wirksame und im Terein mit der Spannung des Randringes die Dotterumwachsung wohl in erster Linie bedingende Kraft scheint nicht genügend gewirkt zu haben, denn bei der rorhandenen Zahl von (17) Trsegmenten dürfte nur noch ein kleines Dotterloch rorhanden sein, während die Keimhant bei diesem operierten Embryo erst zwei Drittel des Dotters umwachsen hat.

Besonders wertvoll wird dieser Fall durch die Klarheit, mit welcher die Bedentung des Randringmaterials zum Aufbau seitlicher Organe des Embryos hervortritt. Die seitlichen Organe hören umsomehr rostralwärts auf, je weiter lateralwärts sie liegen: Am 9. Ursegment die Seitenplatten, am 11. der Urnierengang, am 16. die intermediäre Zellenmasse.

Darin, dass der Randring wesentlich zum Aufbau lateraler Organe verwendet wird, stimmt dieser Fall mit den vorher beschriebenen überein. Ein Unterschied gegeniiber dem Embryo IV, welcher aus derselben Brut stammt, zur selben Zeit und in derselben Entfernung rom Knopf operiert ist, besteht aber darin, dass beim Embryo IV das zwischen Operationsstelle und Knopf gelegene Randringstiick nur Verwendung gefunden hat bis zum 8. Ursegment, während dieselbe Strecke beim Embryo $V$ bis zum 16. Segment benutzt worden ist.

Dieser Unterschied ist augenscheinlich bedingt durch die verschieden schnelle Bewegung des Randrings beider Embryonen. Zu der Zeit, in welcher beim Embryo IV die Gegend des späteren 8. Ursegments von der Operationsstelle errreicht wird, mithin das ganze zwischen Knopf und Operationsstelle befindliche Randringmaterial verbrancht ist, kann beim Embryo $T$ noch nicht das gesamte Randringmaterial verbraucht gewesen sein, weil hinter dem 8. Ursegment noch Seitenplatten, Urnierengang, intermediäre Zellenmasse gebildet sind. Es wird also in der Zeit, in welcher beim Embryo IV der ganze Randringteil zwischen Knopf und Operationsstelle verbraucht ist, beim Embryo $V$ nur ein Teil benutzt worden sein, so dass der Rest dieser Strecke erst bei der weiteren Entwicklung, d. h. zu späterer Zeit, verbraucht worden ist. Dies ist jedoch nur möglich, wenn das 
Zellenmaterial des Randrings sich langsamer bewegt hat. Ist diese Schlussfolgernng; welche auf der Gleichheit der verwendeten Randringstrecken basiert, richtig, so folgt, dass beim Embryo $T$ dasselbe Material in etwas anderer Weise rerwendet worden ist als bei Embryo IV.

\section{Embryo VI.}

(Taf. II, Fig. 17; Taf. IIT, Figg. $32-37$. )

Über die allgemeinen Daten siehe Embryo IV.

Flächenbild: Der Embryo befindet sich zur Zeit der Konserrierung auf dem Stadium des Dotterlochschlusses. Die Operationsstelle ist bei Betrachtung in auffallendem Licht schwer zu erkennen, da die Wucherung in ihrer Umgebung fehlt. Sie liegt, wie das Bild bei durchfallendem Licht zeigt (Fig. 32), auf der linken Seite, hinter dem 10. Ursegment, dicht neben dem Medullarrohr und scheint mit ihm in Verbindung zu stehen. Hinter der Operationsstelle dentet eine schmale Spalte die Dotterbucht an, welche wir bei allen bisher beschriebenen Embryonen gefunden haben, und deren kraniales Ende ron der Operationsstelle begrenzt wird. In der Höhe der letzteren macht das Medullarrohr einen Bogen, in dessen Konkavität die Operationsstelle liegt. Die ror und hinter dieser Ausbiegung befindlichen Teile des Embryos rerlanfen gestreckt. Das hintere Stiick weicht ron der Richtung, welche das vordere hat, etwas nach rechts ab.

Auf der rechten Seite werden 18 Ursegmente gezïhlt (die Abgrenzung des letzten ist nicht sehr dentlich), auf der linken Seite ist nur noch der kraniale Rand des 11. zu erkennen, da die Region der folgenden durch die Zellen der Operationsstelle verdeckt wird. Das hintere Stiick des Embryos ist so symmetrisch ausgebildet, wie ein normaler (nicht operierter) Embryo. Eine kleine kreisförmige (̈)ffnung deutet den Rest des Dotterloches an.

Sehnittbilder: Die Wirkung der Operation macht sich bereits weit rorn bemerkbar. Sie ist mit Sicherheit schon in der Gegend hinter den Gehörbläschen zu erkennen, daran, dass der laterale Rand der Seitenplatten nicht soweit reicht als derjenige der rechten Seite. Im Bereich der vorderen Lrsegmente wird die geringere Stürke der mesodermalen Organe auf der operierten Seite umso dentlicher, je nïher man der Operationsstelle kommt (Fig. 33). Am meisten sinnfällig ist dies bei den Seitenplatten, welche nicht soweit seitlich reichen wie rechts und nicht unter allmählicher Verdünnung zugeschärft endigen, sondern nach kurzem Terlanf mit abgerundeter Kante aufhören. Der Irnierengang enthält auf dem Querschnitt nu ungef:̈hr die Hälfte der \%ellkerne wie der entsprechende Querschnitt der nicht operierten Seite. Die Zellmassen der Tena cardinalis sinistrit und der linken Lrsegmente sind links bedentend schwächer. 
Auch das Eutoderm reicht rechts weiter seitlich als links. Dagegen scheinen Medullarrohr und Chorda symmetrisch ausgebildet zu sein. Die aufgezühlten Unterschiede werden immer grösser, je nüher wir der Operationsstelle kommen.

In der Nïhe derselben sind auf der operierten Seite im Bereich des den zerstörten Bezirk umgebenden Zellwalles das Medullarrohr und die Seitenplatten nicht roneinander abzugrenzen. Die durch die Operation gesetzte Zerstörung ist nur gering, der abgetötete Bezirk ist klein und der Zellwall in seiner Umgebung ist nur schwach ausgebildet. Ein Schnitt durch das kraniale Ende des toten Bezirks (Fig. 34, Taf. III) zeigt Medullarrohr und Seitenplatten wieder deutlich voneinauder abgegrenzt. Das Medullarrohr ist stark nach der operierten Seite geneigt und besitzt einen nach iinks gerichteten Anhang veränderter Zellen. Die Seiteuplatten sind nur schmal, sind aber dentlich in parietales und viscerales Blatt geteilt. Die Anlage der Tena cardinalis (intermediäre Zellmasse) fehlt hier röllig. Links rom toten Bezirk liegt der Randringabschnitt, welcher durch die Operation rom Anschluss an den Embryo zurïckgehalten wurde. Er besteht ans zwei Blättern, welche dem normalen Randring zukommen, den Ektoderm und dem Mesoentoderm und ist von normalem Aussehen.

Vier Schnitte hinter dem geschilderten Schnitt hören liuks die Seitenplatten röllig auf, der Crsegmentquerschnitt ist noch geringer als bei Fig. 34 . 8 Schnitte (ì 10. 1.) weiter erscheint die schmale, an die Operationsstelle sich auschliessende Bucht, d. h. der Raum zwischen Embryo und linkem Randringteil. Sie ist ron der Deckschicht iiberzogen. Am 16. Schnitt befindet sich der linke Randringteil schon dicht neben dem Embryo. Auf dem 17. Schnitt häugen embryonales und Randring-Entoderm miteinander zusammen. Auf dem 30. Schnitt sind keine Spuren der Trennung zwischen linkem Randring und Embryo mehr rorhanden.

Ton hier an geht das linke Randringmaterial wieder ein in den Aufbau des Embryos, dessen linke und rechte Hälfte (Fig. 35) einen nur geringen Unterschied in der Menge des Mesoderms zeigen. Weiter kaudal wird dieser Lnterschied noch geringer wie der Schnitt durch die Mitte der Kupfferschen Blase (Fig. 36) beweist, nur reicht links das Mesoderm nicht soweit seitwärts als rechts.

Das Terhalten der Gegend des Dotterlochs (Fig. 3i) unterscheidet sich kaum von den entsprechenden Bildern nicht operierter Embryonen.

Ergebnisse und Folgerungen: Zwischen diesem Embryo und den Embryonen II und IV besteht eine grosse Ähulichkeit darin, dass die Operationsstelle bis an den Embryo herangekommen und das Gebiet der Seitenplatten, des Truierengangs und der intermediären Zelleumasse einnimmt, das Medullarrohr aber, Chorda und medialen Teil der Ursegmente nicht geschädigt hat. Eine gewisse Übereinstimmung besteht auch darin, 
dass die Operationsstelle beim Embryo II in der Höhe des 7. bis 9. Lrsegments, beim Embryo IV kaudal rom S., bei Embryo VI kaudal rom 10. Ursegment liegt. Die mehr kandale Lage bei letzteren wird dadurch erklärt, dass die Operation auf einem um ein weniges älteren Stadium stattfand.

Auf die Richtigkeit der bei den rorhergehenden Embryonen erhaltenen Schliisse iiber die Bedentung des Randrings für die Bildung lateraler Organe des Körpers sind die Zustände am hinteren Ende dieses Embryos (VI) gewissermassen die Probe, insofern, als der hintere Körperabschnitt wieder Seitenplattenmesoderm enthält, nachdem der Randring sich hinter der Operationsstelle mit dem Knopf vereinigt hat, während derjenige Teil, welcher infolge der Operation kein Randringmaterial erhalten hat, nur Ursegmentmesoderm besitzt.

\section{Operationsstelle $90^{\circ}$ rom Knopf entfernt.}

\section{Embryo VII.}

(Taf. III Figg. 38, 39, 40, 41.)

Allgemeines: Der Embryo ist aus derselben Brut wie die Embryonen II und IIL; er wurde in demselben Stadium operiert, die Operationsstelle liegt aber $90^{\circ}(2 \mathrm{~mm})$ entfernt rom Knopf auf der rechten Hälfte des Randrings (s. Fig. 38).

Die Konservierung geschieht am 16. Tage nach der Befruchtung, zu welcher Zeit bei den normalen Embryonen derselben Brut schon mehr wie drei Viertel des Dotters umwachsen und 12-14 Ursegmente vorhanden sind.

Flächenbild: Der Embryo scheint in allen Teilen so symmetrisch ansgebildet zu sein, wie es kaum besser bei einem normalen sein kann. $\mathrm{Er}$ ist gerade und besitzt jederseits 12 Ursegmente. Eine geringe Ungleichheit scheint im hinteren Stiick vorhanden zu sein, in welchem der ungegliederte Mesodermstreifen der rechten (operierten) Seite weniger breit ist als der linke.

Das Dotterloch ist birnförmig. An der Spitze des schmaleren Teils liegt die Operationsstelle; sie ist ziemlich weit vom Knopf entfernt.

Der zwischen Knopf und Operationsstelle befindliche Randringteil ist ausserordentlich duinn und zart; seine Grenze gegen das Dotterloch ist bei schwacher Vergrösserung kaum zu sehen. Der andere Teil des Randrings zeigt iiberall annähernd die gleiche Stärke.

Die sehr kleine Operationsstelle ist durch eine besondere Einbuchtung des Randrings und eine dichte Anhäufung von Dotterkernen bezeichnet. Der Zellenwall im Umkreis des abgetöteten Bezirks ist hier sehr niedrig.

Schuittbilder: Die Schnittbilder beweisen die völlig symmetrische Ausbildung der beiden Körperhälften bis weit in das Gebiet des ungegliederten Mesodermstreifens hinein. Erst in der Gegend der Küpfferschen Blase 
(Fig. 40) wird dic schwïchere Ausbildung des Mesnderms der rechten (operierten) Seite bemerkbar. Innerhalb des Kunpfes ist die Ungleichheit bedentender, aber immerhin nicht sehr gross (Fig. 41).

Frgebuisse und Folgerungen: Die Operationsstelle selbst hat sich dem Knopf nicht ganz $u m$ die Hälfte ihres urspriinglichen Abstandes genïhert (von $2 \mathrm{~mm}$ bis anf 1,2 $\mathrm{mm}$ ). 1)as Randringmaterial zwischen ihr und dem Knopf ist aber fast rollständig zum Embryo gekommen. Deshalb hat die Symmetrie des letzteren wohl anch nur eine geringe Störung erlitten. Die Tergleichung dieses Resultats mit den Ergebnissen der Operationen, welche nur $45^{0}$ rom Knnopf entfernt sind, zeigt, dass ein grösseres Randringstück die seitlichen Organe eines lïngeren Stückes des Embryos enthält.

\section{Operationsstelle $180^{\prime \prime}$ rom Knopf entfernt.}

Allgemeines: Die Embryonen VHI und IX stammen ans derselben Brut und aus demselben Versuch, sind aber zu rerschiedener Zeit konserviert: Embryo VIII zur Zeit des Dotterlochschlusses, Embryo IX fünf Tage später.

Die Operationsstelle (s. Taf. IV Fig. 42 Op.) liegt auf dem Randring $180^{\circ}$ rom Knopf entfornt, genan gegenïber dem Embryo. Zur Zeit der Operation ist der Dotter etwa halb ron der Keimscheibe umwachsen, die Embryonen besitzen entweder keine oder ein bis drei Ursegmente.

Am 18. Tage nach der Befruchtung, am vierten Tage nach der Operation, wird Embryo VIII konserviert. Zn dieser Zeit befinden sich die normalen Embryonen anf dem Stadium des Dotterlochschlusses und besitzen 16-17 abgegliederte Ursegmente.

Embryo IX wird am 23. Tage nach der Befruchtung, 9 Tage nach der Operation, (also 5 Tage später als Embryo TIII) konserriert. Die ihm gleichalterigen normalen Embryonen haben 36 abgegliederte Ursegmente.

\section{Embryo VIII.}

(Taf. IV, Figg. 42, 43, 44-46.)

Flächenbild: Der Embryo (Fig. 43a) ist rorzüglich entwickelt. Er ist rollkommen gerade; seine linke und rechte Hälfte sind symmetrisch ansgebildet; 18 Ursegmente werden jederseits gezählt. Das hintere Ende des Embryos ist etwas schmaler als es gewöhnlich in diesem Stadium der Fall ist. Der Knopf geht allmählig nach hinten in den Randring iiber.

Der Randring (Fig. 43b) zeigt ein röllig ron der Norm abweichendes Terhalten. Statt des runden, oder spaltförmigen aber kurzen Dotterlochs, sehen wir hier einen in der Verlängerung des Embryos sich erstreckenden schmalen Spalt, welcher fast sü lang ist wie der Embryo selbst. Das rordere 
Ende der. Spalte reicht nicht bis an den Knopf; es ist ron diesem getrennt durch einen kurzen Zellenstreifen, welcher ans der Vereinigung entsprechender Stiicke der beiden Randringhälften entstanden ist. Am hinteren Ende der Spalte liegt die Operationsstelle, ohne starke Zellwuchermng und ohne beträchtliche Anhäufung ron Dotterkernen. Am iibrigen Teil der Spalte stehen linke und rechte Randringhälfte in gleichmässiger Ausbildung einander gegeniiber.

Schnittbilder: Die Durchsicht der Schnittserie bestätigt den schon beim Flächenbild herrorgehobenen völlig normalen Zustand des Embryos und seiner Organe, deren Entwicklungszustand dem erreichten Stadinm entspricht.

Nur das hintere Ende des Knopfes hinter der Kuptfersehen Blise ist insofern etwas weiter entwickelt, als die beiden primären Keimschichten durch eine schmale Spalte und durch die epitheliale Anordnung der diese Spalte begrenzenden Zellen eine Strecke weit roneinander geschieden sind (Fig. 44), was sonst im hinteren Abschnitt des Kinopfes erst nach Dotterlochschlnss der Fall ist.

Die Randringhälften zu beiden Seiten der Spalte sind schwach ausgebildet; die beiden primären Keimschichten sind nicht deutlich roneinander abzugrenzen (Fig. 45). Über die Spalte hinweg zieht die Deckschicht. Der sichere Nachweis, dass am hinteren Ende des Spaltes die Operationsstelle liegt, wind durch den in Fig. 46 abgebildeten Schnitt gefiihrt.

\section{Embryo IX.}

(Taf. IT, Figg. 42, 47, Figg. 48-51.)

Allgemeines: Ausser dem rorher (S. 69) bemerkten ist hier noch nachzutragen: 4 mit diesem Embryo zu gleicher Zeit und in derselben Weise operierte nnd zu gleicher Zeit konservierte Embryonen haben 36, 37, 38, 39 Ursegmente, 4 gleichaltrige normale Embryonen haben 36 Ursegmente.

Flächenbild: (Fig. t7a, b.) Der Embryo ist seinem Alter entsprechend entwickelt, wie die Vergleichung mit den ihm gleichaltrigen aus derselben Brut stammenden normalen Embryonen beweist. Er hat 39 Crsegmente. Sein hinteres Ende weicht von der geraden Richtung des Körpers etwas nach rechts alb.

Hinter ihm liegen in einer gebogenen Tinie hintereinander angeordnet drei dichtere Zellenhaufen sowic die Operationsstelle. Tetztere ist noch bedeutend weiter rom Knopf entfernt als es beim Embryo TII der Fall ist. Zwischen dem hinteren Ende, den drei Zellenhanfen mud der Operationsstelle ist an dem zalrt angefürbten Eächenpräparat nichts rom Randring \% erkennen. Die Operationsstelle ist anch in diesem liall ohne starke Wucherung und zeigt wenig Dotterkerne.

Schnittbilder: Anch die Schnitte ergeben den völlig normalen Znstand des Embryos. Die Abläsung des hinteron Endes und damit das Frei- 
werden des hinteren Körperabschnittes vom Dotter ist durch seitlicho Finfaltung (Fig. 48) eingeleitet. An der Schwanzknospe ist die Kupflersehe Blase nicht mehr als Hohlram vorhanden, doch sind ihre Wäude noch zu erkennen. In den reutralen Abschnitten des hinteron Körperendes und in den angrenzenden Teilen der Dottersackwand sind die bekanuten. nm lic Zeit des Dotterlochschlusses einsetzenden degenerativen Torgänge zu sehen.

Hinter dem Eubryo ist von einer Naht, in welcher die bejden Randringhälften zur Vereinigung gekommen sind, nichts zu sehen. Nur wenige, dichter liegende /aellen denten die Stelle an, an welcher diese Tereinigung wohl stattgefunden hat. In der Gegend des ersten Zellenhaufens (Fig. 49) sind linker und rechter Randringteil noch nicht miteinander vereinigt. Nur die Deckschicht stellt die T'erbindung her. Die Zellenanhäufung liegt hier im linken Randring. Fast alle Zellen zeigen degenerative Erscheinungun. Weiter hinten (Fig. 50,51) sind beide Randringhälften wieder miteinander verbunden; ïberall aber sicht man in den Zellen die Zeichen degenerativer Vorgänge.

Ergebnisse und Folgerungen: (fiu die Embryonen TIII und IX.) Diese Tersuche zeigen, dass ein erheblicher 'Teil des Randringmaterials ausgeschaltet werden kann rom Auschluss an den Embryo, ohne dass letrterer in seiner Entwicklung beeintrichtigt wird. Dabei ist freilich zu bedenken, dass der hier ausgeschaltete Teil wesentlich der dem Kunpf gerade gegeniiberliegende Randringabschnitt ist, von welchem auch bei normaler Entwicklung eiu 'Teil während und nach l)otterlochschluss zugrunde geht. Dieser Tersuch zeigt aber, dass der dem Kinopf gegenuiber liegende Raudringabschnitt nicht den Schwanz des Forellenembryos enthält, wie es nach $\mathrm{His}$ der Fall sein soll.

\section{Embryo $X$.}

(Taf. T Fig. 52.)

Auch bei diesem Embryo liegt die Operationsstelle $180^{\circ}$ rom Knopf entfernt. Die Operation findet aber auf einem bedeutend älteren Stadium statt als bei den Embryonen VIII und IX, nämlich auf einem Stadium, in welchem das Dotterloch nur noch ungefähr 1 mm gross ist und der Embryo 15-17 Ursegmente besitzt.

Konserviert wird der Embryo vier 'Tage später, zu welcher Zeit die gleichaltrigen Embryonen derselben Brut 31-32 Ursegmente besitzen.

Das Frgebuis der Operation ist insofern etwas anders als bei den Embryonen TII und IX, als die Operationsstelle nicht linter, sondern unter dem Schwanz liegt (Fig. 52 Op.).

Der Embryo hat 29 Trsegmente, sein hinteres Körperende ist dicker als bei entsprechenden normalen Embryonen; das unsegmentierte hintere Stück ist kiirzer, denn es ist nu 0, $45 \mathrm{~mm}$ lang, währeud es nach deu Messungen vou H. Virchow bei 31 Trsegmenten $0,6 \mathrm{~mm}$ lang sein miisste. 
Die Schnittbilder beweisen, dass der dorsale Teil ein normales Medullarrohr, normales Mesoderm, normale Chorda und Kupffersche Blase enthält, dass aber die Zellen seines rentralen Teils die Einwirkung der Operation zeigen.

Hieraus geht hervor, dass der dem Knopf gegeniiber liegende Randriugabschnitt sich nicht hinte $\mathbf{n}$ an den Knopf anschliesst, nm den Embryo zu verlängern, sondern dass ans ihm ventrale Teile hervorgehen.

b) Operation an beiden Randringinälften. (In gleicher Entfernming links und rechts rom Knopf.)

\section{Embryo XI.}

\section{(Tilf. T Figg. 53-55.)}

Allgemeines: Dieser Embryo stammt aus derselben Brut wie die Embryonen II und III. Die Operation (Fig. 53a) findet statt am 15. Tage nach der Befruchtung auf einem Stadium, in welchem ungefähr 12 Ursegmente ausgebildet sind nud der Durchmesser des Dotterlochs noch beinahe $2 \mathrm{~mm}$ beträgt, an zwei symmetrisch zum Kinopf gelegenen Punkten, sowohl an der linken wie an der rechten Hälfte des Randrings.

Die Konservierung erfolgt drei Tage später, am 18. Tage nach der Befruchtung. Die normalen Embryonen haben zur selben Zeit 24 bis 26 Ursegmente.

Flächenbild (Fig. $53 \mathrm{~b}$ ): Der Embryo besitzt 22 Ursegmente. Sein vorderes Ende ist normal ausgebildet. Der Rumpf ist leicht gebogen. Die Ursegmente der rechten Seite haben in der Zeichmung einen kleineren Querdurchmesser als die der linken Seite. Sie sind in Wirklichkeit aber auf beiden Seiten gleich gross, ihre verschiedene Grösse ist nur dadurch vorgetäuscht, dass das Medullarrohr rechts weiter ausladet als links und deshalb den medianen Teil der rechten Ursegmente verdeckt. Bei tieferer Einstellung kann die Gleichheit der linken und rechten Ursegmente mit Sicherheit erkannt werden.

Der Knopf ist im Tergleich mit entsprechenden normalen Embryonen breit, er iiberragt den Randring in stiirkerem Masse als es sonst in diesem Stadium der Fall ist, und erreicht den gegeniiberliegenden Randringteil.

Das Dotterloch ist noch nicht ganz geschlossen, was bei einem Embryo von 22 Ursegmenten gewöhnlich der Fall ist. Es hat die Form einer queren Spalte. An ihren seitlichen Enden liegen die beiden Operationsstellen. Embryo und Dotterloch bilden zusammen eine T-Figur.

Die Randringabschnitte, welche links und rechts zwischen dem Knopf und den Operationsstellen liegen, sind nicht dium wie bei den Embryonen V und VII, sondern sehr zellenreich. Dasselbe gilt ron dem Randringteil, welcher dem Kinopf gegenüber liegt. 
Schnittbilder: Am Embryo findet sich nichts ron der Norm Abweichendes. Die Differenzierung der Organe entspricht seinem Alter; linke und rechte Ursegmente sind gleich gross. Auch am Dottersackentoblast ist, abgesehen davon, dass die Zahl der Dotterkerne unterhalb des Embryos sehr erheblich ist und nach der î́ upferschen Blase zu immer grösser wird, nichts Besonderes zu bemerken.

Die Schnitte durch das lintere Körperende zeigen, dass die am Flächenbild sichtbare kräftige Ausbildung in gleichmässiger Weise die drei Keimb]ätter betrifft. (Fig. 54, 55.) Besonders auffallend ist dies in der Gegend der Kupfferschen Blase an dem drei bis vier Zellen hohen Entoderm, welches sonst an dieser Stelle nur eine bis zwei Lagen hoch zu sein pflegt. Am Ḱnopf ist das Medullarrohr mit Ausnahme der letzten acht Schnitte seitlich vom Mesoderm abgegrenzt (Fig. 55), was hier sonst erst bei Dotterlochschluss eintritt.

Der Knopf berührt zwar den gegenüberliegenden Randringteil, ist aber nicht mit ihm rerschmolzen. An letzterem sind die bei und nach Dotterlochschluss eintretenden degenerativen Vorgänge vorhanden, während sie in den ventralen Teilen des Ḱnopfes und den sich an ihn anschliessenden Randringabschnitten nicht vorhanden sind.

Ergebnisse und Folgerungen: Der Wert dieses Versuchs besteht in dem Nachweis, dass ein grosser Teil des Randrings nicht notwendig ist zum Aufbau des Embryos; deñ der Einwicklungsgrad des letzteren entspricht dem Stadium nach Dotterlochschluss, in welchem bei normalen Embryonen auch die durch die Operation ausgeschalteten Teile des Randrings den Knopf erreicht haben. Dieser Versuch beweist somit dasselbe, was die $180^{\circ}$ rom Knopf entfernten Operationen (Embryonen VIII, IX) gezeigt haben und sichert die dort gezogenen Schlüsse, denn bei den Embryonen VIII und IX wïre es immerhin denkbar, dass ein Teil des Zellenmaterials des hinter dem Knopf liegenden Randrings in ähnlicher Weise zum Embryo gekommen wäre, wie es bei den Embryonen I, V, VII der Fall ist. Dies ist aber beim vorliegenden Embryo (XI) infolge der doppelseitigen Operation uumöglich.

c) Operation am Knopt selbst.

\section{Embryo XII.}

(Taf. V, Figg. 56-59).

Allgemeines: Die Embryonen XII und XIII stammen aus derselben Brut und aus demselben Versuch. Die Operation findet statt am 28. II., am 14. Tage nach der Befruchtung, zu einer Zeit, in welcher $0-2-6 \mathrm{Ur-}$ segmente bei den normalen Embryonen gezählt werden. (Fig. 56, 60.) Die Eier dieser Brut zeigen grosse individuelle Schwankungen hinsichtlich des 
in der gleichen Zeit erreichten Stadiums, trotzdem es die Eier eines Weibchens befruchtet mit dem Sperma eines Männchens sind.

Die Operation (Fig. 56) betrifft den Knopf; es sollte versucht werden, ihn in seine linke und rechte Hälfte zu spalten. Dies wurde nicht erreicht, da der Knopf entweder durch die Operation zerstört wurde oder aber seine Zellen so alteriert wurden, dass sie sich nicht normal weiter entwickelten. Statt der Spaltung des Knopfes wird also eine Zerstörung erzielt.

Die Konservierung erfolgt am dritten l'age nach der Operation zu einer Zeit, in welcher die normalen Embryonen derselben Brut 18-20 Ursegmente besitzen, und der Randring bei den an weitesten vorgeschrittenen Embryonen sich bis auf eine stecknadelkopfgrosse Öfunng zusammengezogeu hat, während andere noch ein Dotterloch von 1,0:1,5 mm Durchmesser haben.

Flächeubild (Fig. 57): Bei Embryo XII liegt vor der Operationsstelle das der Zeit entsprechend entwickelte vordere Stiick, welches dem Kopf und dem Rumpf bis etwa zum ersten Ursegment entspricht.

An der Operationsstelle ist eine Wucherung entstanden, welche bei der Konservierung infolge des Drucks der Eischale etwas deformiert und nach rechts verlagert ist.

An diese Operationsstelle schliesst sich der Randring direkt an. Derselbe hat den Dotter zum grossen 'Teil umwachsen; er zeigt ausser den Randringcharakteren keinerlei besondere Differenziermugen wie Chorda, Medullarrohr, Ursegmente.

Schnittbilder: Der ror der Operationsstelle gelegene Körperteil ist vollständig normal entwickelt. Ursegmente sind nicht vorhanden.

Am vorderen Rande des infolge der Operation veränderten Bezirks gehen die Veränderungen der Zellen uu wenig in die Tiefe, so dass hier nur die dorsalen Teile des Medullarrohrs zerstört sind. Je weiter man aber sich der Mitte der Operationsstelle nühert, desto tiefer greift die Zerstörung, bis schliesslich im Zentrum die Wirkung auch am Dottersackentoblast zu erkennen ist an den schon vielfach erwähnten und abgebildeten Veränderungen, während das darüber gelegene Zellenmaterial des Kínopfes völlig zerstört ist (Fig. 58). Dabei sind an den Stellen, an welchen die Operation nur oberflächlich eingewirkt lat, die in der Tiefe liegenden Organe bezw. Organteile in ihrer typischen Lage vollkommen erhalten.

Der auf die Operationsstelle folgende Randring zeigt nur die bekannten Randringcharaktere (Fig. 59), ohne irgend welche weiteren Differenzierungen.

\section{Embryo XIII.}

(Taf. VI, Figg. (60-64)。

Flächenbild (Figr. 61): Das vordere Stück des Embryos, welches vor der Operationsstelle entwickelt ist, reicht bis zum dritten Ursegment. Das 
Medullarrohr ist etwas nach rechts ungelegt, wie es auch bei normalen Embryonen häufin vorkommt, so dass die rechte Seite scheinbar schwächer ausgebildet ist als dic linke.

An der Operationsstelle befindet sich ein dichter Zellenhanfen. Hinter diesem liegt der Randring, dessen beide Hälften einen schmalen, in der Verlängerung des vorderen Embryostücks liegenden Spalt begrenzen. Tnnerhalb des Randrings sind keine Differenzierungen wie Chorda, Ursegmente etc. zu sehen.

Schnittbilder: Das vor der Operationsstelle gelegene Stück des Embryos ist völlig normal ausgebildet; linke und rechte Hälfte sind gleich gross. Das Medullarrohx ist recht kräftig (Fig. 62). Hinsichtlich des durch die Operation im Knopf hervorgerufenen Zustands gilt dasselbe wie beim Embryo XII.

Die Schnitte durch den Randring (Fig. 63, 6t) zeigen die typischen Randringcharaktere.

Ergebnisse und Folgerungen: Die Embryonen XII, XIII zeigen, dass das Lüngen wachstum des Embryos an den Knopf gebunden ist, da nach seiner Zerstörung die Verlängerung des Körper's aufhört, während die schon vorhandenen Teile des Kopfes und Rumpfes völlig ungestört sich der Zeit entsprechend ausbilden und der Randring die Umwachsung vollführt. Letzterer ist für sich allein nicht imstande, embryonale Organe wie Chorda, Ursegmente etc. hervorzubringen.

2. Operationen am Randring vor Bildung des Ḱnopfes.

Allgemeines: Die Embryonen XIV bis XXVI stammen aus einer Brut und aus einem Tersuch.

Die Operation findet statt zu einer Zeit, in welcher bei der Mehrzahl der Keimscheiben der Knopf noch nicht vorhanden ist (s. Fig. 65, 73, 79, welche das Operationsstadium der Fmbryonen XIV, XV, XVI zeigen); einige haben ihn allerdings schon gebildet; bei der Mehrzahl aber tritt er erst am folgenden Tage auf (s. Fig. 85, 94; Operationsstadium der Embryonen XVII, XTII, XIX).

Als Operationsstelle wird gewählt derjenige Teil des Keimscheibenrands, an welchem der erste Umschlag entstanden ist, d. i. später der Kopf des Embryos liegt. Es werden nur solche Eier operiert, an denen diese Gegend mit genügender Sicherheit erkannt werden kaun.

Bei einer ersten Gruppe von Keimscheiben wird versucht, nur die eine Hälfte der Gegend des ersten Umschlags entweder rechts oder links von der Medianlinie zu operieren. Aus dieser Gruppe stammen die Embryonen XIV bis XIX. 
Hierbei muss gleich gesagt werden, dass es nicht gelang, die eine Hälfte genau bis zur Mittellinie zu zerstören. Die nekrobiotischen Vorgänge, welche die Folge der Operation sind, greifen of über die Mittellinie hinaus, manchmal erreichen sie dieselbe nicht.

Bei einer zweiten Gruppe wird versucht, genau am Rande innerhalb der Mittellinie zu operieren. Hier müssen nach den Resultaten zwei Untergruppen unterschieden werden: Bei der Mehrzahl der operierten Eier ist die Operationsstelle sehr gross, ein Embryo ist nicht gebildet. (Embryonen XX bis XXIV.) Bei einigen (wenigen) Embryonen, bei denen die Operationsstelle sehr klein ist, sind Spaltbildungen entstanden. (Embryonen XXV, XXVI.)

Die Operation findet statt am 11. Tage nach der Befruchtung, die Konservierung sieben Tage später (am 18. Tage nach der Befruchtung), zu einer Zeit, in welcher die nicht operierten Embryonen derselben /ucht sich teils auf dem Stadium von $3 \pm$ Umwachsung mit 8 bis 10 Ursegmenten, oder auf dem Stadium des Dotterlochschlusses befinden und 12 bis 14 Ursegmente besitzen.

\section{a) Operation seitlich neben der Mittellinie.}

\section{Embryo XIV.}

(Taf. VI, Figg. 65-72).

Flächenbild (Fig. 66): Der Embryo besteht aus einem vorderen Stiick, welches beide Seitenbälften entwickelt zeigt, und einer sich daran nach hinten anschliessenden rechton Körperbälfte. Die Grenze beider Abschnitte liegt ungefähr in der Gegend, in welcher das Gehörbläschen zu suchen ist. In derselben Höhe befindet sich auch die Opcrationsstelle, an welche sich der linke Randring anschliesst. Dieser lüuft zunächst annïhernd parallel zum Embryo und biegt ungeführ in der Höhe des Knopfes mit scharfem Bogen in denjenigen Teil des Randrings um, welcher in latitudinalem Verlauf den Dotter umkreist. Der dem Embryo parallel laufende Randringteil besitzt vollkommen die morphologischen Charaktere des den Dotter umkreiseuden Randringabschnitts; Differenzierungen embryonaler Organe sind an ihm nicht zu erkennen. Die Bucht zwischen Lmbryo und Randring ist iiberdeckt von der Deckschicht, unter welcher zahlreiche Dotterkeme liegen.

Die Operationsstelle erreicht nicht die Mittellinie des Embryos. Sie ist von derselben getrennt durch Zellen, welche der linken Hülfte des Medullaurohrs sowie dem linken Koptmesoderm angrehören und kaudalwärts immer geringer an Zahl werden, um schliesslich ganz (an lilichenbild in der Höhe des ersten Ursegments) zu verschwinden.

Der Fiopf des Embryos ist noch stark in der Fläche ausgebreitet. Deshalb ist es (am Flächenpräparat) nicht möglich, die Grenzen der einzelnen Hirnabschnitte zu erkennen. 
Die linke Augenblase ist gleichfalls nicht zu sehen.

Der Rumpf ist S-förmig gebogen, er besitzt Medullarrohr, Chorda und rechts sechs abgegliederte Ursegmente. Von mesodermalen Organen der linken Körperhälfte ist nichts zu erkennen. Der Knopf ist von erheblicher Dicke; er springt beträchtlich nach der Dotterbucht vor.

Die Chorda ist viel dïnner als es bei normalen Embryonen gleichen Alters der Fall ist, sie wird undeutlich in der Höhe des ersten Ursegments und verliert sich kaudal in dem Zellenmaterial des Knopfes.

Die sechs ersten Ursegmente haben noch keine lateralen Grenzen, sie gehen direkt iiber in das Mesoderm der Seitenplatten.

Der an den Knopf unter rechtem Winkel sich anschliessende rechte Teil des Randrings ist beträchtlich zellenreicher als der linke an die Operationsstelle grenzende Randringabschnitt.

Schnittbilder: Alle Organe des Kopfes, vor allem die Nervenplatte, sind noch flach ausgebreitet, während in dem Stadium, welches der Embryo seinem Alter und der Zahl der Ursegmente nach erreicht hat, das Medullarrohr schon völlig nach der Mittellinie zusammengeschoben sein müsste.

Die Augenanlagen sind links und rechts als halbkugelige (auf dem Schnitt) Höcker vorhanden. An den seitlichen und kaudalen Zellen der linken Anlage aber macht sich schon die Nähe der Operationsstelle bemerkbar durch das Vorhandensein zahlreicher, stark färbbarer Körnchen und Kügelchen, sowohl in den Zellen wie in den oberflächlichen Lagen des Dotters, wie wir es schon öfter beobachtet haben. Je näher man der Operationsstelle kommt, umso mehr macht sich die flache Ausbreitung der Organe des Kopfes bemerkbar (Fig. 67, 68). Sie ist am stärksten in der Höhe der Operationsstelle. Hier (Fig. 67) zeigt sich, dass nur ein kleiner medianer Teil der linken Körperhälfte nicht betroffen ist von der Operation und der in ihrem Umkreis eingetretenen Zellenwucherung.

Am Dottersackentoblast ist die schon oft beschriebene Anhäufung von Dotterkernen in der Umgebung der Operationsstelle vorhanden.

Verfolgen wir die Serie weiter kaudalwärts, so sehen wir die linke Körperhälfte immer schwächer werden, derart, dass sie in der Höhe des dritten Ursegments nur noch durch wenige Zellen dargestellt wird. Cranial vom dritten Ursegment steht der Embryo mit dem linken Randringteil durch eine mehrere Zellenlagen hohe Brücke in Verbindung (Fig. 69). Sie ist die direkte Fortsetzung des embryonalen Ectoderms, Entoderms, Mesoderms, und hängt zusammen mit dem linken Randring, welcher in dieser Gegend kräftig ausgebildet ist und die beiden primären Keimschichten als deutlich gesonderte Lagen erkennen lïsst. Irgendwelche Organdifferenzierungen sind nicht vorhanden.

Der Rumpf zeigt in der Gegend vor dem ersten Ursegment eine verhältnismässig breite Chorda (Fig. 68). Am Rückenmark sind nach der Stellung 
der Kerne die linke und rechte Hälfte deutlich von einander abzugrenzen. Die rechte Hälfte ist noch flach ausgebreitet, wie es im Kopf der Fall ist. Von der linken Hälfte ist nur der mediane Teil vorhanden, Mesoderm und Entoderm der linken Körperhälfte sind noch verhältnismässig stark und sowohl voneinander wie vom Rïckenmark deutlich abgegrenzt. Seitlich aber stehen sie miteinander und mit dem Entoderm in Verbindung.

An dieser Stelle (Fig. 68) befindet sich der Zusamenhang mit dem linken Randringabschnitt, welcher sich distalwärts an die Operationsstelle anschliesst. Die grosse Menge ron Dotterkernen zeigt die Nähe derselben an.

Im Bereich der vorderen Ursegmente schwinden allmählig die Teile der linken Körperhälfte und zwar derart, dass zuerst (ungefähr in der Höhe des zweiten Ursegments) die Reste der linken Hälfte des Medullarrohrs nicht mehr von den Zellen der rechten Hälfte abgegrenzt werden können (Fig. 69), während die letzten Mesoderm- und Entodermzellen der linken Hälfte noch etwas weiter kaudalwärts (bis zum vierten Ursegment) zu verfolgen sind. Sie sind im Bereich des 5. Ursegments völlig verschwunden, so dass von hier an eine Halbbildung vorliegt (Fig. 70-72).

Die Organe der rechten Körperhälfte zeigen innerhalb der Region der abgegliederten Ursegmente insofern eine Abweichung von dem Zustand eines normalen Embryos dieses Alters und Entwicklungsgrades, als sie noch etwas in der Fläche ansgebreitet sind. In der rechten Hälfte des Medullarrohrs wird ein Centralkanal angelegt, dadurch, dass 1. sich diejenigen Zellen, welche an die freie Oberflïche grenzen und bei der normalen Entwicklung die rechte Auskleidung des Centralkanals geliefert hätten, sich in epithelialer Anordnung zusammenlegen, wie es an der den Ursegmenten zugekehrten Oberfläche des Medullarrohrs der Fall ist, und dass 2. zwischen diesen beiden epithelartig angeordneten Zellenlagen die anderen Kellen in derjenigen Anordnung liegen, wie es im Tnnern des Medullarrohrs normaler Embryonen dieses Alters der Fall ist (Fig. 69). Wichtig ist, dass diese Anordnung sclion vorkanden ist in einer Gegend, in welcher noch ein Teil der linken Medullarrohrhälfte vorhanden ist (Fig. 68). Sie wird umso deutlicher, je näher wir dem Knopf kommen (Fig. 71).

Die Chorda, welche in der Gegend der vorderen Ursegmente etwas schwächer ausgebildet ist (Fig. 69), (wenn auch nicht so schwach, wie es im Flächenbilde schien) als es dem normalen Zustand dieses Stadiums entspricht, wird nach dem hinteren Körperende wieder kräftiger (Fig. 70).

Am Mesoderm der rechten Scite ist nichts besonderes zu bemerken.

Das hintere Körperende zeigt die Anfänge einer Nachbildung des Mesoderms und des Entoderms der linken Körperhälfte. Schon in einiger Ent- . fernung vor dem Knopf, in einer Gegend, in welcher die Chorda noch deutlich von den benachbarten Organen abgegrenzt ist, befindet sich links ron 
Medullarrohr und Chorda, zwischen diesen Organen und dem Dotter eine Zellenlage, welche kaudalwärts imner mächtiger wird, in der Gegend der Fig. 70 mit dem Entoderm der rechten Körperbälfte, in der Gegend der Kupfferschen Blase mit deren Wand zusimmenhängt, und noch weiter kaudal mit dem noch nugesonderten, konzentrisch geschichteten Material der embryonalen Achsenorgane zusammenhängt (Fig. 72).

Der Hohlraum im Entoderm des Knopfes (Fig. 71) entspricht nur der rechten Hälfte der Kupfferschen Blase; dies ergibt sich aus ihrer geringen Grösse und ihrer seitlichen Lage.

Die Dotterbucht zwischen Embryo, Operationsstelle und linkem Randringabschnitt ist vollständig von der Deckschicht ïberzogen und enthält in der oberflächlichen Schicht des Dotters zahlreiche Dotterkerne.

Ergebnisse und Folgerungen: Die Operation hat seitliche Teile der linken Kopfhälfte zerstört, hat aher die unmittelbar neben der Medianlinie befindlichen Teile der linken Hälfte nicht betroffen. Hinter der Operationsstelle steht der Raudring mit dem Embryo durch eine breite Zellenbrücke noch eine kurze Strecke weit in Verbindung. Daraus folgt, dass 1. der verdickte Teil der jungen Keimscheibe zur Zeit der Operation schon den ganzen Kopf des Embryos darstellt, 2. dass die Zerstörung der Zellen den Rand der Keimscheibe nicht betroffen hat, sondern etwas davon entfernt war.

Aus der Tatsache, dass in der Höhe der Operationsstelle die medialen Teile der linken Hälfte noch vorhanden sind, folgt, dass die Operation in einiger Entfermung von der Mittellinie stattgefunden hat.

Damit stimnt ïberein, dass beim Embryo (Fig. 66) die kaudal von der Operationsstelle befindlichen Abschnitte des Kopfes und Rumpfes nur die medialen Teile der linken Körperhälfte enthalten, während die lateralen Teile derselben fehlen. Infolge dessen ist durch die Operation entweder anch die Anlage dieser Teile zerstört, oder sie ist am Anschhuss an die medialen Teile verhindert worden, talls sie in dem lateral von der Operationsstelle liegenden Randringabschnitt enthalten ist.

Letztere Möglichkeit ist aber auszuschliessen, da der linke Randringabschnitt jenseits der Operationsstelle keine Differenzierungen embryonaler Organe aufweist.

Wemn nun durch die Operation sowohl seitliche Teile des Kopfes, als auch die Anlage der linken Rumpf hälfte zugleich zerstört worden sind, so muss das Lagerungsrerhältnis der genannten Bezirke zueinander vor Bildung des Knopfes ein anderes sein als später: Während der Knopf nach seiner Bildung der hinterste Punkt des Embryos ist, muss das Zellemmaterial, aus welchem er entsteht, in früherer Zeit mehr lateral vou der Mittellinie liegen.

Die hiernach sich ergebende Tage der Operationsstelle ist in Fig. 65 dargestellt worden. 


\section{Embryo XV.}

(Taf. VII, Figg. 73, 74, 75-78).

Flächenbild: Ton der grossen Operationsstelle gehen aus, links ein anscheinend halber Embryo, rechts der Randring (Fig. 74).

Die Operationsstelle ist eine aus zahlreichen Zellen bestehende Wucherung, welche beträchtlich über das Niveau ihrer Umgebung hervorragt. In ihrem ganzen Umkreis ist eine radiäre Anordnung der Dotterkerne vorhanden.

Der Embryo hat 14 deutlich erkennbare Ursegmente; er zeigt gleich dem vorher beschriebenen (XIV) verschiedene Krümmungen und eine erhebliche flächenhafte Ausbreitung seines vorderen Körperteils. Das vordere Stück des Kopfes mit Ausnahme eines Teils der linken Augenblase ist von der Wucherung eingenommen. Vom Gehörbläschen ist nichts zu erkennen. In der Gegend des Hinterhirns aber tritt die flächenhafte Ausbreitung mehr und mehr zuriick, und in der Höhe des achten Ursegments erscheint das Medullarrohr als runder Strang.

Der transversale Durchmesser der Ursegmente ist etwas grösser, der kraniokaudale etwas geringer als bei normalen Embryonen derselben Ursegmentzahl. Thre mediale Grenze liegt rentral von dem seitlichen Rand des Nedullarrohres, so dass sie ebenso wie die Chorda erst bei tiefer Einstellung des Mikroskops sichtbar wird. Das hintere Ende des Embryos geht allmählig über in den linken Randringteil.

Am rechten Randring sind keine Differenzierungen embryonaler Organe zu sehen.

Schnittbilder: Die Mitte der Operationsstelle, in welcher das tote Feld liegt, befindet sich ungefähr in der Höhe der ersten Schnitte, welche durch die linke Augenblase gehen. Die sekundäre Wucherung und die nekrobiotischen Vorgänge an den Zellen in seiner Umgebung haben eine grosse Ausdehnung gewonnen. Sie reichen rostralwärts bis zum vordersten Ende des Gehirns, überschreiten nach links die Mittellinie und haben auch die linke Hälfte des Gehirns in Mitleidenschaft gezogen, so dass sogar noch ein Teil der linken Augenanlage ergriffen ist. Kaudalwärts nimmt die Intensität dieses Prozesses allmählig ab, denn in der Höhe der letzten Schnitte, welche noch die Augenanlage treffen, sind nur die dorsalen Teile des Gehirns, sowie das Mesoderm und Entoderm der rechten Seite ergriffen.

In der Gegend des Gehörbläschens (Fig. 75) sind die Organe der linken Seite dem Stadium entsprechend ausgebildet. Das Gehörbläschen hat sich noch nicht vom Ektoderm losgelöst, das Entoder'm erhebt sich zur Bildung der Kiemenspalten. Auf der rechten (operierten Seite) dagegen fehlt jede Andeutung der Gehörblase; rom Mesoderm und Entoderm, deren gegenseitige Abgrenzung hier nicht zu erkennen ist, sind nur wenige $/ \mathrm{ellen}$ vorhanden. 
Etwas weiter kaudalwärts sind Mesoderm und Ektoderm auch auf der rechten Seite dentlich roneinander getrennt; ersteres wird umso stïrker, je näher wir der Ursegmentregion kommen. Das erste Ursegment der linken Seite ist nicht grösser als das der rechten. Weder Medullarrohr noch Chorda zeigen hier die geringste Ungleichheit ihrer Seitenhülften. Der operierten Seite fehlen nur die Seitenplatten, wïhrend das Entoderm soweit lateralwïrts reicht, als die Ursegmente.

Weiter kaudalwärts fällt auf die ansserordentlich geringe Grösse des Nedullarrohrs (Fig. 76). Auch die Chorda ist diinner als bei normalen Embryonen. Ferner ist hervorzuheben, dass die Ursegmente bezw. das Mesoderm der rechten (operierten) Seite nach dem Knopf zu andauernd kleiner werden. Die Ungleichheit beider Seitenhälften ist besonders deutlich in der Gegend der Kupfferschen Blase (Fig. 77), welche selber anscheinend bilateral-symmetrisch ausgebildet und ron annähernd normaler Grösse ist.

Der an den Knopf sich anschliessende linke Randringabschnitt ist zunächst sehr zellenreich (Fig. 78), wird aber in einiger Entfernung rom Knopf allmählig dünner.

Am rechten Randringabschnitt sind ausser der Sonderung in die beiden Keimschichten keinerlei Differenzierungen embryonaler Organe zu entdecken.

Ergebnisse und Folgerungen: Dieser Fall erlaubt in bezug anf die Lagerung des Zellenmaterials am Rande der jungen Keimscheibe keine anderen Schliisse als der vorher geschilderte Embryo XIV. Er zeigt, dass die Zerstörung von Teilen der jungen Keimscheibe, welche seitlich dicht neben der Mittellinie liegen, anch nur seitliche Teile des späteren Embryos betrifft und zwar 1. durch direkte Zerstörung die schon an ihrer richtigen Stelle befindlichen Organe des Kopfes, 2. (indirekt) Organe des Rumpfes durch Zerstörung von Zellen, welche die betreffenden Organe des Rumpfes bilden sollten.

Die wahrscheinliche Lage der Operationsstelle ist in Fig. 73 dargestellt.

\section{Embryo XVI.}

\section{(Taf. VII Figg. 79, 80, 81-83).}

Flächenbild: Die Wucherung, welche sich in der Umgebung der Operationsstelle ausgebildet hat, ist wohl die grösste, welche ich beobachtet habe. Die hellere Stelle in ihr bezeichnet die Gegend der stärksten Einwirkung des elektrischen Stroms (Fig. 80).

Der Randring hat den Dotter zum grössten Teil umwachsen; das Dotterloch misst $1,55 \mathrm{~mm}$ im queren, 2,75 mm im Läugsdurchmesser. Es steht in direktem Zusammenhang mit der Dotterbucht, an deren Scheitel die Operationsstelle liegt. Der rechte Schenkel der Dotterbucht wird ron einem kleinen, kïmmerlichen Embryo gebildet, während der linke Schenkel ans dem unveränderten Randring besteht. Es ist am Flächenbild nicht 
leicht zu erkennen, dass der rechte Schenkel der Dotterbucht ein Embryo ist, denn ansser einer dünnen, nach dem Kuopf sich rerbreiternden Chorda sind weder Sinnesorgane, noch Ursegmente zul erkennen:

Schnittbilder: Die Bestätigung und Sicherstellung dieser Befunde ergibt erst die Schnittuntersuchung. Sie zeigt, dass die bekannten Teränderungen der Zellen, welche an den durch die Operation zerstörten Bezirk angrenzen, sich sekundär fortgesetzt haben, auf das vordere Ende des Embryos, denu innerhalb desselben sind trotz der T'eränderungen noch Medullarrohr, Chorda, Mesoderm abzugrenzen. Daraus folgt aber, dass die Teränderung an dieser Stelle sekundär erfolgt ist, da zur /eit der Operation und noch etliche Zeit später, die genannten Organe sich noch nicht gesondert hatten. Ein Schnitt ungefähr durch die Mitte des Fmbryos (Fig. 81) belehrt uns am besten ïber seinen Entwicklungszustand. In bezug auf das Grössenverhältnis der linken und rechten Hälfte zueinander ist dieser Schnitt das relkleinerte Gegenstïck zu der Fig. 76 vom Embryo XT. Dasselbe zeigt auch der Schnitt durch die Mitte der Kupf ferschen Blase (rgl. Fig. 82 von Embryo XVI mit Fig. 77). Eine Strecke weit hinter dem Knopf ist im Randring noch eine deutliche Tremung in obere und mntere Keimschicht vorLanden (Fig. 83), während der linke Abschnitt des Randrings an keiner Stelle (S. Fig. 81-83) diese Sonderung erkennen lässt, obwohl er verhältuismässig zellenreich ist. Die Dotterbucht ist bis zur Gegend der $K u p f f e r s c h e n$ Blase (also bis zum Schnitt Fig. 82) ron der Deckschicht bedeckt, unter welcher eine Anzahl von Dotterkernen in der oberflächlichen Schicht des Dotters liegen.

Ergebuisse und Folgerungen: Tom Kopf des Embryos ist niehts rorhanden, sein Platz wird ron der Operationsstelle eingenommen. Demnach sind diejenigen Zellen zerstört worden, welche den Kopf hätten bilden sollen. Der schwache in der Entwicklung zurickgebliebene Rmmpf ist mit der rechten Randringhälfte in Verbindung, während die linke Randringhälfte nur zur Umwachsung des Dotters beigetragen hat, im iibrigen aber die unveränderten Randringcharaktere bewahrt hat. Daraus folgt, dass die rumptbildenden Zellen nur mit der rechten Randringhälfte in V'erbindung geblieben sind. Da nun die Operation am Rand der jungen Keimscheibe stattgefunden hat, so müssen die nieht zerstörten rumpfbildenden Zellen seitlich vom kopfbildenden 'Teil gelegen haben. Ihre Bildungsenergie oder aber ihre Zahl kann nur gering gewesen sein, da der von ilnen gebildete Rumpf nur rudimentir ist, denn die Chorda, sowie die Kupfersche Blase sind kleiner als bei normalen Embryonen und die Ursegmentgliederung des Mesoderms ist bisher ausgeblieben, obwohl nach den Befunden an gleichalterigen normalen Embryonen 14 Ursegmente vorhanden sein müssten.

Nerkwirdig bleibt jerloch, dass der Rumpf nieht eine Halbhildnug ist, sondern aus einer linken und einer rechten Hälfte besteht. 
Das Operationsstadium (Fig. 79) zeigt die wahrseheinliche Lage des zerstörten Materials.

\section{Embryo XVII.}

(Taf. V111, Figg. 85, 86, 87-93).

Flächenbild: Das Aussehen dieses Embryos (Fig. 86) gleicht in den wesentlichen Ziigen demjenigen des Embryos XV (Fig. 74). Die Operationsstelle liegt am vorderen Ende des Kopfes und erreicht ebenfalls die linke Augenanlage. Das vordere Stiick des Rumpfes liegt flach ausgebreitet auf dem Dotter, während der dem Knnopf benachbarte Abschnitt eine grössere Konzentration nach der Achse hin anfweist. Auch die bei den Embryonen XIV und XV und anch früher schon beobachteten Krümmungen des Körpers fehlen nicht.

Der Untersehied ron Embryo XV liegt hauptsächlich darin, dass Embryo XVII etwas weiter entwickelt ist. Er hat 17 Ursegmente (Embryo XV hat 14), die Umwachsung des Dotters ist weiter vorgesehritten, die Gehörblase der linken Seite ist auch am Fläehenbild deutlich zu erkennen.

Die mehr ins einzelne gehende Betrachtung dieses Falles ergibt Folgendes: Die Operationsstelle ist gross und erscheint als eine Wucherung, welche die Gegend des gesammten Vorderhirns und sogar noch den medialen Teil der linken Angenblase einnimmt. Die Mittelhirngegend ist gut abgegrenzt von den benachbarten Organen. Das linke Gehörbläschen ist zu erkennen, das rechte fehlt. Die vorderen Ursegmente sind sehr breit, die hinteren aber verschmälern sich allmählig in transversaler Richtung, ohne dass jedoch ihr kranio-kaudaler Durchmesser zunimmt. Das Medullarrohr begrenzt direkt die Dotterbucht. Der Knopf springt stark gegen das Dotterloch vor.

Bei tieferer Einstellung des Mikroskops erscheinen (in der Zeichnung Fig. 90 nicht dargestellt) unter der linken Hälfte des Medullarrohrs, die Chorda und die Ursegmente der rechten Körperhälfte. Sie sind schmaler als die entsprechenden linken Segmente, sind im rorderen Rumpfabschnitt nur undentlich zu erkennen und nicht scharf voneinander abzugrenzen; sie werden aber nach dem hinteren Körperende zu immer deutlicher.

Der linke Randringabschnitt schliesst sich direkt an den Knopf an, der rechte begrenzt zunächst die Dotterbucht und dann das Dotterloch. Dotterbucht und Dotterloch zusammen haben ungefähr birnförmige Gestalt. Der längste Durchmesser beider beträgt $2,64 \mathrm{~mm}$, der quere Durchmesser des Dotterlochs ist gleich $1 \mathrm{~mm}$.

Schnittbilder: Die im Umkreis der Operationsstelle eingetretenen nekrobiotisehen Vorgänge sind an den Zellen des Nervensystems bis zum rostralen Ende des Gehirns vorhanden. Das rechte Mesoderm und Entoderm dieser Gegend sind vollständig bis zur Augenblase hin ergriffen (Fig. 87). Sogar 
die im Innern der linken Augenblase befindlichen Zellen zeigen erhebliche Teränderungen. Dagegen ist der ventrale Teil des Gehirns von der Abgangsstelle der Augenstiele an (Fig. 87, 88) unversehrt geblieben.

Das tote Feld der Operationsstelle liegt in der Gegend der Augenstiele. Hier (Fig. 87) ist der rechte Randring vollständig getrennt von dem Embryo. An dieser Stelle ist ausser dem ventralen Gehirmabschnitt noch ein Teil der äusseren Zellenlage des rechten Augenstiels erhalten, sowie einige Mesodermzellen der rechten Kopfhälfte in dem Winkel zwisehen Augenstiel und Gehirn.

Weiter kaudalwärts sind die nekrobiotischen Vorgänge nur auf die dorsalen Teile des Kopfes beschränkt, sodass in der Höhe der Fig. 88 der grösste Teil des Gehirns und der linken Augenblase das normale Aussehen besitzt, wenn wir von der (sekundären) Schieflage der Medianebene absehen. Diese Verlagerung des Embryos dürfte wohl dureh das Fehlen bezw. geringere Grösse der seitlichen Organe auf der operierten Seite zu erklären sein. Das Mesoderm und das Entoderm der rechten Kopfhälfte ist zellenreicher (Fig. 88) als auf den vorhergehenden Sehnitten. Seitlich vom Kopf liegt der rechte Randringabsehnitt, welcher in der Nähe der Operationsstelle etwas gewulstet ist; weiter kaudalwärts aber (5 Schnitte hinter Fig. 88) zeigt er den gewöhnlichen Bau.

Der Sehnitt durch die Gehörblase (Fig. 89), welcher abgesehen ron der geringen weiteren Entwicklung dem entsprechenden Schnitt (Fig. 75) des Embryos XV gleicht, zeigt ein wohl ausgebildetes Medullarrohr ron beinahe normaler Grösse. Die linke Gehörblase ist rom Nervenrohr deutlich getrennt, hängt aber noch mit dem Ektoderm zusammen. (Beim Embryo XV steht sie mit dem Medullarrohr noch in breiter Verbindung). Das Entoderm der linken Seite ist dem Stadium entsprechend zur Bildung der Kiemenspalten erhoben. Auf der operierten Seite fehlt das Gehörbläschen vollstäudig, vom Entoderm und Mesoderm sind mur die medialen Teile rorhanden. Beide Keimblïtter sind deutlich von einander getrennt. Der rechte Randring zeigt in dieser Gegend nichts Besonderes. Die Dotterbucht ist ron der Deeksehicht bedeckt und enthält in den oberflächlichen Schichten eine geringe Zahl von Dotterkernen.

Im Rumpf des Embryos (Fig. 90) besteht das Medullarrohr aus zwei beinahe symmetrischen Seitenhälften; es sind linke und rechte Ursegmente vorhanden, die Chorda besitzt normale Grösse, das Entoderm erstreckt sich auch in die rechte Körperhälfte hinein. Die linken Ursegnnente sind allerdings grössel als die rechten, welche aber im iibrigen regelmässig gebildet sind (Fig. 90, 91) Seitenplatten fehlen auf der rechten Seite vollständig. Jer Sehnitt durch die Kupffersche Blase (Fig. 92) zeigt den Grössenunterschied zwischen rechtem und linkem Mesoderm besonders deutlieh; ebenso ist Lier ein Grössenunterschied zwisehen deu beiden Hällten des Medullarrohrs deutlich zu erkennen. 
Der linke Randring ist dicht hinter dem Knopf sehr zellenreich (Fig. 93); er zeigt die Abgrenzung der beiden primären Keimschichten. Etwas weiter nach hinten besitzt er die normale Dicke.

Die wahrscheinliche Lage der Operationsstelle ist in das Fliichenbild des Operationsstadiums eingetragen (Fig. 85).

\section{Embryo XVIII.}

\section{('Taf. TIII, Figg. 94, 95, 96, 97)}

Flächenbild: (Fig. 95) Die an der Operationsstelle entstandene Wucherung ist ansserordentlich gross, aber nicht sehr dick. Sie besteht aus zwei Stiicken: Einem flachen rundlichen innerhalb der Keimscheibe befindlichen 'Teil und einem Stiick, welches über den Randring hinaus in die Dotterbucht hineinragt. Letzteres scheint nicht an der Stelle, an welcher es liegt, entstanden zu sein, sondern ist wahrscheinlich ein bei der Konservierung verlagerter Teil der Wucherung, da es ausserhalb des Randrings keine organische Verbindung mit dem Dotter besitzt.

An die Operationsstelle schliesst sich der Embryo an, welcher schräg nach links zieht und am Knopf unter stumpfen Winkel mit dem linken Randring zusammentrifft. Nach rechts von der Operationsstelle geht der rechte Randringabschnitt aus. Er zeigt keine Differenzierungen embryonaler Organe.

Der Embryo verhält sich ähnlich wie der Embryo XVI, indem am Flächenbild ausser der Chorda und dem Knopf keinerlei Organe zu erkennen sind.

Die Umwachsung des Dotters ist bis auf ein Drittel beendigt.

Schnittbilder: An der Operationstelle sind nur noch die tiefen, direkt dem Dotter aufliegenden Zellschichten vorhanden, die oberflächlichen Zellenlagen fehlen vollständig, so dass von den Organen des Kopfes nicht die geringsten Spuren zu finden sind.

Die letzten durch die Wucherung gehenden Schnitte zeigen wenigstens eine Andeutung von Medullarrohr, Chorda, Mesoderm; doch sind die Zellen selber im Zerfall begriffen. Je mehr wir aber bei der Betrachtung der Schnittserie uns von der Operationsstelle entfernen, desto deutlicher wird der Aufbau des Embryos. Nedullarrohr und Chorda sind zunächst sehr klein (Fig. 96), nehmen jedoch caudalwärts allmählig an Masse zu (Fig. 97). Dabei ist auch wieder die Ungleichheit der beiden Körperhälften vorhanden, indem die rechte (operierte) Seite bedentend zellenärmer ist und der Seitenplatten vollständig entbehrt.

Die Lage der Operationsstelle zur Zeit der Ausfïhrung der Operation ist in Fig. 94 eingetragen.

\section{Embryo XIX.}

(Taf. IX, Figg. 98, 99-101).

Flächenbild: Der Zustand dieses Embryos (Fig. 98) entspricht dem beim vorhergehenden Embryo (XVIII) erhobenen Befund, so dass die 
Schilderung sich beschränken kann auf die Hervorhebung des Übereinstimmenden und Abweichenden.

Die Umwachsung ist weiter vorgeschritten, so dass der rechte Randringabschnitt dem Embryo in geringer Entfernung gegentiberliegt und die Dotterbucht ein schmaler Spalt ist. Der quere Durchmesser des Dotterlochs beträgt $1,55 \mathrm{~mm}$, der Durchmesser von Dotterbucht und Dotterloch $3 \mathrm{~mm}$.

Tom Kopf ist wie beim Embryo XVIII nichts zu erkennen, ebensowenig Ursegmente; dagegen ist bei höherer Einstellung die Anlage des Centralkanals im Medullarrohr deutlich sichtbar.

Schnittbilder: Ton den Organen des Kopfes ist keine Spur erhalten. In der Nähe der Operationsstelle (Fig. 99) sind an den dorsalen Teilen des Rumpfes die schon oft erwähnten sekundären Veränderungen der Zellen zu sehen, von welchen in dem abgebildeten Schnitt (Fig. 99) nur die Chorda ganz frei ist. Weiter kandalwärts aber (Fig. 100) sind Medullarrohr, Chorda, Entoderm, rechtes und linkes Mesoderm vorhanden. Nu fehlt dem Mesoderm der rechten Seite die Seitenplattenregion. Sie wiirde rorhanden sein, falls der rechte, dem Embryo dicht anliegende Randring mit dem vorhandenen rechten Mesoderm verschmelzen würde. Die ungleiche Grösse der linken und rechten Körperbälfte tritt anch in diesem Falle wieder am lilarsten hervor in der Gegend der Kupfferschen Blase (Fig. 101).

Ergebnisse und Folgerungen zu den Embryonen XVII bis XIX: Die Embryonen XVII bis XIX stimmen in bezug auf die prinzipiellen Punkte mit den Embryonen XIT bis XVI iiberein. Sie unterscheiden sich ron ihnen dadurch, dass sie etwas weiter entwickelt sind. Daraus darf wohl geschlossen werden, dass ihre Keimscheiben zur Zeit der Operation twas weiter entwickelt waren, was umso wahrscheinlicher ist, als znr Zeit der Operation festgestellt wurde, dass einzelne Kieimscheiben den anderen mm ein Geringes in der Entwicklung voraus sind. Da nun die Embryonen XIV bis XVI ror Bildung des Knopfes operiert sind, so sind es die Embryonen XVII bis XIX in einem etwas weiter entwickelten Stadium, in welchem das Zellenmaterial der linken und der rechten Hälfte des Knopfes schon näher zur Mittellinie zusammengerückt ist, vielleicht entsprechend dem Stadium, welches in den Figg. 85 und $94 \mathrm{im}$ Umriss dargestellt ist.

Wenn nun die Operation anf einem solchen Stadium das Zellenmaterial einer Seite nicht ganz bis an die Mittellinie zerstört (s. Fig. 85, 94), so muss ron ihm ein grösserer Teil iibrig bleiben als es der Fall ist hei mehr seitlicher Lage dieses Materials. Nun hat die Operation bein Eubryo XVII ungefïhr ebensoviel von der rechten Kopfhälfte zerstört wie beim kmbryo XV und dehint sich bei beiden Embryonen nach links und hinten annähernd gleich weit aus. Dagegen ist die rechte Rumpthälfte des Embryos XVII stiirker entwickelt als beim Fmbryo XV. Aus dieser Tatsache folgt, dass bei ersterem eine geringere Zahl der rumptbildenden Zellen der rechten 
Körperhälfte zerstört worlen ist. Bei Voraussetzung gleicher Lage ist dies am einfichsten zu erklïren durch eine grössere Konzentration des betreffenden Zellenmaterials nach der Mittellinie hin, dem da die Lage der Operationsstelle bei beiden Embryonen dieselbe ist, wie aus den Befunden am Kopf folgt, kann der verschiedene Erfolg am Rumpf wohl nur begriindet sein in einer abweichenden Lage des Zellemmaterials, aus welchem der Rumpf entsteht, in den beiden ungleich weit entwickelten Ḱeimscheiben.

Dieses Resultat stimmt auch mit den Beobachtungen der normalen Entwicklung überein, ans welchen die Konzentrierung des auf jüngeren Stadien fiach ausgebreiteten Materials wach der Mittellinie hin folgt.

Bei den Embryonen XVIII, XIX ist ebenso wie bei Embryo XVI der ganze koptbildende Bezirk zerstört, nur ein Teil des rumpfbildenden Bezirkes ist übrig geblieben und zwar im Zusammenhang mit der linken Randringhälfte. Der gebildete Rumpf besitzt eine linke und eine rechte Hälfte, doch ist die der Operationsstelle zugekehrte Hälfte schwïcher ansgebildet als der mit dem Randring in Verbindung stehenden und entbehrt der Seitemplatten. Sie ist aber schwächer als bei dem Embryo XVI. Diese Tatsache führt zu denselben Schlïssen bezïglich des Zustandes und der Tage der rumpfbildenden Teile an der jungen Keimscheibe, welche soeben bei der Besprechung des Embryos XVIII gezogen worden sind.

b) Operationen in der Mittellinie.

a) Vollständiges Fehlen des Embryos.

\section{Embryonen $\mathrm{XX}$ bis XXIV.}

(Taf. IX, X, Figg. 102-117).

Um Wiederholungen zu vermeiden, sollen die 5 Fälle nicht einzeln, sondern zusammen betrachtet werdın. Sie gehören, wie schon weiter oben gesagt wurde, zu der Gruppe ron Operationeu, bei welchen der Versuch gemacht wurde noch vor Erscheinen des Kuopfes am Rande der jungen Keimscheibe genan in der Mittellinie zu operieren, an der Stelle des ersten Umschlages, wo später der Kopf liegt. Dabei sollte, wenn möglich, nur ein kleines Stiick des Randteils zerstört werden.

Letzteres ist nur in wenigen Fällen gelungen. Bei der Mehrzahl hat die Operation einen so grossen Bezirk der Keimscheibe zerstört (s. Fig. 102), dass überhaupt kein Embryo gebildet worden ist. Trotzdem hat der Randring der Zeit und dem Stadium entsprechend den Dotter umwachsen.

Die verschiedenen Phasen dieser Umwachsung zeigen die Embryonen XX-XXIV.

Die Operationsstelle ist mit Ausnahme von Ei XXI (Fig. 106) gross und zeigt makroskopisch wie mikroskopisch die schon bei den vorhergehenden Embryonen geschilderten Zustände. Ei XX (Fig. 103) hat noch ein weites 
Dotterloch, bei Ei XXI (Fig. 106) ist die Umwachsung weiter vorgeschritten, die Eier XXII, XXIII (Fig. 110, 113) sind im Stadium des Dotterlochschlusses, denn die beiden Randringhälften stehen einander dicht gegenüber, bei XXII (Eig. 110) ist sogar schon eine teilweise Verschmelzung der beiden Randringhälften eingetreten. Ei XXIV (Fig. 115) zeigt die vollkommene Vereinigung. Schnittbilder: Das wesentlichste Ergebnis der Schnittuntersuchung ist, dass an keiner Stelle des Randrings der 5 Eier irgendwelche Andentungen von Differenzierungen embryonaler Organe zu erkennen sind; [s. zu Ei XX (Fig. 103) die Schnitte Fig. 104, 105; zu Ei XXI (Fig. 106) die Schnitte Fig. 107, 108, 109; zu Ei XXII (Fig. 110) die Schnitte Fig. 111, 112; zu Ei XXIII (Fig. 113) den Schnitt Fig. 114; zu Ei XXIV (Fig. 115) die die Schnitte Fig. 116, 117].

Ergebnisse und Folgerungen: Von Bedeutung ist zunächst, dass der Randring auch bei vollständigem Fehlen des Embryos die Umwachsung des Dotters vollfiihrt, und zwar entsprechend der Zeit und dem Entwicklungsgrad dêr normalen nicht operierten Embryonen, sowie nach denselben Regeln, welche bei der normalen Entwicklung vorhanden sind, in dem 1. jeder einzelne Randringabschnitt in meridionaler Richtung fortschreitet, dabei aber 2. etwas in der Richtung zum Embryo hin verschoben wird. Besonders interessant ist es hierbei, dass die zweite Bewegungsrichtung trotz des Fehlens des Embryos vorhanden ist, denn darin zeigt sich besonders deutlich, dass die bei der Umwachsung des Dotters im Randring wirkenden Krräfte autonomer Natur sind und dass sie nicht vom Embryo aus geregelt oder beeinflusst zu werden brauchen. Andererseits aber beweist das Fehlen jeder Organdifferenzierung im Randring, dass ihm die Fühigkeit zur Bildung achsialer Organe des Embryos fehlt, er dient wesentlich zur Bildung des Dottersackes, d. h. ventraler Teile. Welcher Art diese Teile sind, kann aus diesem Versuch nicht ersehen werden, da auch die älteren Stadien (Fig. 110, 113, 115) noch keine charakteristischen Formationen erkennen lassen.

Aus der Tatsache, dass der Embryo vollständig fehlt, folgt, dass die Operation das Material zerstört hat, aus welchem er gebildet werden sollte. Dies ist also in dem dickeren Teil des Keimscheibenrandes enthalten (s. Fig. 102), an welchem zuerst die untere Keimschicht entsteht.

\section{B) Spaltbildungen. ${ }^{1}$ )}

\section{Embryo XXV.}

Flächenbild: In vorderen 'Teil des Embryos hängen beide Körperhälften miteinander in der Medianlinie zusammen. Die Rumpfhälften aber

1) Die beiden Embryonen XXV, XXVI sind schon in einer früheren Mitteilung (49) verwendet worden: von einer Wiederholung der Figuren musste der Kosten wegen Abstand genommen werden. Ieh bitte deshalb an genamuter Stelle nachschlagen zu wollen. Kmbryo XYY ist abgebildet auf 'Tafel XVI Fig. 9-14; Embryo XXVI auf Tafel XV Fig. 1-8. 
sind getrennt durch die Dotterbucht, deren vorderes Ende durch die kleine, schwer zu erkemende Operationsstelle bezeichnet wird. Die Umwachsung des Dotters ist nahezu vollendet.

Am Kopf sind weder Augenblasen noch Gehörbläschen deutlich zu erkennen. Die Trennung beider Körperhälften voneinander findet in der Gegend vor dem ersten Ursegment statt.

Links sind 16, rechts 18 Ursegmente vorhanden. Die entsprechenden Teile beider Körperhälften liegen einander nicht in gleicher Höhe gcgenüber. Ls ist eine geringe Verschiebung um 3 Ursegmente eingetreten, so dass das erste Ursegment der rechten Körperhälfte in gleicher Höhe mit dem 4. der linken Hälfte liegt. Jede der beiden Hälften besitzt ein Medullarrohr, eine Chorda, eine Reihe Ursegmente nebst Seitenplatten, einen noclı ungegliederten Körperabschnitt und den Knopf.

Schnittbilder: Eine annähernd normale Ausbildung der Organe zeigt sich nur in den ersten 11 Schnitten (it $10 \mu$ ), am 12. Schnitt beginnt schon ron der dorsalen Seite her eine trennende Spalte zwischen den beiden Hälften des Medullarrohrs aufzutreten, welche beim 34. Schnitt auch ventral durchschneidet. Die beiden Medullarrohrhälften liegen aber auch nach erfolgter ventraler Trennung so dicht aneinander, dass es zu verstehen ist, warum beim Flächenbilde diese so weit rostralwärts reichende Spaltung (bezw. Nichtvereinigung) der beiclen Hälften nicht wahrgenommen wurde. In jeder der Medullarrohrhälften ist die Bildung eines Centralkanals eingeleitet; es ist ein geringer Grössenunterschied zwischen der schwächeren medialen und der stärkeren lateralen Hälfte vorhanden.

Die Augenblasen sind mit Sicherheit nicht zu bestimmen, ein paar kleine Ausbuchtungen der Hirnwand, an denjenigen Stellen, an welchen die Augenstiele ausgehen müssten, können mit einiger Wahrscheinlichkeit als rudimen . täre Augenblasenanlagen gedeutet werden. Die Gehörbläschen sind aber (in jeder Hälfte eins) gut ausgebildet. Die Chorda ist in der Gegend der Gehörbläschen nicht sicher zu erkennen. Sie wird erst weiter kaudalwärts deutlich. Der Spalt zwischen den beiden Medullarrohrhälften wird dorsal rom Ektoderm überbrückt und enthält zahlreiche locker angeordnete (Mesoderm?) Zellen.

Der Spalt wird auf den folgenden Schnitten immer weiter, die in ihm liegenden lockeren Zellen zahlreicher, das Ektoderm, weiter kranial den Spalt überspannend, senkt sich mit immer mehr ventral reichender Falte in die Tiefe und tritt mit den locker liegenden Zellen und dem Entoderm in Verbindung. Dadurch entsteht eine mittlere Zellenmasse, welche etwas weiter kaudalwärts unterbrochen ist, so dass von hier an beide Körperhälften gänzlich voneinander getrennt sind.

In dem Winkel, welcher durch die beiden getrennten Körperhälften gebildet ist, finden wir die Operationsstelle. Beide Körperhälften haben 
je ein Medullarrohr, cine Chorda sowie das ihnen zukommende Mesoderm und Entoderm. An jedem Medullarrohr trennt die Anlage des Centralkanals die Zellmasse in zwei beinahe gleiche Hälften, doch ist die schwächere Ausbildung der medialen Hälfte immerhin zu erkennen. Der linke Chordaquerschnitt ist grösser als der rechte. An der medialen Seite jeder Hälfte liegt ein diekes Ektoderm, welches mit dem Entoderm in Verbindung steht. In dem Raum zwisehen diesem Ektoderm, der medialen Fläche des Medullarrohrs und der Chorda befinden sich lockere Zellen, welche die Fortsetzung der schon oben genannten Zellen sind. Zu welchem Blatt sie zu rechnen sind, kann hier noch nicht gesagt werden; erst auf den folgenden Schnitten zeigt es sich, dass sie als mesodermale Zellen zu betrachten sind, da sie an der Grenze des 4. bis 5. Ursegments auf der linken Seite eine ursegmentartige Anordnung zeigen. Auf der rechten Seite nimmt die Kahl dieser Zellen immer mehr ab.

Von den anderen Organen in dieser Gegend ist zu bemerken, dass die Chorda der rechten Hälfte dicker ist als die der linken Hülfte, während es weiter kranial umgekehrt ist. Das Entoderm der linken Hälfte iiberragt das mediale Ursegment um ein weniges in medialer Richtung.

Das mediale Mesoderm der linken Seite, von dessen ursegmentartiger Anordnung oben die Rede war, hört am Anfang des 7. Ursegments auf. An der rechten Hälfte endigt es schon in der Höhe des 4. Ursegments; doch ist es möglich, dass es in Gestalt von einer oder zwei Zellen, denen man es nicht ansehen kann, ob sie etwa zum Entoderm zuzurechnen sind, sich auch an anderen Stellen erhält. Deutlich erkennbar tritt mediales Mesoderm an der linken Hälfte erst wieder auf in der Höhe der Mitte des 8. Ursegments und in der rechten Hälfte am Anfang des 6. Ursegments, wo es wieder in Form eines Bläschens von 10-12 epithelial angeordneten zylindrischen Zellen crscheint. An der linken Körperhälfte ist es bedeutend schwächer, nur als drei bis vier unregelmässig angeordnete Zellen (am Querschnitt) vorhanden.

Am Anfang des 8. Ursegments der rechten Seite verschwindet das mediale Mesoderm und erscheint erst wieder im Bereich des 17. Ursegments, während es auf der linken Hälfte bis zur Gegend des Canalis neurentericus bleibt.

Die Kupffersche Blase ist in der linken Kööperhälfte iiherhaupt nicht vorhanden, auf der rechten liegt an entsprechender Stelle zwischen den ventralen Zellen des Knopfes eine kleine Höhle, welche ausser ihrer Lage keinen der bekannten Charaktere aufweist, sodass es mentsehieden bleiben muss, ob wir es hier mit einer - wenn auch äusserst rudimentïren Kupfferschen Blase zu tun haben.

\section{Embryo XXVI.}

Flächenlild: Das kraniale Stïck des Kopfes ist ron normalem Ausschen, dem Alter und dem Stadium entsprechend. Die Trenumg der heiden 
Körperhälften beginnt schon in der Höhe der kranialen Grenze der Gehörbläschen. Die beiden Hälften weichen in einem Winkel von ungefähr $30^{\circ}$ auseinander. Die Zahl der Ursegmente, welche auf beiden Seiten gleich ist, beträgt 16. Der Randring hat den Dotter noch nicht vollständig umwachsen, die Durchmesser des Dotterloches sind am kouservierten Präparat 2,3:2,5 mm.

Die Augenanlagen sind auf dem Stadium, in welchem die Becherbildung beginnt; von der Linsenanlage ist noch nichts zu sehen. Die Kiemenbogenanlagen sind nicht so deutlich, als es zu erwarten ist, dagegen entspricht die Ausbildung der Gehörbläschen völlig dem Stadium.

Die Stelle, an welcher die Operation stattgefunden hat, ist auch an diesem Embryo schwer zu erkenuen. Nur eine reichliche Anhäufung von Dotterkernen und einige locker liegende Zellen am Scheitel des Winkels. welchen die beiden auseinanderweichenden Körperhälften mit einander bilden, deuten die Operationsstelle an.

Jede der beiden Hälften besitzt ein Medullarrohr, eine Chorda, eine Reihe von 16 Ursegmenten und die dazı gehörenden Seitenplatten. Das Medullarrohr grenzt mit seiner einen Seite an den die beiden Körperhälften trennenden Spalt. In seiner Mitte erkennt man als helleren Streifen die Anlage des Centralkanals; die Chorda liegt unter dem lateralen Teil des Medullarrohrs, die Ursegmente sind noch Hach ausgebreitet.

In der hinteren Körperregion, von der Höhe der letzten Ursegmente bis zum Knopf, grenzen die Medullarrohre beider Körperhälften nicht mehr an den Dotter. Sie sind ron demselben geschieden durch einen Zellenstreifen, welcher an der linken Körperhälfte, nach dem Knopf zu, allmählig schwächer, an der rechten aber stärker wird. In keinem der beiden Knöpfe ist am Flächeubild die Kupffersche Blase zu erkennen.

Der zwischen den beiden Körperhälften liegende Dotter ist ron der Deckschicht bedeckt und enthält zahlreiche rundliche Dotterkerne. Nach dem Dotterloch zu hören Deckschicht und. Dotterkerne mit einer leicht gebogenen Grenze auf.

Schnittbilder: Das vordere Stiick des Kopfes ist von normalem Bau. Wenige Schnitte (3 i. 10 " ) hinter den Augenanlagen sind die dorsalen Ränder der beiden Medullarrohrhälften nicht mehr zur Vereinigung gekommen, so dass zwischen ihnen ein schmaler seichter Spalt bleibt, welcher rom Ektoderm iiberbrückt wird. Dieser Spalt wird mit jedem folgenden Schnitt tiefer, bis schliesslich in der Gegend kaudal von den Gebörblasen die beiden Medullarrohrhälften nur noch ventral zusammenhängen.

Dabei verdienen zwei Punkte besondere Beachtung: 1. dass durch die Anordnung der Zellen in jeder der beiden Medullarrohrhälften ein Centralkanal angelegt ist, 2. dass unterhalb des die Spalte zwischen den beiden Medullarrohrhälften überbrïckenden Ektoderms eine Menge locker angeordneter Zellen liegen. 
Die Anlage des Centralkanals teilt jede der Medullarrohrhälften in einen lateralen, zellenreicheren und einen medialen, zellenärmeren 'Teil, ein Verhalton, welches bis in den Knopf hinein bleibt.

Über die histologischen Charaktere der erwähnten lockeren Zellen lässt sich nichts positives aussagen; sie sind vom Medullarrohr scharf abgegrenzt, besitzen aber keine scharfe Grenze gegen das Ektoderm.

Die Chorda zeigt innerhalb der bisher geschilderten Region eine plötzlich (auf drei Schnitten) sich vollziehende Terbreiterung, ungeführ vier mal so breit, als ihr Durchmesser an dieser Stelle bei einem gleich alten normalen Embryo ist. Die mittlere Partie dieses verbreiterten Teils enthält viele unregelmässig gestaltete, stark gefärbte Schollen und Brocken, welche anf einen Zerfall der Elemente hindenten. Nur die seitlichen Teile haben den typischen Chordabau.

Ventral von der Chorda liegt eine einschichtige Lage platter Zellen, deren Zusammenhang mit den seitlichen hochzylindrischen Entodermzellen für ihre Zugehörigkeit zu diesen spricht. Ton den seitlichen Organen ist nichts Abweichendes zu bemerken.

Der Dotter zeigt in dieser Gegend die uns bekannten Zeichen der Operation, durch welche die Spaltung (oder vielmehr die Nichtvereinigung der linken und rechten Hälfte) des Knopfes hervorgerufen wurde, in Gestalt einer dichten Anhäufung von Dotterkernen und anderer charakteristischer Teränderungen.

Die Betrachtung der Schnitt-Serie ergibt, dass die vollständige Trennung der beiden Körperhälften weiter kaudal erfolgt, als es nach dem Flächenbild zu erwarten ist. Der tiefe Spalt zwischen den beiden Medullarrohrhälften ruft am Flächenbild den Auschein einer kranial weiter reichenden Spaltung hervor.

Bis zum dritten Ursegment besteht jede der beiden Körperhälften nur aus der Hälfte eines Embryos, wenn anch die Chorda sich in der Grösse des Querschnitts kaum von dem Aussehen entsprechender ganzer Embryonen unterscheidet und jede Medullarrohrhälfte durch den angelegten Centralkanal den Schein einer ganzen Bildung erweckt.

Die Ursegmente und die Seitenplatten jeder Hälfte sehen nicht anders aus, als bei normalen Embryonen. Das Entoderm aber reicht in der Richtung zur Spalte stets weiter als die Chorda, welche unter der lateralen Hälfte des Medullarrohrs liegt.

An der linken Körperhälfte tritt in der Höhe des 4., 5., 6. Ursegments ein im Querschnitt dreiseitiges und höchstens aus zehn epithelial angeordneten Zellen bestchendes Bläschen auf, welches in dem Raum zwischen der medialen Wand des Medullarrohrs, der Chorda nud dem Entoderm liegt. Nach dieser Lage und nach der Anordnung der Zellen erscheint es als ein kleines Ursegment. Es tritt in der Höhe des kranialen Endes des 4. Ursegments 
plötzlich auf, wird im Gebiet des 5. und 6. immer zellenärmer und verschwindet am Anfang des 7. vollständig.

An der rechten Körperhälfte ist etwas derartiges bis zum 6. Ursegment nicht vorhanden und anch an der linken Seite tritt eine ähuliche Bildung vom 7. bis zum 16. Ursegment nicht wieder auf.

In der Region des ungegliederten Mesoderms, dicht hinter dem letzten Ursegment, tritt annïhernd symmetrisch an beiden Körperhälften neben dem Medullarrohr und der Chorda der rom Flächenbild bekannte Zellstreifen auf, welcher nach Lage und Ban als Mesoderm zu bezeichnen ist. Er ist links schwächer als rechts. Die an der Oberfläche liegenden Zellen sind epithelial angeordnet, die inneren Zellen liegen regellos durcheinander, so dass infolge der hier nicht rorhandenen Seitenplatten das Bild eines Ursegmentsquerschnittes vorgetäuscht wird. Das Entoderm reicht auf manchen Schnitten ebensoweit medial, wie das mediale Mesoderm, auf anderen Schnitten bleibt es etwas zuriuck, stets ragt es aber medial über die Chorda hinaus. Das Medullarrohr liegt nicht mehr geneigt, wie in der Mitte des Rumpfes. Der Unterschied zwischen der medialen schwächeren und der lateralen stärkeren Hälfte jedes Medullarrohrs ist in dieser Gegend sehr augenfällig. Das laterale Nesoderm zeigt einen gauz normalen Bau.

Bei der Durchmusterung der Schnittserie ergiht sich wie beim Flächenbild das allmählige Schwächerwerden des medialen Mesodermstreifens nach dem Knopf hin.

Besonders lehrreich ist der Schnitt durch die Mitte der Kupfferschen Blase der rechten Körperhälfte (an der linken ist sie nicht vorhanden). Sie ist in dorsoventraler Richtung stark abgeplattet; in der dorsalen Wand fehlt die regelmässige Anordnung der Kerve, welche derselben das charakteristische Aussehen gibt, ihre ventrale Wand besteht aus zwei Zellenlagen. Die Anordnung der dorsal von ihr gelegenen Chorda- und Medullarrohrzellen ist wie gewöhulich, abgesehen davon, dass auch hier schon die schwächere Ausbildung der medialen Hälfte sich bemerkbar macht. Die Zellen des medialen Mesodermstreifens gehen ohne Grenze über in die Zellen, welche die Wand der Kupfferschen Blase bilden.

Tnnerhalb der linken Körperhälfte ist, wie schon gesagt wurde, keine Kupffersche Blase vorhanden. Abgesehen hierron ist an den Organen dieser Seite weiter nichts Besonderes zu bemerken.

Kandal ron dem Gebiet der Kupfferschen Blase liegt eine beträchtliche Anhäufung ron Zellen, in welcher eine Spalte die Grenze der oberen und der unteren Keimschicht bezeichnet; die Zone, an welcher beide Keimschichten ineinander iibergehen, ist ausserordentlich breit. Das Entoderm ist als besonders abgegrenzte Lage nicht zu erkennen. Die Anordnung der Kerne ist noch ähnlich wie in der Gegend der Kupffferschen Blase; die Zugehörigkeit der Zellen oder Zellengruppen zur oberen oder 
unteren Keimschicht ist innerhalb der breiten C̈bergangszone nicht zu bestimmen.

Noch in grösserer Entferung vom Knopf ist eine starke Anhäufung ron Zellenmaterial vorhanden; doch ist hier die Anordnung der Zellen viel unregelmässiger.

Ergebnisse und Folgerungen aus den Embryonen XXV, XXVI: Der Beginn der Spaltung beider Köörperhälften darf erst ron dem Punkte an gerechnet werden, an welchem ihre ventralen Teile nicht mehr mit einander in der Mittellinie zusammenhängen. Als Marke hierfür dient am besten die Chorda - die weit rostralwärts reichende Spaltung der dorsalen Teile des Medullarrohrs ist auf mangehafte Connascenz zurickzuführen; sie kommt deshalb für die Beurteilung, an welcher Stelle die Spaltung beginnt, nicht in Betracht. -

Nach diesen Gesichtspunkten erfolgt die Trennung der beiden Körperhälften beim Embryo XXVI kurz hinter den Gehörblasen, beim Embryo XXV schon im Bereich derselben.

Bei beiden Embryonen haben wir in jeder Körperhälfte ausser der Hälfte des Medullarrohrs, der Chorda, des Entoderms und des Mesoderms noch teilweise eine Nachbildung des Mesoderms der fehlenden Hälfte.

Medullarrohr und Chordahälfte sind durch Umlagerung ihrer Zellen zu einem ganzen Gebilde geworden. Diese Tatsache ist von grosser Bedeutung für die Dentung der Befunde der Embryonen XIV-XIX, denn sie beweist mit Sicherheit, dass ans dem Bildungsmaterial einer Körperhälfte ein Medullarrohr und eine Chorda hervorgehen kann, die nur in geringem Maasse sich unterscheiden von den entsprechenden Organen, welche ans dem Bildungsmaterial beider Körperhälften entstehen. Da es num bei den Embryonen XXV und XXVI wohl ausser Zweifel ist, dass jede der beiden Körperhälften ausschliesslich aus den zu ihrer Bildung bestimmten Zellen hervorgegangen ist ohne Beteiligung ron Material der anderen Körperhälfte, so dürfte es gestattet sein am Nedullarrohr und der Chorda beider Hïlften nach besonderen Kennzeichen zu suchen, welche charakteristisch sind für die ans dem Bildungsmaterial einer Knopfhälfte herrorgegangenen und durch Regeneration vervollständigten Rumpfhälfte.

Die Chorda liegt fast in allen Schnitten seitlich im Winkel zwischen der lateralen Wand des Medullarrohrs nud der medialen W'and der Ursegmente, ihr Querschnitt ist meistens kleiner als bei normalen Embryonen. Letzteres ist nicht, wie man annehmen könnte, etwas Selbstrerstïndliches; denn bei der eigenartigen Durcheinanderschiebung der Chordazellen, durch welche ans dem seitlichen Nebencinander linker und rechter Kellen ein Hintereinander wird, ist es möglich, dass auch der Chordaquerschnitt einer Halbbildung ganz oder stellenweise die Grösse einer normalen Chorda hat. 
I)avon abgesehen ist der geringere Chordaquerschnitt wohl stets ein positives Zeichen dafür, dass an dem Aufbau der Chorda weniger Zellen beteiligt sind.

Am Medullarrohr sind dic beiden Hälften meist ungleich gross und zwar ist die der Operationsstelle zugekehrte Hälfte zellenälmer als die andere.

Als weitere ebenfalls mit Rücksicht auf die Deutung der Zustände an den Embryonen XIV-XIX wertvolle Besonderheiten der Spaltbildungen sind zu nennen, dass das Entoderm im Bereich des Rumpfes stets medial iiber die Chorda hinausragt und dass eine Nachbildung des Mesoderms der fehlenden Körperhälfte eingetreten ist.

Letztere ist mvollständig und zwar 1. der Grösse nach, indem a) nur ein ursegmentartiges Gebilde von geringeren Dimensionen gebildet ist und b) die Seitemplatten ganz fehlen; 2. der Ausclehnung nach, insofern als sic, a) nicht in der ganzen Länge des gegliederten und ungegliederten Körperabschnitts und b) an den beiden Hälften desselben Embryos in verschiedener Stärke und an verschiedenen Stellen auftritt.

So haben wir beim Embryo XXVI nachgebildetes Mesoderm an beiden Körperhälften im Bereich des ungegliederten Mesodermstreifens und an einem kleinen Bezirk in der Höhe des 4.-6. Ursegments der linken Körperhälfte. Am Embryo XXV ist das nachgebildete Mesoderm vorhanden, an der linken Hälfte bis zum Knopf, mit Ansnahme eines kleinen Gebietes in der Höhe des 7. und Anfang des 8. Ursegments, an der rechten Hälfte dagegen fehlt es in der Gegend des 4.-6. und 8.-17. Ursegments.

Ferner ist von Interesse, dass die Kupffersche Blase in guter Ausbildung mur in der rechten Hälfte des Embryos XXVI vorhanden ist, während sie in den linken Hälften beider Embryonen fehlt und die Höhle in der rechten Hälfte des Embryos XXV nicht mit Sicherheit als Kupffersche Blase bezeichnet werden kann.

3. Bildung des Embryos bei unterbliebener Umwachsung des Dotters.

\section{Embryo XXVII.}

(Taf. X Figg. 118-121).

Allgemeines: Dieser Embryo wurde zufällig erhalten bei einem der ersten Operationsversuche. Über die Ursache seiner Entstehung vermag ich nichts Bestimmtes anzugeben, denn die Eischale war bei den Eiern dieses Versuches so undurchsichtig, dass trotz kräftiger Durchleuchtung die Orientierung am Rande der Keimscheibe zur Zeit der Entstehung des Knopfes unmöglich war und damit anch die Operationsstelle nicht genau lokalisiert werden konnte.

Die Operation findet statt am 10. Tage nach der Befruchtung, zn einer Zeit, in welcher der Knopf eben gebildet ist; die Konservierung erfolgt 
6 Tage später, während die normalen Embryonen sich anf dem Stadium des Dotterlochschlusses befinden.

Flächenbild: Der Embryo (Fig. 118) ist mit 12 Ursegmenten zwar $n \mathrm{~m}$ ein Geringes in der Entwicklung zurück; er ist aber in iibrigen normal ausgebildet. Die einzige Abweichung rom normalen Zustand besteht darin, dass er eine kleine kreisrunde Keimscheibe durchsetzt, deren Randring von äusserster Zartheit ist und erst in nächster Nähe des Knopfes etwas zellenreicher wird.

Die Operationsstelle liegt dicht ror dem Kopf im Bereich des Randrings.

Schnittbilder: (Figg. 119--121). Anch hierbei zeigt sich, dass der Embryo kräftig und normal ausgebildet ist; sein hinteres Körperende ist sogar zellenreicher als bei entsprechenden normalen Embryonen. Der Raud besitzt trotz seiner Zartheit die typischen Charaktere in dem Vorhandensein der unteren Schicht und dem Verhältnis zu den Dotterkernen, welche ebenfalls nur soweit seitlich reichen als der zellige Randring.

Ergebnisse und Folgerungen: Das wesentlichste Ergebnis dieses Versuchs ist, dass die Umwachsung des Dotters nicht die notwendige Torbedingung zur Bildung des Embryos ist; wäre dies der Fall, so hätte sich hier kein Embryo bilden dürfen. Für die Frage, ob die Zellen des Randrings sich dem Rande folgend zum Knopf begeben haben, und trotz unterbliebener Umwachsung den Embryo gebildet oder auch nur Anteil genommen haben an seiner Bildung, dafür ergibt die Betrachtung dieses Falles nichts Bestimmtes. Die ausserordentliche Zartheit des Randrings beweist hier nichts, denn dies ist laut Protokoll an allen Eiern dieser Brut vorhanden.

\section{B. Volumen-Berechnung.}

1. Vorbemerkungen.

Die Volumenbestimmungen an Lachsembryonen, aus welchen W. His (29) den Schluss zieht, dass die Bildung des Knochenfischembryos in der Umlagerung (ohne Volumenvermehrung!) eines Materials besteht, welches „zu Beginn der Formungsperiode in Gestalt eines flachen Klumpens beisammen war", sind bis jetzt noch nicht wiederholt worden.

Obwohl die Ergebnisse der oben geschilderten Experimente schon für sich allein geniigend sein dïrften zum Nachweis, dass der Rumpf des Embryos nicht durch die Zusammenlagerung der beiden Randringhïlften entsteht, bin ich doch der Meinung, dass die Sorgfalt und Miihe, welche His seinerzeit auf die volumetrische Untersuchung verwendet hat, es erfordern, den ron diesem Autor eingeschlagenen Weg zu betreten, ahgesehen ron der Bedeutung, welchen eine solche mit den heutigen Hilfsmitteln der Mikrotechnik unter- 
nommene Untersuchung hat fiir die Fällung eines positiven Urteils über den Wert solcher Nassenbestimmungen im allgemeinen und besonderen.

Die Tatsache, dass $\mathrm{H}$ is zunächst aus plastischen Rekonstruktionen das Tolumen eines Lachsembryos nach eben rollendeter Umwachsung auf 0,73 chmm, dasjenige einer ganzen Keimscheibe im Beginn der Embryobildung mit $0,78 \mathrm{cbmm}$ bestimmte, dann aber zwei Jahre später mit verbesserter Methode die Tolmmina einer Reihe jüngerer und älterer Embryonen zu $0.523,0,553,0,546,0,548,0,546$ cbmm bestimmte soll ausser acht gelassen werden, deun anch hente ist noch nicht die Zeit zu einer exakten Tolumenbestimmung so junger Embryonen gekommen.

Die Schwierigkeiten, welche einer solchen Bestimmung entgegenstehen, sind zunächst die verhältnismässig grosse individuelle Tariation nicht allein zwischen den Eiern verschiedener Bruten, sondern auch an den Eiern desselben Individuums, Unterschiede, welche nicht allein Verschiedenheiten der Grösse, sondern auch des Entwicklungsgrades sind. Wenn num auch diese Terschiedenheiten bei morphologischen Untersuchungen weniger störend sind, so spielen sie bei Massenbestimmungen eine umso grössere Rolle, denn bei der Kreisform der jungen Keimscheibe und der Kugelform des Eies bedingen selbst geringe Grössenunterschiede des Durchmessers schon erhebliche Unterschiede des Volumens.

Ich habe versucht, diese Schwierigkeiten dadurch zu umgehen, dass ich 1. nu Eier eines Meibchens befruchtet mit dem Sperma eines Männchens benutzt habe, 2. dadurch, dass nur Eier ron annähernd gleicher Grösse konserviert wurden und dass 3. eine grössere Anzahl ron Volumenbestimmungen angefertigt wurlen, um Zufälligkeiten möglichst zu vermeiden.

Fine viel grössere Fehlerquelle liegt in der Unzulänglichkeit der Methoden des Fixierens und Härtens, des Einbettens, Schueidens und Aufkilebens der Schnitte.

In den Fixierungs- und Härtungsmethodeu insoferu, als Quellungeu und Schrumpfungen, Nichtfällung oder Auslaugung schon gefällter Eiweisskörper das Tolumen verändern. Man könnte ja daran denken, durch einheitliche Handhabung derselben Methode hier einen gleichbleibenden Fehler. $2 u$ schaffen, welcher nicht in Rechnung käme, sobald es sich um die Feststellung relativer Verhältnisse handelt, doch darf man nicht vergessen, dass die verschiedenen Entwicklungsstadien mit ihrem verschiedenen Gehalt deutound protoplasmatischer Substanzen und wohl auch verschiedenen osmotischen Verhältnissen kein gleichartiges Material sind. Deshalb diufte zu vermuten sein, dass die verschiedenen Stadien in verschiedener Treise selbst bei Anwendung derselben Methode sich verhalten werden, während innerhalb desselben Stadiums eine gewisse Gleichartigkeit rorhanden sein diurfte. Einen Beweis für die künstliche Erzengung sehr erheblicher V'eränderungen und somit eine Probe anf die Richtigkeit der eben entwickelten Ideen bieten die 
Morulastadien, deren wach der Fixierung vorhandenes lockeres Gefuige bei lebenden Keimscheiben nicht rorhanden ist.

Ton den Einbettungs-Methoden kommt hier in Betracht der Einschluss in Paraffin, bei welchem fast immer eine grössere oder geringere Stiickverkleinerung eintritt. Sie ist bei den einzelnen Embryonen ungleich und muss deshalb jedesmal besonder's berechnet werden aus der Zahl der Schnitte und der Grösse des Flächenbildes, welches vor der Einbettung angefertigt wird. Es ist daher selbstrerständlich, dass die Grösse des Fläehenbildes authentiseh sein muss, was dureh Photographieren des Embryos und eines neben ihn gelegten Massstabs mit geniigender Genanigkeit geschehen kann.

Eine sehr erhebliche Quelle ron Trrtïmern ist die Zusammenschiebung der Schnitte beim Schneiden, welehe jedoch leicht rermieden werden kaun. Über diesen Punkt ist verschiedentlich geschrieben worden, und wie es zu sein pflegt, haben die Kritiker hüben und driben etwas iiber das Ziel hinausgeschossen. Man mag mir deshalb gestatten, meinen vermittelnden Standpunkt kurz darzulegen: Versehiehungen der Schnitte können sowohl hei querer wie bei sehräger Messerstellung rorkommen. Ob sie rermierlen werden, hängt ab ron dem Verhältnis zwischen der Grösse des Blockes, der Konsistenz des Paraffins, und der Dieke des Schnitts. Auch die schräge Messerstellung schïtzt nicht vor Verzerrungen, wenn man von 100 qmm Fläche Schnitte von 3 "Dicke erzielen will. Man wird deshalb bei jedem einzelnen Objekt Tersuche anstellen müssen und daruach entweder querc oder schräge Messerstellung wählen.

Auch die Befestigung der Schnitte auf dem Objectträger kann die Ursache ron Fehlern werden, insofern, als bei Anwendung von Wasser zur Streckung ron Schnitten oder Schnittbändern eine zu geringe oder zu grosse Streckung eintreten kann.

Schliesslich haften dann noch, selbst wenn alle diese Fehlerquellen nach Möglichkeit rermieden sind, auch den Methoden der Tolumenlestimmung mannigfache Mängel an.

\section{Methodik der Untersuchung.}

Angesichts aller dieser Sehwierigkeiten, deren Erkennung und Termeidnug erst nach einer Anzahl ron Vorrersuchen gelang, bin ich zur Befolgung folgender Methode gekommen.

Die zur Verwendung gekommenen Keimscheiben und Embryonen der Forelle (Trutta fario) sind von einer Brut (Fier eines Weibehens befruchtet mit Sperma eines Männchens). Sie sind sïntlich nach derselben Methode konserviert und weiter behandelt worden. Torfixierung in Chromessigsäure, abhlasen des Dutters in physiologiseher Kochsalzlösung, Nach- 
fixierung in Sublimat. Dann Alkohol $70 \%$ mit Jod, Alkohol 80\%, $90 \%, 95 \%$.

In $95 \%$ Alkohol werden die Elïchenbilder photographiert zugleich mit einem beigelegten Massstab. Bei älteren Embryonen, an denen die genaue Bestimmung des vorderen und des hinteren Endpunktes Schwierigkeiten macht, wird die Dotterhaut rechteckig zugeschnitten, damit sichere Messpunkte zur Berechnung der Paraffinverkürzung vorhanden sind. (Natïrlich muss in diesen Fällen das ganze Keimhautstiick geschnitten und aufgeklebt werden.)

Einbettung erfolgt nach Alkohol 99,8\%, Xylol, Xylol-Paraffin in Paraffin. Hierin bleiben die Embryonen höchstens 10-15 Minuten.

Schneiden mit quer gestelltem Messer. Schnittdicke teils $10 \mu$, teils $20 \mu$. Aufkleben mit Glycerin-Eiweis und Wasser. Färbung durch Hämatoxylin nach Boehmer.

Auszïhlung der Schnitte und Berechunng der Paraffinverkürzung.

Dann Tolumenbestimmung. Sie besteht in der Berechnung des Flächeninhalts sämtlicher Schnitte der Serie, Korrektur der gewonnenen Zahl unter Berïcksichtigung der berechneten Paraffinverkïrzung und Multiplikation mit der ebenfalls korrigierten Schnittdicke. Die erhaltene Zahl gibt den Kubikiuhalt des Embryos an.

Der Flächeninhalt der Schnitte kann auf verschiedene Weise ermittelt werden: 1. durch Aufzeichnen der Schnittkonturen bei bekaunter Vergrösserung auf Nillimeterpapier und Auszählung des Flächeninhalts, 2. durch Aufzeichnen der Schnittkonturen auf ein Papier von gleichmässiger Dicke und gleichmässigem Gericht seiner einzelnen Stellen, von welchem das Gewicht eines Quadratmillimeters berechnet wird. Schneidet man aus einem solchen Bogen die Schnitte heraus, so erlaubt eine einfache Rechnung den Flächeninhalt aus dem Gericht zu bestimmen.

Beide Methoden geben, wie eine angestellte Probe bewiesen hat, nur wenig verschiedene Resultate. Sie sind daher als gleichwertig zu betrachten. Infolgedessen kann man mit gutem Gewissen die leichtere dieser Methoden, die zweite, wählen, welche ausserdem noch in unserem Falle geeigneter ist als die an erster Stelle genaunte. Sie ist leichter zu haudhaben als das mühselige und zeitraubende Zählen der Quadrate, und geeigneter, weil die richtige Auszählung der Quadratmillimeter bei schmalen Streifen, welche etwa schmaler sind als 1 oder $2 \mathrm{~mm}$ und gar noch die Quadrierung des Millimeterpapiers kreuzen, sehr unsicher ist.

Die geeigneten Vergrösserungen und Schnittdicken sind solche, welche durch zehn teilbar sind, weil die alsdann anwendbare Dezimalrechnung den rechnerischen Teil der Arbeit sehr vereinfacht. Deshalb sind als Schnittdicke 10 " und 20 ", zur Zeichuung der Schnittbilder die Vergrösserung von 100 gerählt worden. 
Den besten Emblick in die Ausfïlirung der genannten Methoden wird das folgende, ausführlich geschilderte Beispiel gewühren, welches zugleich zcigt, dass die beiden obengenannten Arton zur Bestimmung des Flächeninhalts der Schnitte als gleichwertig betrachtet werden können.

Zuerst wird die Berechnung nach der Wïge-Methode dargestellt werden, bei welcher auch die Ausführung der Korrektur der ermittelten Werte, die infolge der Stückrerkleinermng (durch die Einbettung) notwendig ist, gezeigt werden soll; dann wird die Berechnung derselben Keimscheibe nach der Auszählungsmethode geschildert werden.

1. Allgemeine Bemerkungen: Die Keimscheibe ist bei 20 facher Vergrösserung gezeichnet. (Die photographische Aufnahme des Flächenbildes mit beigelegtem Masstab erwies sich erst später als notwendig; bei dieser zu den Vorversuchen gehörenden Keimscheibe wurde die Photographie noch nicht rerwendet.) Sie wird in Paraffin eingebettet, in eine Schnittserie von 153 Schnitten a 10 "zerlegt, welche mit Eiweiss-Glycerin und Wasser auf den Objektträger anfgeklebt und mit Boebmer's Hämatoxylin gefüibt werden. Einschluss in Kanadabalsam.

Aus der Grösse des Flächenbildes wird der Durchmesser der kreis. runden Keimscheibe zu 1,7 mm berechnet. Dies miisste bei 10 "Schnittdicke 170 Schnitte ergeben. Es sind aber nur 15: rorhanden. Dieser Unterschied ist durch die Stückverkleinerung infolge der Paraffineinbettung herrorgerufen. Die Grösse der Schrumpfung muss in Prozenten berechnet werden. Dies geschieht durch folgenden Ansatz:

Wreun $1,7 \mathrm{~mm}$ geschrumpft sind auf $1,53 \mathrm{~mm}$, d. h. um $0,17 \mathrm{~mm}, u m$ wieriel schrumpfen $100 \mathrm{~mm}$ ?

Als Resultat ergibt sich, dass die Schrumpfung 11, ${ }^{\prime \prime}$ o beträgt.

2. Berechnung nach der Wiegemethode: Ein Bogen weissen Papiers wird ausgemessen; er ist $331,5 \mathrm{~mm}$ lang, $211 \mathrm{~mm}$ breit, hat also cinen Flächenimhalt von 69946,5 qmm. Da scin Gewicht $6,14 \mathrm{~g}$ beträgt, wiegt 1 qmm 0,00008778 g.

Auf diesen Bogen werden die Konturzeichnungen der Schnitte bci genau 100 facher Vergrösserung gezcichnet. Dabei ist es nicht notwendig, sämtliche Schnitte der Serie zu skizzieren. Dies ist nur am Anfang und Ende erforderlich, wo die Grösse der aufeinanderfolgenden Schnitte sehr verschieden ist. In den mittleren Teilen der Serie geniigt es, je den 10. Schnitt zu nehmen bei Serien ron $10 "$ Schnittdicke, je den 5. Schnitt bei $20 \mu$ Schnittricke.

Es wurlen demmach gezeichnet sïmtliche Schnitte 1-10 und 141-153; ferner die Sehnitte $20,30,40 \ldots 140$. Alstann werden die emzehnen Skizzen sorgfïltig mittels Seheere heransgeschnitten und gewogen. Es wiegen 1. die Stiicke der Schnitte $1-10$ und $141-153=0.83$ g. ‥ Die Stiicke der Schnitte $20,30,40 \ldots 140=1,83 \mathrm{gr}$. mithin die Sehnitte $11-140=18,3 \mathrm{~g}$. 
Das Gesantgewicht der Stiicke sämtlicher Solnitte von $1-153$ also 19,13 g.

Da nun 1 qum des Papiels $0.00008778 \mathrm{~g}$ wiegt, so repräisentieren $19,13 \mathrm{~g}$ desselben 217931 ymm. Dies ist der Flächeninhalt sämtlicher auf das 100 fache rergrösserter S'chnitte.

Aus dieser Zahl erhält man duch Multiplikation mit der 100 fach vergrösserten Schnittdicke das Tolumen der 100 tach vergrösserten Keimscheibe und aus diesem durch Abstreichung vou 6 Stellen den Ramminhalt der unvergrösserten eingebetteten Keimscheibe. Das erhaltene Resultat ist jedoch zu klein im Vergleich zu dem Volumen des ungeschrumpften Keims. Dies wïrde nicht in Betracht kommen, wenn die Stückverkleinerung bei allen Keimscheiben denselben Tert hätte. I)a sie nun aber bei den einzelneu Embryonen verschieden ist und in ziemlich weiten Grenzen schwank $\mathrm{t}$ so muss in jedem einzelnen Fall eine besondere Korrekturberechnung angestellt werden. Sie wird folgendermassen ausgefüht:

3. Korrekturberechunug: Die Keimscheibe ist kreisrund, die Schrumpfung beträgt in der einen Dimension $11,1 \%$, in der zweiten ist sie aunähernd gleich gloss, wie die Ausmessung des Mittelschuitts durch die Keimscheibe zeigt. Wie gross die Schrumpfung in der dritten Dimension ist, entzieht sich der Feststellung. Sie muss deshalb nach den Sichrumpfungen der beiden anderen Dimensionen bestimms werden, worin ein sehr erheblicher Maugel der Tolumenberechnungen besteht.

Sie darf hier wohl ebenfalls mit 11,1\% in Rechnung gestellt werden.

Zunächst ist der Flächeninhalt der Schnitte zu korrigieren. Dies geschieht durch folgende Rechnung: Wenn $1 \mathrm{qmm}$ um 11,1\% schrumpft, so wird seine Fläche verkleinert auf 0,7921 qmm. In dem oben ermittelten Flächeniuhalt sämtlicher Schnitte der Serie werden also je 0,7921 qmm einem ganzen qum des ungeschrumpften Embryos entsprechen. Der Bruch 217931:0.7921 ergibt nunmehr den korrigierten Flächeninhalt sämtlicher Schnitte mit 275130 qmm.

Aus diesem erhalten wir durch Multiplikation mit der 100 fach vergrösserten Schuittdicke von 11,1 $\mu$, also mit 1,11 das korrigierte Tolumen der ganzen 100 fach vergrösserteu Keimscheibe zu $305394,30 \mathrm{cbmm}$ und daraus nach Abstreichung vou 6 Dezimalstellen das tatsächliche Volumen der Keimscheibe zu 0,305 cbmm.

4. Berechnuug nach der Zählmethode: Auf Millimeterpapier werden genau dieselben Schnitte wie bei der Wiegemethode bei derselben Vergrösserung eingezeichnet. Innerhalb jeder Konturzeichnung werden die Quadratmillimeter gezählt.

Die Zählung ergibt für die Flächen der Schnitte $1-10=2451$ qmm; für die Schnitte $141-153=7148$ qmm, zusammen 9599 qmm; für die Flächen der Schnitte $20,30,40 \ldots 140=20934$ qmm, also fuir die 
Schnitte $11-140=209340$ qmm. Mithin ist der Flächeninhalt sämtlicher. Schnitte von $1-153=218939 \mathrm{qmm}$. d. h. im Vergleich zu dem Resultat der Wiegemethode 1008 qmm mehr.

Dieser Unterschied zwischen den Resultaten beider Methoden beträgt also noch nicht $1 \%$. Dadurch ist die Gleichwertigkeit beider Methoden geniigend nachgewiesen.

3. Übersicht der untersuchten Stadien.

$\mathrm{H}$ is (29) hat Tolumenbestimmungen ron 4 Stadien A, B, D und einem Embryo nach Schluss der Tmwachsung mitgeteilt.

Ton diesen entspricht A einer Keimscheibe kurz ror Entstehung des Knopfes; B ist etwas juinger als das Stadium der rautenförmigen Embryonalanlage (Fr. Kopsch, Stad. II, Fig. 2, auch abgebildet in O. Hertwig. Handbuch Bd. I, S. 34, Fig. 10b; S. 802, Fig. 382). Stadium D entspricht ungefähr dem Stad. IV oder T (Fr. Kopseh, Fig. 4, 5. ist auch abgebildet in O. Hertwigs Handbuch Bd. I, S. 34, Fig. 10d, e und S. 802, Fig. 334). Als letztes Stadium habe ich untersucht Embryonen, bei welchen das Dotterloch sich eben geschlossen hat. (Etwas ïlter als Stad. X Fr. Kopsch. auch abgebildet in O. Hertwigs Handbuch Bd. I, S. 34, Fig. 10 k.)

Es sollen hier mitgetcilt werden die Bestimmungen an folgenden 18 Kéeimscheiben bezw. Embryoneu.

1. Keimscheibe im Begini der Ausbreitung: Ser. 213 (20 "I); Ser. 210 $(10 \mu)$; Ser. $211(20 \mu)$.

2. Keimscheibe kurz ror Entstehung des Knopfes (His Stad. A), Ser. $214(10 \mu)$; Ser. 215 (20 ॥); Ser. 220 (20 ॥); Ser. 222 ( $20 \mu)$.

3. Fr. Kopsch Stad. If (His Stad. B), Ser. 206 (10 11$)$; Ser. 208 $(10$ "1); Ser. 218 (20 " ; Ser. 224 (10 "1).

4. Fr. Kopsch Stad. T (H is Stald. D), Ser. 209 (10 1 ); Ser. 205 $(200,1)$; Ser. $226(20 \mu)$.

5. Fr. Kopsch Stad. X, XI, Ser. 207 (10 "1); S'er. 219 (0॥); Ser. 227 (20 "I); Ser. $228(10 " \prime)$.

4. Volumenbestimmungen.

a) Tolumenbestimunugen an Keimscheiben. Welche im Beginn der Ausbreitung sich befinden und die untere Keimschicht an einem kleinen Teil des Randes gebildet hahen.

Schnittlicke $20 \mu$.

\section{Serie 213.}

1)urchmesser der Kémscheibe im Photo in allen Richtungen $15 \mathrm{~mm}$. Vergrösserung 10,1538 fach. 
Daraus berechnet sich die Grösse der Keimscheibe zu 1,477 mm.

Die Kahl der Schnitte betrïgt 62 it 20 ", sie entsprechen einem durch die Einbettung verkleinerten Durchmesser von $1,24 \mathrm{~mm}$. Wenn nun $1.477 \mathrm{~mm}$ anf $1.24 \mathrm{~mm}$, d. h. um $0,237 \mathrm{~mm}$, schrumpfen, so beträgt die Stückverkleinerung $16,016 \%$, die korrigierte Schnittdicke ist also $2: 3,82$ "1.

Es wiegt 1 qmm des benutzten Papiers 0,00009478 g.

Es wiegen Schnitte $1-9$ und $55-62=1,05 \mathrm{~g}$. Sichnitte 14, 19, $2 t \ldots$ bis $5 t=1,68 \mathrm{~g}$, also Schnitte $10-54=8,40 \mathrm{~g}$ und sämtliche schnitte ron $1-62=9,45 \mathrm{~g}$.

Ihre Gesamtfläche ist demnach 99704 qmm.

Bei $16,046 \%$ Schrumpfung entsprechen 0,7058 qmm der ermittelten Gesamtfäche $1 \mathrm{cmm}$ ungeschrumpfter Fläche; die korrigierte Fläche ist also $=1 \pm 1263 \mathrm{qmm}$.

Sie ergibt nach Multiplikation 2,382, d. h. mit der korrigierten 100 fach rergrösserten Schnittdicke das knrrigierte Volumen der $100 \mathrm{fach}$ vergrösserteu Keimscheibe mit 336488,466 cbmm.

Nithiu beträgt das Volumen der Keimscheibe Serie $213=$ $0,336488 \mathrm{cbmm}$.

Das unkorrigierte Volumen beträgt 0,199408 cbmm.

\section{Serie 210 .}

Schnittdicke $10 \mu$.

Durchmesser der Keimscheibe im Photo $16 \mathrm{~mm}$ in der einen, $16,5 \mathrm{~mm}$ in der anderen Richtung.

Tergrösserung 10,1538 fach.

Grösse der Keimscheibe in der einen Richtung 1,575 mm; in der anderen $1,62 \mathrm{~mm}$.

Schnittrichtung parallel dem längeren Durchmesser.

Zahl der Schnitte 135 it $10 \mu$.

Stückverkleinerung im kürzeren Durchmesser $14,01 t \%$, im längeren Durchmesser nur 9,25\%. Die Stiickverkleinerung im kürzeren Durchmesser ist in gewöhulicher Weise aus der Zahl der Schnitte und dem vorher bestimmten Durchmesser der Keimscheibe berechnet, die Terkiirzung im langen Durchmesser wird nach der Länge des längsten Mittelschnitts $(1,47 \mathrm{~mm})$ berechnet.

Die korrigierte Schnitticke ist 11,62 "

1 qmm des benutzten Papiers wiegt 0,00008835 g.

Es wiegen die Schnitte $1-10$ und $121-135=1,22 \mathrm{~g}$; die Schnitte $20,30,40 \ldots$ bis $120=2,09 \mathrm{~g}$, also die Schnitte $11-120=20,9 \mathrm{~g}$ und sämtliche Schuitte von $1-135=22,12 \mathrm{~g}$.

Ihre Gesamtfläche ist demnach 250367 qmm. 
Die Schrumpfung beträgt in der einen Dimension $9,25 \%$, in der zweiten 14,01\%; sie soll in der dritten Dimension ebenfalls zu 14,01\% angenommen werden. Bei einer Schrumpfung ron $9,25^{\circ}{ }_{0}^{\prime}$ in der einen Dimension und $14,01^{\circ}$, in der anderen, entsprechen je $0,7803 \mathrm{qmm}$ der ermittelten Gesamtfläche $1 \mathrm{gmm}$ der ungeschrumptten Fläche. Die korrigierte Fläche wird berechnet zu 320859 qumm.

Sie ergibt nach Multiplikation mit 1,162, d. h. der korrigierten 100 fach vergrösserten Schnittdicke das korrigierte Tolumen der $100 \mathrm{fach}$ rergrösserten Keimscheibe mit 372838,158 cbmm.

Mithin beträgt das Tolumen der Keimscheibe Serie $210=$ $0,372838 \mathrm{cbmm}$.

Das unkorrigierte Tolumen beträgt 0,250367 cbmm.

\section{Serie 211.}

Schnittdicke $20 "$ ".

Gestalt der Keimscheibe wie bei Ser. 210 elliptisch; der lange Durchmesser am Photo 18,5 mm, der darauf senkrechte, kiirzere 17,0 $\mathrm{mm}$.

Vergrössermug 10,1538 fach.

Grösse der Keimscheibe im längeren Durchmesser $1,82 \mathrm{~mm}$, im kïrzeren $1,67 \mathrm{~mm}$.

Schnittrichtung parallel zum kleinen Durchmesser.

Zahl der Schnitte 81 it 20 ".

Stiickverkleinerung im längeren Durchmesser $7,68 \%$, im kïrzeren $8,37^{\circ} 0^{\circ}$. Dieser Unterschied ist so geringfiigig, dass seine Nichtbeachtung erst in der vierten Stelle des Endresultats sich bemerkbar macht. Deshalb soll eine gleichmässige Schrumpfung ron 7,68\% für alle drei Dimensionen angenommen werden.

Die korrigierte Schnittdicke ist 21,66 $\mu$.

1 qmm des benutzten Papiers wiegt $0,00009414 \mathrm{~g}$.

Es wiegen die Schnitte $1-10$ und $76-84=1,18 \mathrm{~g}$; die Schnitte 15, 20, 25... bis 75 (also je der fünfte Schnitt) $=2,56 \mathrm{~g}$, also die Schnitte $11-75=12,80 \mathrm{~g}$ und sämtliche Schnitte von $1-84=13,98 \mathrm{~g}$.

Ihre Gesamtfläche betrïgt demnach 148502 qmm.

Bei ciner gleichmässigen Schrumpfung ron $7,68 \%$ entsprechen je 0,8522 (qmm der ermittelten Gesamtfliche 1 rmm der ungeschrumpften Fläche. I)ie korrigicrte Fläche wird berechnet zu 174257 qmm.

Sic ergiebt nach Multiplikation mit 2,166, d. h. der korrigierten 100 fach vergrösserten Schnittdicke das korrigierte Volumen der 100 fach vergrösserten Keimscheibe mit 377460,662 cbmm.

Mithin beträgt das Volumen der Keimscheibe Serie உil = $0,377460 \mathrm{cbmm}$.

Das unkorrigierte Tolumen beträgt $0,297004 \mathrm{cbmm}$. 
b) Volumenbestimmungen an Keimscheiben, bei welchen die untere Keimschicht schon in der ganzen Peripherie oder an ihrem grössten Teile vorhanden ist.

\section{Serie 214.}

Schnittdicke $10 \mu$.

Durchmesser des Photos $17 \mathrm{~mm}$ in allen Richtungen.

Vergrösserung 10,1538.

Grösse der Keimscheibe 1,6742 mm.

Zahl der Schnitte 147 i $10 \%$.

Stuickverkleinerung $12,196^{\circ}$ in der Richtung, welche senkrecht zur Schnittebene liegt, $8,613 \%$ in der Richtung der Schnittebene selbst. Bei der Korrektur der Fläche ist demnach die Schrumpfung in der einen Timension 8, $613^{\circ}$, , in der anderen, deren Bestimmung sich der direkten Feststellung entzieht, soll sie zu 12,196\% angenommen werden.

Die korrigierte Schnittdicke ist 11,38, .

1 qmm des benutzten Papiers wiegt 0,00008924 g.

Es wiegen die Schnitte $1-18$ und $139-147=1,45 \mathrm{~g}$; die Schnitte $28,38,48 \ldots$ bis $138=1,9 \mathrm{~g}$; also die Schnitte $19-138=19,00 \mathrm{~g}$ und sämtliche Schnitte $1-1 \pm 7=20, \pm 5 \mathrm{~g}$.

Thre Gesamtfläche beträgt demuach 229157 qmm.

Bei einer Schrumpfung ron $12,196 \%$ in der einen Dimension und $8,613 \%$ in der anderen entsprechen je 0,8024 qmm der ermittelten Gesamtfläche 1 qmm der ungeschrnmpften Fläche. Die korrigierte Fläche wird berechnet zu $285589 \mathrm{qmm}$.

Sie ergibt durch Multiplikation mit 1,138, d. h. der korrigierten 100 fach vergrösserten Schnittdicke, das korrigierte Tolumen der 100 fach vergrösserten Keimscheibe mit 329000, $282 \mathrm{cbmm}$.

Mithin beträgt das Tol umen der Keimscheibe Serie $214=$ $0,329 \mathrm{cbmm}$, das unkorrigierte Tolumen beträgt $0,229157 \mathrm{cbmm}$.

\section{Serie 215.}

Schnittdicke $20 \mu$.

Durchmesser des Photos $16 \mathrm{~mm}$ in allen Richtungen.

Tergrösserung 10,1538 fach.

Grösse der Keimscheibe 1,57 mm.

Zahl der Schnitte 70 ì $20 \mu$.

Stiickverkleinerung $10,828 \%$.

Korrigierte Schnittdicke 22,428 $\mu$.

1 qmm des benutzten Papiers wiegt $0,00009450 \mathrm{~g}$.

Es wiegen die Schnitte $1-11$ und $62-70=1,51 \mathrm{~g}$; die Schnitte 16, $21,26 \ldots$ bis $61=1,44 \mathrm{~g}$, also die Schnitte $12-61=7,20 \mathrm{~g}$ und sämtliche Schnitte $1-70=8,71 \mathrm{~g}$. 
Ihre Gesamtflüche beträgt demuach 92169 qmm.

Bei einer gleichmässigen Schrumpfung ron $10,828 \%$ entsprechen je 0.7951 qmm der ermittelten Gesamtfläche 1 qmm der ungeschrumpften Fläche. Die korrigierte Fläche wird berechnet zn $115921 \mathrm{qmm}$.

Sie ergibt durch Multiplikation mit 2,2428 , d. h. der korrigierten 100 fach rergrösserten Schnittdicke das korrigierte Volumen der $100 \mathrm{fach}$ vergrösserten Keimscheibe mit $259987 \mathrm{cbmm}$.

Mithin beträgt das Tolumen der Keimscheibe Serie $215=$ (1,259987 c b bmm.

Das unkorrigierte Tolımen beträgt 0,186338 cbmm.

\section{Serie 220.}

Schnittlicke $20 "$ ".

Durchnesser des Photos $19 \mathrm{~mm}$ in allen Richtungen.

Tergrösserung 10,0769 fiach.

Grösse der Keimscheihe 1,585 mm.

Zahl der Schnitte 87 ì 20 "

Stiickrerkleinerung $7,69^{\circ}{ }_{0}$.

Korrigierte schnittdicke 21,666"..

1 cqmm des benutzten Papiers wiegt $0.000103 \mathrm{~g}$.

Es wiegen Schnitte $1-9$ und $75-8 \mathrm{i}=1,4 \mathrm{~g}$; die Schnitte 14 . $19,24 \ldots$ bis $7 t=2,1 \pm \mathrm{g}$, also die Schnitte $10-7 t=10.70 \mathrm{~g}$ und sämtliche Schnitte von $1-87=12,17 \mathrm{~g}$.

Ihre Gesamtfläche beträgt demnach 118155.3398 qmm.

Bei einer gleichmässigen Schrumpfung ron $7,69^{\circ}$, entsprechen je 0.8521 der ermittelten Gesamtfläche je 1 qmm der ungeschrumpften Fläche. Die korrigierte Fläche wird berechnet zn 138663 qmm.

Sie ergibt durch Nultiplikation mit 2,1666, d. h. der korrigierten 100 fach rergrösserten Schnittdicke, das korrigierte Tolumen der 100 fach vergrisserten Keimscheibe mit 3004ㄱ, 2 chmm.

Nithin beträgt das Tolumen der Keimscheibe Śerie $220=$ $0,300+27$ c $\cdot b \mathrm{~mm}$.

Das unkorrigierte Tolumen ist $0.236: 310 \mathrm{cbmm}$.

\section{Serie 222.}

Schuittlicke $20 \%$

Durchmesser des Photos $20,5 \mathrm{~mm}$ in allen Richtungen.

Vergrösserung 10,0769 fach.

Grïsse der Keimscheibe $2,034 \mathrm{~mm}$.

Zahl del Schnitte 91 ì $20 \%$.

Stuickrerkleinerung $10,52^{0}, 8$.

Korrigierte Schnittdicke 2.2.35 "I. 
1 qmm des benntzten Papiers wiegt 0,000102 g.

Es wiegen Schnitte $1-8$ mol $84-91=1,22 \mathrm{~g}$ : Schnitte 13, 18, $23 \ldots$ bis $83=2,38 \mathrm{~g}$ : also die Sichnitte $9-83=11,90 \mathrm{~g}$ und sämtliche Śchnitte $1-91=13,12 \mathrm{~g}$.

Thre Gesamtfläche beträgt demnach 128350 yщum.

Bei einer gleichmässigen Schrumpfing von 10,52\% cntsprechon je 0,80066 qum der ermittelten Gesamtfläche je 1 qmm der ungeschrumpften Fläche. Die korrigierte Fläche wird berechnet zu 159122 qmm.

Sie ergibt durch Multiplikation mit 2,235, d. h. der korrigierten 100 fach vergrösserten Schnittdicke, das korrigierte Volumen der 100 fach relgrösserten Keimscheibe mit $355637,670 \mathrm{cbmm}$.

Mithin beträgt das Tolumen der Keimscheibe Serie $222=$ $0.355637 \mathrm{cbmm}$.

Das mkorrigierte Tolumen ist $0,25670 \mathrm{cbmm}$.

c) Volumenbestimmungen an Keimscheiben, welche zwischen den stadien I und II von Fr. Kopseh stehen.

Schnittdicke $10 \%$.

\section{Serie 206}

Sagittaler Durchmesser des Photos 19,5 mm, querer Durchmesser 21,0 mm. Vergrösserung $10,1538 \mathrm{fach}$.

Grösse der Keimscheibe im sagittalen Durchmesser 1,92 mm, im quereu Durchmesser $2,068 \mathrm{~mm}$.

Schnittrichtung sagittal.

Zahl der Schnitte 199 ì $10 \mu$.

Stückverkleinerung im queren Durchmesser $3,771^{9} / 0$, im sagittalen ebenfalls zu 3,771 berechnet.

Torrigielte Schuitticke 10,391 $\mu$.

1 qmm des benutzten Papiers wiegt 0,0000703 $\mathrm{g}$.

Es wiegen Schnitte $1-11$ und $182-199=0,765 \mathrm{~g}$; die Schnitte 21, $31,41 \ldots$ bis $181=1,55 \mathrm{~g}$, also die Schnitte $12-181=15,5 \mathrm{~g}$ und sämtliche Schnitte von $1-199=16,265 \mathrm{~g}$.

Thre Gesamtfäche beträgt demnach 231365 qmm.

Bei der gleichmässigen Schrumpfung von 3,771\% entsprechen je 0,9257 qmm der crmittelten Gesamtfläche je 1 qmm der ungeschrumpften Fläche. Die korrigierte Fläche wird berechnet zu 249935 qmm.

Sie ergibt durch Multiplikation mit 1,0391, d. h. der korrigierten 100 fach vergrösserten Schnittdicke, das korrigierte Tolumen der $100 \mathrm{fach}$ vergrösserten Keimscheibe mit $259707,458 \mathrm{cbmm}$.

Mithin beträgt das T o l u men der Keimscheibe Serie $206=0,259707 \mathrm{cbmm}$.

Das unkorrigierte Volumen ist $0,231365 \mathrm{cbmm}$. 


\section{Serie 208.}

Schnittdicke 10 "

Sagittaler und transversaler Durchmesser des Photos $20,75 \mathrm{~mm}$.

Vergrösserung 10,1538 fách.

Grösse der Keimscheibe $2,043 \mathrm{im}$ sagittalen und transversalen Durchmesser.

Schnittrichtung sagittal.

Zahl der Schnitte 192 i 10 "l.

Stückverkleinerung im queren Durchmesser 6,0196\%, ebenso im sagittalen.

Korrigierte Schnittdicke 10,64 $"$.

1 c $\mathrm{mm}$ des benutzten Papiers wiegt 0,00009:321 g.

Es wiegen Schnitte 1-13 und 18t-192=0,87 g; Schuitte 23, 33, $43 \ldots$ bis $183=2,025 \mathrm{~g}$, also die Schnitte $14-183=20,5 \mathrm{~g}$ und sämtliche Schnitte von $1-192=21,12 \mathrm{~g}$.

Thre Gesamtfläche betrïgt demnach 226585 qmm.

Bei der gleichmässigen Schrumpfung von $6,0196^{\prime \prime} / 0$ entsprechen je 0,8832 qmm der ermittelten Gesamtfläche je 1 r $\mathrm{mm}$ der ungeschrumpften Fläche. Die korrigierte Fläche wird berechnet zu 256550 , imm.

Sie ergibt durch Multiplikation mit 1,064, d. h. der korrigierten 100 fach vergrösserten Schnittdicke, das korrigierte Volumen der $100 \mathrm{fach}$ rergrösserten Keimscheibe mit $272969,23 \mathrm{cbmm}$.

Mithin beträgt das Vol u men der Keimscheibe S e rie $208=0,27 \geq 969 \mathrm{cbmm}$.

Das unkorrigierte Volumen ist $0,226585 \mathrm{cbmm}$.

Schnittdicke $20 \mu$.

\section{Serie 218.}

Sagittaler Durchmesser des Photos 21,0 mm, querer Durchmesser 20,5 mm.

Vergrösserung 10,1538 fach.

Grösse der Keimscheibe im sagittalen Durchmesser 2,068 mm, in queren $2,018 \mathrm{~mm}$.

Schnittrichtung sagittal.

Zahl der Schnitte 96 à 20 ".

Stückverkleinerung im queren Durchmesser $4,85 \%$, im sagittalen ebenfalls $4,85^{\circ}{ }_{0}$.

Korrigierte Schnittdicke 21,02 " .

1 rmm des benutzten Papiers wiegt 0,00009492 g.

Es wiegen Schnitte $1-10$ und $86-96=1,1 \mathrm{~g}$, Schnitte 15, 20, $25 \ldots$ bis $85=2,275 \mathrm{~g}$, also die Schnitte $11-85=11,375$ g und sämtlich Schnitte von $1-96=12,475 \mathrm{~g}$.

Ihre Gesamtflïche beträgt demnach 131426 qmm.

Bei der gleichmäissigen Schrumpfung von $4,85 \%$ entsprechen je $0.905: 3 q_{q} \mathrm{~mm}$ der ermittelten Gesamtflïche jo 1 ymm der ungeschrumpften Fläche. Die korrigierte Fläche wird berechuet zu 115165 ymm. 
Sic ergibt durch Multiplikation mit 2,102, d. h. der korrigierten 100 fach vergrösserten Schnittdicke, das korrigierte Tolumen des loofach vergrö̈scrten Keimscheibe mit 305136,830 chmm.

Mithin betrïgt das Vol u men der Keimscheibe Serie $218=0,305136 \mathrm{cbmm}$.

Das unkorrigierte Volumen ist $0,262852 \mathrm{cbmm}$.

\section{Serie 224.}

Sclmittdicke $10 \mu$.

Sagittaler Durchmesser des Photos 21,5 mm, querer Durchmesser $20,5 \mathrm{~mm}$.

Ver'grösserung 10,0769 fach.

Grösse der Keimscheibe im sagittalen Durchmesser 2,1335 mm, im queren $2,03 \pm 3 \mathrm{~mm}$.

Schnittrichtung sagittal.

Zahl der Schuitte 191 à $10 \mu$.

Stiickrerkleinerung im queren Durchmesser $6,1121^{\circ} / 0$, im sagittalen Durchmessel ebenso.

Korrigierte Schnittdicke 10,6507,".

1 qmm des benutzten Papiers wiegt 0,0001022: g.

Es wiegen Schnitte 1-12 und 183-191=0,87 g; die Schnitte 22, $32,42 \ldots$ bis $182=2,2 \mathrm{~g}$; also die Schnitte $13-182=22,0 \mathrm{~g}$ und sämtliche Schnitte von $1-191=22,87 \mathrm{~g}$.

Thre Gesamtfläche beträgt demnach 223733 qmm.

Bei der gleichmässigen Schrumpfung von 6,1121\% entsprechen je 0,88147 qmm der ermittelten Gesamtfläche je 1 qmm der ungeschrumpften Fläche. Die korrigierte Flïche wird berechnet zu 253818 qmm.

Sie ergibt durch Multiplikation mit 1,0650 $\bar{t}$, d. h. der korrigierten 100 fach vergrösserten Schnittdicke, das korrigierte Volumen der 100 fach vergrösserten Keimscheibe mit 270333,937 cbmm.

Nithin beträgt das Vol n men der Keimscheibe S e ric $224=0,270333 \mathrm{cbmm}$.

Das unkorrigierte Volumen ist $0,223733 \mathrm{cbmm}$.

d) Volumenbestimmungen an Keimscheiben, welche den Stadjen IV, V ron Er. Kopsch entsprechen.

\section{Serie 209.}

Schnittdicke $10 \mu$.

Sagittaler Durchmesser des Photos 31,5 mm, querer Durchmesser 30,5 mm. Vergrösserung 10,1538 fach.

Grösse der Keimscheibe in sagittaler Richtung 3,1022 mm, in querer $3,00: 3 \mathrm{~mm}$.

Schuittrichtung quer:

Zahl der Schnitte 284 ì $10 \mu$. 
Stïckverkleiuerung im sagittalen Durchmesser $8,45^{\circ} 0 \mathrm{im}$ queren ebenfalls $8,45 \%$.

Korrigierte Schnitticke 10,923 ",.

Da die Schnitte nunmehr recht gross sind, so reicht ein Bogen Papier nicht mehr zur Aufzeichnung der Skizzen aus, es miissen mehrere Bogen benutzt merden, deren verschiedenes Gewicht eine gesonderte Berechnung erfordert.

Es wiegen a) die Schnitte $1-10=0,245 \mathrm{~g}$; die Schnitte 15, 20, 25 . . bis S5 $=0,595 \mathrm{~g}$, also die Schnitte $1 \mathrm{l}-85=2,975 \mathrm{~g}$ und die gesamten Schnitte $1-85=3,22 \mathrm{~g}$. Ton dem hier verwendeten Bogen wiegt $1 \mathrm{gmm}$ 0,00009329 g, mithin ist der Flächeninhalt der Schnitte $1-85=$ $34516 \mathrm{qmm}$.

b) Es wiegen die Schnitte $90,95,100 \ldots$ bis $165=0,735 \mathrm{~g}$, also sämtliche Schnitte $86-165=3,675 \mathrm{~g}$. Von dem hicr verwendeten Bogen wiegt 1 qmm $=0,00008542 \mathrm{~g}$; mithin ist der Flächeninhalt der Schuitte 86-165 $=43022 \mathrm{qmm}$.

c) Es wiegen die Schnitte $170,175,180 \ldots$ bis $200=0,293 \mathrm{~g}$; also sämtliche Schnitte $166-200=1.465 \mathrm{~g}$. Von dem hier vertrendeten Papier wiegt $1 \mathrm{gmm}=0,01009235 \mathrm{~g}$; mithin ist der Elächeninhalt der Schnitte $166-200=15863$ r $1 \mathrm{~mm}$.

d) Es wiegen die Schnitte $271-284=0,6 \pm \mathrm{g}$; die Schuitte 205,210 , $215 \ldots$ bis $270=2,45 \mathrm{~g}$, also die Schnitte $201-270=12,25 \mathrm{~g}$ und sämtliche Schnitte $201-284=12,89$ g. Von dem hier verwendeten Bogen wiegt $1 \mathrm{r} \mathrm{mm}=0,00009239 \mathrm{gr}$, mithin ist der Elächeninhalt der Schnitte 201 - 281 $=1395017$ (1mm.

Dic Gesamtfïche aller Schnitte 1-284 betrïgt 232918 ymm.

Bei der gleichmässigen Schrumpfung ron 8,45\% entsprechen je 0,8381 qmm der crmittelten Gesamtfläche je 1 qmm der ungeschrumpften Eläche. Die kolrigrierte Fläche wird berechnet zu 277792 cmm.

Sic ergibt durch Multiplikation mit 1,0923, d. h. der 100 fach vergrösserten horrigrierten schnittlicke, das korrigierte Tolumen der loofach vergrösserten Keimscheibe mit $303+32,2$ cbmm.

Mithin beträgt das Volumen der Keimschribe Serie $209=$ (1,30349.2 cbmm.

Das unkorrigierte Volumen ist $10,292918 \mathrm{cbmm}$.

Aus dem so erhaltenen Volumen kann der Rauminhalt der Embryonalanlage und des zelligen Randrings berechnet werden a) dadurch, dass man das Volumen der sogenamnten "Mittelscheibe" berechnet und ron der Gesamtzahl abzicht; b) dadurch, dass man mittels der Wägemethode den Inhalt der Fmbryonalanlage bestimmt und dazu den des Randrings addiert. 
a) Als "Nittelscheibe" soll derjenige Teil der Keimscheibe bezeichnet werden, welcher nach Abzug des Randrings übrig bleibt und morphologisch als Dach der Kicimhöhle bezeichnet wird. Ihre Flïchen- und Inhaltsberechnung wäre einfach, wenn nicht die Embryonalanlage noch eine Strecke weit in ihrem Gebiet lïge. Darum muss der Flächenraum, welcher auf Rechnung des betreffenden vorderen Stiickes des Embryos kommt, von dem Flächeninhalt der Mittelscheibe alogezogen werden, ehe man das Volumen der letzteren bestimmen kann.

Die Breite des Randrings wird an verschiedenen Schnitten gemessen. Seine innere Grenze ist nicht genau festzustellen, deshalb muss seine Ausdehnung nach dieser Richtung etwas willkïrlich bestimmt werden. Sie soll unter Zulgrundelegung einer Anzahl ron Messungen am Mittelschnitt durch die Keimscheibe und an benachbarten Schnitten anf 0,3 mm angenommen werden. Da der sagittale Durchmesser des Keims 3,1022 mm, der quere 3,003 mm beträgt, so kann wohl zur Vereinfachung der Rechnung die Keimscheibe als kreisrund mit einem Durchmesser von $3 \mathrm{~mm}$ angenommen werden. Alsdann ist der Durchmesser der Mittelscheibe $2,4 \mathrm{~mm}$ und ihre Fläche berechnet sich $\mathrm{zu} 4,5216 \mathrm{cmm}$, Wenn man sie als plane Scheibe ansieht und ihre geringe Wölbung ansser Acht lässt, bei deren Beriicksichtigung ein etwas grösseres Resultat zu erwarten ist.

Ton dieser Summe ist in Abzug zu bringen derjenige Teil der Embryonalanlage, welcher im Bereich der eben berechneten Flïche liegt. Dieser Teil erstreckt sich iiber 70 Schnitte der Serie, ist also 0,76461 mm lang. Nehmen wir nun die Breite des Embryos zu $1 \mathrm{~mm}$ an, so sind 0,7461 qmm von der vorher ermittelten Fläche abzuziehen. Dies ergibt 3,75699 qmm, welche den Flächenraum desjenigen Teils der Keimscheibe angeben, welcher nach Abzug der vom Embryo und rom Randring eingenommenen Fläche übrig bleibt.

Durch Multiplikation mit der durchschnittlichen Dicke der Mittelscheibe, deren mittlerer Wert aus verschiedenen ungleichen Stellen mit $11 \mu$ bestimmt wird, ergibt sich das Volumen des zu berechnenden Teiís der Mittelscheibe zu $0,041326 \mathrm{cbmm}$.

Nach Abzug dieses Wertes von dem vorher bestimmten Volumen der ganzen Kieimscheibe im Werte von $0,303432 \mathrm{cbmm}$ ergibt sich als Volumen der Embryonalanlage und des Randrings $0,26210 \mathrm{cbmm}$.

Dieser Wert eher ist zu hoch als zu niedrig, da an zweifelhaften Stellen, wie bei Bestimmung der Randringbreite und der Breite der Embryonalanlage lieber dasjenige Maass gewïhlt rurde, bei dessen Benutzung der Gewinn auf Seiten des Embryos und des Randrings liegt, um der Möglichkeit zu entgehen durch Berechnung eines geringeren Wertes eine Vergrösserung des Unterschiedes zwischen den Volumina des Embryos rom Schluss der Umwachsung und dem Inhalt von Embryo + Randring dieses Stadium zu erzengen. 
b) Nach der Wiege-Methode wird das Volumen des Embryos und des ihm zunächst liegenden Teils des Randrings berechnet zu $0,181832 \mathrm{cbmm}$. Der hierbei noch nicht berechnete Randringteil ist $6 \mathrm{~mm}$ lang. Sein Volumen soll festgestellt werden, indem der durchschnittliche FJächeninhalt seines Querschnittes als Grundfläche, seine Lünge als Höhe einer prismatischen Säule angenommen wird. Da ersterer im Durchschnitt 0,01 qmm gross ist, so beträgt das Volumen dieses Randringteils 0,06 cbmm. Durch Addition der beiden Volumina erhäit man das Volumen der. Embryonalanlage und des Randrings mit 0,24 cbmm.

Die Differenz zwischen beiden Rechnungen beträgt $0,02 \mathrm{cbmm}, \mathrm{d}$. h. ein Zwölftel bezw. ein Dreizehntel. Welche von beiden einen grösseren Anspruch auf Genauigkeit hat, ist nicht zu entscheiden. Die Ungleichheit des Resultats ist wohl zum grössten Teil auf Rechnung der verschiedenen Methoden zu setzen, und mag als Beweis dafuir dienen, auf wie unsicherem Boden anch heute noch derartige Tolumenbestimmungen stehen.

Schnittdicke $20 \%$.

\section{Serie 225.}

Sagittaler Durchmesser des Photos $31 \mathrm{~mm}$, querer Durchmesser $30 \mathrm{~mm}$. Vergrösserung ist 10,0769 fach.

Grösse der Keimscheibe in sagittaler Richtung 3.0763 mm, in querer $2.9771 \mathrm{~mm}$.

Schnittrichtung quer.

Zahl der Schnitte 14i) à थo "l

Stückverkleinerung im sagittalen Durchmesser 5,7309.\% im queren Durchmesser ungefähr ebenso gross.

Korrigierte Schnittdicke $21,215 !$ 。

a) Es wiegen Schnitte $1-12=0,47 \mathrm{~g}$; Schnitte $17,22,27, \ldots$ bis 722 $=0,68 \mathrm{~g}$, also die Schnitte $13-72=3,40 \mathrm{~g}$ und die Schnitte $1-72$ $=3,87 \mathrm{~g}$. Ton dem hier verwendeten Papier wiegt $1 \mathrm{qmm}=0,00010107 \mathrm{~g}$. mithin ist der Flächeninhalt der Schnitte $1-72=38290 \mathrm{qmm}$.

b) Es wiegen die Schnitte 123-145=2,945 g; die Schnitte 77, 8.2. $87, \ldots$ bis $122=1,36 \mathrm{~g}$, also die Schnitte $73-122=6,80 \mathrm{~g}$ und die Schnitte $73-145=9,45 \mathrm{~g}$. Von dem hier verwendeten Papier wiegt 1 q $\mathrm{mm}$ $=0,00010079 \mathrm{~g}$; mithin ist der Elächeninhalt der Schnitte 7:3-145 $=96686$ qmm.

Die Gesamtfläche sämtlicher Schnitte ron $1-11.5$ betrïgt a lso 134976 q $\mathrm{mm}$.

Bei der gleichmässigen Schrumpfung von $5,7: 3{ }^{\circ} "$ entsprechen jc 0,8887 qmm der ermittelten Gesamtflïche je 1 qum der ungeschrumpften Fläche. Die korrigierte Fläche wird berechnet zu 151880 qmm. 
Sie ergibt durch Multiplikation mit 2,1215, d. h. der 100 fach vergrösserten korrigierten Schnittdicke das korrigierte Volumen der 100 ach vergrösserten Keimscheibe mit :32213t chmm.

Mithin beträgt das Tol umen der Keimscheibe Serie 225 $=0,32213+\mathrm{cbmm}$.

Das unkorrigierte Volumen ist 0,269952 cbmm.

Das Volumen der Embryonalanlage und des seitlich von ihr liegendeu Abschnitts der Keimscheibe und des Randrings betrïigt 0,208897 cbmm.

Zu dieser Berechnung ist allein der hintere Teil der Keimscheibe von Schnitt 92-145 benutzt worden. Es wiegen die Schnitte $92-122=5,875 \mathrm{~g}$ die Schnitte $123-145=2,945 \mathrm{~g}$, mithin die Schnitte $92-145=8,82 \mathrm{~g}$. 1 qmm des benutzten Papiers wiegt 0,00010079 g, also ist der Flächeninhalt der Schnitte $92-145=87508$ qmm. Da nun bei der Schrumpfung von $5,73 \%$ je 0,8887 qum der ermittelten Fläche je 1 qmm der ungeschrumpften Fläche entsprechen, so wird die korrigierte Flïche berechnet zu $98467 \mathrm{qmm}$, welche nach Multiplikation mit 2,1215, d. h. der 100 fach vergrösserten korrigierten Schnittdicke das korrigierte Volumen des 100 fach vergrösserten hinteren Teils der Keimscheibe mit 208817 cbmm ergeben.

Der Flächeninhalt des 100 fach vergrösserten Randringquerschnitts wird aus 14 Schnitten berechnet zn durchschnittlich 89 qmm. Bei Berücksichtigung der Schrumpfung von 5,7:3\% wird der korrigierte Flächeninhalt des Randringquerschnitts zu 0,01 qmm bestimmt.

Die Lïnge des noch nicht berechneten Randringteils beträgt $5,6 \mathrm{~mm}$. Nehmen wir nun den Querschnitt als Basis, die Länge als Höhe eines Prismas, so erhalten wir das Volumen des noch nicht berechneten Randringabschuittes mit $0,056 \mathrm{cbmm}$.

Durch Addition zu dem hinteren Teil der Keimscheibe wird das Volumen ron Embryo - Randring mit 0,264t97 cbmm erhalten.

Schnittdicke 20 "

\section{Serie 226.}

Sagittaler Durchmesser des Photos 30,5, querer Durchmesser 3,0.

Vergrösserung ist 10,0769 fach.

Grösse der Keimscheibe in sagittaler Richtung 3,0267 mm, in querer $2,9771 \mathrm{~mm}$.

Schnittrichtung quer.

Zahl der Schnitte 140 ì 20 ".

Stückverkleinerung in sagittaler Richtung $7,490^{\prime}{ }_{0}$ in querer Richtung $6,39 \%$.

Korrigierte Schnittdicke 21,619 $\mu$.

a) Es wiegen die Schnitte $1-15=0,86 \mathrm{~g}$. die Schnitte 20, 25, 30, bis $70=0,69 \mathrm{~g}$, also die Schnitte $16-70=3,45 \mathrm{~g}$ und die Schnitte $1-70$ 
$=4,31$ g. 1 gmm des rerwendeten Papiers wiegt 0,0001068 g, mithin ist der Flächeniuhalt der Schnitte $1-\tau 0=40355$ qmm.

b) Es wiegen die Schnitte 75, 80, 85, ... bis $120=1,1 \mathrm{~g}$, mithin die Schnitte $71-120=7.0 \mathrm{~g}$; fermer wiegen die Schnitte $121-140=3.88 \mathrm{~g}$, also die Schnitte $71-140=10,88$ g. 1 c $1 \mathrm{~mm}$ des hier verwendeten Papier's wiegt 0,00011 g: mithin beträgt die Fläche der Schnitte 71-140) $=98909$ qmm.

Die Gesamtfläche sämtlicher Schuitte 1-1 10 beträgt demnach $1: 39264$ q $\mathrm{mm}$.

Bei der Schrmmpfung ron 6,39" o und $7,49^{\circ}{ }_{0}$ entsprechen je 0,8659 qmm der ermittelten Gesamtfläche je 1 qmm der ungeschrumpften Fläche. Die liorrigierte Fläche wird berechnet zu 160831 r $\mathrm{mm}$

Sie ergibt durch Multiplikation mit 2,1619, d. h. der korrigierten 100 fach vergrösserten Schnittdicke das korrigierte Volumen der 100 fach vergrösserten Keimscheibe mit 347700 cbmm.

Mithin beträgt das Tolumen der Kícimscheibe Serie 226 $=0,34779 \mathrm{cbmm}$.

Das unkorrigierte Tolumen ist $0,278529 \mathrm{cbmm}$.

Das Volumen der Embryonalanlage und des seitlich ron ihr liegenden Teils der Keimscheibe und des Randrings betrigt 0,215086 cbmm.

Zu dieser Berechnung sind benutzt die Schnitte 91-140. Es wiegen die Schnitte $95,100,105, \ldots$ bis $120=1,12 \mathrm{~g}$, also die Schnitte $91-120$ $=5,60 \mathrm{~g}$; ferner wiegen die Schnitte $121-140=3, S \mathrm{~s}$, mithin die Schnitte $91-140=9,18$ g. 1 qmm des verwendeten Papiers wiegt 0,00011 g, mithin ist der gesante Flächeninhalt der Schnitte $91-140=86181$ qmm. Da num bei der Schrumpfung von $6,399^{\circ}$ "in der einen Dimension und vou $\tau, 49{ }^{0}{ }_{0}$ in der anderen je 0,8659 amm der ermittelten Fläche je 1 qmm der ungeschrumpften Fläche entsprechen, so betrïgt die korrigierte Fläche 99527 qum, welche nach Multiplikation mit 2,1619; d. h. der korrigicrten 100 fach vergrösserten Schnittdicke das korrigierte Tolumen des 100 fach vergrösscrten hinteren Teils der Keimscheibe mit $215086 \mathrm{cbmm}$ ergeben.

Der Flächeninhalt des 100 fach rergrösserten Randringquerschnitts wird aus 10 Schnitten berechnet zu durchschnittlich 111 qmm.

Bei Beriicksichtigung der Schrumpfung von $6,39 \%$ und $7,49{ }^{\circ} 0$ wird der korrigierte Querschnitt des Randrings bestimmt zu $0,0128 \mathrm{qmm}$.

Die Lïuge des noch nicht berechneten Randringteils betrïgt $5,6 \mathrm{~mm}$. Nehmen wir num den Querschnitt als Basis, die Lainge als Höle eines Prismas, so erhalten wir das Volumen des noch nicht bercchmeten Randringalbschnitts mit $0,017 \mathrm{cbmm}$.

Durch Addition zu den hinteren Teil der Keimscheibe wird das Volumen ron Embryo + Ranring mit 0,286086 cbmm erhalten. 
e) Volumen-Bestimmungen an Embryonen bei Dotterlochschluss, welche etwas älter sind als Stadium $\mathrm{X}$ von Fr. Kopsch.

\section{Serie $20 \%$.}

Schnittdicke 10 "1.

Bei diesem Embryo kann am Photo das hintere Ende nicht genan erkannt werden. Deshalb wird zur Berechnung der Stückverkiirzung die Entfernung zwischen dem vorderen Kopfende und dem Rande des Dotters gemessen, sie beträgt am Photo $=42,5 \mathrm{~mm}$.

Vergrösserung 10,15.38 fach.

Die Lünge des gemessenen Stïckes betrügt also $4,185 \mathrm{~mm}$.

Schnittrichtung: quer.

Zahl der Schnitte $38 t$ ¿ 10 " (davon treffen den Embryo nur die Schnitte 1-342).

Stückverkleinerung in der sagittalen Richtung $8,133^{\circ} / 0$.

Korrigierte Schnitticke 10,898 "'.

Es wiegen die Schnitte $1-12+193-202=0,97 \mathrm{~g}$, die Schnitte $22-192+312-342=22,3 \mathrm{~g}$, mithin die Schnitte $1-342=23,27 \mathrm{~g}$.

1 qmm des benutzten Papiers wiegt 0,00010229 g, mithin beträgt die Gesamtfläche sïmtlicher Schnitte 227490 clmm.

Bei einerSchrumpfung von $8,133 \%$, welche freilich nur für die Schrumpfung in sagittaler Richtung berechnet ist, entsprechen je 0,8439 q $\mathrm{mm}$ der ermittelten Gesamtfläche je 1 qmm der ungeschrumpften Fläche. Die korrigierte Fläche wird berechnet zu 269451 qmm.

Sie ergibt durch Multiplikation mit 1,0898, d. h. der 100 fach vergrösserten korrigierten Schnittdicke, das korrigierte Volumen des 100 fach vergrösserten Embryos mit $293647 \mathrm{cbmm}$. Mithin beträgt das Volumen des Embryos Serie 207=0,293647 cbmm.

Das unkorrigierte Volumen ist 0,22749 cbmm.

Hierzu kommt noch das Volumen der Dottersackhant, welches zu 0,06 chmm auf folgende Weise bestimmt ist.

Die Durchschnittsgrösse des Forelleneies betrïgt nach $\mathrm{H}$ is $4-5,3 \mathrm{~mm}$, nach meinen eigenen Messungen ist die mittlere Grösse 4, こ mm, was mit den Angaben von $\mathrm{His}$ einigermalsen stimmt.

Die Dicke der Dottersackhaut betriggt nach $\mathrm{H}$ is zur Zeit der beendeten Umwachsung bei der Forelle 1 \%. Ich habe selber in einer Anzahl ron Eiern Dickenmessungen der Dottersackhaut gemacht, weIche dieses Mass bestätigen. Es ist freilich nicht möglich, die Dicke von 1 " als absolut sicher zu bezeichnen, denn sie ist an den Stellen der Kerne oftmals grösser. Ausserdem ist zu bedenken, dass die Messungen, an geschrumpften Keimbäuten gemacht sind. Jedenfalls aber meine ich behaupten zu dürfen, dass eine Dicke von 1 " wohl der unteren Grenze sich nähert und nicht etwa zu gross ist. Dieser 
Punkt ist von Bedentung für die Tergleichung der Volumina ïlterer und jüngerer Keimscheiben und Embryonen.

Die Oberfläche des Forelleneies beträgt bei $4,5 \mathrm{~mm}$ Durchmesser $=$ 63,585 qmm, von dieser Fliche ist abzuziehen der Raum, welcher vom Embryo bedeckt ist und schon bei seiner Volumen-Bestimmung berechnet worden ist. Dieser T'eil betrïgt 3,4617 qmm für den ungeschrumpften Embryo. Es soll der noch ïbrigbleibende Teil der Eioberfläche rund zu 60 rmm angenommen werden. Daraus ergibt sich das Volumen der Dottersackhaut bei Annahme einer Dicke von 1 " zu $0,06 \mathrm{cbmm}$.

Das Tolumen des Embryos und der Dottersackhaut beträgt daher $0,353647 \mathrm{cbmm}$.

\section{Serie 219.}

Schnittdicke $20 \mu$.

Länge des Photos vom vorderen Kopfende des Embryos bis zum hinteren Ende des rechteckig zugeschnittenen Dotters $39,5 \mathrm{~mm}$.

Vergrösserung 10,1538 fach.

Die Länge des gemessenen Stiickes betrïgt also $3,88 \mathrm{~mm}$.

Schnittrichtung quer.

Zahl der Schnitte des gemessenen Stiickes 177 it 20 ". Von ihnen gehen Schuitt 1-172 durch den Embryo.

Stiickverkleinerung 8,762", in sagittaler Richtung.

Korrigierte Schnitticke $21,9209 \mu$.

Es wiegen die Schnitte $1-7+158-161=0,62 \mathrm{~g}$, die Schnitte $12,17,22, \ldots$ bis $157+167,172=2,87 \mathrm{~g}$, also die Schnitte $8-157+$ $167-171=14,35 \mathrm{~g}$ und die gesamten Schnitte $1-172=14,97 \mathrm{~g}$.

1 qmm des verwendeten Papiers wiegt $0,00010751 \mathrm{~g}$, mithin betrïgt der Flächeninhalt sämtlicher Schnitte 139242 qmm.

Bei der Schrumpfung von 8,762\% des sagittalen Durchmessers, welche auch für die beiden anderen Durchmesser angenommen werden soll, entsprechen je 0,8324 qmm der ermittelten Fläche je 1 qmm der ungeschrumpften Fläche. Die korrigierte Fläche wird berechnet zn 167277 qmm.

Sic ergibt durch Multiplikation mit 2,192, d. h. der 100 fach vergrösserten korrigierten Schnittdicke, das korrigierte Volumen des 100fach vergrösserten Embryos mit $366671 \mathrm{cbmm}$.

Mithin betrïgt das Volum en des Embryos Serie $219=0,366671 \mathrm{cbm} \mathrm{m}$.

Rechnet man hierzu das Volumen der noch nicht beriicksichtigten Dottersackhant, welches beim vorhergehenden Embryo bestimmt wurde zn $0,06 \mathrm{cmm}$; so erhält man als Volumen des Embryos und der Dottersackhaut 0,426671 chmm.

Das unkorrigierte Volumen des Embryos betrïgt 0.278484 cbmm. 
Schnittdicke $20 \%$.

\section{Serie 22\%.}

Lïnge des Photos vom rorderen Kopfende des Enbryos an bis zum hinteren Ende des rechteckig zugeschnittenen Dotters 39,0 1 mm.

Vergrösserung 10,0769 fach.

Länge des gemessenen Stückes betrïigt also $3,87 \mathrm{~mm}$.

Schnittrichtung quer.

Zahl der Schnitte das gemressenen Stückes 182 i 20 "1; von ihnen treffen 162 den Embryo.

Stïckverkleinerung $5,948^{\%} / 0$ in sagittaler Richtung.

Korrigierte Schnittdicke 21,2618 "

Es wiegen die Schnitte 1-8 + $159-162=0,65 \mathrm{~g}$, die Schmitte 13, $18,23, \ldots$ bis $158=2,37 \mathrm{~g}$; also die Schnitte $9-158=11,85 \mathrm{~g}$ und die Schnitte $1-162=12,50 \mathrm{~g}$.

1 qmur des verwendeten Papiers wiegt $0,00009985 \mathrm{~g}$, mithiu beträgt der Flächeninhalt sümtlicher Schnitte 125187 qumm.

Bei der Schrumpfung des sagittalen Durchmessers ron $9,948 \%$, welclre auch für den transversalen und antero-posterioren angenommen werden soll, entsprechen 0,8845 qmm der ermittelten Fläche, je 1 qmm der ungeschrumpften Fläche. Die korrigierte Fläche wird berechnet zu 141522 qmm.

Sie ergibt durch Multiplikation mit 2,126, d. h. der 100 fach vergrösserten korrigierten Schnittdicke, das korrigierte Volumen des $100 \mathrm{fach}$ vergrösserten Embryos mit 300875 cbmm.

Mithin beträgt das Volumen des Embryos Serie $227=0,300875 \mathrm{cbmm}$.

Rechnet man hierzu das Volumen der Dottersackhaut nit $0,06 \mathrm{cbmm}$, so crhält man für das Volumen des Embryos und der Dottersackhaut $0,360875 \mathrm{cbmm}$.

Das unkorrigierte Volumen des Embryos beträgt 0,250374 cbmm.

Schnittdicke $10 \mu$.

\section{Serie 228.}

Länge des Photos vom vorderen Kopfende des Embryos an bis zum hinteren Ende des rechteckig zugeschnittenen Dotters $44,5 \mathrm{~mm}$.

Vergrösserung 10,0769 fach.

Die Länge des gremessenen Stiickes beträgt also $4,415 \mathrm{~mm}$.

Schnittrichtung quer.

Zahl der Schnitte des gemessenen Stiickes 412 i $10 \mu$; ron ilnen treffen 375 den Embryo.

Stückverlileinerung 6,681\% in sagittaler Richtung.

Korrigierte Schnittdicke 10,71 $\mu$.

Es wiegen die Schnitte $1-15+316-325=1,23 \mathrm{~g}$, die Schuitte $25,35,45, \ldots$ bis $315+335,345, \ldots$ bis $375=2,485 \mathrm{~g}$, also die Schnitte $16-315+326-375=24,85 \mathrm{~g}$ und sïmtliche Schnitte $1-375=26,08 \mathrm{~g}$. 
1 qmm des verwendeten Papiers wiegt 0,00010736 g, mithin beträgt der Flücheninhalt sämtlicher Schnitte 242921 rmm.

Bei der Schrumpfung des sagittalen Durchmessers von $6,681 \%$, welche auch für den transversalen und antero-posterioren Durchmesser angenommen werden soll, entsprechen 0,8708 qmm der ermittelten Fläche, je 1 qmm der ungeschrumpften Fläche. Die korrigierte Fläche wird berechnet zu $278.963 \mathrm{qmm}$.

Sie ergibt durch Multiplikation mit 1,071, d. h. der 100 fach verTabelle der berechneten Volumina.

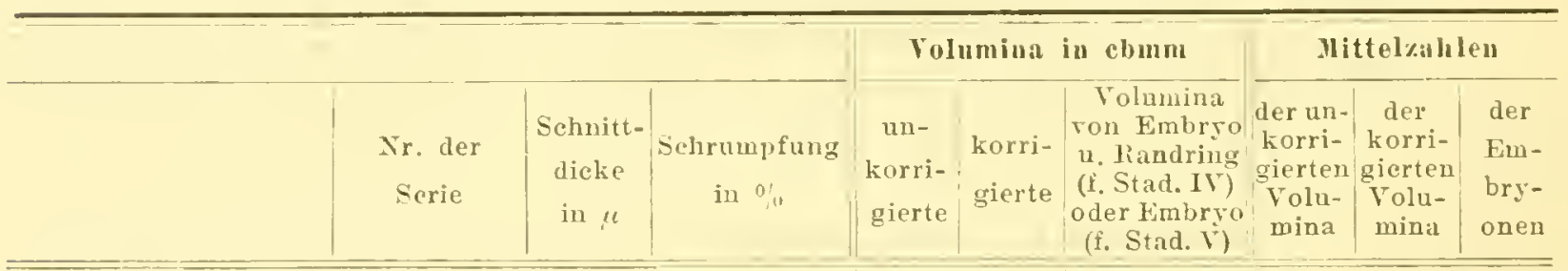

\section{Stadium I.}

Die Keimscheibe befindet sich im Beginn der Ausbreitung; sie hat an einem geringen $\mathrm{Be}$. zirk des Randes die untere Keimsehicht gebildet.

\section{Stadium II.}

Die untere Schicht entweder am ganzen Umfang der 2.Serie 215 Keimscheibe oder 3. Serie 200 am grössten 'Teil 4. Serie 2:2 desselben gebildet.

Stadium III.

1. Serie 206 10 "

Entspricht den ‥ Serie $20810 \mu$ Stadium II ron Fr. 3. Serie $21820 "$ " Kopsch.

4. Serie 2.24 $10 \mu$

Stadium IV. 1. Serie $20910 \mu$

Entspricht den 2.Scrie.205 20 " Stadien IV, I von 3. Serie.226 "20" Fr. Kopsch.

\section{Stadium V.}

Dotterlochschluss 1. Serie $2(17 \quad 10$ "1 rintsprechend dem Sitadium $\mathrm{X}$ von $\mathrm{Fr}$. Hopsch. 3. Serie $227 \div 0 " 11$ 4. Serie $2.2810 " 1$
2. Serie:219 20 "
$16,046 \% \quad 0,199 \quad 0,336$

14,014 , u. $0,250 \quad 0,372$

$9,2,5$

\begin{tabular}{llll|l}
$7,68 \quad$ и. & 0,297 & 0.37
\end{tabular}

$8.37 "$

$12,1960 \%$ ㄴ. $0,2 \cdot 290,329$ 8,613,

$10.828, \quad 0.1860,259$

$\tau, 69,0,2360,300$

$10,52 \quad, \quad 0,2560,355$

\begin{tabular}{ll|l|l|l}
3,771 & $0 / 0$ & 0.231 & 0,259
\end{tabular}

\begin{tabular}{ll|l|l|l|l}
6,0196, & 0.2 .26 & $0,27.2$
\end{tabular}

\begin{tabular}{ll|l|l|}
4,85 & $\quad 0,262$ & 0,305
\end{tabular}

$6,112, \quad 0,2030.270$

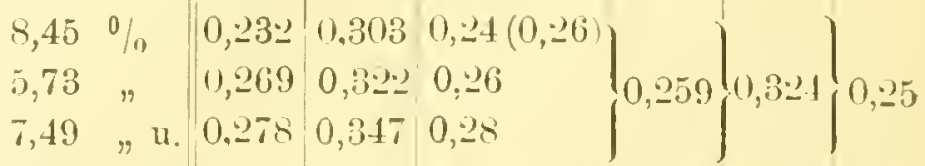

6.39 "

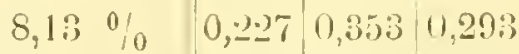

\begin{tabular}{ll|l|l|l|l}
8,76 & $\because$ & 0,278 & 0.426 & 0,366
\end{tabular}

\begin{tabular}{ll|llll}
5,94 &.. & 0.2511 & 0.360 & 0,300
\end{tabular}

$\begin{array}{llllll}6,68 \quad, \quad 0,242 & 0,358 & 0,298\end{array}$
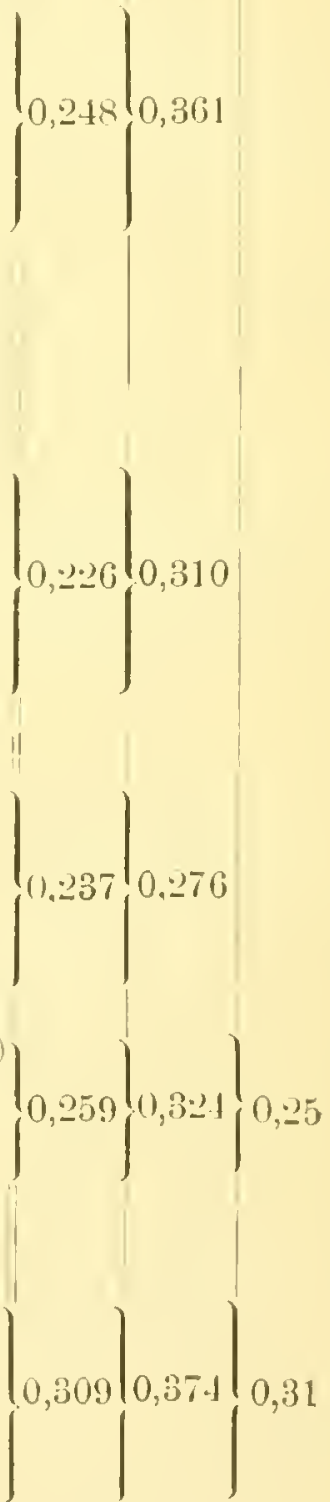
grösserten korrigierten Schnittläiche, das ko rrigierte Volumen des 100 fach vergrösserten Embryos mit 298769 cbmm.

Mithin betrïgt das Tolumen des Embryos Serie $228=0,298769 \mathrm{cbmm}$.

Rechnet man hierzu das Volumen der Dottersackhaut mit $0,06 \mathrm{cbmm}$, so crhält man für das Tolumen des Embryos und der Dottersackhaut 0,358 769 clomm.

Das unkorrigierte Volumen des Embryos beträgt 0:242921 cbmm.

5. Ergebnisse der Volumen-Berechnungen.

Bei Betrachtung nebenstehender Tabelle fällt zunächst auf die Verschiedenheit der Stïckverkürzung. Sie schwankt zwischen $3,771 \%$ und $16,046 \%$. Es ist klar, dass die Vernachlässigung der notwendigen Korrektur ganz erhebliche Unterschiede bedingen muss, weil schon eine Schrumpfung der drei Dimensioneu ron je $10 \%$ das Volumen eines Körpers um mehr als ein Viertel verkleinert. Trotzdem aber zeigen, abgesehen ron Stad. I, auch schon die unkorrigierten Volumina der aufeinanderfolgenden Stadien II bis V cine allmähliche Zunahme. Ein solches Resultat kann aber nur zufüllig sein, denn sobald die Schrumpfung in irgend einem Stadium nur um die Hülfte kleiner oder grösser wäre, würde die gleichmässige Stufenfolge gestört werden.

Deshalb ist bei Untersuchungen wie der eben dargestellten die Berechnung und Berücksichtigung der Stückverkürzung nicht zu umgehen und bei der Yergleichung der Resultate dïrfen nur die korrigierten Volumina benutzt werden.

Die korrigierten Volumina der Stadien I und II sind im Verhältnis zul den folgenden (III, IV, V) ausserordentlich gross. Besonders auffallend ist dies bei Vergleichung der Stadien I und V, deren Rauminhalt beinahe gleich gross ist. Diese Tatsache könnte als Bestätigung der Feststellung von His (29, S. 209) dienen, dass vom Schluss der Furchungszeit bis zur vollendeten Aufreihung des Embryos das Tolumen des Kieims dasselbe bleibt, wenn nicht 1. schon das folgende, nur wenig weiter entwickelte Stadium (II) ein erheblich kleineres Volumen besïsse, und wenn nicht 2. die Stadien III, IV, T eine allmählich zunehmende Grösse zeigten.

Es muss nun nach den Gründen gesucht werden, durch welche entweder die Tolumina der Stadien I und II zu gross oder die Stadien III bis $V$ zu klein geworden sind.

Hier giebt die Betrachtung der Serien sofort Aufschluss, denn es zeigt sich, dass zwischen den Zellen der beiden jüngeren Stadien zahlreiche kleinere und grössere Lïcken vorhanden sind, welche mit berechnet wurden und so das zu hohe Volumen erzeugt haben, während in den Stadien III bis $V$ die Zellen liickenlos aneinanderschliessen. 
Erst in zweiter Linie kommt die Frage nach der Entstehung der Zwischenräume zwischen den Zellen der jüngeren Stadien. An lebenden Keimscheiben anderer Knochenfischarten habe ich sie niemals gesehen, sie sind auch an den konservierten Keimscheiben anderer. Spezies viel geringer als gerade bei der Forelle. Ich bin geneigt, sie als Fixierungsprodukte anzusehen, welche durch das grössere (puellungsvermögen und den weniger festen Zusammenhang der Zellen jüngerer Stadien entstehen, dadurch dass die bei der Fixierung gequollenen Zellen bei der Alkoholhärtung wieder schrumpfen. Diese Anschaunng wird sehr erheblich dadurch unterstützt, dass die Keimscheiben bis zur Zeit der beginnenden Ausbreitung sich sehr leicht rom Dotter ablösen und namentlich in ihren basalen Zellenlagen bedeutend mehr aufgelockert sind als in den peripheren (vergl. dazu His 29, Taf. LX, Fig. 1; Wenckebach 96, Taf. XVI, Fig. 6), zu welchen die Fixierungsflüsigkeit schneller und konzentrierter gelangt und darum intensiver einwirkt Wenn es aber richtig ist, dass die Auflockerung der jüngeren Keimscheiben durch ein grösseres Quellungsvermögen der Zellen verursacht wird, so muss diese Verschiedenheit durch Unterschiede entweder der osmotischen Zustände der einzelnen Zellen oder des chemischen Aufbaus bedingt sein.

Die Feststellung des ersten Punkts entzieht sich zur Zeit der Beurteilung: fuir die Unterschiede im chemischen Aufbau spricht das verschiedene Aussehen der mikroskopischen Bilder, welche jedem Untersucher von Ḱnochenfischmaterial wohl bekannt sind und sich darin zeigen, dass die Zellen jiingerer Stadien dunkler sind, wïhrend sie bei ïlteren heller und durchsichtiger werden. Diese Verschiedenheiten sind auch an lebenden Keimscheiben anderer Spezies mehr oder weniger deutlich zu sehen. Die Ursache des Durchsichtigerwerdens ist wohl der Verbrauch deutoplasmatischer Bestandteile während der individuellen Entwicklung der cinzclnen Zelle, was z. B. bei Amphioxus und den Eiern niederer Tiere besonder's leicht festzustellen und schon von rerschiedener Seite beschrieben ist.

Bei der Beurteilung der Tolumenvermehrung miissen wir daher die beiden ersten Stadien ausschliessen und dürfen nur die Stadien III bis V verwenden. Bei diesen zeigt sich, dass die Zunahme der ganzen Keimscheibe vom Stadium der beginnenden Embryobildung bis zum Stadium des hufeisenförmigen Embryos ungefähr ein Sechstel betrïgt und dass die weitere Zunahme bis zum Dotterloch-Schluss ebenfalls ein Sechstel ist, so dass die Masse der Koimscheibe vom Stadium der beginnenden Embryobildung bis zur vollendeten Umwachsung des Dotters um etwas mehr als ein Drittel des ursprïnglichen Volumens zunimmt.

Die Kunalume des Volumens ron Embryo und Randring des Sitadiums IV bis zu dem Volumen, welches der Embryo am Schluss der Umwachsung besitzt, hetrïgt ein liertel. Dabei muss besonders 
hervorgehoben werden, dass die Berechnung der jüngeren Stadien cher zu gross, die der ïlteren eher zu lilein ist.

Ich komme somit zu Ergebnissen, welche denjenigen von $H$ is (29) nicht cntsprechen, und ich bin genötigt, eine Erklärung fïr diesen Unterschied zu suchen. Ich finde sic in dem Erhaltungszustand der von His benutzten Embryonen. Die ron diescm Autor gegebenen Photos zeigen, dass die Verquellung der unteren Keimschichten nicht allein auf den Stadien der Morula, sondern auch noch in seinem Stad. D eingetreten ist (vergl. Fig. 4, Taf. IX, His 29). Deshalb musste das Volumen des Stad. D zu gross werden, wobei co freilich ein besonders ungliicklicher Zufall ist, dass es so vorziiglich mit dem Volumen des Endstadiums ïbereinstimmt. Hiernach liegt keir Grund mehr vor, die Einzelbestimmungen von $\mathrm{H}$ is schrittweise zu vergleichen, denn wenn die Basis unzulänglich ist (in diesem Fall die ungeeignete Fixierung), so sind auch alle darauf gegrïndeten Angaben unzulänglich. Ich möchte aber hier hinzusetzen, dass diese Beurteilung keine abfällige sein soll, de..n ich bin iiberzeugt, dass die Konservierung der von His benutzten Embryonen zu den besten ihrer Zeit gehört. Dass die Fixierung nicht senïgend gut ist für die Volumenbestimmungen, liegt an der Schwierigkeit der Bearbeitung des Knochenfischmaterials im allgemeinen und an der damals noch in den Anfüngen befindlichen Fixierungstechnik im besonderen. 


\section{Ergebuisse.}

In diesem Abschnitt sollen die im beschreibenden Teil geschilderten Tatsachen und ihre Ergebnisse mit Riicksicht auf einige streitige Fragen der frühen Entwicklungszeit des Forellemembryos unter W'iudigung der Literatur iibersichtlich im Zusammenhang dargestellt werden.

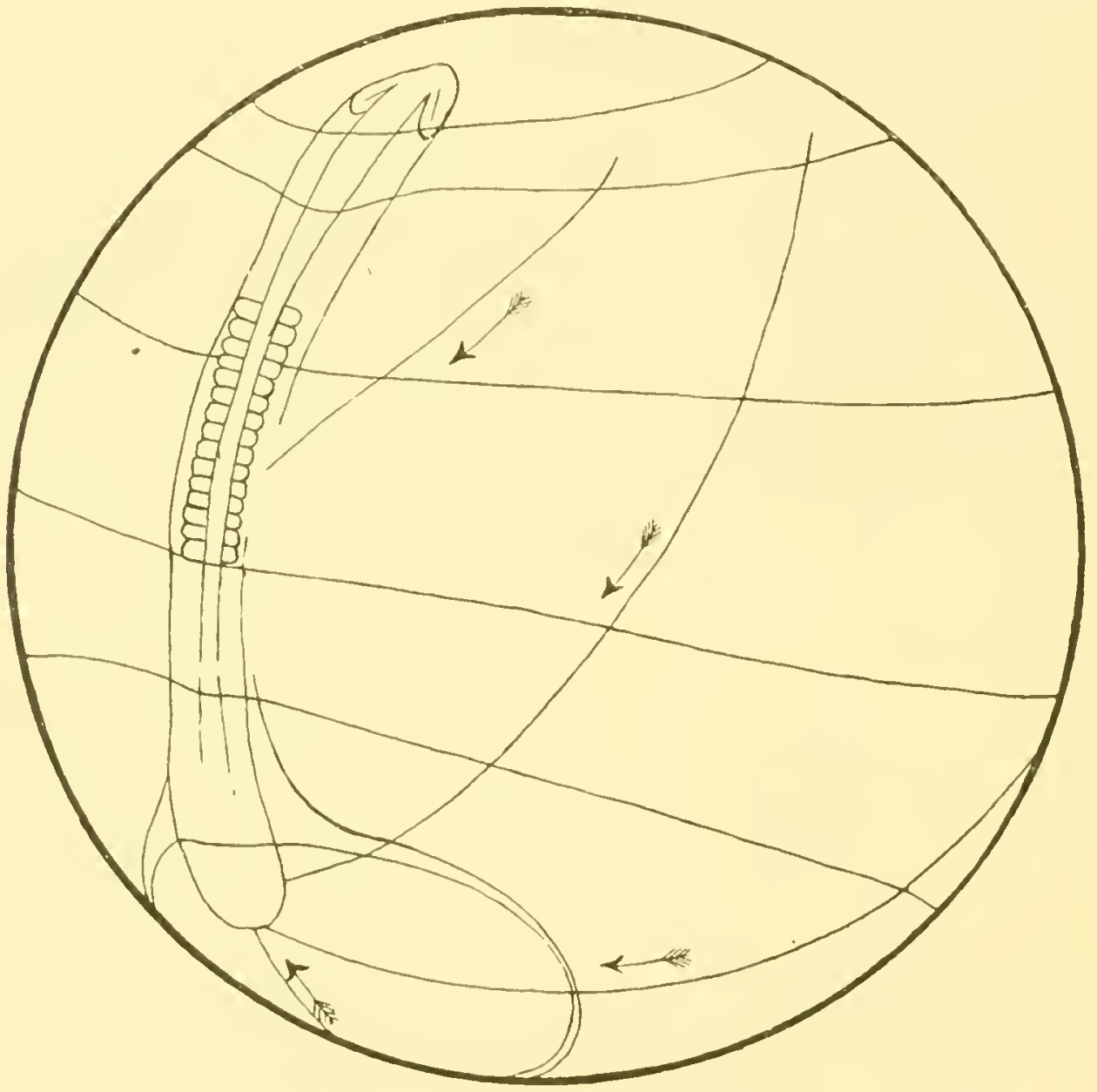

Fig. $1 \lambda$.

Dabei werden auch die für andere Knochentisclispezies rorhandenen Angaben gewürdigt werden.

\section{A. Die Insbreitung des líeims iiber den Dotter.}

Bei dieser Frage sind Lüngenwachstum des Embryos und Ausbreitung des Keimhautrandes nicht voneinander zu trennen; sie müssen im Zusammenhang betrachtet werden, da das liaudale Ende des .randstindigen" Lmbryos, der "Knopf", ein Teil des Keimhautrandes ist. 
Die Ergebnisse über diese beiden Punkte fasse ich in folgende Sïtze zusammen (s. 'Textfig. 1, A, B):

1. Der Embryo wiichst nach hinten lin aus, sein vorderes Kopfende kann als (annähernd) fester Punkt betrachtet werden, dessen Abstand vom Mittelpunkt der jungen Keimscheibe sich gar nicht oder nur wenig vergrössert.

2. Die Umwachsung des Dotters erfolgt unter excentrischer Ausbreitung und excentriseher Zusammenzichung des Randrings. Dabei macht diejenige Stelle, welche dem Knopf gerade gregeniiberliegt, den Ï̈ngsten $W$ eg, indem sie sich in demselben Meri-

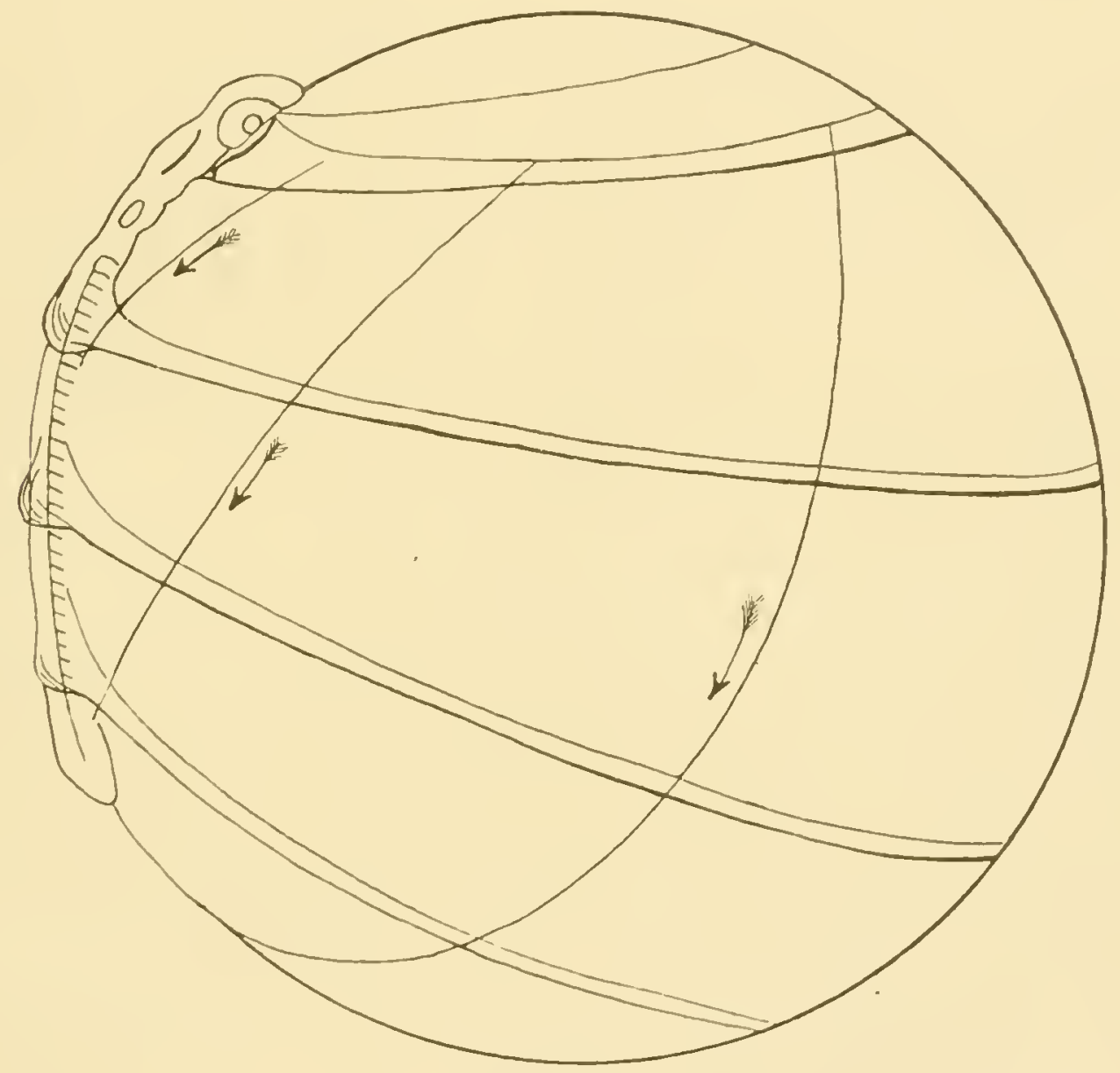

Fig. 113.

Fig. 1 A. I3. Umwachsungssclema des Forelleneies. Fntworien unter Zugrundelegung der in den Textfiguren 3-6 dargestellten Operationsresultate.

A. Hall,e Seitenansicht. B. Prolil.

Vie in der Riehtung der 'fejle verlaufenden linies bezejchuen die von den betreffenden Randringstrol]en zurtickgelegten Wuge.

dian über den Dotter bewegt, in welchem der Embryo auswächst, während die anderen Randringteile sich eine umso kürzere Strecke fortbewegen, je näher sie dem Knopfliegen, wobei sie die von Pol zu Pol gezogenen Meridiane unter grösserem oder kleinerem Winkel kreuzen. Der Knopf selber legt zwar cinen grösseren 
Weg zuriick als die ihm benachbarten Kandringabschnitte, doch ist dieStreckenochnichthalb sogross (bei der Forelle ungeführ $90^{\circ}$ ) als die des ihm gerade gegeniibcrliegenden Randringabschnitts.

Zu diesen Schlïssen führt die Betrachtung sämtlicher oben beschriebener operierter Embryonen, deren geeignetste zur Erläuterung näher betrachtet werden sollen.

Zur Erleichterung des Verstïndnisses habe ich eine Anzahl vou Skizucn beigefiigt, auf welchen das Operationsstadium, die Operationsstelle und das Endresultat ineinander projiziert sind auf ein Forellenei ron durchschnittlicher Grösse $(4,5 \mathrm{~mm})$.

\section{1. Über die Wachstumsrichtung des Embryos.}

Ich halte mich hier einstreilen nur an die E]gebnisse der Operationen, die anderen bisher rorhandenen Beweise werden bei Besprcchung der Literatur aufgeführt werden. Diejenigen Embryonen, welche in sehr jungen Stadien operiert worden sind (Fig. 70, 77, 90) lehren am deutlichsten, dass der Kopf als fester Punkt betrachtet werden kann und dass der Embryo nach hinten hin auswächst. Würde er nach vorn auswachsen, so miisste die Operationsstelle ihre Lagebeziehung zum hinteren Körperende behalten und der Embryo miisste vor ilır liegen.

Es könnte jedoch eingewendet werden, dass die Operation das Auswachsen des Embryos nach vorn gehindert habe, so dass er gezwungen wäre, sich in der entgegengesetzten Richtung zu verlängern. Gegen eine solche Auffassung sprechen aber diejenigen Operationen, bei welchen infolge der grösseren Entfermung der Operationsstelle rom Knopf eine Beeinflussung der Wachstumsrichtung wenigstens für die erste Zeit nach der Operation wohl ausgeschlossen erscheint. (Fig. 1, 9, 15, 23, 27, 32, 39, 43.) Diese Fïlle beweisen ebenfalls, dass der Embryo nach hinten hin auswächst.

Wem mu der Kopf als fester Punkt betrachtet werden kann, und die Terlängerung des Embryos nach hinten liin erfolgt, so entspricht die Lünge des Embryos bei Dotterlochschluss der Grösse des rom Knopf während der Dotterumwachsung zuriickgelegten Weges.

Damit kommen wir zum nächsten Punlit.

\section{Die Umwachsung des Dotters.}

Die Länge des Forellenembryos bei Dotterlochschluss schwankt zwischen 3 und $4 \mathrm{~mm}$. Die Eigrösse beträgt im Mittel $4,5 \mathrm{~mm}$, und die Lünge eines Meridians 1t,13 mm. Da num die Krimscheibe zur Zeit der Bildung des Knopfes $60^{\circ}$ der Eiperipherie umfasst, d. h. ein Sechstel des Meridians, so müssen der Knopf und der ihm gegenïberliegende Punlit des Randrings zusammen fünf Sechstel der Meridianlänge $=11,78 \mathrm{~mm}$ zurücklegen. T'on dieser Strecke kommen anf Rechnung des Embryos $3,5 \mathrm{~mm}$, so dass für 
den dem Knopf gegenüberliegenden Punkt des Randrings 8,28 mm iibrig bleiben.

Damit haben wir die Grundlagen zur Beurteilung der Dotterumwachsung gewonnen, denn während der Knopf um $3,5 \mathrm{~mm}$ auswächst, schreitet der ihm gegenïberliegende Randringabschnitt (in derselben reit) um mehr als das Doppelte fort.

Aus dieser Feststellung folgt unter Berücksichtigung des geraden Verlaufs des Randrings, dass die einzelnen Randringteile einen umso kürzeren Weg zurücklegen, je näher sie dem Knopf liegen.

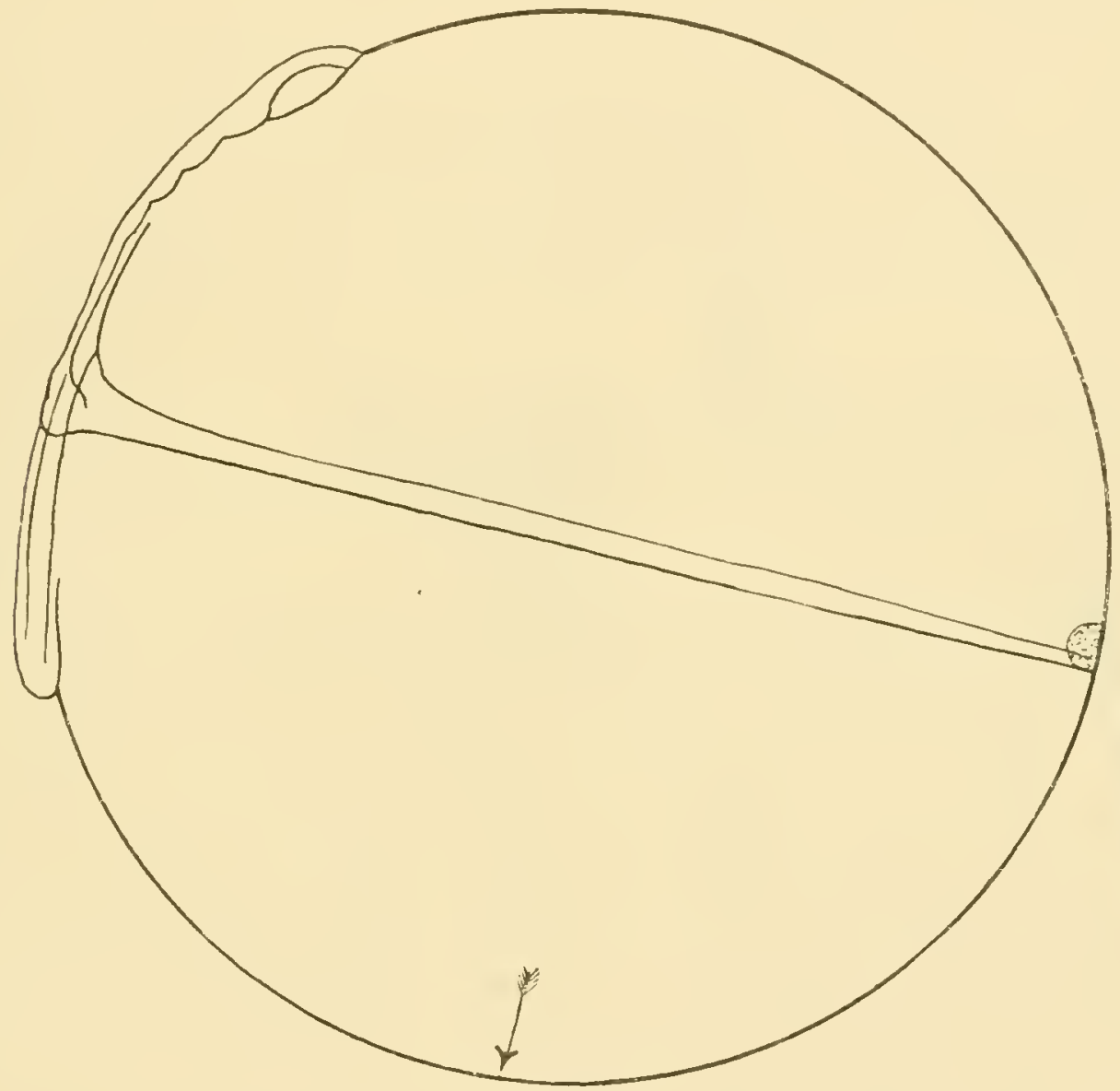

Fig. 2.

Profilansicht eines Forelleneies mit eingetragenem Operationsstadium und dem erzielten Resultat (nach Embryo VIII.)

Operationsstelle (in der Figur punktiert) au Randring $180^{\circ}$ vom Knopf entfernt; ilure spätere Lage ist durch den Pfeil bezeichnet.

Wir haben somit allein aus der Erkenntnis, dass der Embryo nach hinten auswächst, genaue Daten erhalten über die Art und Grösse der Verschiebung zweier Punkte des Randrings, und haben eine allgemeine Vorstellung gewonnen von dem Verhalten der anderen Randringabschnitte bei der Umwachsung. Wie sie sich dabei im einzelnen verhalten, zeigen die Ergebnisse der verschiedenen Operationen. 
Petrachten wir zunächst, um ein [rteil zu gewinnen über den Einfluss der Operation auf die Bewegung der von ihr betroffenen Randringstelle, die Operationen am Knopf und an dem ihm gegenüberliegenden Randringabschnitt, deren Bewegungsgrösse bei der normalen Entwicklung wir schon kennen, so sehen wir, dass bei denjenigen Fällen, in welchen die dem Konopf gegenibberliegende Stelle betroffen ist, die Terschichung dieses Punktes mehr oder weniger verringert ist, und dass die benachbarten Randringal,schnitte bei Dotterlochschluss keine kreisförmige, sondern eine spaltförmige Öffnung begrenzen, welche in der Verlängerung der embryonalen Achse liegt (Fig. 43 'Taf. TV).

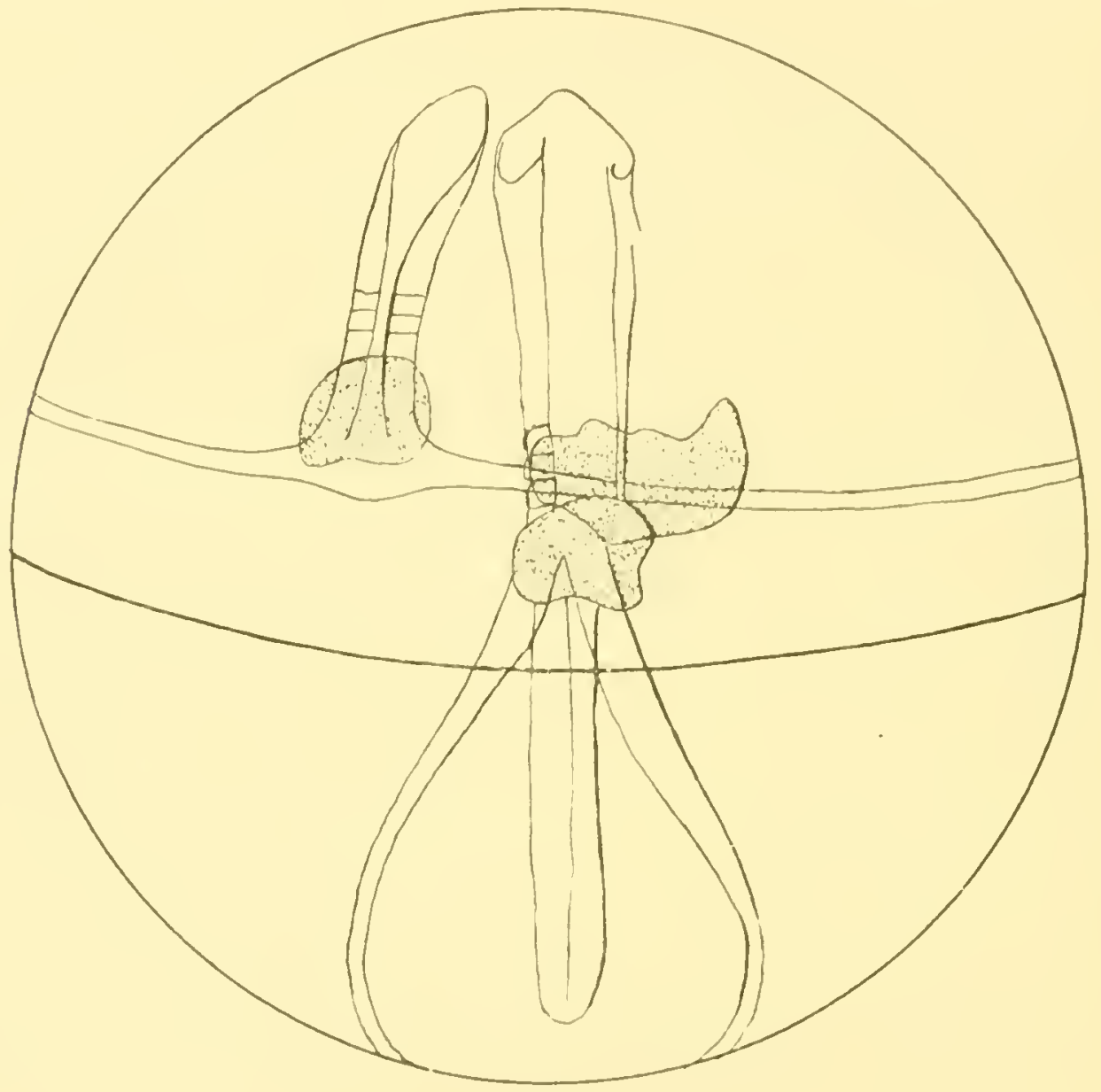

Fig. 3.

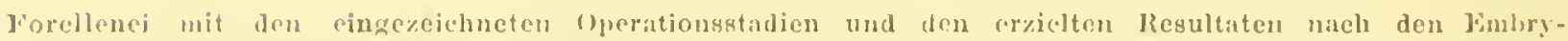
onen XII, XIII.

Gperationstrellen punktiert. Jer lialquator ist durch die anerverlaufende gebogene linie bezeichnet.

Die Liange dieses Spaltes gribt die Grösse der Hemmung an. Sie heträgt bei Embryo VIII beinahe die Hïlfte des von der operierten Stelle hei ungestörter Unwachsung ruriickzulegenden Weges (siehe Textfigur ' 2$)$.

Ganz ähnlich scheint es bei denjenigen Operationen zu sein, welche den Tinopf hetreffen. Auch hier ist die operierte Stelle (s. Textfig. 3) nur wenig woiter bewegt, und an Stelle des runden Dotterlochs finden wir einen 
in der Verlängerung der embryonalen Achse liegenden Spalt, dessen Ränder von den beiden Randringhälften gebildet werden. 'J'rotzdem sind diese Fiille nicht mit den vorhergehenden zusammen verwerthar, demn die Operation liat durch die /erstirung des Knoples die Bildung dos hinteren Körperondes vollkommen verhindert, wodurch schon allein die Hemmung und damit rlic Bildung des spaltförmigen Dotterlochs erklärt werden kámn.

Somit können zur Beurteilung der durch die Operation luedingten licwegungshinderung nur dirjenigen Fälle benutzt werden, bei welchen die den Knopf gegenüberliegende Randringstelle betroffen ist. Aus ihnen ergibt sich, dass durch die Operation cine bald grössere, bald greringere Verminderung der Bewegung der betroffenen Randringstelle hervorgerufen wird.

Dieses Ergebnis werden wir bei der Beurteilung der Operationen an anderen Randringstellen beriicksichtigen miissen.

Nunmehr können wir versuchen, für die einzelnen Randringabsclunitte Grösse und Richtung der Bewegung aus den Ergebnissen der Operationen abzuleiten.

Dies scheint am leichtesten $\% u$ sein bei denjenigen Fällen, in wolchen durch dic Operation die Bildung des Embryos gan\% verhindert worden ist oder in welchen durch Zerstöıuıg des Knopfes nur die Bildung eines grösseren oder geringeren hinteren Körperstücks unterblieben ist.

Betrachten wir zunäichst die an zweiter Stelle erwähntrn Fälle, so fällt auf, dass die Länge des spaltfürmigen Jotter]ochs (s. Fig. f; J'af. VI) zusammon mit dem vorderen Stück des Fmbryos und der Operationsstelle zicmlich genau der Grösse cines normalen Embryos vom Stadium des Dotterlochschlusses

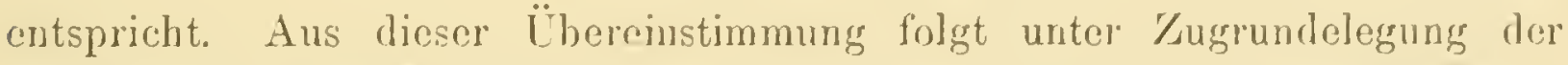
schon gewonnenen Kenntnisse, dass die dem Knopf gegenüberliegende Randringstelle genau die Strecke durchmessen hat, welche sie bei ungestörter Entwicklung des Embryo: zurückgelegt lıaben würde. Dieso Tatsache kann verwertet werden im Simne ciner gewissen Unabhängigkeit der Dotterumwachsung von der Bildung des embryonalen Körpers. Wrenn aber der Randring für sich allein im Stande ist, den Dotter zu unwachsen umd wemu dabei ein Punkt (in diesem Fall der dem Knopf gerade entgregengesetztos) die normale Riclutung und Giösse ler Bewegung besitzt, so könnte man geneigt sein. dies auch für die übrigen Teile des liandrings zu verallgemeinern und jhre Lage zu beiden Seiten des spaltfïrmigen Dotterlochs (s. Fig. 6.) und Textfig. 3) als übereinstimmend zu betrachten mit drerjenigon, welche sic bei der normalen Entwicklung gewinnen, wenn jildung des Embryos und Umwachsung gleichzeitig geschehen und könnte dann writcr den Schluss ziehen, dass der Randring in der von His angenoununonen Art den Embryo bildet. Solche Siclilusse wälen aber nach den bisher gewonuenen Ergebnissen dieser allgemeinen Betraclitung noch nicht zulässige, denn wil 
haben gesehen, dass eine spaltförmige Aneinanderlagerung der Randringhälften auch eintritt bei einer Hemmung der normalen Bewegung einer Randringstelle (s. Embryo VIII Fig. 43) und eine solche Hemmung liegt ja auch in diesem Falle dadurch vor, dass infolge der Zerstörung des Knopfes die Bildung des hinteren Körperendes verhindert und damit eine beinahe vollkommene Hemmung der normalen Bewegung der an den Knopf grenzenden Randringabschnitte eingetreten ist.

Genau dieselben Überlegungen sind anzustellen und dieselben Schlïsse ergeben sich bei denjenigen Fïllen, in welchen (durch die Operation auf jüngeren Stadien) die Bildung des Embryos ganz ausgeblieben ist (Fig. 110, 113, 115). Auch in diesen Fällen haben wir ein spaltförmiges Dotterloch, dlessen Länge ungefähr der Grösse eines normalen Embryos bei Dotterlochschluss entspricht. Ja es ist sogar (Fig. 113) kuirzer, was wohl in dem Simne zu verwerten ist, dass die dem Knopf gerade gegenüberliegende Stelle des Randrings einen grösseren Weg zurückgelegt hat, als es bei der normalen Entwicklung der Fall ist. Dies lässt vermuten, dass bei der Umwachsung verschiedene Faktoren in Tätigkeit treten und einander in mannigfacher Weise beeinflussen können.

Einer dieser Faktoren ist uns aus der Betrachtung der normalen Entwicklung wohl bekannt, denn er ist des öftern beschrieben worden, und ist an lebenden Eiem leicht zu sehen. Es ist die Spannung innerhalb des Raudrings, welche eine so bedentende Einschnïrung des Dotters hervorrufen kann, dass der noch nicht von der Keimhaut bedeckte Abschnitt des Dotters in den lotzten Phasen der Umwachsung bruchsackartig aus dem Dotterloch hervortritt [s. Jablonowski (37) Fig. 3 Taf. I].

Andere Faktoren werden wir bei der Betrachtung derjenigen Operationen kennen lernen, welche den Randring zwischen den beiden schon besprochenen Punkten in grösserer oder geringerer Entfernung rom Kinopf treffen. Aus diesen werden wir zunächst die Grösse und Richtung kennen lernen, mit welcher die einzelnen Randringabschnitte bei der Umwachsung ïber den Dotter bewegt werden; daraus werden wir daun Schlüsse ziehen können über die Krräfte, durch welche diese Bewegungen bedingt sind, und werden ihre relative Intensität abschätzen.

Sehen wil zunächst die Operationen an, bei welchen auf dem Stadium der rautenförmigen Embryonalanlage (Stad II Fr. Kopsch 46) die Operationsstelle $45^{\circ}$ rom Knopf entfernt ist (Fig. 9 'Taf. I). An dem alis dieser Keimscheibe hervorgegangenen Embryo liegt die Operationsstelle in der Seitenplattenregion des 7.-9. Ursegments (s. Textfig. 4, A, B). Daraus folgt, dass die durch die Operation gekennzeichnete, $45^{\circ}$ vom Knopf cutfernte Stelle des Randringss während der Ausbreitung der Keimhant in schrïger Richtung die ron Pol zu Pol gezogrenen Meridiane kreuzend, von ihrer ursprünglichen Stclle aus (in der Richtung des Pfeils siche Texttig. 4) iiber 
den Dotter bewegt worden ist. Diese 'latsache ist umsomeln von Interesse, als iunerhalb der Umwachsungsphase, in wolcher dieser Punkt sich zum Knopf hinbewegt, der Keimhautrand länger wird, da der Dulchmesser der Ḱeimhaut bis zur Erreichung des grössten Kúnelkreises wäichst.

Während man ohne Kenntnis dieses Operationsergebnisses annehmen duirfte, dass die Dehnung des Keimhautrandes bei der Ausbreitung del Keimhant die cinzelnen Abschnitte gleichmässig oder ihrer Dicke entsprechend mehr oder weniger stark betrifft, erkennen wir aus dieser Operation, dass der Keimhautrand des Stadiums der halben Umwachsung nul einem Teil des Kímhautrandes des Stadiums mit rautenförmiger Embryonalanlage entspricht, weil die dem Embryo benachbarten Randringteile in der Zeit bis zur Erreichung der halben Umwachsung zum Kopf hinbewegt worden sind. Die Grösse des zum Embryo gelangten Randringabschnitts können wir wohl jederseits als ein Sechstel des gesamten Keimbautrandes vom Ausgangsstadium dieses Versuchs annehmen, denn wil sehen, dass auch von den jenseits der Operationsstelle befindlichen Randringteilen eine gewisse Strecke noch vor der Vollendung der halben Umwachsung den Kínopf erreicht haben wiirde. IVir werden also berechtigt sein, zu sagen, dass der zur Zeit der halben Umwachsung vorhandene Randring nur den vorderen zwei Dritteln des Keimhatrandes vom Stadium des rautenförmigen Embryos entspricht.

Da nun der Umfang der Keimscheibe (bei Annahme eines Durchmesser's vou $2,5 \mathrm{~mm}$ ) $7,8 \mathrm{~mm}$ gross ist, Wovon zwei Drittel gleich $5,2 \mathrm{~mm}$ sind, und da der grösste Krugellireis eines Eies von $4,5 \mathrm{~mm}$ Durchmesser gleich $14,13 \mathrm{~mm}$ ist, so wird zur Zeit der halben Umwachsung jeder Teil des Randrings auf annähernd das Dreifache seiner Länge, welche er zur Zeit der Operation hatte, ausgedehnt sein müssen, wenn wil von der durch Zellteilung und Zellvergrösserung etwa erfolgten Materialzunahme absehen. Dieses Ergebnis erklärt wohl zur Geniige die ausserordentlich schwache Ausbildung des Randrings zur Zeit der halben Umwachsung und die Schwierigkeit zu dieser /eit die drei Keimblïtter in ihm nachweisen zu wollen.

Nach dieser Abschweifung liehren wir zu den uns hier zunächst interessierenden Fragen zurïck und sehen zu, was fïr Schliusse sich aus der Bewegung der Operationsstelle auf die im Randring wirkenden Kräfte ziehen lassen.

Die Anuäherung der Operationsstelle an den Embryo zeigt, dass eine in der Richtung des Randrings wirkende Kraft existiert, welche die in ihm vorhandene Spamnung erzeugt. Ausser dieser aber wirkt noch eine andere, in meridionaler Richtung angreifende Kraft auf die Operationsstelle. Die Resultante aus beiden Fräften ist der von der Operationsstelle zuriickgelegte, die von Pol zu Pol gezogenen Meridiane in schräger Richtung kreuzende IVeg. Wenn wir nun die Länge des Weges, welchen die Operationsstelle 


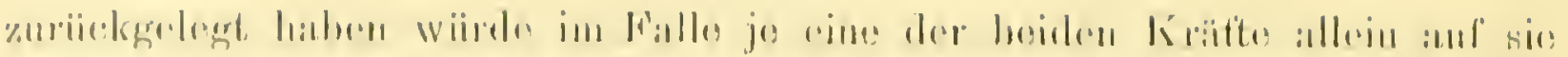

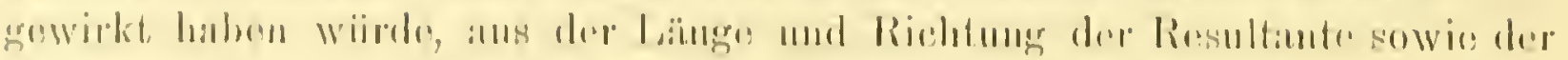

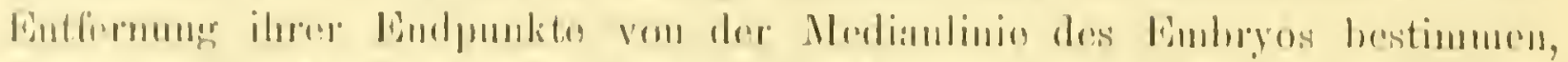

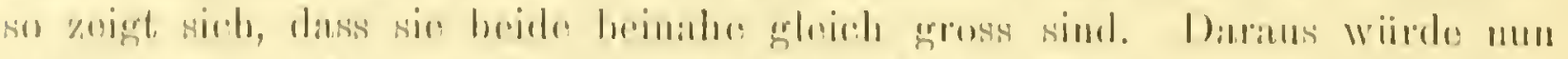

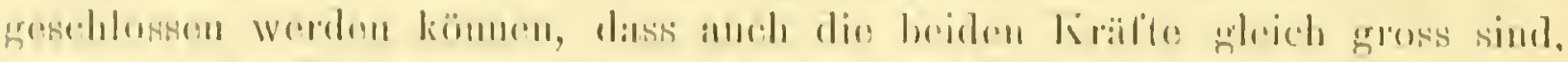

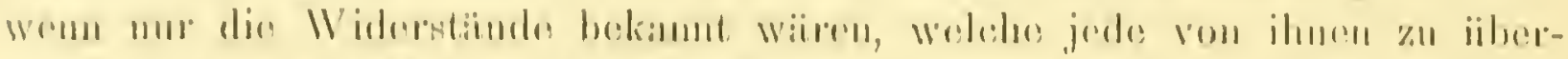

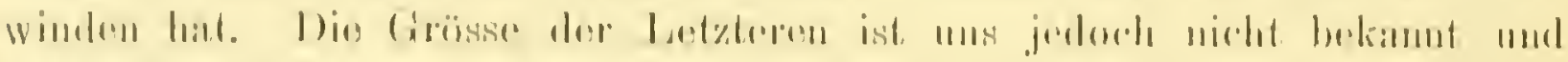

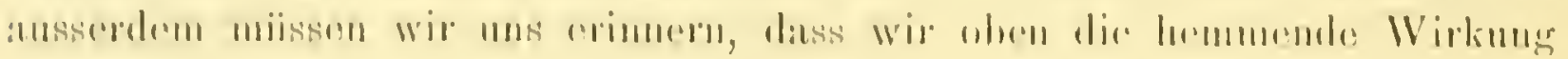

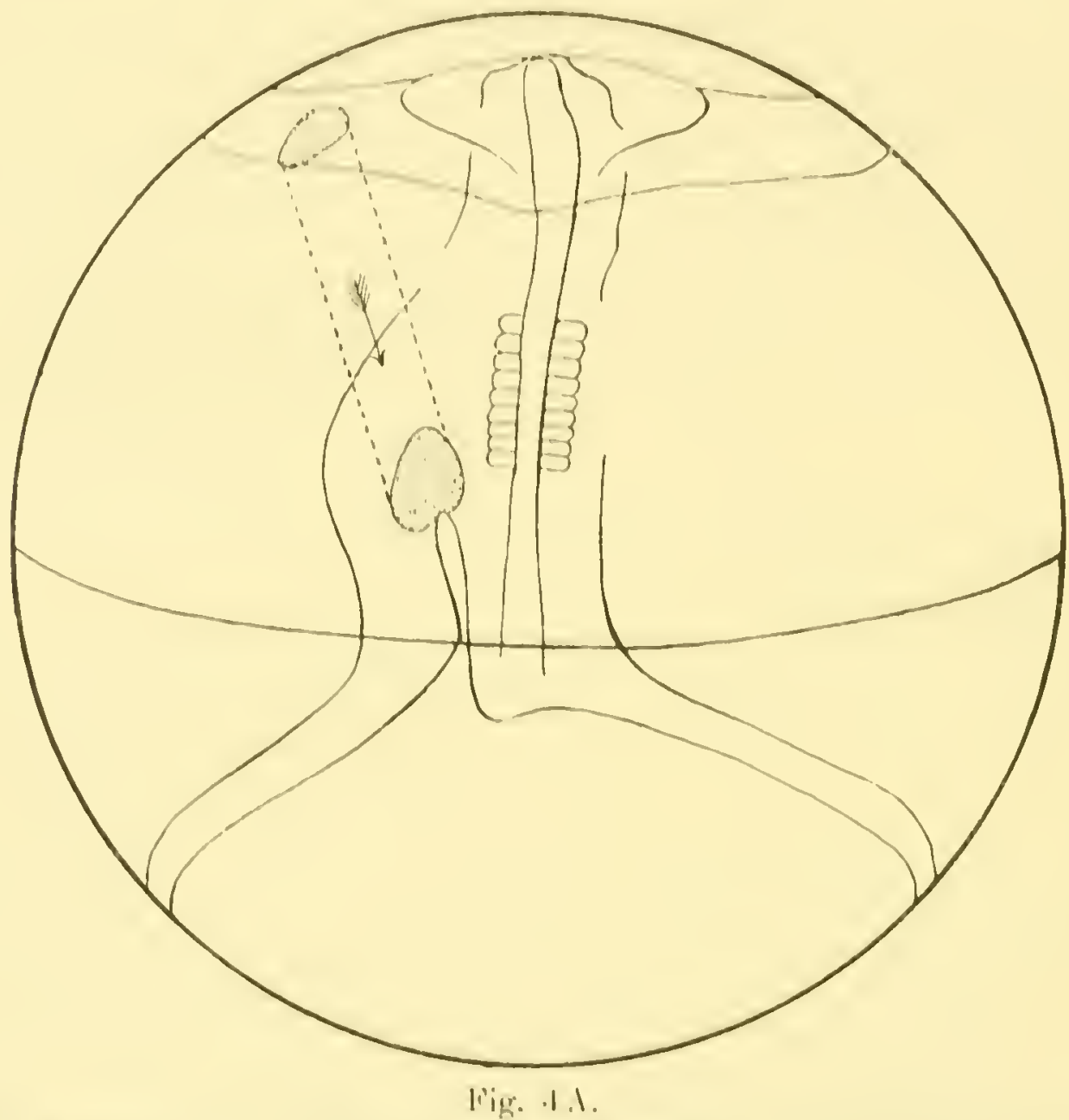

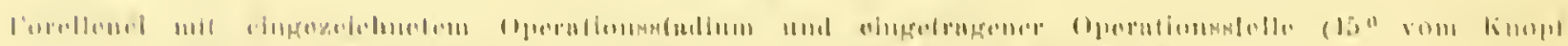

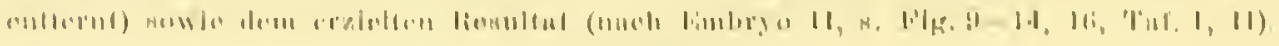

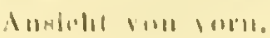

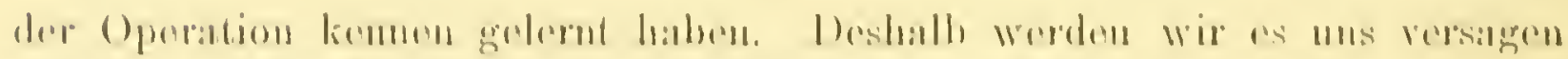

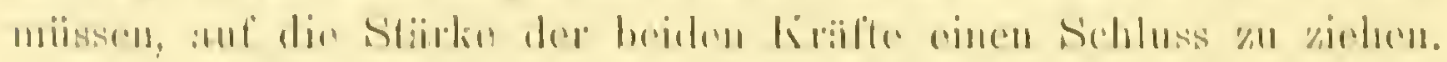

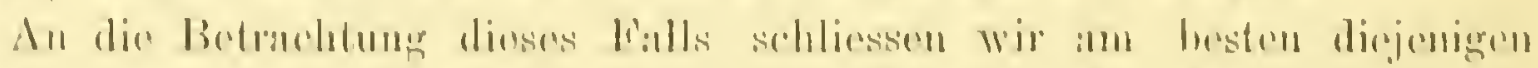

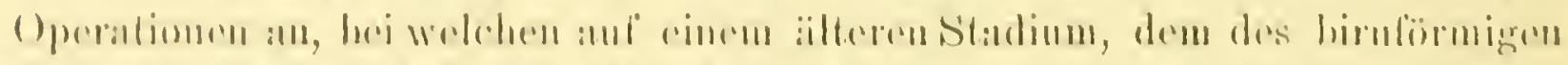

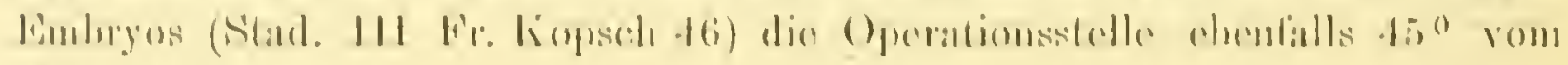
linople antfernt ist.

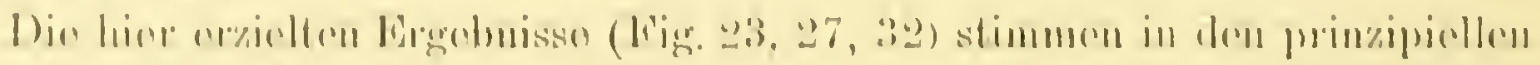

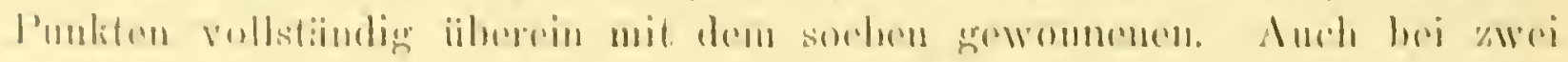




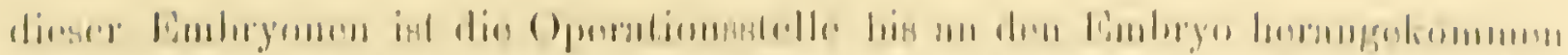

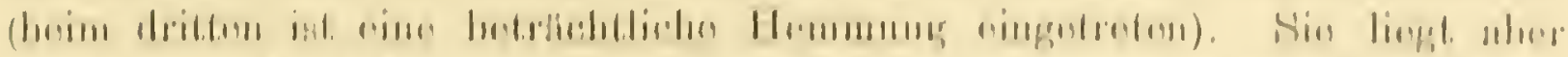

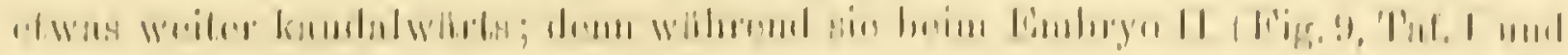

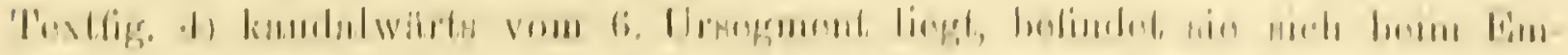

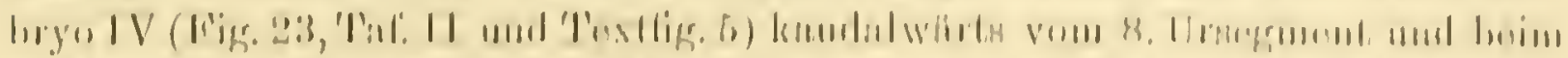

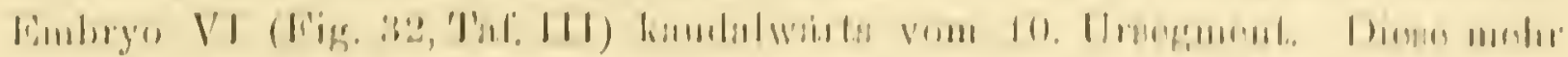

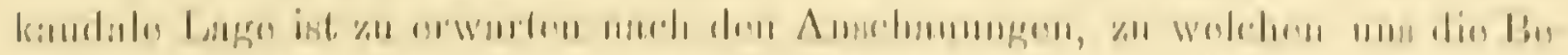

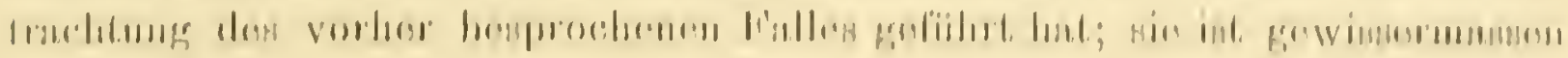

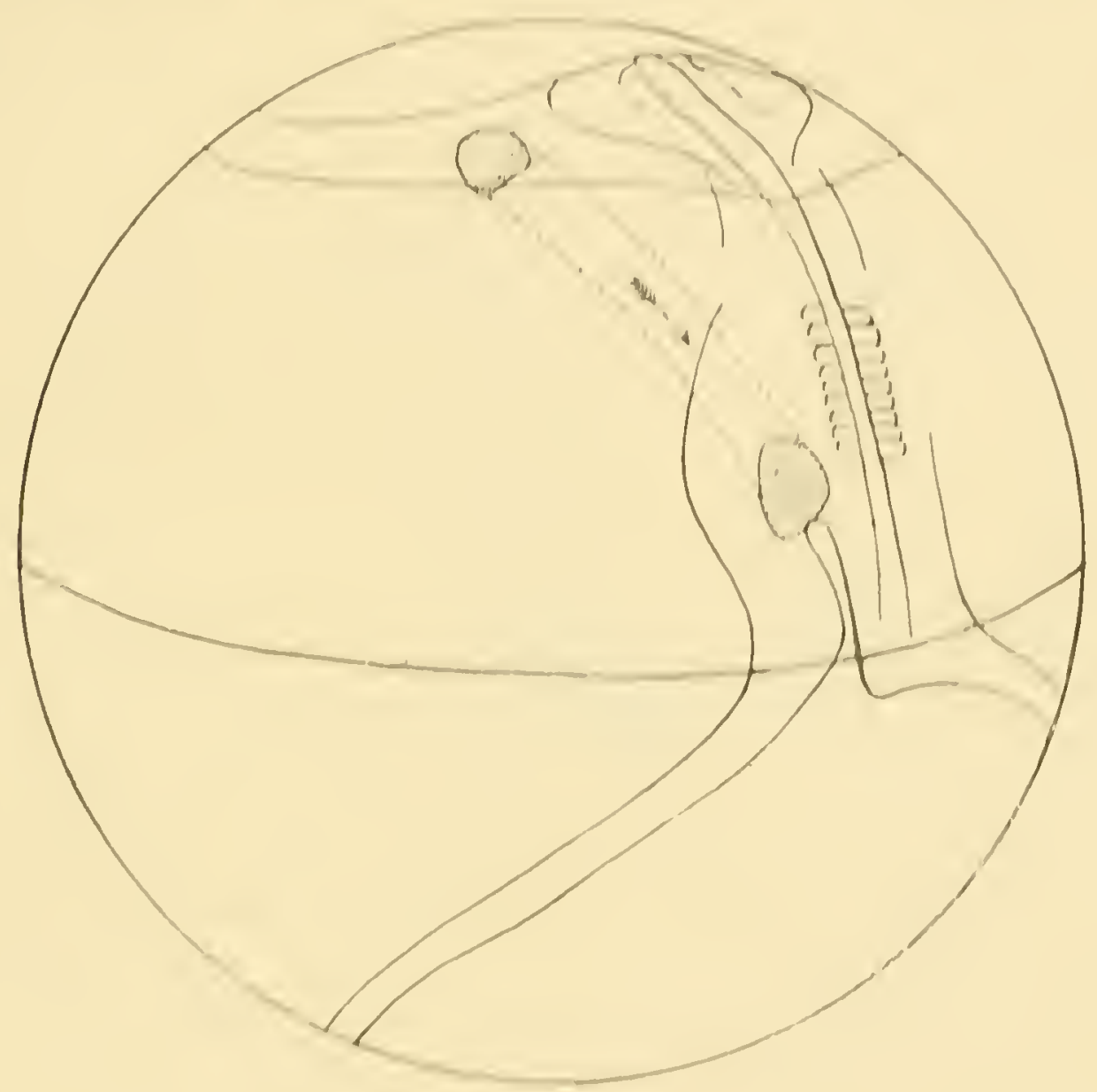

lifi., 11:,

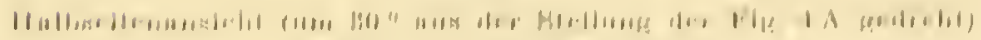

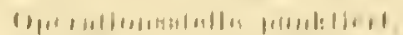

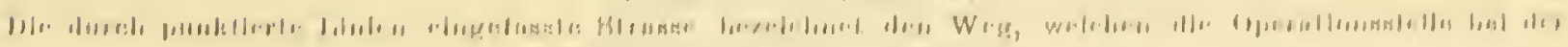

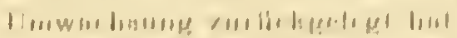

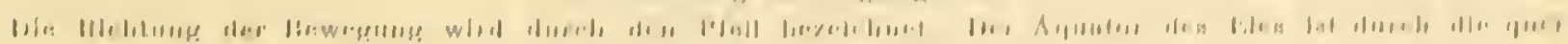

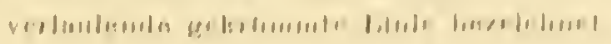

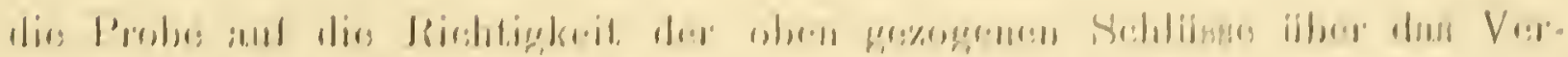

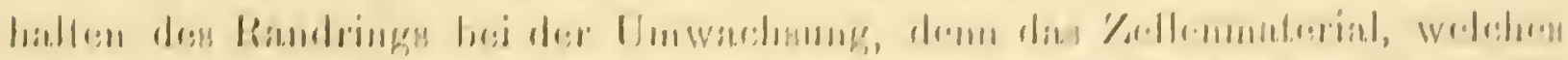

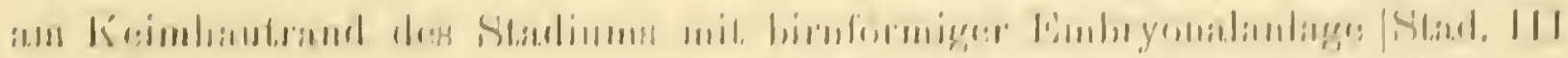

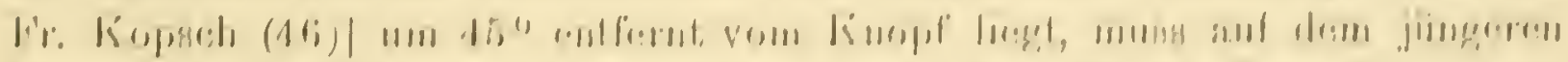

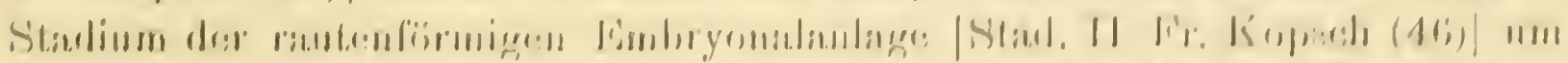

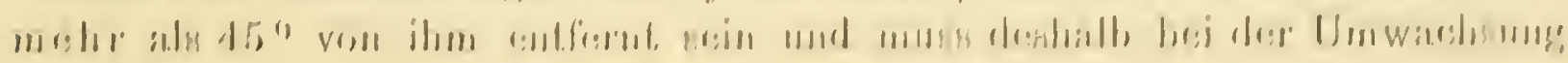


an eine Stelle des Embryos geschafft werden, welche weiter kaudalwärts liegt.

Diese Übereinstimmung der Resultate bei den Operationen an verschiedenen Stadien (IT und III) ist umso wertvoller, als es sich um Versuche handelt, welche zn verschiedener Zeit an Eiern verschiedener Bruten und auf verschiedenen Stadien vorgenommen sind. Wie gross die Übereinstimmuug ist, kann am besten erkannt werden, wenn man eine durchsichtige Umrisszeichnung ron Textfig. 5 auf Textfig. 4 legt und die Wege der Operationsstellen mit einander vergleicht.

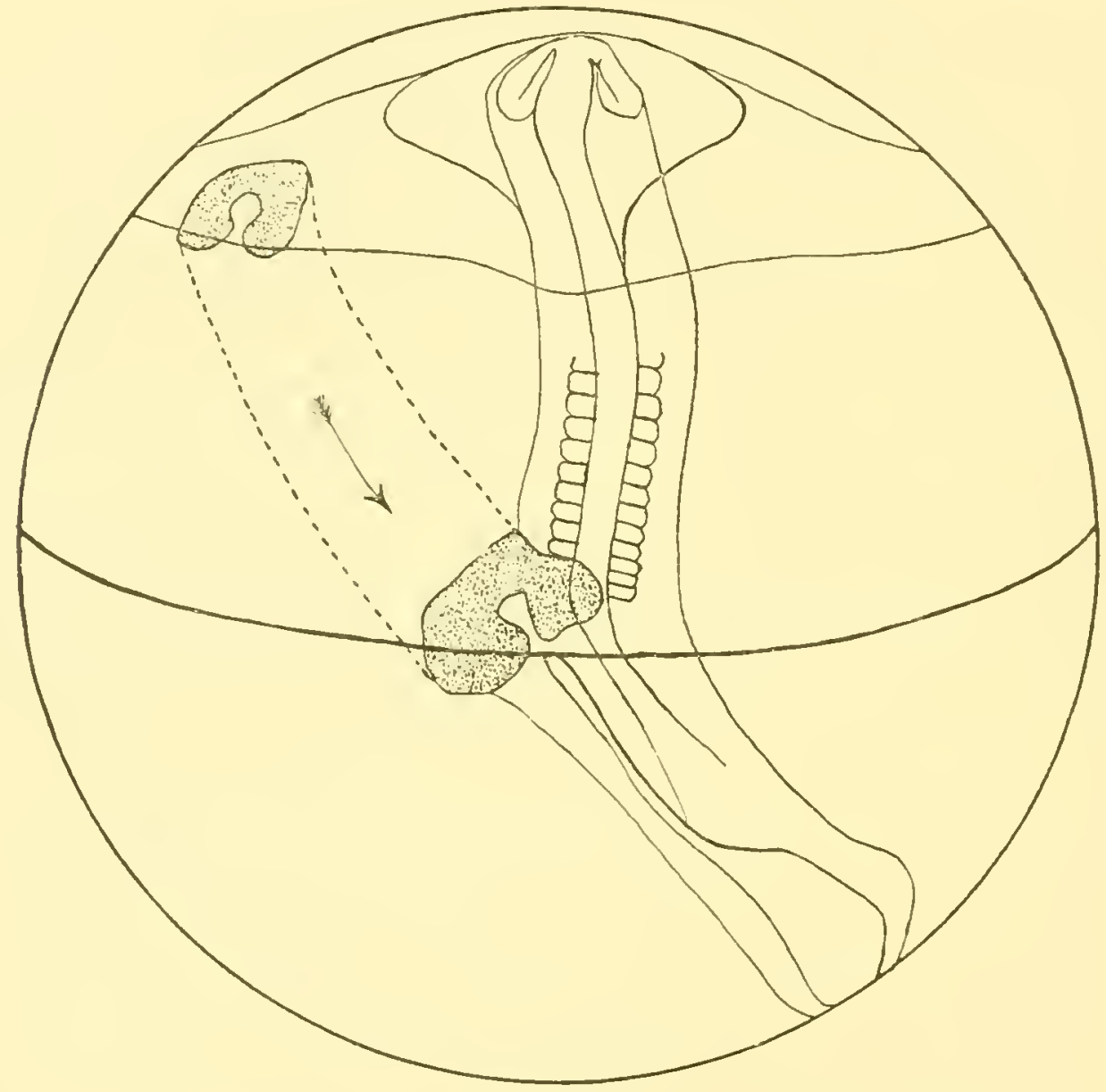

Fig. $5 \mathrm{~A}$.

Forellenei mit eingezeiehnetem Operationsstadium und eingetragener Gperationsstelle (450 vom Knopf entferut) sowie deu erzielten Kesultat (nach Embryo IT; s. Fig. 23, T'afel II)

Ausicht von vorn.

Die Hemmung, welche beim Embryo V (Fig. 27. 'laf. III) eingetreten ist, kommt wohl auf Rechnung der grossen Operationsstelle. Gleichwohl ist ihre Verschiebung in derselben Richtung erfolgt, wie bei den anderen hier abgebildeten Embryonen desselben Versuchs, und dass an dem jenseits der Operationsstelle befindlichen Randringabschnitt dieselben beiden Kräfte in latitudinaler und meridionaler Richtung wirksam sind, zeigt der Zustand des sich an die Operationsstelle anschliessenden Randringteils. 
Eine bisher noch nicht besprochene Erscheinung ist die Zellenarmut des zwischen Operationsstelle und Embryo befindlichen Randringteils. Sie ist, wie hier gleich gesagt sein soll, stets vorhanden, wenn die Operationsstelle in einiger Entfernung rom Embryo liegen geblieben ist (vergl. Fig 1, 27, 39)

Es ist nun zu untersuchen, wohin die Zellen gekommen sind und da bleibt nur die Möglichkeit iibrig (s. Seite 50 ), dass sie in latitudinaler Richtung sich bewegend oder bewegt werdend zum Embryo gekommen sind. Dabei ist von besonderer Bedeutung, dass die Zellen dieses Randringstiickes in der Richtung zum Embryo weiter bewegt worden sind, obwohl infolge

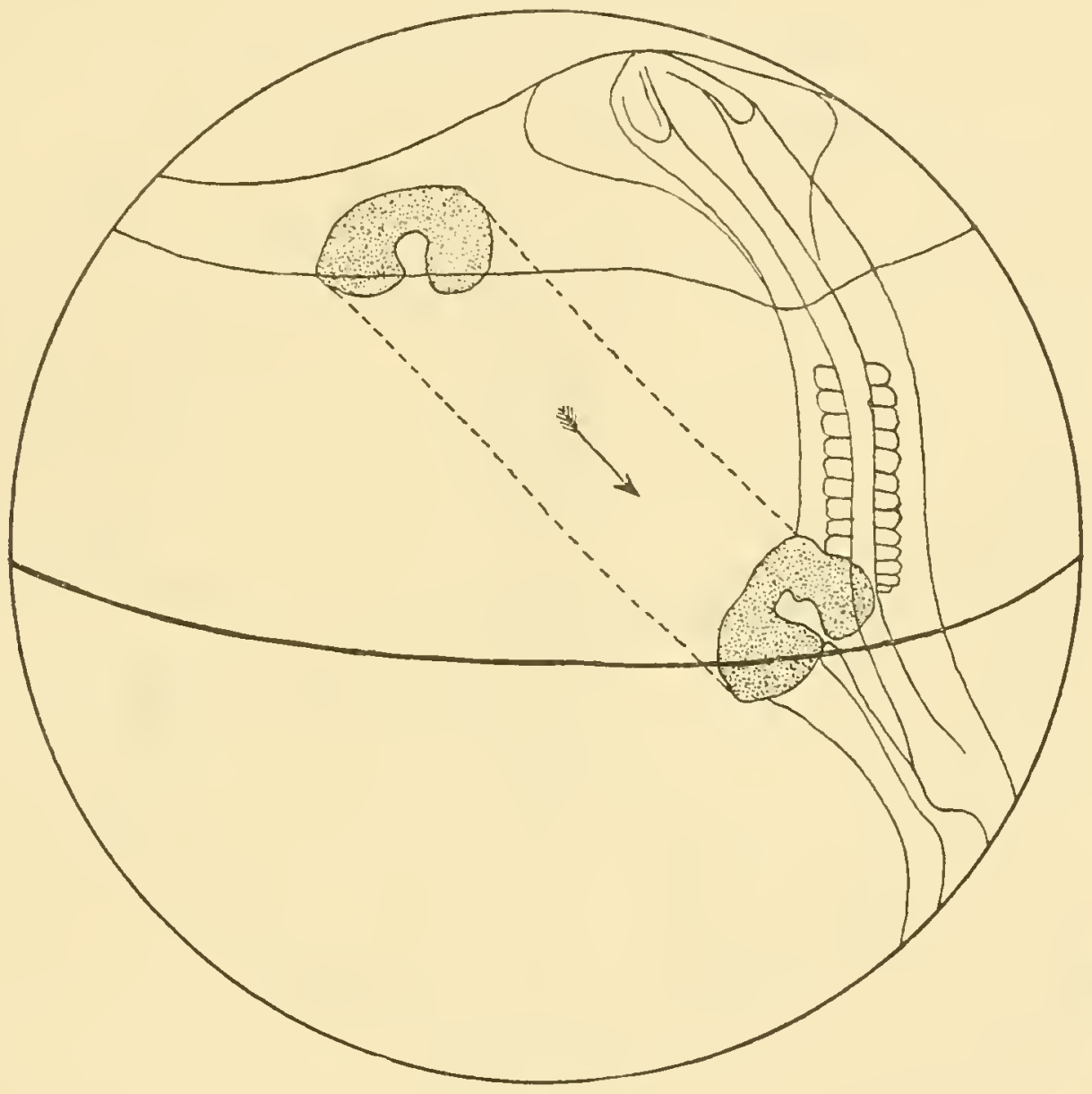

Fig. 5 B.

Halbseitenansieht (um $30^{\circ}$ ans der Stcllung der Fig. 5 A gedreht). Operationsstelle punktiert.

1)ie dureh punktierte Linien eiugefasste Strasse bezeichnet den Weg, welehen die Operationsstelle bei der Umwaehsung zurüekgelegt hat.

1)ie Riehtung der Bewegung wird dureh den Pfeil bezeichnet.

J)er Äquator des Eies ist durch die quer verlaufende gekrümmte Linie bezeiehnet.

des Stillstandes der Operationsstelle eine Art Schub von Seiten der anderen Randringteile ausgeschlossen ist. Daraus folgt, dass die latitudinale Bewegungsrichtung des Randringmaterials jedem einzelnen kleinsten Teil zukommen muss, dass es sich weder allein um eine Art Anziehung von seiten des Embryos, noch alleir um eine Art Schub von seiten entfernter Rand- 
ringteile handelt. Gegen die erste Möglichkeit spricht der Zustand des jenseits der Operationsstelle befindlichen Randringstückes, gegen die zweite die Tatsache, dass trotz der Hemmung durch die Operationsstelle das zwischen ihr und dem Knopf befindliche Zellenmaterial zum Embryo gelangt ist.

Es ist vielmehr möglich, dass bei der normalen Entwicklung beide Ursachen zusammen wirksam sind und dass, wenn die eine ausgeschaltet wird, die andere allein zur Geltung kommt.

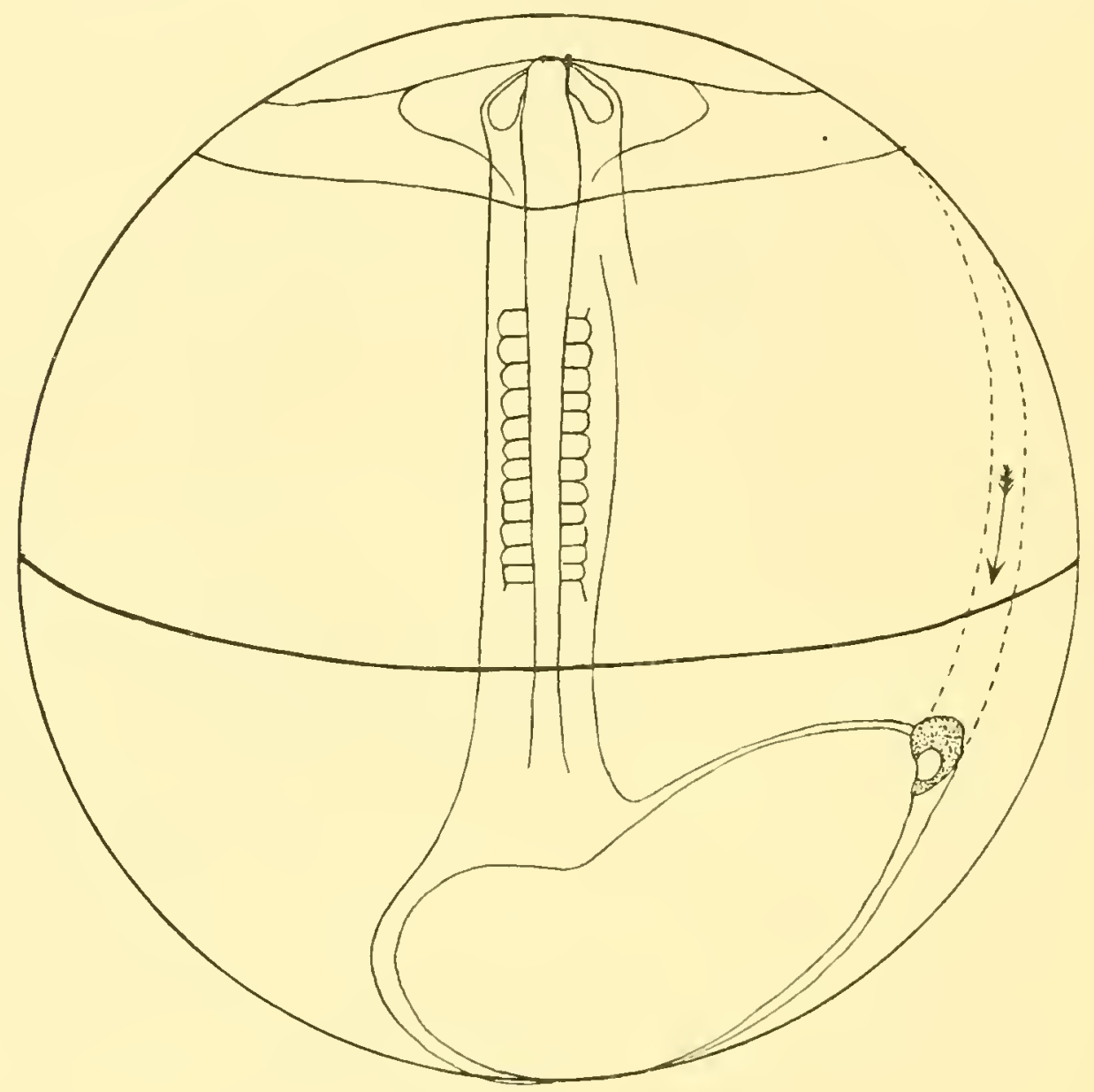

Fig. 6 A.

Ansicht ron rorll.

Forellenei unit eingezeiehnetem Operationsstadium und eingetragener Uperationsstelle (900) vom knopi entfernt) sowie dem erzielten Resultat. (nach Fmbryo VII, s. Fig. 39, Tafel IIH.)

Operationsstelle punktiert.

Andrerseits liegt die Möglichkeit vor, dass es sich um allgemeine, in jeder Zelle des Randringes enthaltene Fïhigkeiten handelt, indem durch Summierung der an den einzelnen Zellen zur gegebenen Zeit eintretenden Zellvermehrung, Volumens- und Dimensionsïndermgen, sowie kleinster Terschiebungen grosse Massenwirknngen hervorgebracht werden. Ich muss gestehen, dass diese Art der Betrachtung (s. Goette 16, Rauber 77) mir im Hinblick auf die Ergebnisse der Entwicklungsphysiologic. zur Zeit dic annelmmbarste erscheint. 
Wir kommen nun zur Besprechung des letzten in diesem Kapitel heranzuzichenden Versuchs, welcher die Verschiebung des auf Stadium II (Fr. Kopsch 46) $90^{\circ}$ vom Knopf entfernten Randringteils zeigt. Embryo VII (Fig. 39, Taf. III und Textfig. 6 A,B).

Hier ist leider eine Hemmung eingetreten, welche dic normale Bewegung des betroffenen Randringstiickes etwa um ein Viertel des zurïckzulegenden Weges verkiirzt, und welche sowohl in latitudinaler als auch in meridio-

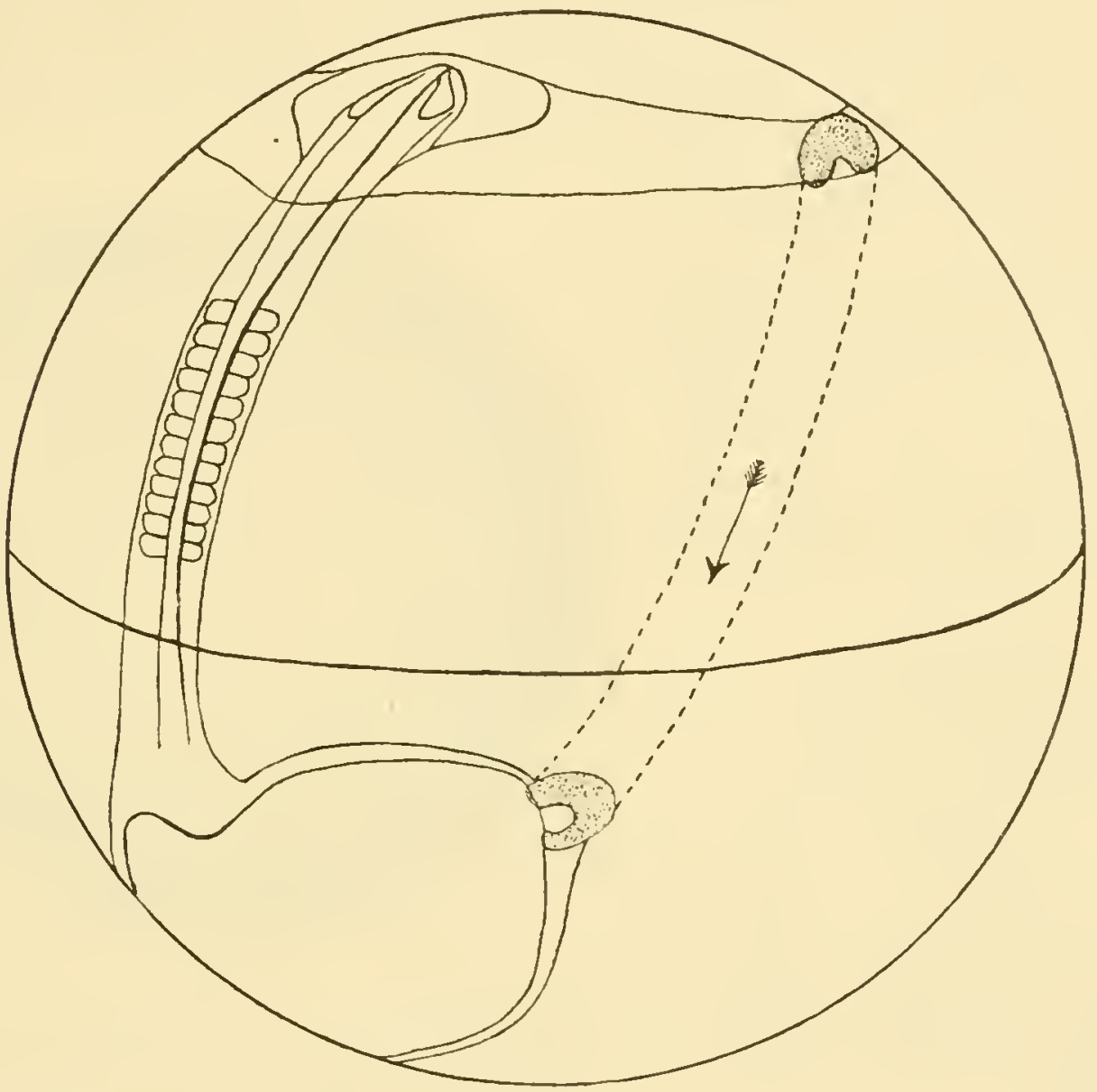

Fig. 6 B.

Halbseitenansicht (um $30^{\circ}$ aus der Stellung der Fig. $6 \Lambda$ gedreht).

Die vou punktierten Linien eingefasste strasse bezeichnet den Weg, welchen die Operationsstelle bei der Unwachsung zurückgelegt hat.

Die Richtung der Bewegung wird durch den Pfeil bezeichnet.

Der Äluator des Eies ist durch die quer rerlaufende gekrümmte Linie bezeichnet.

naler Richtung gewirkt hat. Dass eine Hemmung eingetreten ist, folgt aus der seitlich ansgezogenen Figur des Dotterlochs.

Unter Berïcksichtigung dieser Hemmung bestätigt das Ergebnis dieses Versuchs die vorher gezogenen Schliisse, dass die zwischen Knopf und entgegengesetztem Punkt des Randringes befindlichen Teile umso weiter kaudalwärts (in Beziehung zum Embryo) gelangen, je weiter sie ursprünglich rom Knopf entfernt waren, und dass der von ihnen bei der Umwachsung zurïck- 
gelegte Weg die ron rol zu Pol gezogenen Meridiane unter grösserem oder geringerem Winkel kreuzt.

Fassen wir nun die Ergebnisse der besprochenen Tersuche zu einem einheitlichen Bild zusammen, so ergibt sich fiir die Forelle über das Vorschreiten des Keimhautrandes und über den Weg sciner einzelnen Punlite Folgendes (s. Textfig. 1):

Die Ausbreitung der Keimhant über die Dotterkugel erfolgt excentrisch zur Mitte der jungen Keimscheibe und zwar so, dass derjenige Punkt des Randes, welcher dem Embryo gerade gegeniiberliegt, die weiteste Strecke zurücklegt, während alle anderen Punkte einen umso kürzeren Weg beschreiben, je nüher sie der Embryonalanlage sind. Thr Weg kreuzt die ron Pol zu Pol gezogenen Meridiane unter verschiedenem Winkel.

Das vordere (rostrale) Ende des Embryos verïndert seine Entfernung von der ursprïnglichen Nitte der Keimscheibe entweder gar nicht oder nur um ein weniges. Das hintere Ende, der Knopf, legt

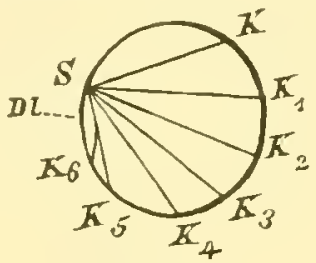

Fig. 7.

Umwachsungssclema für das Forellenei nach (lellacher.

S. Schwanzende des Embryos.

$h-h$. Fortschreitendes rorderes (Kopfende) der Keimhaut.

Dl. Dotterloch.

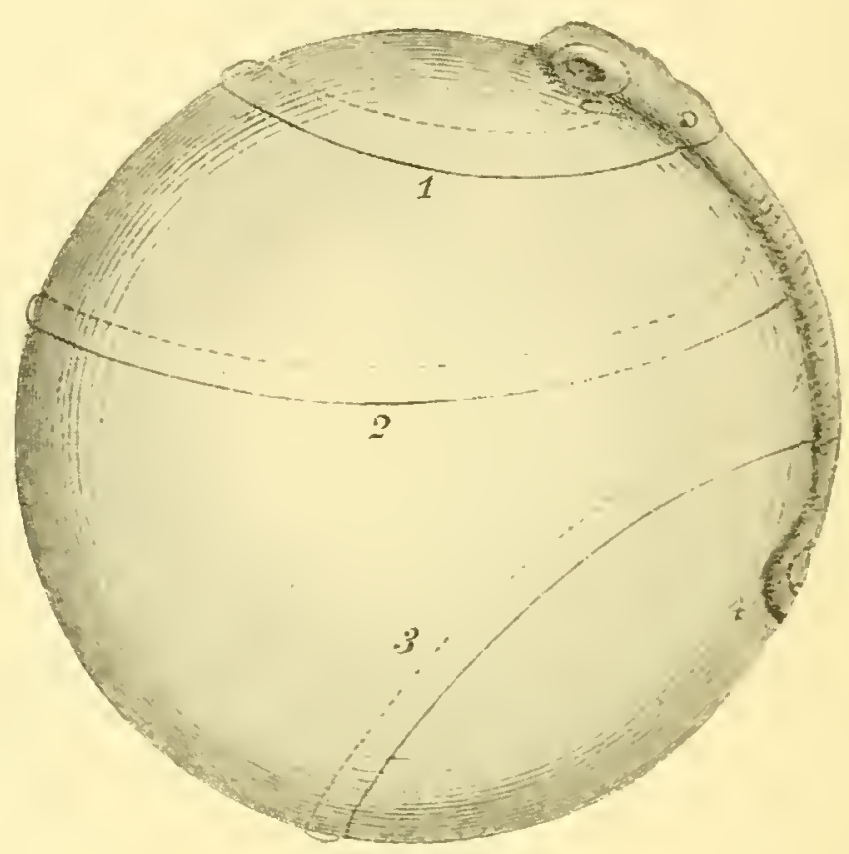

Fig. 8 .

Schema ron der Aubbreitung der Keimhant bein Lachsei nach llis. Vier bei 10 facher Vergrosserung aufeinander projizierte Stadien. 1 entspricht His Stad. I), 4 dem Schluss der Umwachsung.

einen weiteren Treg iiber die Eikugel zuriick als die benachbarten Randringabschnitte, jedoch noch nicht die Hälfte des Weges, welchen der ihm gerade gegenuiberliegende Punkt des Keimhautrandes beschreibt.

Derjenige Punkt des Randrings, welcher auf dom Stadium des rautenförmigen Embryos $45^{\circ}$ vom Knopf entfernt ist, gelangt im Lauf der Umwachsung in die Gegend des 7. Ursegments; der Punkt, welcher in demselben Stadium $90^{\circ}$ vom Knopf entfernt ist, befindet sich zur Zeit des Dotterlochschlusses im unsegmenticrten hinteren Stiick des Embryos; der 1:350 entfernte Punkt dient zur seitlichen Begrenzung des Dotterlochs; der $180^{\prime \prime}$ entfernte zu" hinteren Begrenzung desselben. Da nun die seitlichen und hinteren Teile des engen Dotterlochs teils zugrunde gehen, teils verbraucht werden zur 
Bildnng ventraler Teile des hinteren Körperabschnitts, wie es H. Virchow (9:3) festgestellt hat, was ich erstens für die normale Entwicklung bestïtigen kann, und wie es zweitens aus dem Experiment (Embryo $\mathrm{X}$ ) folgt, so ist auch das Schicksal dieser Randringabschnitte bekannt.

Diese Ergebnisse stimmen in den wesentlichen Punkten iiberein mit Anschaumngen, welche von anderen Autoren in frïherer Zeit entwickelt worden sind, sie bestätigen aber nicht allein eine von den verschiedenen der vorhandenen Theorien über die Umwachsung des Dotter's, sondern bringen die Frage insofern weiter, als für die Forelle die Wege der einzelnen Randringstellen in ihren Grundziigen festgelegt werden. Sie erheben nicht den Anspruch, absolut genau zu sein, dazu sind die einzelnen in Betracht kommenden Faktoren zu variabel, dock werden sie eine Anzahl nicht zutreffender Angaben aus früherer Zeit endgültig beseitigen und, wie ich hoffe, den Anstoss geben zu wciteren Untersuchungen.

Welche ron den Angaben der Autoren durch die geschilderten Beobachtungen und ihre Ergebnisse gestiitzt und erklürt, oder aber beseitigt merden, wird Gegenstand der folgenden Zeilen sein.

Wie wir am Schluss der'historischen Einleitung gesehen haben, sind bis jetzt vier Ansichten iiber die Umwachsung des Dotters ausgesprochen worden:

Das Vorrïcken des Keimhantrandes erfolgt: 1. allseitig gleichmässig [Kupffer 1868; (51)]. 2. Excentrisch, wobei der Knopf in loco bleibt [Oellacher 1883, (67); s. Textfigur 7]. 3. Excentrisch, indem der Kopf das punctum fixum bildet [His 1874, 1878; s. Textfigur 8]. 4. Excentrisch, in der Art, dass zwar zunüchst der ganze Keimhautrand gleichmässig vorwächst, dann aber der

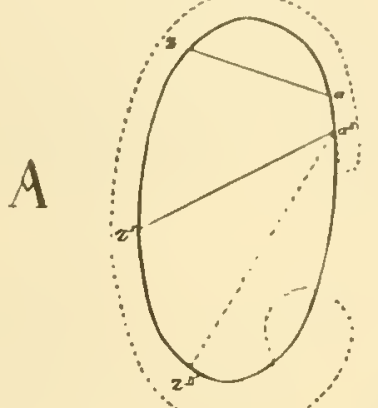

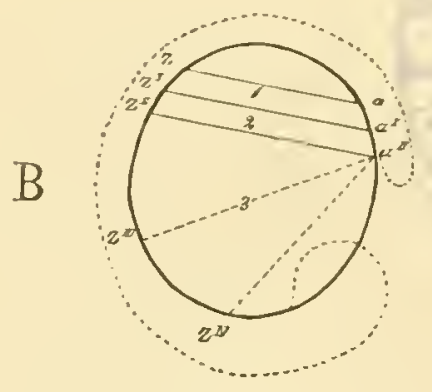

Fig. 9.

Umwachsungssehemata nach Mieez, von Kow al ewsti.

A. bei ejner unbekanuten marinen Teleostierform. $B$. bei Carassius auratus. $a, a^{\prime}, a^{\prime \prime}$ hinterer Blastodermrand.

$z, z^{\prime}, z^{\prime \prime}$ vorderer Blastodermrand. Knnopf stehen bleibt und nur der vordere Teil den Rest der Umwachsung vollfüht [Miecz von Kowalewski (53); s. 'Textfigur 9].

Zwei von diesen Anschanungen, die von Oellacher und die von Kowalewski sind, was die Forelle betrifft, durch die Ergebnisse ohne weiteres widerlegt; sie waren anch ohne dies sehr unwahrscheinlich, wie es auch aus der geringen Zahl ihrer Anbänger hervorgeht. Zur Auschauung Oellachers, welche H. E. Ziegler als ganz willkürlich bezeichnet, hat sich nur Wilson und neuerdings anch Boeke (8; s. Textfigur 10) bekannt, welche durch eine unbewiesene Voraussetzung, die als konstant angenommene Lage der Ölkugel des Serranus- bezw. Muraenaeies, zu einem unbewiesenen 
Schluss kommen mussten; die Ansicht Kowalewskis wird nur ron Henneguy geteilt.

Von den beiden anderen Theorien entspricht dem durch His (29) für den Lachs (s. Textfig. 8) gegebenen Schema ron der Ausbreitung der Keimhaut vollkommen das von mir im Jahre 1894 (44, s. Textfigur 11) aus der Betrachtung der normalen Entwicklung für die Forelle abgeleitete und nunmehr durch die Ergebnisse der Operationen sichergestellte Bild rom Ablauf der Umwachsung. - Mit der durch Kupffer (fiir andere Knochenfischeier) geäusserten Ansicht lässt sie sich nicht vereinigen.

Es liegt mir jedoch fern die Beobachtungen und Folgerungen Kupffers und der zahlreichen anderen Autoren, welche ihm zugestimmt haben, aus dem abweichenden Verhalten des Forelleneies für unzutreffend zu erklären,

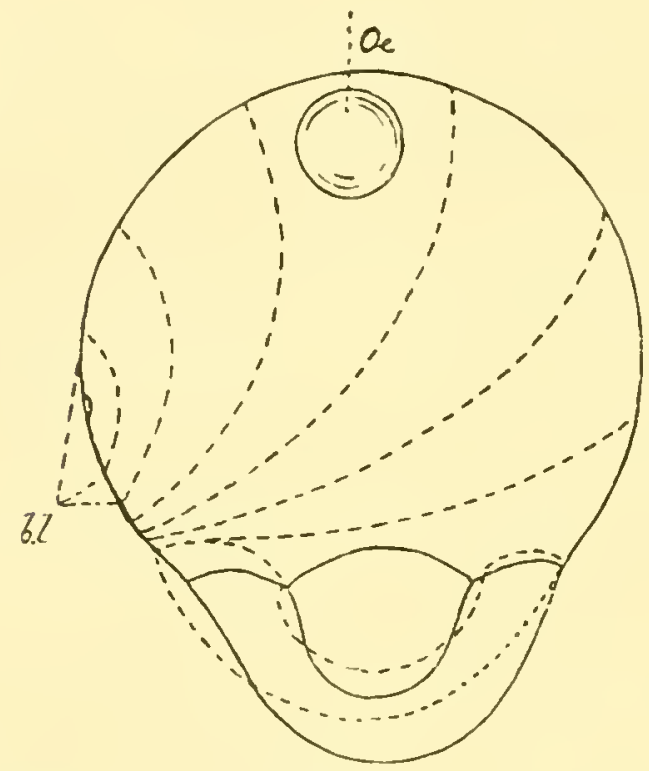

Fig. 10 .

Scliematische Darstellung der Dotterumwachsung :11 einem Ei von Muraena No. 1 mach Boeke. De, ÖItropfen, $B l$, Blastoporus.

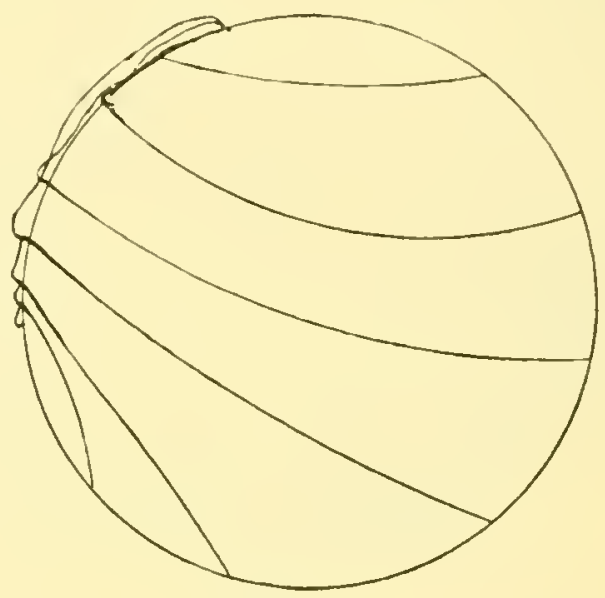

Fig. 11.

Umwalisungssehema nach Fr. Kopseh (14). 1894 entworfen nach Untersuchung der Oberflachenbilder der Forelle.

obwohl manche der zugunsten von Kupfers Anschaung beigebrachten Beweise nur geringen oder gar keinen Wert besitzen. Tch tue es um so weniger, als es mir nach eigenen, liickenhaften Beobachtungen an einer Anzah] anderer Knochenfischeier scheint, dass für manche Eier die Anschauung Kupffers im wesentlichen zutrifft. Ob dies sicher der Fall ist, muss durch weitere Untersuchungen bewiesen werden.

Kupffer selbst (55) war weit daron entfernt, die Anschaungen ron His durchaus abzuweisen, soweit sie den Lachs betreffen, bei welchem die Verhältnisse, wie er anerkemnt; schon deshalb anders liegen miissen, weil der Embryo bei Dotterlochschluss nur etwas mehr als $90^{\circ}$ der Eikugel bedeckt, während or beim Hering und Stichling im ,Momente des Abschlusses" der Umwathsung $180^{\circ}$ eimnimmt. Die Bedeutung diese: 
Unterschiedes für die Vergleichung erkennt auch $\mathrm{H}$ is (29) an, freilich ohne die Beobachtungen Kupffers so objektiv zu wiirdigen, als dieser Autor es mit seinen Befunden getan hat, dem Kupffer erkannte wohl, dass bei der Ausdehnung des Lachsembryos iiber $90^{\circ}$ der Eikugel die Ausbreitung des Keimhautrandes excentrisch vor sich gehen müsste, wie es $\mathrm{H}$ is geschlossen hat, weun der Kopf des Embryos in der Tat ein fester Punkt ist. Er verlangte den Beweis dafür mit vollem Recht, doch hat His nicht versucht, ihn zu fülıren, weil er nicht darauf ausgegangen ist die „Stellung der Keimscheibe zur Eihant und zur fest gedachten Dotterkugel festzustellen", sondern nur den Gegensatz zeigen wollte von "embryonalem und ausserembryonalem Wachstum, besonders aber die Anfiigung des Rumpfes an den .....Kopf"“, "deshalb wurde das rordere Kopfende als fester Punkt gewählt".

Der von Kupfer verlangte Beweis ist durch die Operationen erbracht und das Schema, melches $H$ is von der Ausbreitung der Keimhant beim Lachs entworfen hat (s. Textfigur 8), ist also zugleich ein vollkommen den Tatsachen entsprechendes Umwachsungsschema für das Forellenei (vergl. Textfiguren 1 und 8).

Eine andere Frage ist es, wie sich der Embryo zum Mittelpunkt der Keimscheibe verhält. Bleibt das vordere Kopfende in seiner ursprünglichen Entfernung oder vergrössert sich der Abstand vom Centrum, wie Goronowitsch aus der normalen Entwicklung und Schmitt aus den Zuständen an Doppelbildungen geschlossen hat?

Sehen wir zunächst, welche Tatsachen der normalen Entwicklung hier herangezogen werden kömen, ehe wir die Ergebnisse der experimentellen Untersuchung und der Teratologie würdigen.

1. Lageverhältnis des centralen Teils des Dottersackentoblasts (centrales Syncytium H. Virchows) zu Keimscheibe und Embryo. Bei den Salmoniden liegt unter der zelligen Morula der centrale Teil des Dottersackentoblasts (H. Virchows „centrales Syncytium"). Central deswegen genannt, weil es in annähernd centraler Lage unterhalb der Morula liegt. Es liegt allerdings nicht ganz genau central, sondern schon, wie ich nachweisen konnte, zur Zeit seiner Bildung (Fr. Kopsch 50) um ein geringes näher zum embryobildenden Randbezirk.

Es bestehen nun, wie schon Goronowitsch (17) gewusst, und $\mathrm{H}$. Virchow (93) ausfiihrlich auseiuandergesetzt hat, bestimmte räumliche Beziehungen des Dottersackentoblasts zu den überliegenden Teilen der Keimhant, für welche auch aus den Ergebnissen der Operationen sich mancherlei Beweise ergeben. Für den centralen Teil des Dottersackentoblasts ist es die Beziehung zum vorderen Ende des Embryos. Er liegt in der Mehrzahl der Fälle, welche ich daraufhin untersuchen konnte, dicht vor dem rostralen Ende des Kopfes: oder in weniger zahlreichen Fällen in geringer Entfermung von ihm. Dies 
gilt für alle Stadien vom Beginn der Embryobildung bis zum Schluss der Umwachsung (s. Textfigg. 14, 15, 16).

Dieser Befund steht in direktem Gegensatz zu der Darstellung, welche Goronowitsch ron dem Verhältnis zwischen dem Centralteil des .:Parablasten" und seineu Randteilen gibt. Deshalb sei es unir gestattet, mein abweichendes Urteil näher zu begrïnden.

H. Virchow hat sich die Zustïude am Syncytium ganz besonders angelegen sein lassen bei seinen Untersuchungen über Salmonidenentwicklung. In den von ihm publizierten Arbeiten findet sich besonders betont die Beziehung des Keims zu entsprechenden Teilen des Syncytiums. Über das

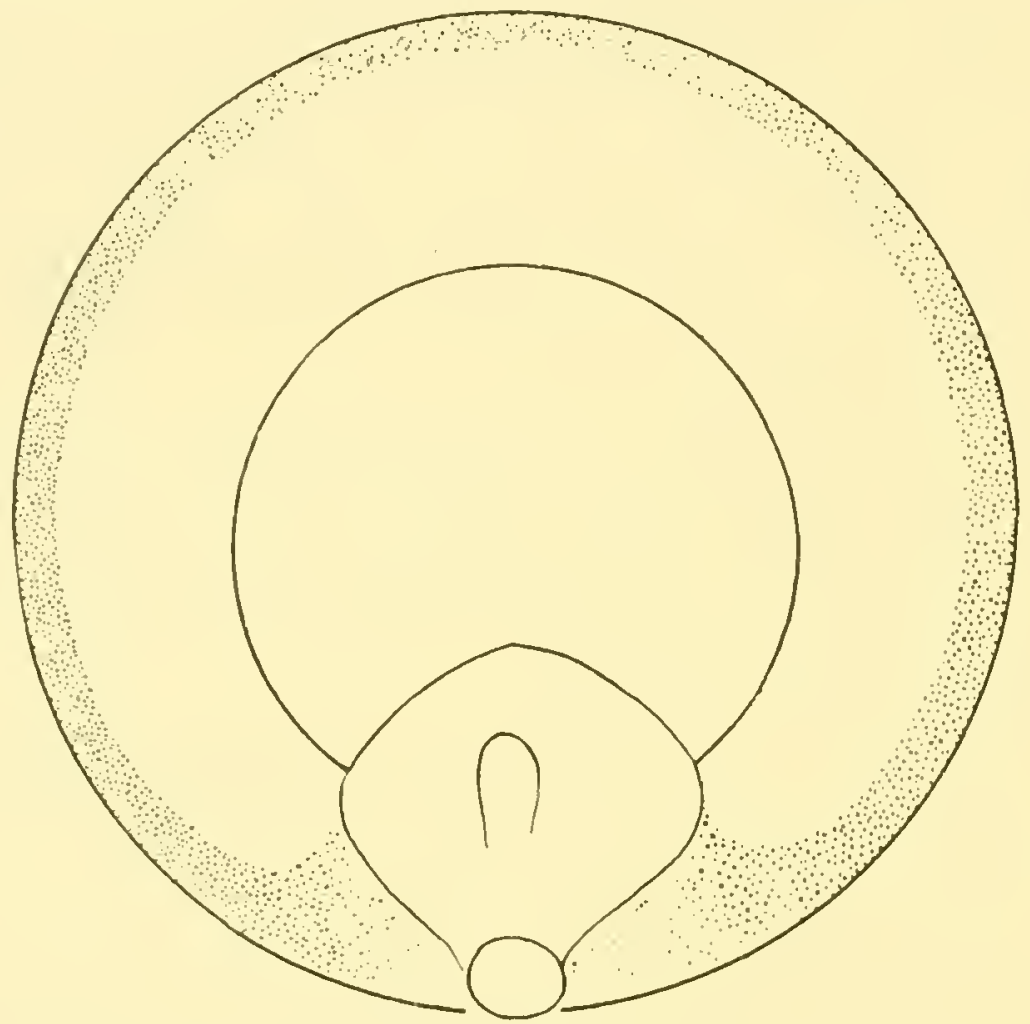

Fig. 12.

Forel!enkeimscheibe mit innerem king (nach dem Protokoll ron H. Virchow.) Durchmesser der ganzen Scheibe $3,8 \mathrm{~mm}$, des inneren Rings 2,1 mm. Abstand clesselben vom Randring rorn $1,0 \mathrm{~mm}$. Embryo 1,4 mm lang.

Stadium der rautenförmigen Embryonalanlage. Randring punktiert. Massitab $20: 1$.

Lagerungsverhältnis des centralen Syncytiums aber zum vorderen Kopfende finden sich in seinen Mitteilungen keine bestimmten Angaben, obwohl er auch hierauf besonders sein Augenmerk gerichtet hat.

Nachdem ich den Gegensatz zwischen meiner Anschaumg iiber das Verhältnis des centralen 'Teils vom Dottersackentoblast zum Randteil gegeniiber der von Goronowitsch geäusserten festgestellt hatte, schien es mir ron grossem Werte, von anderer Seite ein Urteil hieriiber beibringen zu können.

H. Virchow unterzog sich anf meine Bitte der Mïhe, seine unfangreichen Protokolle mit Ruicksicht auf diesen Punkt durchzusehen und gestattete mir seine Notizen zu benutzen. 
Aus der zahlreichen Menge seiner Einzelbeobachtungen geht hervor, dass das centrale Syncytium während der ganzen Umwachsungseit und auch später noch dicht vor dem Kopf des Embryos sich befindet und dass das peripherische Syncytium ebenso wie der zellige Randring sich excentrisch zu ihm ausbreiten und zusammenziehen.

Wenn nun der centrale Teil des Dottersackentoblasts wïhrend der ganzen Umwachsung seine Lage dicht vor dem Kopf behäl, wie die Textfiguren 14, 15, 16 zeigen, so darf wohl geschlossen werden, dass der Forellenembryo sich nicht entfernt vom ursprünglichen Mittelpunkt der Keimscheibe.

2. Der innere Ring. Wir verstehen, wie schon im Kapitel III gesagt worden ist, unter imnerem Ring eine Bildung innerhalb des unter der Kieimhaut befindlichen Dotters, welche durch eigenartige Lagerung der Ölkugeln und durch ein optisches Verhalten der oberflächlichen Dotterteile ausgezeichnet ist, wie es sonst nur im Bereich des syncytischen Randringes rorkommt. Statt eines Ringes können deren zwei oder drei vorhanden sein (s. Textfiguren $12,13,14)$. Ihnen allen ist gemeinsam, dass sie weder zu einander noch zum Rande der Keimscheibe koncentrisch verlaufen. Sie liegen einander am nächsten im Bereich der Embryonalanlage und sind am weitesten voneinander entfernt an dem vor der Embryonalanlage befindlichen Teil der Keimhaut. Sie entsprechen nach der Auffassung ron $\mathrm{H}$. Virchow und mir den Stellen, an welchen sich der Randring auf jüngeren Stadien befunden hat.

In dem Verhalten dieser inneren Ringe haben wir somit

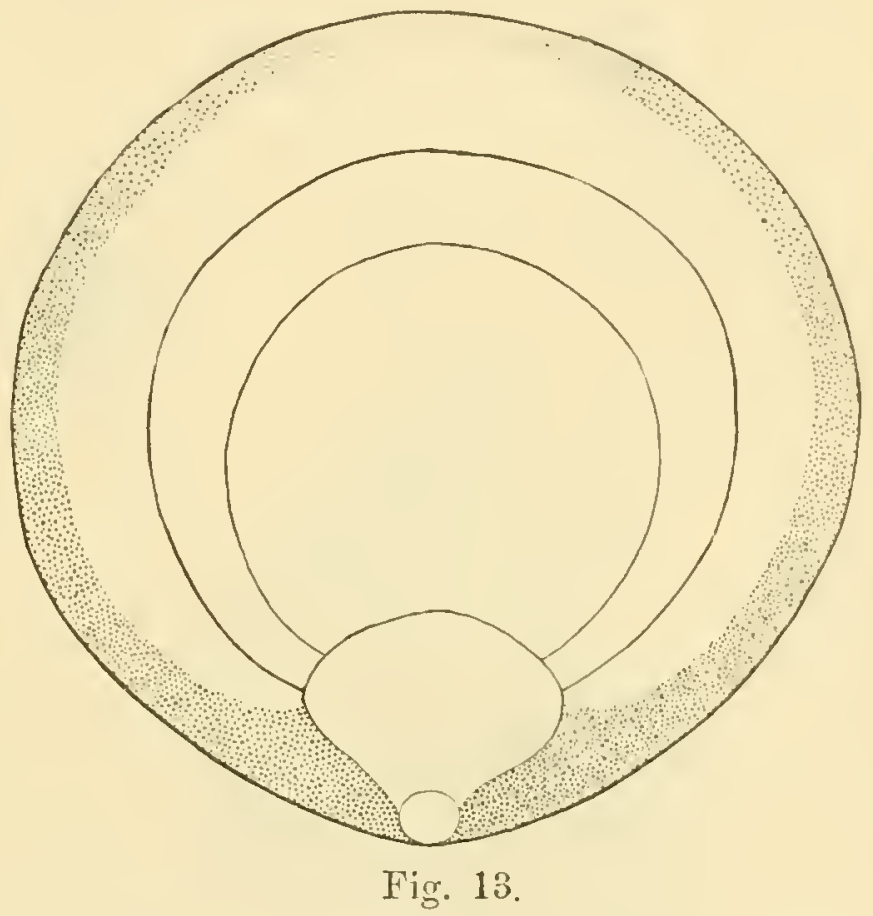

Forellenkeimgcheibe mit $z$ we i inneren Ringen. Eigene Beobachtung.

Stadium der rautenförmigen Embryonalanlage. Randring punktiert. MIasstab 20:1. eine weitere Unterstützung dafür, dass die Keimhaut sich excentrisch ausdehnt zu ihrem Mittelpunkt, welchem der centrale Teil des Dottersackentoblasts entspricht, wobei die geringe, schon bei seiner Entstehung vorhandene Excentricität ausser Acht gelassen werden kam.

Ein weiterer Beweis ist 3. ein Experiment ron Morgan (65, 66), welches ergibt, dass (bei Fundulus) der Kopf sobald er seine Ausbildung beendet hat, ein punktum fixum darstellt, weil die Operationsstelle, welche zur Zeit der Bildung des zelligen Randrings mit einer heissen Nadel in der 
Mitte des Blastoderms angelegt wird, immer dicht vor dem Kopf des Embryos liegt.

Ich selber habe an der Forelle solche Experimente nicht gemacht. Die oben angeführten Beobachtungen am centralen Teil des Dottersackentoblasts und an den inneren Ringen, sowie dic Übertragung des Experiments an Fundulus erlauben wohl den Schluss, dass der Kopf des Forellenembryos sich gar nicht oder nur wenig vom Mittelpunkt der Keimscheibe entfernt.

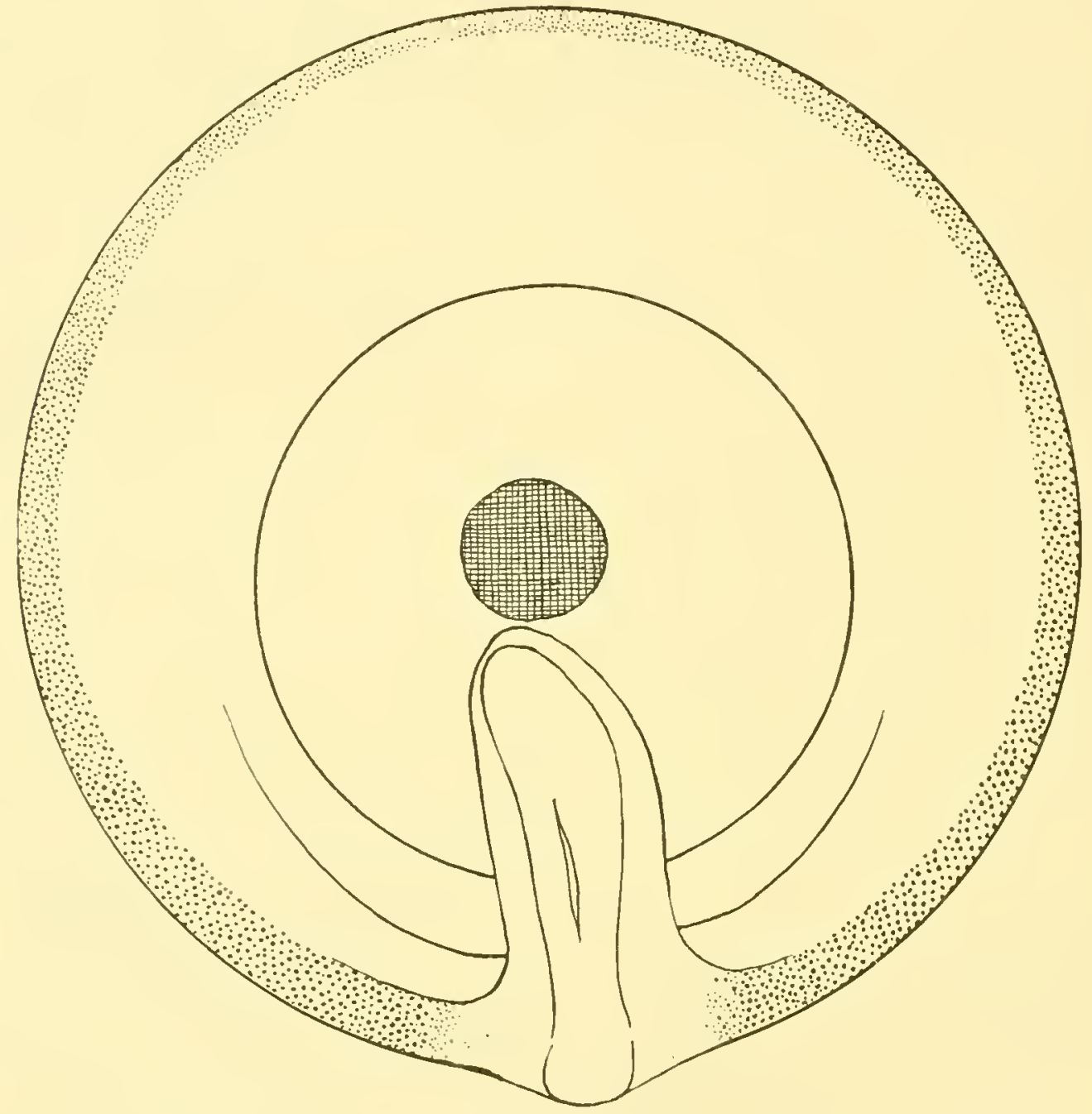

Fig. 14.

Forellenkeimseheibe mit innerem Ring (nach dem Protokoll ron H. Virchow) nnd centralom Teil des Dottersackentoblasts (schraffert) dicht vor dem vorderen Kopfende des Embryos.

(cntspricht Stadium VI von Fr. Kopseln). Randring junktiert. Niassstab 20:1.

Dies Ergebnis entspricht nicht den Schlussfolgerungen, welche Schmitt (83) aus den Zuständen vou Doppelbildungen gezogen hat. Dieser Autor hat auf' Grund der 'Tatsache, dass die Köpfe der Duplicitates anteriores im Lauf der Umwachsung auseinanderriicken, geschlossen, dass der Kopf des Forellenembryos mit Rücksicht auf die Umwachsung des Dotters nicht als fester Punkt zu betrachten ist. 
Der Fehler, auf welchem dieser irrige Schluss beruht, liegt darin, dass der Mittelpunkt einel Keimscheibe, an welcher zwei Embryonalanlagen entstehen', gleichresetzt wird dem Mittelpunkt einer normalen Keimscheibe.

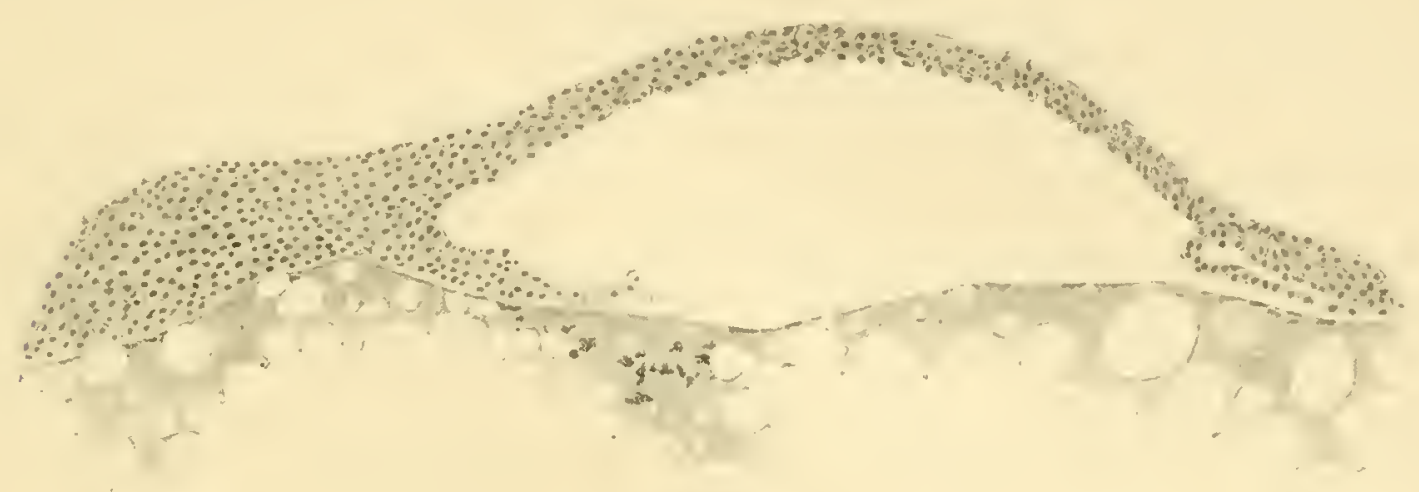

Fig. 15.

Sagitalichuit dureh eine Forelleukeimseheibe. Stadium I, Fr. Kopsch (46). Massstab j0:1.

Etwas nacl links ron der Nlitte liegt im Dotter des Keimlöhleubodens der centrale Teil des botterentoblasts.

Dies ist jedoch micht richtig, denn derjenige Punkt, weleher das Centrum ciner Keimscheibe mit zwei voneinander $180^{\circ}$ entfernten Embryoualanlagen bildet, ist nicht zugleich der Mittelpunkt jeder der beiden miteinander zu

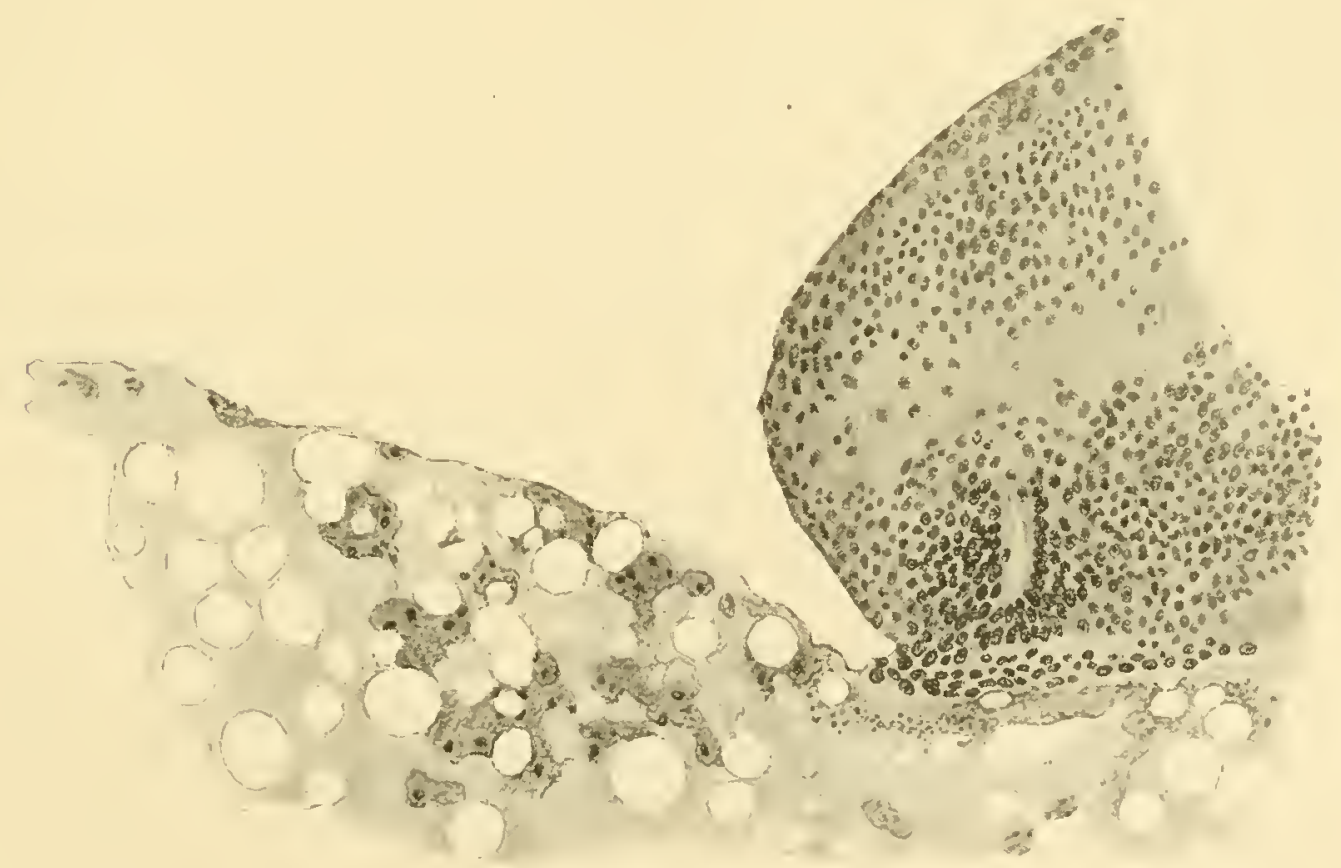

Fig. 16.

Sagittalsehnitt durch den Kopf eines Forellenembryos mit 19 Ursegmenten. Stadium des Dotterlochschlusses. Jer centrale Teil des Dottersackentoblasts (centrales Syneytinm H. Virclinws) liegt dicht ror dem vordersten Kopfencle. Massstab 100:1.

einer (anscheinend einheitlichen) Keimscheibe verbundenen Keimen. Dieser Punkt ist nur der Mittelpunkt der Symmetrielinie der Doppelbildung, nicht aber der jedes der beiden Kíme. Viehmehr liegen die Mittelpunkte jedes 
der beiden Keime in einiger Entfernung von der Symmetrieebene und während sie mit den zn ihnen gehörigen Köpfen in Verbindung bleiben, vergrössert sich bei der Umwachsung des Dotters ihr Abstand rom Mittelpunkt der Symmetrielinie, denn das zwischen den beiden Mittelpunkten und der Symmetrielinie liegende Zellenmaterial ist ja dasjenige, welches bei der normalen Entwicklung die grösste Ausdehnung erfährt.

Wenn also die Köpfe der Duplicitates anteriores auseinanderrücken im Lauf der Umwachsung, so vergrössert sich zwar der Abstand von dem Mittelpunkt der Symmetrieebene, nicht aber der Abstand von dem zu jedem Keim gehörigen Mittelpunkt. Dieser bleibt in der Nähe jedes Kopfendes liegen, wie der wertvolle Befund von H. Virchow (89 S. 70) beweist, welcher gelegentlich bei Duplicitates anteriores den contralen Teil des Dottersackentoblasts verdoppelt gefunden hat.

Die Betrachtung der normalen Entwicklung und die Ergebnisse der Operationen fuiluren also mit Rücksicht auf die Wachstumsrichtung des Embryos, die Ausbreitung des Keims über den Dotter und das Verhältnis zwischen Embryo und ursprïnglichem Mittelpunkt der Keimscheibe zu den Folgerungen, welche am Anfaug dieses Kapitels vorangestellt wrurden.

1. Der Embryo wächst nach hinten hin aus, sein vorderes Kopfende kann als (annähernd) fester Punkt betrachtet werden, dessen Abstand rom Mittelpunkt der jungen Keimscheibe sich gar nicht oder unr wenig vergrössert.

2. Die Umwachsung des Dotters erfolgt unter excentrischer Ausbreitung und excentrischer Zusammenziehung des Randrings. Dabei macht diejenige Stelle, welche dem Knopf gerade gegeniiberliegt den längsten Weg, indem sie sich in demselben Meridian über den Dotter bewegt, in welchem der Embryo auswächst, während die anderen Randringteile sich eine umso kïrzere Strecke fortbewegen, je näher sie dem Knopf liegen, wobei sie die ron Pol zu Pol gezogenen Meridiane unter grösserem oder kleinerem Winkel kreuzen. Der Knopf selber legt zwar cinen grössoren Weg zurïck als die ihm benachbarten Randringabschnitte, doch ist die Strecke noch nicht halb so gross (bei der Forelle ungeführ 90 ") als die des ihm gerade gegenüberliegenden Randringabschnitts.

Diese Sütze gelten in der gegebenen Fassung un für die Forelle, für andere Knnochenfischarten sind sie mehr oder weniger zu ändern.

Die für Fundulus und für die Forelle sichere Feststellung; dass der Embryo nach hinten hin auswächst, erachte ich so lange als allgemein giiltig für alle Knochenfische, bis durch Beobachtung und Experiment sicher bewiesen wird, dass bei einer oder mehreren Arten der Embryo nach vorn auswïchst. 
Dies ist durchaus nicht unmöglich, denu wir haben eine solche Art des Trachstums gesehen beim Embryo XXVII, welcher trotz unterbliebener Unwachsung der Zeit entsprechend ausgebildet ist, und wir sehen sie bei ciner anderen Kilasse, Petromyzon, bei welchem nach Abschluss der sogenannten Gastrulation das embryonale Wachstum nach vorn gerichtet ist, wenn wir die Masse der Dotterzellen als Ausgangspunkt betrachten. Eine solche Art des Wachstums ist aber als sekundär anzusehen, weil die Verlängerung des Körpers auch in diesem Fall durch Neubildung am hinteren Ende erfolgt, dessen Auswachsen nach hinten der primäre Modus ist.

Bei der Dotterumwachsung dagegen sind manuigfache Verschiedenheiten vorhanden, wie aus der Literatur ersichtlich ist, und wie ich es aus eigener Anschauung für wahrscheinlich halte. Ein sicheres Urteil ist nur zu gewinnen durch Kombination des Experiments mit den Ergebnissen sorgfältiger Beobachtung der normalen Entwicklung. Dabei ist festzustellen die Grösse der Dotterbedeckung zur Zeit des Sichtbarwerdens des Embryos und seine Länge in den verschiedenen Phasen der Dotterumwachsung.

Angaben, welche sich stiitzen auf nicht bewiesene Voraussetzungen, wie feste Lage von Oelkugeln u.s. w. sollten nach den nunmehr vorliegenden Erfahrungen nicht mehr als einziges Beweismittel beigebracht werden. Sie können nichts beweisen.

Ich halte es, gestützt auf die Literatur und eigene fragmentarische Beobachtungen, für sehr wahrscheinlich, dass bei kleinen Fiern, deren Morula schon beinahe die Hälfte des ganzen Eies bildet (z. B. Gobiusarten) die Umwachsung nach dem Schema Kupffers verlïuft. Sie muss nach diesem Schema verlaufen, wenn bei feststehendem Kopf der Embryo zur Zeit des Dotterlochschlusses $180^{\circ}$ der Dotterkugel umspannt. Zwischen dieser Art der Umwachsung und der bei der Forelle festgestellten werden mannigfache Zwischenstufen bei verschiedenen Spezies festgestellt werden, ebenso wie wir schon Arten kennen, deren Umwachsungsmodus noch ïber den bei der Forelle festgestellten hinausgeht und sich dem Selachiertypus nähert. Ich meine Batrachus tau (Clapp 9) und Lophius piscatorius (Eycleshymer 13) bei welchen lange vor Dotterlochschluss die beiden Randringhälften hinter dem Knopf zur medianen Vereinigung kommen, so dass wie bei Selachiern eine Dottersacknaht entsteht und ein Dotterblastoporus gebildet wird. Ich erinnere daran, dass ich Ähnliches bei der Forelle künstlich erzeugen kounte durch Operation der dem Knopf gerade gegenüberliegenden Randringstelle, dadurch, dass die Bervegung des betreffenden Teils verlangsamt wurde.

Aus diesen Betrachtungen folgt zuıächst, dass der Umwachsungsmodus abhängt von dem Verhältnis zwischen Eigrösse, Längenwachstum des Embryos und Schnelligkeit der Dotterumwachsung. Dabei kommt der Eigrösse nur eine untergeordnete Bedeutung zu, denu ob das Ei gross oder klein ist, so muss sich die Umwachsung nach K upffers Schema vollziehen, wenn Längen. 
wachstum des Embryos und Umwachsung gleichen Schritt halten. Ungleiches Verhalten beider Komponenten führt entweder einen Zustand herbei, wie wir ihn bei der Forelle finden, oder den bei Batrachus tau und Lophius piscatorius beschriebenen. "Ersterer ist hervorgerufen durch langsameres Wachstum des Embryos bei excentrischer Zusammenziehung des Randrings zum hinteren Köryerende hin. Letzterer ebenfalls durch langsameres Wachstum des Embryos bei koncentrischer oder excentrischer Zusammenziehung nach einem hinter dem Embryo liegenden Punkt.

Die Ursachen dieses verschiedenen Verhaltens sind nicht allein in der Eigrösse zu suchen. Damit wïrden die verschiedenen Modi nicht genïgend erklärt werden können. Die Art des Ablaufs der Umwachsung ist, wie wir gesehen haben, bedingt durch die Bewegung der einzelnen Teile des Randrings, d. h. der einzelnen Zellen, welche in gesetzmässiger, ererbter Art. jede für sich, zur richtigen Zeit ihre Funktionen ausüben, welche sich zum Ganzen summieren und die uns erkenmbaren Massenbewegungen bewirken. Die Ursachen, welche es in frïherer Zeit hervorgerufen haben, dass die Randringzellen der verschiedenen Spezies quantitativ verschiedene Funktionen ausüben, können wir wohl vermuten, einstweilen aber nicht beweisen.

Wenn wir nun die bisher bekannten Tatsachen ïber Längenwachstım des Embryos und Dotterumwachsung in eine alle Arten umfassende Formel vereinigen wollen, so sind die oben für die Forelle gegebenen Sätze umzuwandeln wie folgt:

1. Der Knochenfischembryo wächst nach hinten hin aus. (Geringe Vorwärtsbewegung des vorderen Kopfendes durch interstitielles Wachstum wird nicht in Betracht gezogen).

2. Die Umwachsung des Dotters erfolgt auf verschiedene Art:

a) Unter gleichmässigem Vorschreiten des Randrings (nach Schema Kupffer, Gobius? Gasterosteus?).

b) Unter excentrischer Ausbreitung und excentrischer Zusammenziehung des Randings (Schema His-Kiopsch, Forelle, Lachs).

c) Unter excentrischer Ausbreitung und unter Zusammenziehung mit Bildung einer Dottersacknaht und eines Dotterblastoporus [Batrachus tau (Clapp), Lophius piscatorius (Eycleshymer)].

\section{B. Bildung und Längenwachstum des Embryos.}

Wir haben am Schluss der Literatruribersicht (S. 34) gesehen, dass (abgesehen von geringen Unterschieden) zwei durchaus entgegengesetzte Anschanungen über die Bildung des Knochenfischembryos rorhanden sind: die eine, dass der Embryo von seinem ersten Auftreten an bis zur Erreichung der endgiiltigen '/ahl von Segmenten durch Vermehrung der Zellen seines hinteren noch ungegliederten Körperabschnitts wächst, wobei der Randring 
zum Teil für den Embryo (vou Kupfer 54, 55) verwendet wird oder (Oellacher (67) nur zur Bildung des Dottersackes dient. Nach der andern Anschaung (Konkrescenztheorie) entsteht der Rumpf des Embryos durch achsiale Verschmelzung der beiden Randringhälften ( $\mathrm{H}$ is 24-33, Rauber $75-77$.

Letztere Anschauung hat zwar die geringere Anzahl von Anhängern gefunden, ist aber in die Lehrbücher (O. Hertwig 23, Ch. S. Minot (it) übergegangen.

Die zu ihren Gunsten beigebrachten Beweise sind (durch $\mathrm{His)} \mathrm{1.} \mathrm{die}$ unmittelbare Evidenz; 2. Messungen a) metrischer, b) volumetrischer Art; :3. die Erwägung der bei der Unwachsung stattindenden mechanischen Vorgänge. Dazu fügt Rauber t. die Zustïnde der Spaltbildungen (Hemididymi).

Gegen diese Beweise ist im Laufe der Zeit von den Gegnern vorgebracht worden. 1. Die Evidenz kann, wie Rabl und H. Virchow ausfuihren, ebensogut tür, wie gegen die Konkreszenzlehre verwendet werden.

2a. Auf Grund von Messungen ist Henneguy zur Ablchunng, H. Virchow zu einer nicht ganz unbedingten Ablehnung gekommen.

2b. Den volumetrischen Beweis habe ich selber geprüft und gefunden, dass das Volumen der Keimscheibe rom Beginn der Embryobildung bis zum Schluss der Umwachsung nicht dasselbe bleibt, sondern um etwas mehr als ein Drittel der ursprünglichen Masse zunimmt und dass die Zunahme vou Embryo und Randring des Stadiums IV [Fr. Kopsch (46)] bis zu dem Volumen, welches der Embryo am Schluss der Umwachsung besitzt, ein Viertel beträgt (s. S. 120).

3. Die Erwägung der bei der Umwachsung stattfindenden mechanischen Vorgänge führt nur dann zu dem Resultat, dass während der Umwachsung sämtliches Randringmaterial in der Richtung zum Embryo verschoben wird, weun wir beweisen können, dass 1. der Kopf des Embryos völlig unbeweglich ist oder sich nur wenig von seinem urspriinglichen Platz entfernt, dass 2. nicht etwa Randringmaterial zum Aufbau des Dottersackes gebraucht wird [O ellacher (67), Morgan (66) u. a.] und dass 3. Randringmaterial nicht zu Grunde geht [H. Vir ch ow (93)].

Den schon von K upffer verlangten Beweis dafür, dass der Kopf ein punctum fixum ist, hat $\mathrm{H}$ is nicht angetreten. Dass Randringmaterial zur Bildung des Dottersackes verwendet wird, ist möglich und wahrscheiulich, bis jetzt aber nicht sicher bewiesen; das von $H$. Virchow beschriebene Zugrundegehen von Zellen des Randrings am Schluss der Umwachsung kann ich bestätigen.

4. Die Zustände der Spaltbildungen kömnen auch in anderer Weise, nämlich durch Spaltung des hinteren Endes des Embryos erklärt werden (s. Fr. Kop£ch, 45, 49). Es liegt kein zwingender Grund vor, sie aus der 
Nichtrereinigung der beiden Randringhälften und ihrer Differenzierung in situ entstehen zu lassen.

Wie man sieht, stehen Beweis und Gegenbeweis einander annähernd gleichwertig gegenüber, wenn wir von den erst in dieser Abhandlung beigebrachten Volumenbestimmuugen absehen. Aber auch ihre Ergebnisse, welche nicht ïbereinstimmen mit den von $\mathrm{Hi}$ is erzielten Resultaten, sind nicht unvereinbar mit der Möglichkeit, dass der Embryo entsteht durch mediane Vereinigung der beiden Randlingh:̈llften, denn ob diese Vereinigung ohne oder mit Volumenvermehrung geschieht, ist für das Wesentliche dieses Vorgangs ohne Bedeutung.

Es bleibt demnach nur der experimentelle Weg übrig. Hierbei sind mit Rücksicht auf die genannten beiden Theorien folgende Überlegungen anzustellen zur rationellen Anordnung der Versuche.

A. Wenn der Embryo in die Länge wächst durch Vermehrung der Zellen seines hinteren Körperabschnitts, so muss:

1. Nach Zerstörung dieses Körperteils das Längenwachstum aufhören.

2. Muss nach Zerstörung des vor dem hinteren Körperabschnitt gelegenen Teils des Embryos noch der Rest des Körpers gebildet werden.

B. Wemn jedoch im zelligen Randring die Organe des embryonalen Rumpfes enthalten sind, so müssen dieselben nach Zerstörung der ihnen entsprechenden Stellen fehlen und zwar:

1. Auf der entsprechenden Seite des embryonalen Körpers, wenn die Konkrescenz trotz der Operation stattgefunden hat.

2. Innerhalb des sich in situ differenzierenden Randrings, wenn durch die Operation die Konkrescenz verhindert ist.

Die verschiedenen Operationen, welche nach diesen Gesichtspunkten auf älteren und jüngeren Stadien ausgeführt worden sind, haben unter Würdigung der etwa infolge des Eingriffs hervorgerufenen Hemmungen oder Regenerationen und Regulationen zu folgendem Ergebnis geführt:

Der Forellenembryo wächst nach hinten hin aus durch Vermehrung der Zellen seines hinteren Körperendes unter Aufnahme von Randringmaterial, welches (wesentlich) zur Bildung seitlicher (ventraler) Teile dient.

Ausserdem aber ist die Kenntnis von der Entstehung des Embryos erweitert worden durch dic Operationen an jungen Kreimscheiben. Aus ihnen ergibt sich eine bestimmte regionäre Anordnung für dasjenige Material, welches den Kopf bildet und für dasjenige, aus welchem der Ḱnopf gebildet wird.

Am zelligen Randring der jungen Keimscheibe liegt, flächenhaft ausgebreitet, in der Gegend der ersten Einstülpung das Zellenmaterial fiir den Kopf. Etwas weiter seitlicl davon befinden sich dic Zellen, welche den dorsalen Teil des Knopfes 
bilden. Beide Bezirke nehmen nur einen geringen Teil der Keimscheibenperipherie cin, der grösste Teil des Randrings entbält das Material für die seitlichen (ventralen) Teile des Embryos.

Während der Ausbreitung der'Keimscheibe findet zunächst die Zusammenziehung des kopfbildenden Bezirks statt, auf welche die mediane Vereinigung der linken und rechten Hiilfte des Knopfes folgt. Ihr äusserer Ausdruck ist die Bildung des über den Keimhautrand hinausragenden Hügels, welcher, unter verschiedenen Namen bekannt, von mir als Kinopf bezeichnet worden ist. Er enthält den Canalis neurentericus und bildet durch Auswabsen nach hinten den Rumpf und Schwanz des Embryos, wobei sich ihm während der Dotterumwachsung die

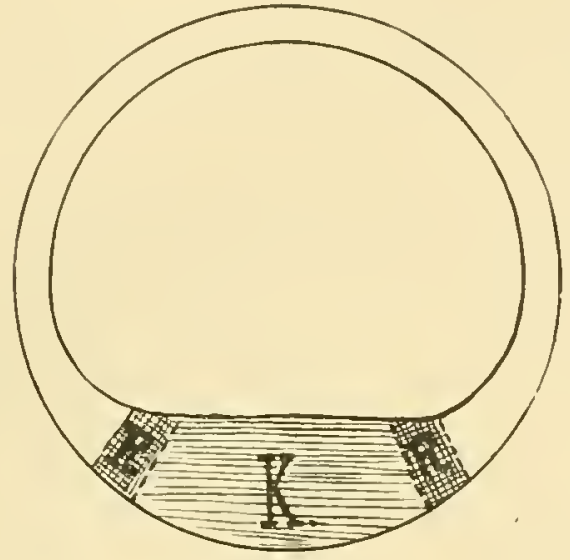

Fig. $17 \mathrm{~A}$.

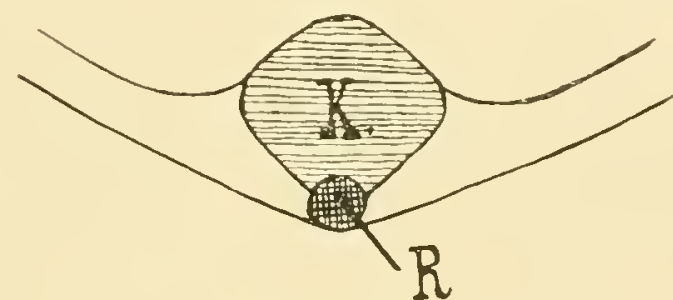

Fig. 17 B.

Schcmata zur Erläuterung der Bildung des Kopfes und des Kuopfes bei Kinochenfischen.

A. Forellenkeimscheibe, 24 Stunden nach der Bildung des ersten Umschlags. Die untere Keimschicht ist schon an der ganzen Peripherie der Keimscheibe vorhanden; sie ist am breitesten an der Stelle, an welcher sie zuerst entstanden ist. Hier liegt das Material $k$, ans welchem der Kopf gehildet wird. Seitlich vou diesem links und rechts das Material $R$, aus welchem der Knopf entsteht.

$B$. Stadinm der rantenförmigen Fmbryonalanlage. Die Lage der in A. seitlich nebeneinander Jefindlichen 'Teile zueinander. $K$-Kopf, $R$-linopf.

übrigen Randringabschnitte zur Bildung der seitlichen (ventralen) Teile des Embryos anschliessen. (Fig. 17, A, B.)

Es besteht also ein Gegensatz in der Bildung des Kopfes einerseits und in der Bildung von Rumpf und Schwanz andrerseits. Der Kopf entsteht aus Zellen, welche seine einzelnen Organe enthalten. Der Rumpf und Schwanz dagegen entstehen durch das Auswachsen des Knopfes, welcher von seinem ersten Erscheinen an das hinterste Stück des Embryos ist.

Friiher habe ich vom embryobildenden und nicht (direkt) embryobildenden Bezirk (45) gesprochen, indem ich der gebräuchlichen Bezeichnung nach unter Embryo denjenigen Teil verstand, welcher das Medullarrohr, die Ursegmente usw. enthält. Morphologisch richtig ist es jedoch, dorsal und 
ventral zu sagen, denn der Dottersack ist der rentrale Teil des Embryos, hervorgegangen aus der Vergrösserung ventraler Teile.

Der Rand der jungen Keimscheibe ist demnach ein in seinen einzelnen Teilen ungleich stark gedehnter Blastoporus. Sehr gering ist die Dehnung der dorsalen Teile, ausserordentlich stark die der ventralen. Dieses Ergebnis ist insofern recht einleuchtend, als der Dottersack eine ventrale Bildung ist.

Dieser Schluss zeigt am dentlichsten den Unterschied meiner Anschanung gegeniiber der von Rauber (75-77), Ryder (82), Minot (64), Hertwig (23) vertretenen Urmundtheorie, denn diese Autoren lassen die ventralen Teile des Blastoporus beinahe völlig ausser acht und sehen angenscheinlich den ganzen Rand des Blastoporus als gleichmässig ausgedehnt an.

Für eine solche Ausdehnung des centralen Nerrensystems liegt aber kein Grund vor, weder in der Stammesentwicklung, noch in der individuellen Entwicklung niederer Tiere, während die von mir vertretene Anschauung eine ausgezeichnete Parallele findet in den entsprechenden Zuständen der Ascidien.

Bei diesen sehen wir am dorsalen Rande des Blastoporus und an dem vorderen Teil des sich zunäichst daran anschliessenden seitlichen Randes die Zellen, welche das Central-Nervensystem bilden. Unter ihnen in derselben Anordnung die Zellen für die Bildung der Chorda, während die hinteren Abschnitte der seitlichen Blastoporuslippen gebildet werden ron denjenigen Zellen, welche das Mesoderm liefern. Bei der Zusammenziehung des Blastoporus tritt eine Verlagerung dieser Zellen ein, derart, dass die seitlich liegenden Mesodermzellen unter (ventral) dem Medullarrohr und seitlich zur Chorda liegen, mit welchen zusammen sie nach hinten hin auswachsen zur Bildung des sogenannten Ruderschwanzes. Bei der Zusammenziehung des Blastoporus kommen ausserdem die an den Seitenrändern desselben befindlichen Medullar- und Chordazellen in der Mittellinie zur Tereinigung. Ein Vorgang, welchen ich in eine Parallele setze zu der Bildung des Ḱnopfes bei den Knochenfischen.

Auf den folgenden Seiten soll nun gezeigt werden, in welcher Weise die angeführten Schlïsse sich aus den Operationen ergeben. Im Zusammenhang damit werden die für- und gegensprechenden Befunde und Theorien der Autoren erörtert werden.

Die eindeutigsten Resultate dürften wohl diejenigen sein, bei welchen nach Zerstörung des Knopfes der Randring allein die Umwachsung vollendet hat (Fig. 57, Taf. V; Fig. 61, 'l'at. VI), ohne dass er irgendwelche embryonale Organe hervorgebracht hätte, während das vor der Operationsstelle gelegene, zur Zeit der Operation schon gebildete Stiick des Embryos, sich genau soweit entwickelt hat, als es der Zeit nach der Fall scin muss.

In dieselbe Gruppe gehören alle diejenigen Operationen, welche auf jüngeren Stadien an der Stelle der ersten Einstiilpung vorgenommen sind 
und bei welchen die Unwachsung des Dotter's vom Randring vollendet wird, ohne dass in ihm embryonale Organe nachzuweisen sind (Figg. 103, 107, T'af. IX; Fig. 110, 113, 115, Taf. X).

Beide Arten von Operationen beweisen, dass der Randring für sich allein nicht imstande ist, Medullarrohr, Ursegmente, Chorda hervorzubringen, was nach der Theorie von His der Hall sein müsste.

Es könnte nun eingewendet werden, dass zwischen Knopf und Randring eine gewisse Abhängigkeit bestünde, derart, dass nur bei vorhandenem Knopf die entsprechenden Differenzierungen im Randring auftreten; ein derartiges Terhältnis ist nach den Ergebnissen der Entwicklungsphysiologie nicht abzuweisen.

Dem widersprechen aber die Operationen, bei welchen die verletzte Stclle gerade gegenüber dem Knopf liegt (Figg. 43a, 43 b, 47 a, 47 b, Taf. IV). In diesen Fïllen hat sich an Stelle des runden ein spaltförmiges Dotterloch gebildet, dessen Ränder miteinander verschmelzen, aber weder Medullarrohr, noch Chorda, noch Ursegmente bilden.

Die Beweiskraft dieser Experimente kann indessen bezweifelt werden, denn es könnte ja sein, dass das Material des Randrings erst bei einer gewissen Zusammendrängung und Umlagerung sich zu den embryonalen Organen differenzierte.

Diese Einwände können nicht erhoben werden, bei denjenigen Versuchen, in welchen die durch die Operation bezeichnete Randringstelle durch die Umwachsung bis an den Knopf herangeschoben worden ist (Fig. 9, Tat. I; Fig. 23, Taf. II ; Fig. 32, Taf. III). In diesen Fällen wäre bei Annahme der Konkrescenzlehre zu erwarten, dass die Operationsstelle einen bestimmten Ort der betroffenen Seitenhälfte des Embryos bis zur Mittellinie hin einnähme. Dies ist nicht der Fall; niemals ist die Operationsstelle im Gebiet des Medullarrohrs und der Chorda gefunden worden. Sie befindet sich in allen Fällen in der Gegend der Seitenplatten und der intermediären Zellenmasse, aus welcher die Vena cardinalis hervorgeht. Wenn aber eine bestimmte Stelle des Randrings die gesamten Organe einer bestimmten Region des Rumpfes enthielte, so müsste die Zerstörung beim Embryo bis zur Medianebene reichen.

Der von dieser Forderung abweichende tatsächliche Befund spricht direkt gegen die Konkrescenzlehre in Hisscher Fassung; von den Anhängern der Urmundtheorie aber könnte der Einwand erhoben werden, dass auf der operierten Seite der Anschluss des Randrings infolge der Operation verzögert wäre und infolgedessen eine Art Regeneration am Medullarrohr, Chorda und Ursegmenten stattgefunden habe. Eine solche Erklärung kann sich stützen auf analoge Erscheinungen bei den Spaltbildungen, woselbst Regeneration von Ursegment-Mesoderm und anderen Teilen der fehlenden Hälfte eintritt. 
Nehmen wir nun an, dass bei verzögertem Anschluss des Randrings der operierten Seite eine solche Regeneration Platz griffe, so müssen wir bedenken, dass bis zum Eintritt jeder Regeneration eine bestimmte Zeit notwendig ist, während welcher sich die iibrigen Teile in der ihnen zukommenden Weise weiter entwickeln werden, wodurch sich ein bei so jungen Embryonen besonders augenfülliger Unterschied beider Seitenhälften ergeben viürde. Selbst wenn also der durch die Operation gesetzte Defekt durch Regeneration gedeckt werden könnte, so mïsste doch zu irgend einer Zeit d. h. bei dem fortschreitenden Lïngenwachstum des Embryos an irgend einer Stelle ein Defekt oder wenigstens eine sehr schwach ausgebildete Region vorhanden sein. Dies ist jedoch niemals beobachtet worden weder bei jüngeren, noch bei älteren Embryonen.

Die Wirkung der Operation zeigt sich direkt an der intermediären Zellmasse und an den Seitenplatten, sowie indirekt an der schwächeren Ausbildung der Ursegmente. Aus diesen konstant gefundenen Tatsachen folgt, dass der Randring wesentlich zur Bildung von seitlichen (ventralen) Organen dient. Ein weiterer Beweis für diese Auffassung ist der Zustand am hinteren Stiick des Embryos VI (Fig. 32, Taf. III), bei welchem in der Höhe der Operationsstelle und des daran sich kandalwärts anschliessenden Spalts die Seitenplatten fehlen, noch weiter kaudalwärts aber wieder vorhanden sind, weil der Randring wieder den Zusammenhang mit dem Knopf gewonnen hat.

Eine weitere Unterstiitzung der Ansicht, dass der Knopf und das vor ihm befindliche unsegmentierte hintere Körperstiick für sich allein imstande sind, das Längenwachstum des Embryos zu besorgen, ist Embryo XI (Fig. 53 b, Taf. V), dessen hinteres Körperstiick ausserordentlich stark und zellenreich ist; obwohl links und rechts die Verbindung mit dem Randring in einem jüngeren Stadium unterbrochen ist.

Die besprochenen Tatsachen führen zu dem ersten der oben angeführten Sätze, dass der Forellenembryo nach hinten hin auswächst durch Vermehrung der Zellen seines hinteren Körperstiicks unter Aufnahme von Randringmaterial, welches (wesentlich) zur Bildung seitlicher (ventraler) Teile dient.

Dies Ergebnis experimenteller Untersuchung bestätigt die Anschaumngen, welche Kupffer in den Jahren 1868 und 1878 (54, 55) geänssert hat, insofern als er die Bildung des Embryos geschehen lässt durch rapide Vermehrung der Zellen in loco unter Verwendung von Randringmaterial, welches durch eine nach dem Embryo hin gerichtete Bewegung an seinen Ort gelangt, wobei er aber unentschieden lassen muss, in welchem Maasse das eine oder das andere zur Geltung kommt. Es bestätigt ferner denjenigen Teil von Oellachers (67) Anschauung, nach welcher das Lingenwachstum des Embryos erfolgt durch rege Zellvermehrung in der Gegend der Schwanzknospe, und deckt sich mit den vor mir von Morgan $(65,66)$ gleichfalls auf experimentellem Wege gewonnenen Schlussfolgerungen, dass der 
Knochenfischembryo auch olne Tnanspruchnahme des Randrings nach linten auswächst, dass aber unter normalen Verhültnissen eine gewisse Menge von Zellenmaterial ans dem Randring in den Embryo gelangt.

In der folgenden Zeit sind meine Anschaumngen im wesentlichen bestaitigt oder angenommen worden ron Jablonowski (36), H. Virchow (93), Rabl (72), Sumner (88), Fischel (14).

Dass verschiedene Autoren, welche an verschiedenem Material mit verschiedenen Methoden arbeiteten, zu völlig iibercinstimmenden Resultaten gelangen, dürfte in der Biologie wohl sehr selten vorkommen. Es genüge einstweilen hervorzuheben, dass Morgan, ich, H. Virchow, Jablonowski,

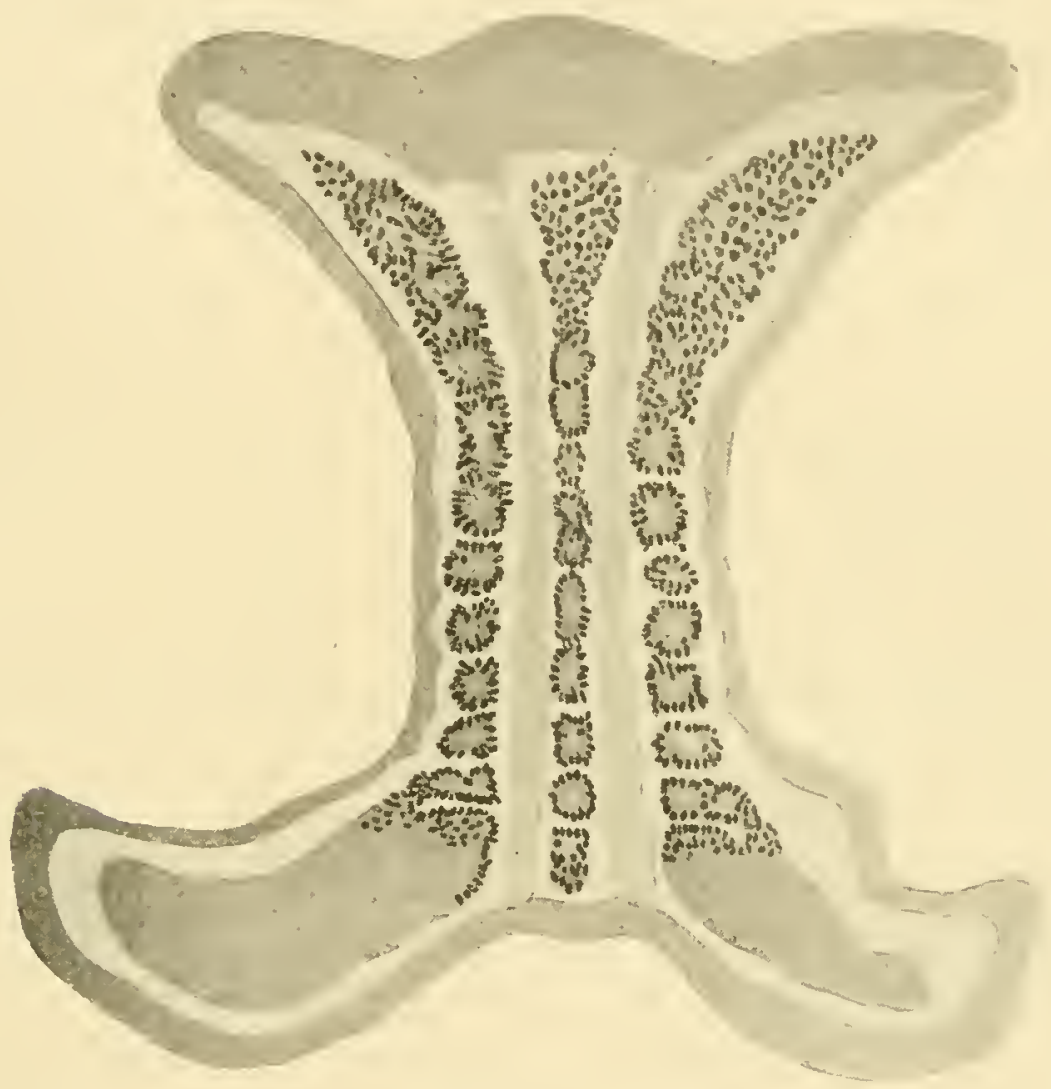

Fig. 18.

luplicitas anterior von Torpedo ocellat a [Dohrn (12) Taf V, Figg. 2.] Embryo ron 1 mm Länge, Hurizontalschnitt kombiniert aus den 6 Sehnitten $20-25$.

Im Verg] eich zum Original etwas rerkleinert.

Sumner, die das Knochenfischmaterial aus eigener Anschaung kennen, darin einig sind, dass das Längenwachstum des Embryos wesentlich durch Vermehrung des im Knopf befindlichen Materials stattfindet, worin wir ausserdem mit der Mehrzahl der Autoren übereinstimmen, welche über das Längenwachstum des Knochenfischembryos auf Grund eigener Untersuchungen urteilen. Weiter mag betont werden, dass Morgan und ich unabhängig von einander dieselben Schliisse auf die V'erwendung des Randringmaterials gezogen haben und dass Sumner, der dritte experimenteIl arbeitende Autor, zu derselben Ansicht gekommen ist. 
Hierzu kommen noch die Beweise aus den Zuständen der Duplicitates anteriores, welche zuerst ron nir und Jablonowski herangezogen worden sind und neuerdings von Schmitt (83) in gleicher Weise verwendet wurden.

Ein ausgezeichnetes Beispiel, welches von den Anhängern der Kionkrescentheorie nicht erklärt werden kann ohne weitere Hypothesen, ist durch Dohrn (12) kïrzlich mitgeteilt worden. Es handelt sich um eine Missbildung von Torpedo ocellata, von welcher ich eine Kopie in Textfigur 18 gebe.

Gegeniuber diesen aus der Beobachtung der Tatsachen gezogenen Folgerungen stiitzen sich die Einwände Hertwigs (22) lediglich auf Analogien aus den von ihm bei Fröschen beobachteten Spaltbildungen. Die Erklärung, welche er von dem Übergang des Randringmaterials in den Knopf gibt, deckt sich nicht mit den Beobachtungstatsachen, da nach Sumner (88) eine Nadel, welche in die Mitte des Knopfes eingestochen wird, dort stehen bleibt, während der Randring sich nicht von hinten her an den Knopf anschliesst, wie es O. Hertwig will. Meine wohl begründete Ansicht bereist die Unrichtigkeit der "Interpretation“ O. Hertwigs. Wenn man die Zustände der Teleostier-Entwicklung interpretieren will durch Beobachtungen an anderen Wirbeltierklassen, so liegen die Selachier weit näher, deren hinteres Körperende klare, leicht analysierbare Zustïnde zeigt (vergl. H. Tirchow 91). Aus ihnen finden die von mir fiir die Kinochenfischentwicklung abgeleiteten Schlïsse volle Bestïtigung. So steht gegen die Interpretation Hertwigs, welche gegriindet ist auf der zum mindesten zweifelhaften, nach meiner Erfahrung und Untersuchung desselben Materials jedoch nicht zutreffenden Erklärung der Spaltbildungen an Froscheieru, die ungleich beweiskräftigere und leicht überselıbare Analogie mit den von H. Virchow bei den Selachiern geschilderten Zuständen. Mit den Vorwurf, dass ich an Stelle der klaren Fassung der Konkrescenztheorie nur dell "unbestimmten und dehnbaren Begriff" der Zuhilfenahme von Randringmaterial gesetzt habe, ist nichts gewonnen, denn wenn eine Thenrie nur um ihrer glatten Form willen richtig wäre, so wiurden wir hente noch glauben, dass die Some sich um die Erde dreht.

Meine Schlussfolgerung, dass ein Gegensatz besteht zwischen dem Entwicklungsmodus des vorderen Körperstiicks und dem ron Rumpf und Schwanz halte ich für einen wichtigen Fortschritt unserer vergleichend embryologischen Kenntnisse, dessen Bedentung unter anderem aus der Arbeit von Jablonowski (36) hervorgeht. Dieser Autor und ich sind in diesem Punkte auf verschiedenen Wegen zu denselben Ergebnissen und denselben Verallgemeinerungen gekommen.

Auf welchem Wege ich meine Auffassung gewinnen musste, soll im Folgenden gezeigt werden. 
Die experimentellen Untersuchungen beganneu mit älteren StadienNachdem sich aus ihnen die soeben besprochenen Schliisse ergeben hatten für die Bedeutung des Knopfes und die Verwendung des Randrings, war es selbstrerständlich, die Untersuchung auf immer jüngere Stadien auszudehnen. Aus diesen ergab sich, dass trotz der geringeren Grösse der Keimscheibe jüngerer Stadien das später im Knopf auf kleinem Raum zusammengedrängte Material mehr in der Fläche ausgebreitet liegt, denn während es mir nicht gelungen ist, die linke und rechte Hälfte des Kinopfes durch Operation voneinander zu trennen, gliickte es an Stadien, welche noch nicht den Kinopf gebildet haben, Spaltbildungen (Hemididymi) in einigen Fällen zu erzielen, in denen die in der Nittellinie angebrachte Operationsstelle nur klein war. Bei grosser Operationsstelle (Figg. 103, 106, Taf. IX; Figg. 110, 113, 115, Taf. X) wird weder Kopf noch Rumpf gebildet, nur der Randring vollendet die Umwachsung ohne irgend welche bestimmt charakterisierte Organe zu bilden. Hieraus folgt, dass die Fläche, welche von der Operationsstelle eingenommen wird, das Material enthalten hat, aus welchem Kopf, Rumpf und Schwanz entstehen.

Über die gegenseitige Lage der einzelnen Teile zueinander innerhalb dieses Bezirkes geben die anderen Embryonen Aufschluss.

Aus der Lage der Operationsstelle bei den Hemididymis, in der Mittellinie, ungefähr in der Höhe des Gehörbläschens folgt, dass zur Zeit der Operation das Zellenmaterial für den hinteren 'Teil des Kopfes und für den Knopf am Rande der Keimscheibe links und rechts vou der Mittellinie liegt, während der vordere Teil des Kopfes sich in einiger Entfernung vom Keimscheibenrand befindet. Die Zellen für den hinteren Teil des Kopfes und für den Knopf können nun zur Zeit der Operation entweder hinter einandes, parallel zur Mittellinie, oder aber neben einander am Rande der Keimscheibe liegen. Wegen der geringen Grösse der Operationsstelle halte ich das Letztere für wahrscheinlicher, denn wäre das an erster Stelle genamnte Lagerungsverhältnis schon vorhanden gewesen, so würde die Operationsstelle weiter nach vorn haben reichen müssen, sie müsste also grösser sein.

Diese Auffassung wird nun weiter bestätigt durch diejenigen Embryonen, bei welchen die am Rande der Keimscheibe gesetzte grössere Operationsstelle nicht genau in der Mittellinie liegt, sonder'n seitlich von ihr angebracht, ungleiche Stïcke der beiden Ḧ̈llften zerstört hat (Figg. 66, 74, 80, 86, 95, 98). Die hier erhaltenen Resultate sind nur zu erklären durch die flächenhafte Ausbreitung desjenigen Zellenmaterials, welches den Kopf bildet und durch die mehr seitliche Lage der später in Knopf vereinigten Zellen. Unter Zugrundelegung dieser Folgerungen habe ich seiner Zeit die in Textfig. 17 A,B abgebildeten Schemata entworfen. Der kopfbildende Bezirk ist durch Parallellinien, das Material des Knopfes durch gekreuzte Linien bezeichnet. Die Lage beider Bezirke am Rande der jungen Gastrula vor Bildung des Knopfes ist dargestellt in Textfig. 17 A, ihre Lage beim rauten- 
förmigen Embryo nach Bildung des Knopfes in Textfig. 17 B. Die ron mir in diesen Textfiguren niedergelegten Anschanungen iiber den Gegensatz zwischen der Bildung des Kopfes und der Entstehung von Rumpf und Schwanz sind bisher bestätigt worden durch Jablonowski (36) und Sumner (88).

J a bl o n ow ski findet, dass im Anfang der Embryobildung eine mediane Naht entsteht durch Zusammenschiebung seitlicher im Rand gelegener Bezirke nach der Mittellinie hin. Sie findet jedoch nur zu Anfang der Embryobildung statt; das weitere Längenwachstum erfolgt durch das im Knopf befindliche Material, welcher ebenfalls durch die mediane Zusammenschiebung gebildet ist.

$\mathrm{S} u \mathrm{~m}$ ner ist sowohl durch Untersuchung der normalen Entwicklung verschiedener, anscheinend besonders günstiger Ḱnochenfischspezies als auch durch das Experiment zu einer Bestätigung meiner tatsächlichen Befunde geliommen. ${ }^{1}$ )

Verschiedenheiten untergeordneter Art werden im Laufe der Zeit wohl noch ausgeglichen werden.

Die Konsequenzen, welche sich aus der hier entwickelten Anschauung ergeben, sind für morphologische Probleme von $\mathrm{H}$. $\mathrm{Virchow}$ (93) gezogen worden, auf dessen Aufsatz in den Ergebnissen von Merkel \& Bonnett für das Jahr 1897 ich ansdrücklich verweise, um dem Leser die unnötige Wiederholung schon besprochener Fragen zu ersparen. In vergleichend embryologischer Richtung sind Jablonowski (36) und ich (48) unabhängig voneinander zu denselben Ergebnissen gekommen. In bezug auf die Analogie mit der Entwicklung der Tunikaten verweise ich auf die kurze Auseinandersetzung S. 150.

Eine ausgiebige Erörterung dieser Fragen wird erst dann angezeigt sein, wenn die fïr die Krnochenfische festgestellten Tatsachen weiter befestigt und ausgebaut sein werden, und wenn ihre Geltung auch bei den iibrigen Wirbeltierklassen nachgewiesen sein wird, wie ich es in weiteren Aufsätzen versuchen will.

1) Während der Drucklegung dieser Arbeit ist eine ausführliche Abhandlung ron Sumner im Archiv für Fntwicklungsmrchanik erschienen, in welcher dieser Autor seine Ansichten in einigen Punkten geändert hat. Fs war nicht mehr möglich denselben hier liechunug zu tragen. 


\section{Literaturverzeichnis.}

1. Agassiz, Alexander and Whitman, C. O.: On the Development of some Pelagic Fish-eggs. Preliminary Notice. Proc. Amer. Acad. of Arts and Sciences. Vol. XX (1884), S. 23-75. 1 Tafel.

2. Aubert, Hermann: Beiträge zur Entwickelungsgeschiehte der Fische. Zeitschrift für wissenschaftliche Zoologie. Bd. V (1854), S. 94-102. Tafel VI.

3. Baer, K. E. von: Untersuchungen über die Entwiekelungsgeschichte der Fische nebst einem Anhange über dio Schwimmblase, Leipzig 1835.

4. Balfour, F. M.: A preliminary account of the development of the Elasmobranch fishes. Quarterly Journal of mieroseopical Seicnce. Vol. XIV, New Series (1874), S. $323-364$. Tafel XIII bis XV.

5. Balfour, F. M.: A monograph on the development of Elasmobranch fishes. London, Maemillan \& Co. (1878), VI und 295 S. XX Tafeln.

6. Balfour, Francis M.: Handbuch der vergleiehenden Embryologie. II. Bd., dentseh ron B. Vetter (1881).

7. Bambeke, Ch. von: Recherches sur l'embryologie des poissons osseux.

I.: Modifieations de l'oeuf non fécondé après la ponte.

II.: Premières phases du développement.

Mémoires couronnés et Mémoires des Savants étrangers publiés par l'Aead. Royale des Sciences, des Lettres et des Beaux-Arts de Belgique. Tome 40. Brüssel 1876, IV und $66 \mathrm{~s}$. LII Tafeln.

8. Boeke, J.: Beiträge zur Entwicklungsgeschichte der Teleostier.

I.: Die Gastrulation und Keimblätterbildung bei den Muränoiden.

Petrus Camper. Dl. II (1903), S. 135-210. Tafel II, III. 18 Textfiguren.

9. Clapp, Cornelia M.: Some points in the development of the Toad-fish. (Batrachus tau). Journal of Morphology. Bd. V (1891), S. 494-501. 3 Figuren.

10. Corning, H. K.: Merocyten und Umwaclsungsrand bei Teleostiern. Festsehrift für Carl Gegenbaur (1896), S. 105-132. Tafel I, II.

11. Cunningham, J. T.: On the Relations of the Iolk to the Gastrula in Teleosteans, and in other Vertebrate Types. Quarterly Journal of microscopical Science. New Series, Vol XXVI (1886), pag. 1-38. Tafel I bis IV.

12. Dohln, Anton: Studien zur Urgeschichte des Wirbeltierlsörpers, 18. bis 21. Mitteilung. Mitteil. zool. Station Neapel. Bd. XV (1902), S. 1-280. Tafel I bis XV.

13. Eyeleshymer, Albert C.: The early development of Amblystoma, with observations on some other vertebrates. Jomrnal of Morphology. Bd. X (1895), S. 343-418. Tafel XVIII bis XXII. 4 Textfiguren.

14. Fischel, Alfred: Über den gegenwärtigen Stand der experimentellen Teratologie. Verhandl. deutsch. patholog. Ges. Bd. V. S. 255-356. 50 Fig. 
15. Goette, Alexander: Zur Entwicklungsgezchichte der Wirbeltiere. Vorläufige Mitteilung. Zentralblatt für die medizinischen Wissenschaften. VII. Jahrgang (1869), S. $404-406$.

16. Goette, Alexander: Beiträge zur Entwickelungsgeschichte der Wirbeltiere. I.: Der Keim des Forelleneies.

Archiv für mikroskopische Anatomie. Bd. IX (1873), S. 679-708. 'Tafel XXYII.

17. Goronowitsch: N.: Studien über die Entwicklung des Medullarstranges bei Knochenfischen, nebst Beobachtungen über die erste Anlage der Keimblätter und der Chorda bei Salmoniden. Morphologisches Jahrbuch. Bd. I (1885), S. 376-445. 'Tafel XVIII bis XXI.

18. Hatschek, Berthold: Beiträge zur Entwicklungsgeschichte und Morphologie der Anneliden. Sitzungsberichte der mathem. physik. Klasse der Kaiserl. Akademie der Wissenschaften zu Wien. LXXIV. Bd., I. Abtlg. (Jahrgang 1876), S. 443-461. 1 Tafel.

19. Hatschek, Berthold: Studien über die Entwicklungsgeschichte der Anneliden, ein Beitrag zur Morphologie dor Bilaterien. Arbeiten aus dem Zoologischen Institute der Universität Wien. 'T. I (1878), 128 S. 8 Tafeln. 10 Textfiguren.

20. Henneguy, L. F.: Sur la ligne primitive des poissons ossenx. Zoologischer Anzeiger. VIII. Jahrgang (1885), S. 103-108.

21. Henneguy, Felix: Recherches sur le développement des poissons osseux. Embryogénie de la truite. II. Partie. Journal de l'Anat. et de la physiol. XXIV année (1888), S. 413-502, 525-617. Tafel XVIII bis XXI. 28 Textfiguren.

22. Hertwig, Oscar: Stritlige Punkte aus der Keimblattlehre der Wirbeltiere. Sitzungsber. Kgl. Pr. Akadem. Wiss. Berlin. Mathem.-phys. Klasse. Bd. XXIV (1901), S. $528-533$.

23. Hertwig, Oscar: Handbuch der vergleichenden und experimentellen Entwicklungsgeschichte der Wirbeltiere. Bd. I. Jena 1903.

24. His, W.: Über dio Bildung des Lachs-Embryos. Sitzungsberichte der naturforschenden Gesellschaft zu Leipzig. I. Jahrgang (1874), S. 30.

25. His. Wilhelm: Unsere Körperform und das physiologische Problem ihrer Entstehung. Leipzig 1874. XIV und 224 Seiten. 140 Figuren.

26. His, Wilhelm: Untersuchungen über die Entwicklung von Kinochenfischen, besonders über diejenige des Salmens. Zeitschrift für Anatomie und Entwicklungsgeschichte. Bd. I (1876), S. 1- 40 . Tafel I, II. 14 Textfiguren.

27. His, Wilhelm: Über die Bildung der Haifischembryonen. Zeitschrift fiir Anatomie und Entwicklungsgeschichte. Bd. IJ (187T), S. 108-124. Tafel VII. 2 Textfiguren.

28. His, Wilhelm: Nene Untersuchungen über die Bilduug des Hühnerembryo I. Archiv für Anatomie und Physiologic. Anatom. Abtlg. Jalrgang 1877, S. 112-187. Tafel V, VI. 7 Textflguren.

29. His, Wilhelm: Untersuchungen über die Bildung des Knochenfischembryo (Salmen). Archiv für Anatomic und Entwicklungsgeschichte. Jahrgang 1878, S. 180-221. Tafel IX. 11 Textfiguren.

30. His, Wilhelm: Zur Frage der Längsverwachsung von Wirbeltierembryonen. Verhandlungen der anatomischen Gesellschaft. Nï̈nchen 1891, S. 70-83. 13 Figuren im 'Text.

31. His, Wilbelm: Uber mechanische Grundrorginge tierischer Formenbildung. Archiv für Anatomic and Physiologic. Anatom. Abtlg. 1894, S. 1-80. 50 Figuren im Text.

32 His, Wilhelm: Uber die Yorstufen der Gehirn- und der Kopfbildung bei Wirbeltieren. Archiv für Anatomie und Plyysiologie. Anatom. Abtlg. 1894, S. 313-3:31\%. 14 Figuren im Text. lafel XXI. 
33. His, Wilhelm: Sonderang und Charakteristik der Entwicklungsstufen junger Selachierembryonen. Arehiv für Anatomie und Physiologie. Anatom. Abtlg. 1894, S. 337-354. 'Tafel XXI. 18 Figuren im l'ext.

34. Hoffmann, C. K.: Vorläufiye Mitteilung zur Ontogenie der Knochenfische. Zoologischer Anzeiger. III. Jahrgang (1850), S. 607-610;629-634.

35. Hoffmann, C. K.: Zur Ontogenie der Knochenfische. Verhandelingen der Koninglijke Akademie van Wetenschappen. Amsterdam 1881, 168 S. 7 Tafeln. 1882, 60 S. 4 Tafeln.

36. Jablonowski, J.: Úber einige Vorgänge in der Entwicklung des Salmonidencmbryos nebst Bemerkangen über ihre Bedeutung für die Beurteilung der Bildung des Wirbeltierkörpers. Anatomischer Anzeiger. Bd. XIV (1898), S. 532-551. 19 Figuren.

37. Jablonowski, J.: Über die Bildung des Medullarstranges beim Hecht. Abhandlungen und Berichte des Königl. Zoologischen and anthropologisch-ethnographischen Museums zu Dresden. Festschrift (1899), 18 S. Tafel 1 und 5 Figuren.

38. Kastschonko, N.: Zur Entwickelnngsgeschichte des Selachierembryos. Ana= tomischer Anzeiger. Bd. IIJ (1888), S. 445-467.

39. Keibel, F.: Normentafeln zur Entwicklungsgeschichte der Wirbeltiere. Anatomischer Anzeiger. Bd. XI (1896), S. $225-234$.

40. Keibel, Franz: Die Anwendung von Formalingas für Präpariersaalzwecke. Anatomischer Anzeiger. Bd. XV (1899), S. 306-308.

41. Keibel, F.: Die Gastrulation und die Keimblattbildung der Wirbeltiere. Ergebnisse Anatomie und Entwicklungsgesehichte. Bd. I (1901), S. 1002-1119. 43 Figuren.

42. Koehler, R. et Bataillon, E.: Recherches sur l'extension du blastoderme et l'orientation de l'embryon dans l'oeuf des Téléostéens. Comptes rendus de l'Acad. des Sciences. 'Tome 117. Jul.-Dec. 1893, S. 490-493.

43. Kollmann, J.: Gemeinsame Entwicklungsbahnen der Wirbeltiere. Arehiv f. Anat. und Physiol. Anat. Abtlg. Jahrgang 1885, S. 279-306. Tafel XII.

44. Kopseh, Fr.: Oberflächenbilder des sich entwickelnden Forellenkeimes. Velhandl. anat. Ges. Strassburg 1894, S. 60-66. 1 Figur.

45. Kopseh, Fr.: Experimentelle Untersuchungen über den Keimhautrand der Salmoniden. Verhandlungen der Anatom. Gesellsehaft zu Berlin. 1896, S. 113-127. 10 Figuren. 46. Kopseh, Fr.: Die Entwicklung der äusseren Form des Forellenembryo. Areh. milir. Anat. Bd. 51 (1898), S. 181-213. 'Tafel X, XI.

47. Kopsch, Fr.: Experimentelle Untersuchungen am Primitivstreifen des Hühnchens und an Seyllium-Embryonen. Verhandlungen der Anatom. Gesellschaft zu Kiel. 1898, S. $49-67.10$ Figuren.

4ช. Kopsch, Fr.: Gemeinsame Entwickelungsformen bei Wirbeltieren und Wirbellosen. Verhandlungen der Anatom. Gesellschaft zu Kiel. 1898, S. 67-79. 13 Figuren.

49. Kopsch, Fr.: Die Organisation der Hemididymi und Anadidymi der Ḱnochenfische und ihre Bedeutung für die Theorien über Bildnng und Wachstam des Ḱnochenfischembryos. Internat. Nonatsschrift für Anat, und Phys. Bd. XVI (1899), S. $221-267$. Tafel XV-XVII. 4 'Textfiguren.

50. Kopseh, Fr.: Art, Ort und Zeit der Entstehang des Dottersackentoblasts bei verschiedenen Kónochenfischarten. Internat. Monatsschrift f. Anat. und Phys. Bd. XX (1902), S. 101-124. 15 Figuren.

51. Kowalevsky, A.: Die Entwickelung der Haifische. Beobachtungen an Mustelus laevis und Akanthias vulgaris. Berichte der naturforschenden Gesellschaft in Kiew. 1870 (russisch), Bd. I, S. 163. Taf. VII, Fig. 17, 18.

52. Kowalevsky, A.: Weitere Studien über die Entwicklung der einfachen Ascidien. Archiv für mikroskop. Anatomie. Bd.VII (1871), S. 101-130. Tafel X bis XIII. 
53. Kowalewski, Miecz von: Über die ersten Entwicklungsprozesse der Knochen= fische. Zeitschrift für wissenschaftliche Zoologie. Bd. XLIII (1886), S. 434-480. 'Tafel XVII.

54. Kupffer, C.: Beobachtungen über die Entwicklung der Knochenfische. Archiv für mikroskopische Anatomie. Bd. IV (1868), S. 209-272. Tafel Xl'I bis XVIII.

55. Kupffer, C.: Über Laichen und Entwicklung des Ostsee-Herings. Jahresbericht der Commission zur wissenschaftl. Untersuchung der deutschen Meere in Kiel für die Jahre 1874, 1875, 1876. IV., V. und VI. Jalırgang. Berlin 1878. S. 25-35, $177-2.26,4$ Tafeln.

56. Kupffer, C.: Die Entstehnng der Allantois und die Gastrula der Wirbeltiere. Zoologischer Anzeiger. Jhrg. II (1879), S. 520-522, 593-597 und 612-617.

57. Kupffer, C.: Die Gastrulation an den meroblastischen Eiern der Wirbeltiere and die Bedeutung des Primitivstreifs. Archiv für Anatomie und Physiologie. Anatom. Abtlg. Jahrgang 1882. S. 1-28. Tafel I bis IV. S. 139-156. Tafel TIII, IX. Jahrgang 1884. S. 1-40. Tafel I bis II.

58. Lereboullet, A.: Sur le développement du brochet, de la perche et de l'ecrevisse. Annales des sciences natmelles IV. Ser. Zoologie. 'I. I (1854), S. 237-289.

59. Lereboullet, A.: Recherches d'embryologie comparée sur le déreloppement de la truite, du lézard et du limnée. Annales des sciences naturelles IV. Ser. Zoologie. T. XVI, S. 113-196. Tafel ㄹ, 3.

60. Lereboullet, A.: Recherches d'embryologie comparée sur le déreloppement du brochet, de la perche et de l'écrevisse. Mémoires des Savants étrangers T. XVII. Paris 1862, 359 S. 6 'Tafeln.

61. Lereboullet, A.: Recherches sur les monstruosités du brochet obserrées dans l'oeuf et sur leur mode de production. Annales des sciences naturelles IV. Serie. Zoologie. T. XI, (1863), S. 177-271. Tafel 2, 3.

62. List, Joseph Heinrich: Zur Entwicklungsgeschichte der Knochenfische (Labriden). Zeitschrift für wissenschaftliche Zoologie. Bd. XLV (1887), S. 595-645. 'Tafel XXXI bis XXXIII. 9 Holzschnitte.

63. Locy, William, A.; Metameric Segmentation in the Medullary Folds and Embryonic Rim (Preliminary Communication). Anatomischer Anzeiger, Bd. IX (1894). S. 393-415. 11 Figuren.

64. Minot, Charles Sedgwick: Human Embryology. New York. William Wood and Comp. 1892.

65. Morgan, T. H.: Experimental Studies on the Teleost eggs (Preliminary Communication). Anatomischer Anzeiger VIII (1893), S. 803-814.

66. Morgan, 'T. H.: The formation of the fish embryo. Journal of Morphologr. Bd. $\mathrm{I}$ (1895), pag.419-472. Tafel XXIII bis XXV.

67. Ocllacher, Joseph: Beiträge zur Entwicklung der Knochenfische nach Beobachtungen am Bachforelleneie. Kap. III bis V. Zeitschrift für wissenschaftliche Zoologie. Bd. XXIII (1873), S. 1-115. 'Tafel I bis IV. 1 'Textllgur.

68. Oellacher, J.: 'Terata mesodidyma von Salmo Salvelinus, nebst Bemerkungen über einige andere an Fisehen beobachtete Doppelmissbildungen. Sitzungsburichte der mathem.-naturwissenschaftl. Klasse der K. Akademie der Wissenschaften. Wien. Bj.68, I. Abteilung (Jahrgang 1873). S. 299-325. 3 Tafeln.

69. Perenyi, Joseph von: Beitriige zur Fmbryologio von 'Torpedo marmorata (Torpedo Galvanii Risso). (Vorläufge Mitteilung.) Zoolog. Anz., IX. Jahrgang. (1886.) S. $433-436$.

70. Prince, Edward E.: Early Stages in the development of the Food-fishes. The Annals and Magazine of Natural History. V. Ser. Vol. XVII (1856), S. 443. 
71. Rabl, Carl: Theorio des Mesoderms. Morphologisehes Jahrbuch. Bd. XV (1889), S. 113-252. Tilfel VII bis X. 9 Holzschnitte.

72. Rabl, Carl: Vorwort zum ersten Bande der Theorie des Mesoderms. Leiprig 1896, 31 Seiten.

73. Raffaole, Fed.: Le uova gallogianti o le larve dei Teleostei nel golfo cli Napoli. Mitteilungen aus der zoologischen Station zu Neapel. Bd. VIII, S. 1-84. 'T'afel $\mathrm{I}$ bis $\mathrm{Y}$.

74. Raffaele, Fed.: Osservazioni sul foglietto epidermico superficiale degli embrioni dei Pesci ossei. Mitteilungen aus der Zoologischen Station zu Neapel. Bd. XIJ (1897), S. 169-207. Tafel VII.

75. Raber, A.: Primitivstreifen und Neurula der Wirbeltiere, in normaler und pathologischer Beziehung. Leigzig 1877. VI und 85 Seiten. 32 Textfiguren.

76. Rauber, A.: Die Theorien der excessiven Monstra. Archiv für pathologischo Anatomie u. s. w. Bd.71, S. 133-206. Tafel V-VII1, 6 Figg. Bd. 73, S. 551-594. 'Tafel XIY-XVI. Bd. 74, S. 66-125.

77. Rauber, A.: Formbildung und Formstörung in der Entwicklung von Wirbeltieren. Morphologisches Jahrbuch. Bd. V (1879), S. 661-705. 'Tafel XXXIX-XXXXI. Bd. VI (1880), S. 1-48.

78. Rieneck: Über die Schichtung des Forellenkeims. Archiv für mikroskop. Anatomie. Bd. V (1869), S. 356-366. Tafel XXI. Fig. 1 und 2.

79. Romiti: Studi di embriologia. Rivista clinica di Bologna. Dec. 1873.

S0. Rückert, J.: Über die Anlage des mittleren Keimblattes und die erste Blntbildung bei Torpedo. Anatomischer Anzeiger. II. Jahrgang (1887), S. 97-112, 154-176,

81. Rückert, J.: Verhandlungen der anatom. Gesellschaft. München 1891. S. 84.

82. Ryder, John A.: On the formation of the embryonic axis of the Teleostean Embryo by the concrescence of the rim of the blastoderm. American Naturalist. Vol. XIX (1885), S. 614, 615.

83. Schmitt, F.: Über die Gastrulation der Doppelbildungen der Forelle, mit besonderer Berüclisichtigung der Concrescenztheorie. Verhandl. deutsch zool. Ges. 1902. S. 64-83. 7 Figuren.

84. Schwarz, Daniel: Untersuchungen des Schwanzendes bei Embryonen der Wirbeltiere nach Beobachtungen an Selachiern, Knochenfischen und Vögreln vergleichend dargestellt. Zeitschrift für wissenschaftliche Zoologie. Bd. 48 (1889), S. 191-223. 'Tafel XII bis XIV und 9 Holzschnitte.

85. Sedgwick, Adam.: Notes on Elasmobranclı Development. Quarterly Journal of microscopical science. Vol XXXIII. N. S. (1892), S. 559-586. Tafel XXXV. 1 Figur.

86. Semper: Die Verwandtschaftsbeziehungen der gegliederten Tiere. III. Strobilation und Segmentation. Arbeiten aus dem Zool.-zootom. Institut in Würzburg. Bd. III (1876-1877), S. 115-404. Tafel V bis XV.

87. Stricker, S.: Untersuchungen über die Entwickelung der Bachforelle. Sitzungsberichte der mathematisch-naturwissenschaftlichen Klasse der $K$. Akademie d. Wissensch. Wien. LI. Bd.. II. Abtlg. (1865). S. 546-554, פ Tafeln.

88. Sumner, Francis Bertody: Kupffers Vesicle and its Relation to Gastrulation and Concrescence. Memoirs New York Academy of Sciences. Vol. II, Part. II (1900), S. 47-84, 34 Textfiguren.

89. Virchow, Hans: Über das Dottersyncytium und den Keimhautrand der Salmoniden. Verhandlungen der Anat. Gesellschaft in Strassburg. 1894, S. 66-77. 8 Figuren. 90. Virchow, Hans: Die Entwicklung des Gefässbezirkes auf dem SelachierDottersacke. Sitzungsbericht der Gesellschaft naturforschender Freunde zu Berlin. 1895, S. $98-103$. 
91. Tirchow, Hans: Sehwanzbildung bei Selachiern. Sitzungsbericht der Gesellschaft naturforschender Freunde zu Berlin. 1895, S 105-120.

92. Virchow, Hans: Über den Keimhautrand der Salmoniden. Verhandlungen der Anatomischen Gesellschaft in Basel. 1895, S. 201-218. 9 Figuren.

93. Tirchow, Hans: Dottersyncytium, Keimhautrand und Beziehungen der Konkreszenzlehre. Ergebnisse der Anatomie und Entwicklungsgeschichte (Merkel und Bonnet). Bd. VI (1897), S. 593-651.

94. Vogt, C.: Embryologic des Salmones. VI und 328 Seiten nebst Atlas Neuchâtel 1842.

95. Weil, Carl: Beiträge zur Kenntnis der Entwicklung ler Knochenfische. Sitzungsberichte der mathematisch-naturwissenschaftlichen Klasse der Kaiserl. Akademio der Wissenschaften. Wien. Bd. 65, Abtlg. III (Jahrgang 1872), S. 171-179. 2 Tafeln.

96. Wenckebach, K. F.: Beiträge zur Entwicklungsgeschichte der Knochenfische. Arch. mikr. Auat. Bd. XXVIII (1886), S. 225-251. 'Tafel XVI, XVII.

97. Wenckebach. K. F.: De embryonale ontwickkeling van de Ansjovis. (Engraulis encrassicholus.) Verhandelingen der Koninklijke Aliademie van Wetenschappen. 26. Teil (1888), 11 S. I Tafel.

98. Whitman: Charles Otis: The Embryology of Clepsine. Quarterly Journal of Microscopical Science. Vol. XVIII, New Scries (1878), S. 215-315. Tafel XII-XV.

99. Wilson, Henry V: The Embryology of the Sea Bass (Serranus atrarius). Bulletin of the United States Fish Commission. Vol. IX for 1889 (1891), S. 209-277. 'Tafel LXXXVIIT bis CVII. 12 Textfiguren.

100. Ziegler, Ernst, Die embryonale Entwickelung von Salmo salar. InauguralDissertation. Freiburg 188:2, 64 S. 3 T'afeln.

101. Ziegler, H. Ernst: Die Entstehung des Blutes bei Knochenfischembryonen. Archiv für mikroskopische Anatomie. Bd. XXX (1887), S. 596-665. 'Tafel XXXVI his XXXYIII. 


\section{Tafelerklärmulg.}

Eine ausführliche Beschreibung der einzelnen Abbildungen hraucht an dieser Stelle nicht gegeben zu werden, um nicht unnötiger. Weise schon einmal Gesagtes zu wiederholez. Deshalb soll bei der Aufzählıng der Figuren nur auf die Seite dis 'Textes rerwiesen werden, auf welcher sic beschrieben sind.

Die Flächenbilder sind bei durchfallendem Licht gezeichnet, die Punktierung; in welcher sie ausgeführt sind, soll den Eindruck des schwach gefärbten Präparats möglichst treu wiedergeben. Die Schnittbilder sind nach Mikrophotographien durchgepaust und unter Kontrolle des Mikroskops weiter ausgeführt worden.

Eine Anzahl von wissenswerten Daten sind, soweit es möglich war, auf den 'Tafelı selbst, neben den Figuren, angebracht worden. So steht bei den Flächenbildern ausser der Vergrösserung die Nummer des Embryos. Ferner ist die Beziehung der Schnittbilder auf das Flächenbild erleichtert durch Bezeichnung der den abgebildeten Schnitten entsprechenden Orte mittels schwarzer Linien, neben welchen die Nummer des entsprechenden Flächenbildes steht.

Die Operationsstadien sind als einfache Konturzeichnungen nach Embryonen derselben Brut, aus welcher der dazu gehörige operierte Embryo stammt, ausgeführt. Ihre V'crgrösserung ist mit wenigen Ausnahmen (Figg. 2, 38, 42) dieselbe, wie bei den operierten Embryonen.

Die Schnittbilder sind von der kaudalen Seite her gesehen. so dass die Lage ron rechts und links im Flächen- und Schnittbild dieselbe ist.

Die Vergrösserung der Flächenbilder ist durchweg 40 fach, die der Schnittbilder 100 fach, mit Ausnahme der Figg. 10-14 und 67-72, welche 150 fach ist. Die stiurere Vergrösserung ist gïnstiger, doch konnte sie nicht durchweg angewendet werden, um nicht die Zahl der Tafeln noch weiter zu vergrösserı.

\section{Tifel I.}

Fig. 1. Flächenbild von Embryo I (s. S. 46). $40: 1$.

Fig. 2. Operationsstadium zu Embryo I. Op. ist die Operationsstelle. $20: 1$. Figg. 3-8. Schnitte durch Embryo I. 100:1.

Fig. 9. Flächenbild ron Embryo II (s. S. 52). $40: 1$.

Figg. 10-14. Schnitte durch Embryo I. 150:1. 


\section{Tafel II.}

Fig. 15. Flächenbild von Embrro III (s. S. 56). 40:1.

Fig. 16. Operationsstadium zu den Embryonen II und III. Op. ist die Operationsstelle $45^{0}$ vom Knopf entfernt. $40: 1$.

Fig. 17. Operationsstadium ron Embrjo IV-VI. 40:1. Eingetragen ist nur dic Operationsstelle fïr Embryo IV: $45^{\circ}$ vom Kuopf entfernt.

Figg. 18-22. Schnitte durch Embryo III. 100:1.

Fig. 23. Flächenbild ron Embryo IV (s. S. 59). $40: 1$.

Figg. 24-26. Schnitte durch Embryo IV. 100:1.

\section{Tafel III.}

Fig. 27. Flächenbild von Embryo $V$ (s. S. 62.). 40:1. (IIierzu rehört als Operationsstadium die Fig. 17 auf Tafel III.)

Figg. 28-31. Schuitte dureh Embryo V. 100:1.

Fig. 32. Flächenbild von Embryo VI (s. S. 66). $40: 1$. (Hierzu gehört als Operationsstadium die Fig. $17^{-}$anf 'Tafel III.)

Figg. 33-37. Schnitte durch_Embrjo VI. 100:1.

Fig. 3S. Operationsstadium ron Embryo VII. 20:1. Op. ist die Operationsstelle 900 rom Knopf entferint.

Fig. 39. Flächenbild von Embryo VII (s. S. 68). $40: 1$.

Figg. 40, 4l. Sehnitte durch Fmbryo VII. 100:1.

\section{Tafel IV.}

Fig. 42. Operationsstadium von den Embryonen VIJI, IX. Op. ist die Operationsstelle $180^{\circ}$ vom Kinopf entfernt. $10: 1$.

Figr. 43 a, b. Flächenbild von Embryo VIII (s. S. 69). 40:1. Der Embrro und der Randring haben im Zusammenhang nicht auf der 'Tafel Platz; deswegen ist in Fig. 43a der Embryo, in Fig. 43 b das hintere Stück des Embryos und der Randring abgebildet.

Figg. 44-46. Schnitte durch den Randring des Embryos VIII. 100:1.

Fig. 47 a, b. Flächenbild von Embryo IX (s. S. 70). 40:1. Der Embryo und die daram sich anschliessende Naht haben im Zusammenhang nicht Platz auf del Tafel; deswegen ist in Fig. 47 a der Embryo allein, in Fig. 47 b die Naht abgebildet. Die punktierte Linie bezcichnet die Richtung der Naht.

Fïgrg. 48-0̈1. Schnitte durch das hintere Ende des Embryos IX und der Naht. 100:1.

\section{Tafel V.}

ligg. 52. Flächenbild von Embryo X (s. S. 71). 40:1. Op. ist die an der Operationsstelle entstandene Wrucherung.

Fig. 53 a. Operationsstadium zu Embryo XI. 40:1. Op. sind die Operationsstellen.

Fig. $53 \mathrm{~b}$. Flächenbild von Embryo XI (s. S. 72). 40:1.

Figg. 51, 55. Schnitte durch Embryo XI. 100:1. 
Fig. 56. Operationsstadium zu Embryo XII. 40:1.

Fig. 57. Flächenbild des Embryos XII (s. S. 73). 40:1.

Figg. 58, 59. Schnitte durch Embryo XII. 100:1.

\section{Tafel VI}

Fig. 60. Operationsstadium zu Embryo XIII. 40:1.

Fig. 61. Flächenbild vou Embryo XIII (s. S. 74). 40:1.

Figg. 62-6t. Schnitte durch Embryo XIII. 100:1.

Fig. 65. Operationsstadium zu Embryo XIV. $40: 1$.

Fig. 66. Flächenbild von Embryo XIV (s. S. 76). 40:1.

Figg. 67-72. Schnitte durch Embryo XIV. 150:1.

\section{Tafel VIY.}

Fig. 73. Operationsstadium zu Embryo XV. 40:1.

Fig. 74. Fläclenbild von Embryo XV (s. S. 80). 40:1.

Figg. 75-78. Schnitte durch Embryo XV. 100:1.

Fig. 79. Operationsstadium zu Embryo XVI. $40: 1$.

Fig. 80. Flächenbild von Embryo XVI (s. S. 81). 40:1.

Figg. 81-83. Schnitte durch Embiro XVI. 100:1.

(Fig. 81 war noch ein Durchschnitt durch Embryo XVI; er ist weggelassen worden.)

\section{Tafel VIII.}

Fig. 85. Operationsstadium zu Embryo XVII. $40: 1$.

Fig. 86. Flächenbild von Embrgo XVII (s. S. 83). 40:1.

Figg. 87-93. Schnitte durch Embryo XVII. 100:1.

Fig. 94. Operationsstadium zu Embryo XVIII. $40: 1$.

Fig. 95. Flächenbild von Embivo XVIII (s. S. 85). $40: 1$.

Figg. 96-97. Schnitte durch Embryo XVIII. 100:1.

\section{Tafel IX.}

Fig. 98. Flächenbild von Embryo XIX (s. S. 85). 40:1. (Stadinm del Operation wie Fig. 94. Taf, VIII.)

Figg. 99-101. Schnitte durch Embryo XIX. 100:1.

Fig. 102. Operationsstadium zu den Embrronen XX-XXIV. 40:1.

Fig. 103. Flächenbild von Embryo XX (s. S. 87). 40:1.

Figg. 104, 105. Schnitte durch Fmblyo XX 100:1.

Fig. 106. Flächenbild von Embryo XXI (s. S. 87). 40:1.

Iigg. 107-109. Schnitte durch Embryo XXI. 100:1. 


\section{Tafel $\mathbf{X}$.}

Fig. 110. Flächenbild von Embryo XXLI (s. S. 87). $10: 1$.

Figg. 111, 112. Schnitte durch Embryo XXII. 100:1.

Fig. 113. Flächenbild von Embrẹ XXllI (s. S. 87). 10:1.

Figr. 114. Schnitt durch Embryo XXIII. 100:1.

Fig. 115. Flächenbild von Embryo XXIV (s. S. 87), 10:1.

Figg. 116, 117. Schnitte durch Embryo XXIT. 100:1.

Fig. 118. Flïchenbild von Embryo XXVII (s. S. 95). 10:1.

Figg. 119-121. Schnitte durch Embrro XXVII. 100:1. 


$$
11
$$





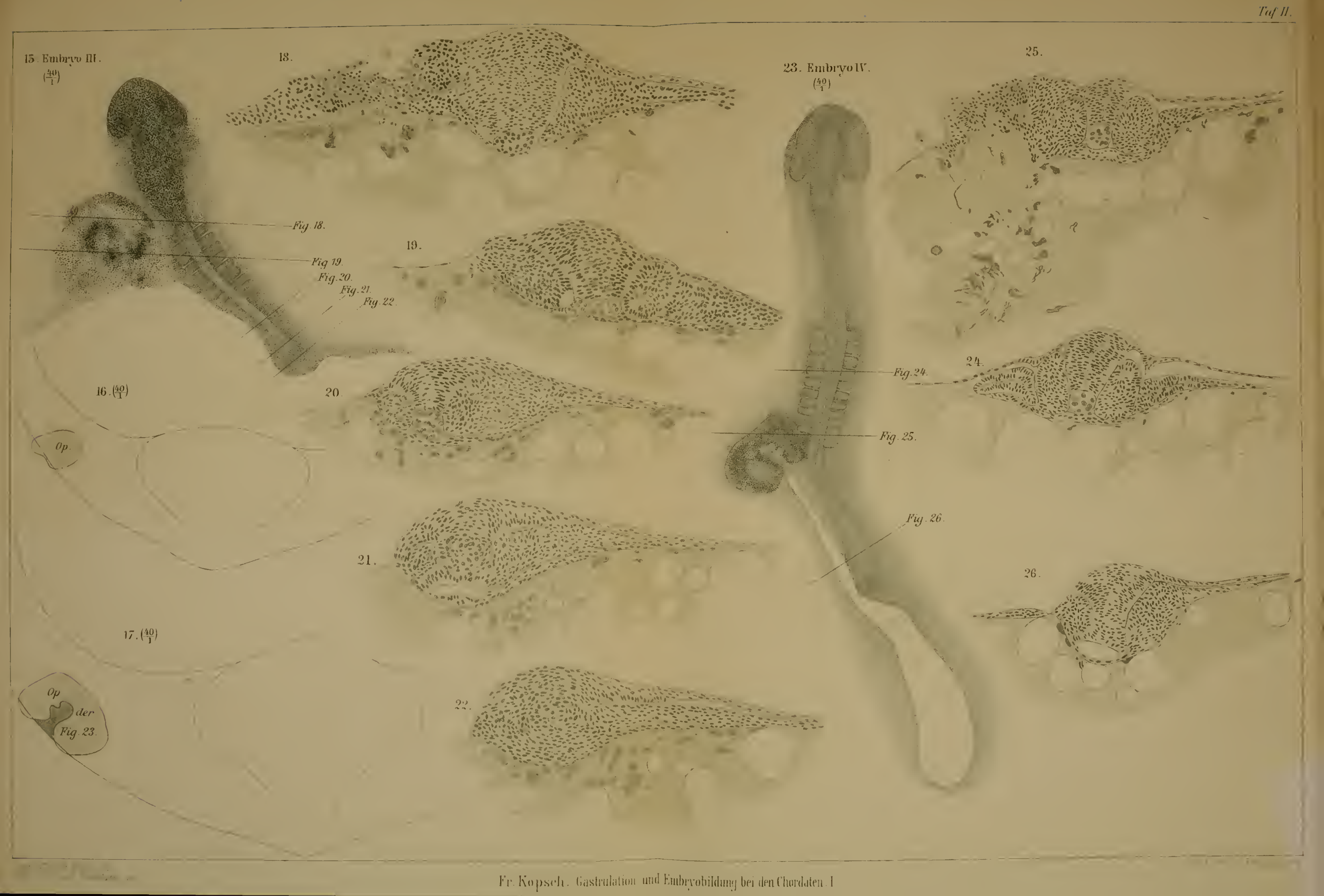





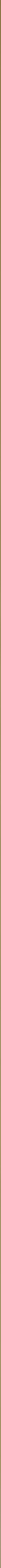

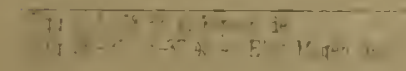





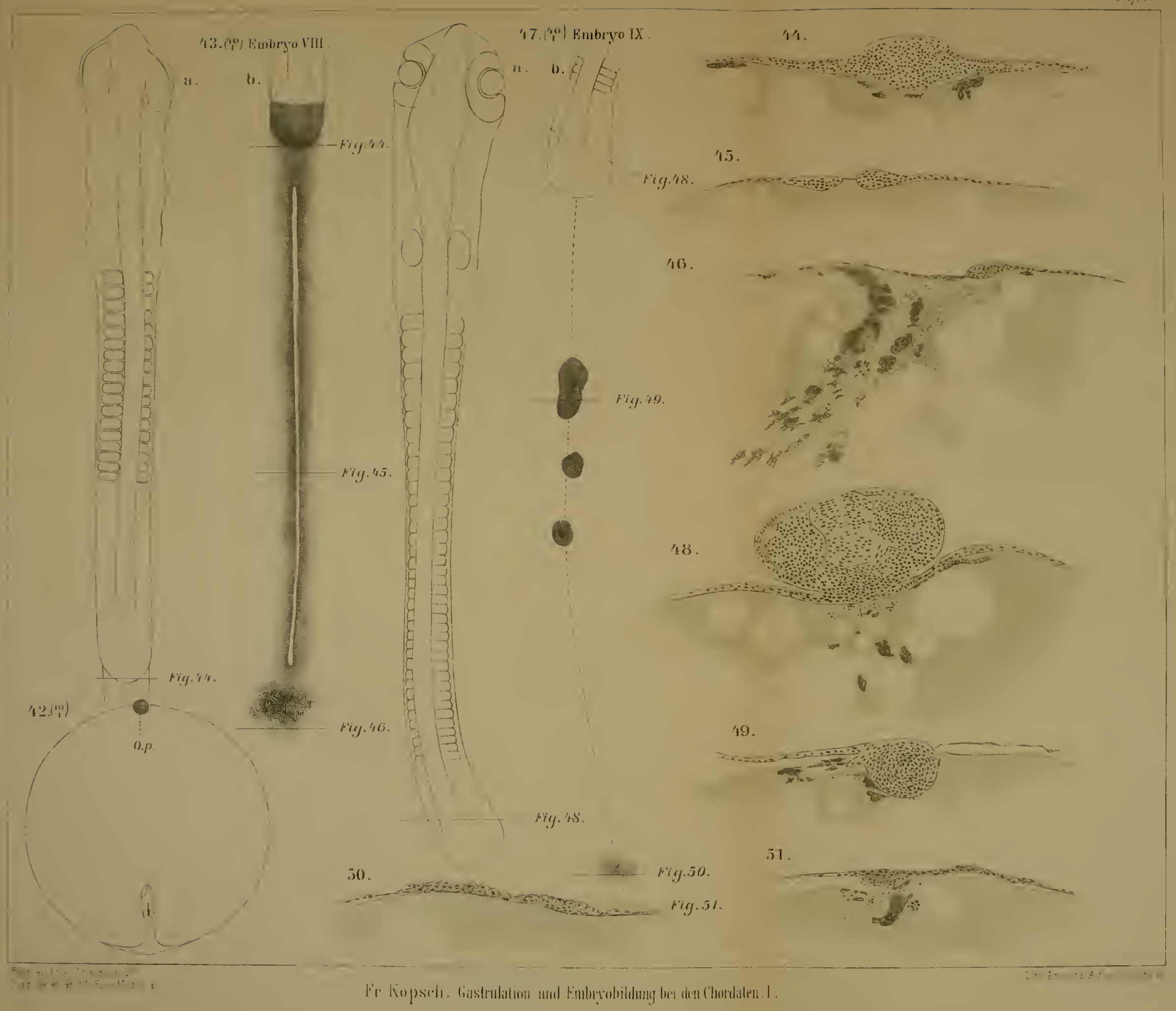





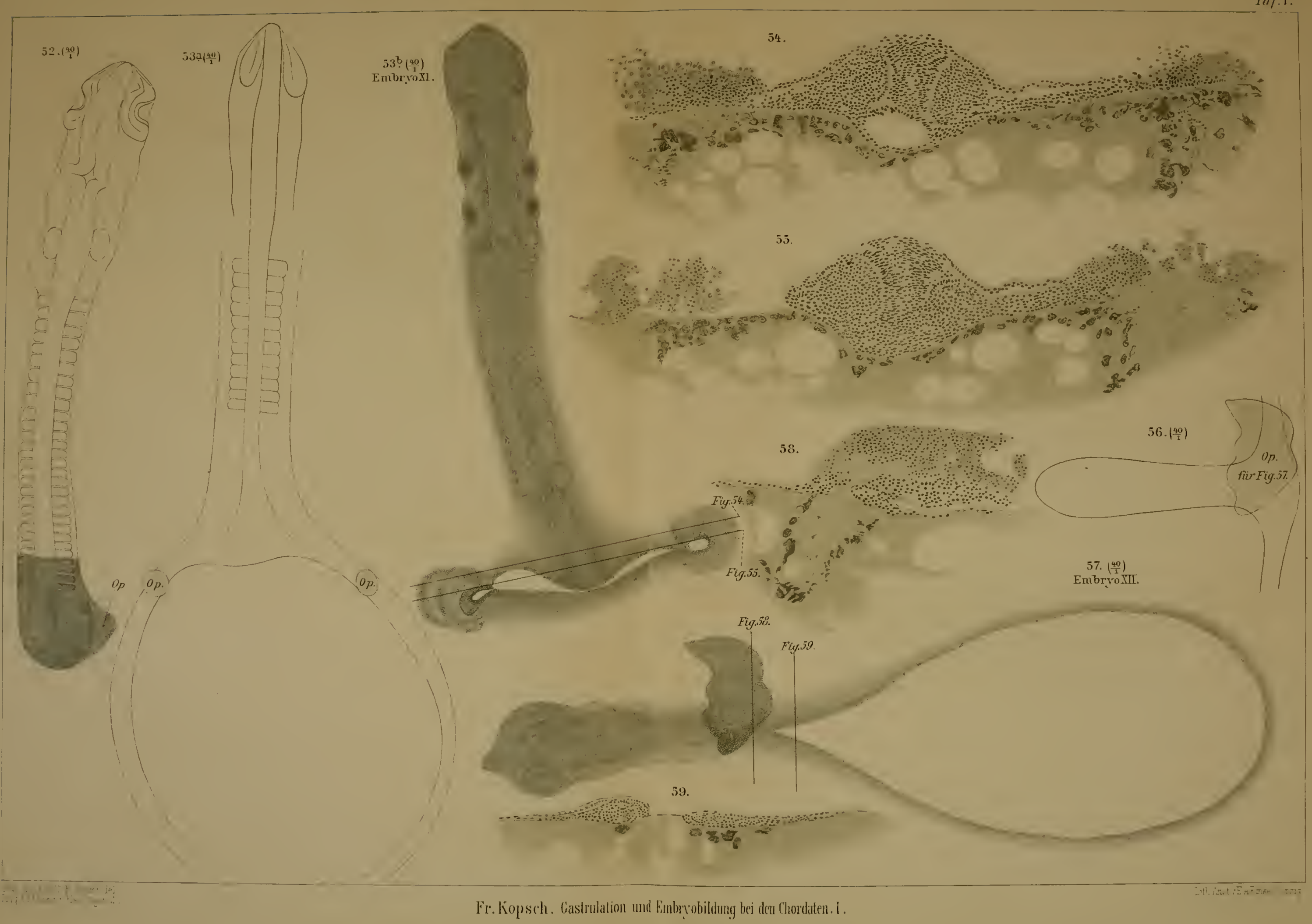






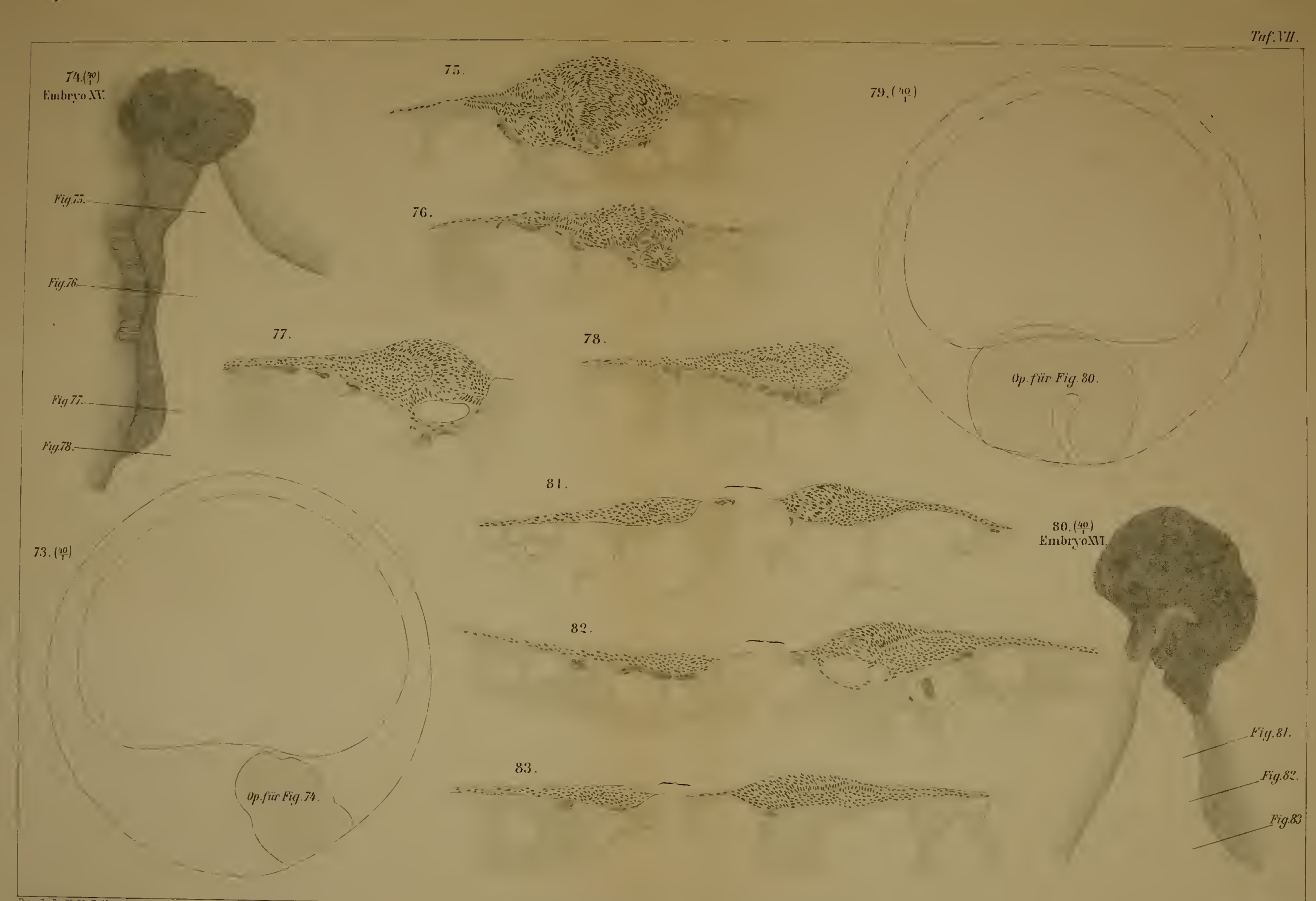





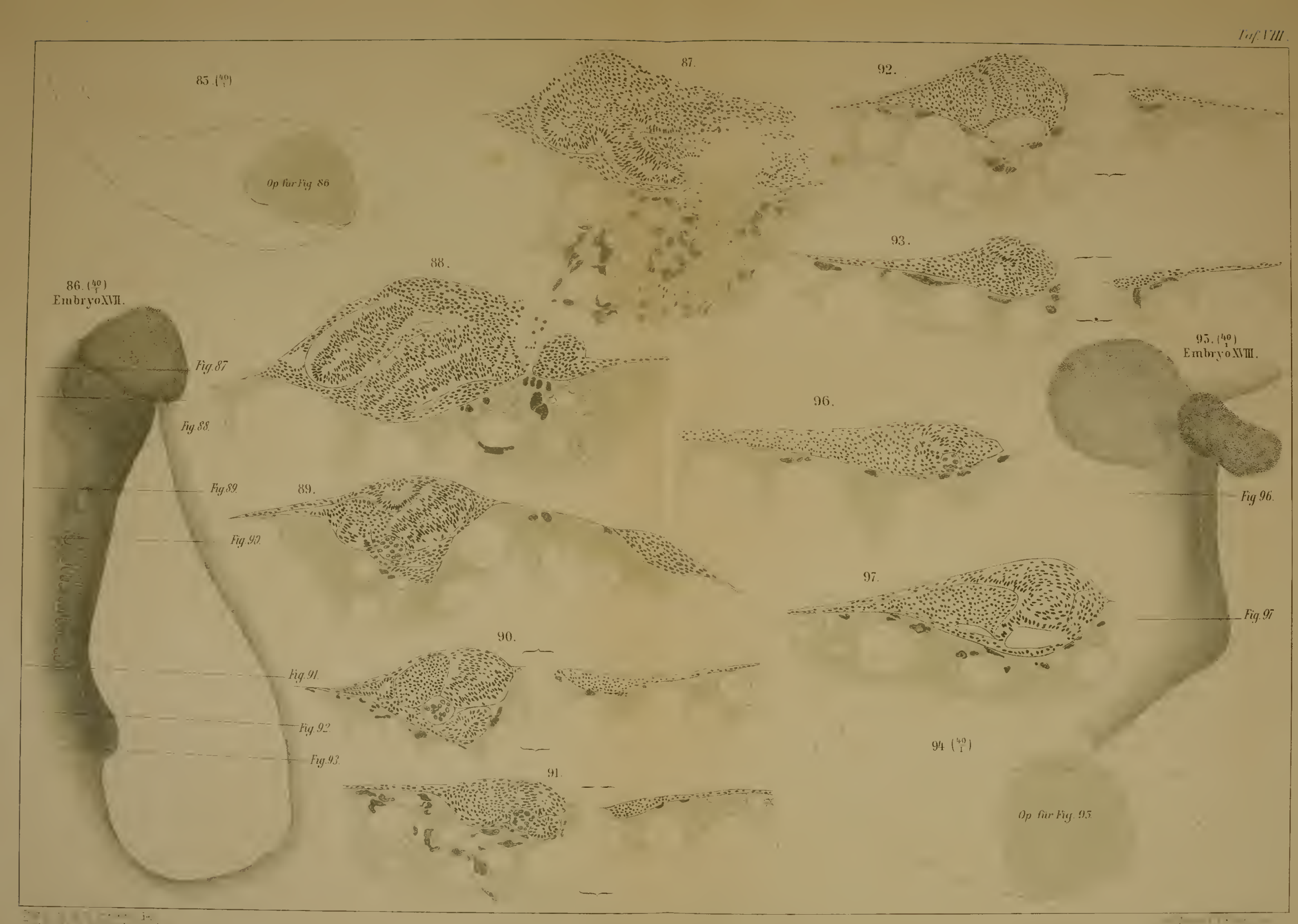





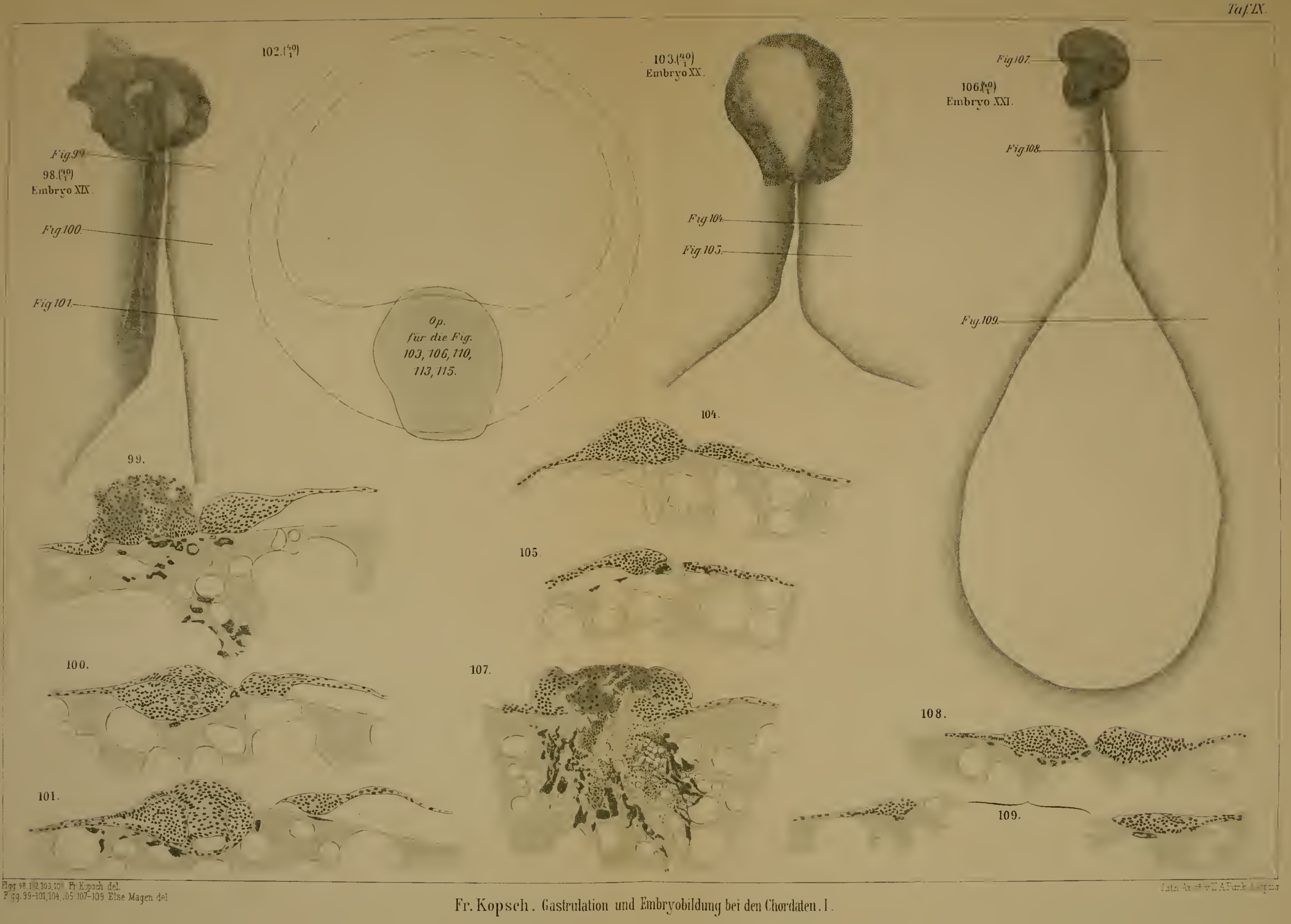





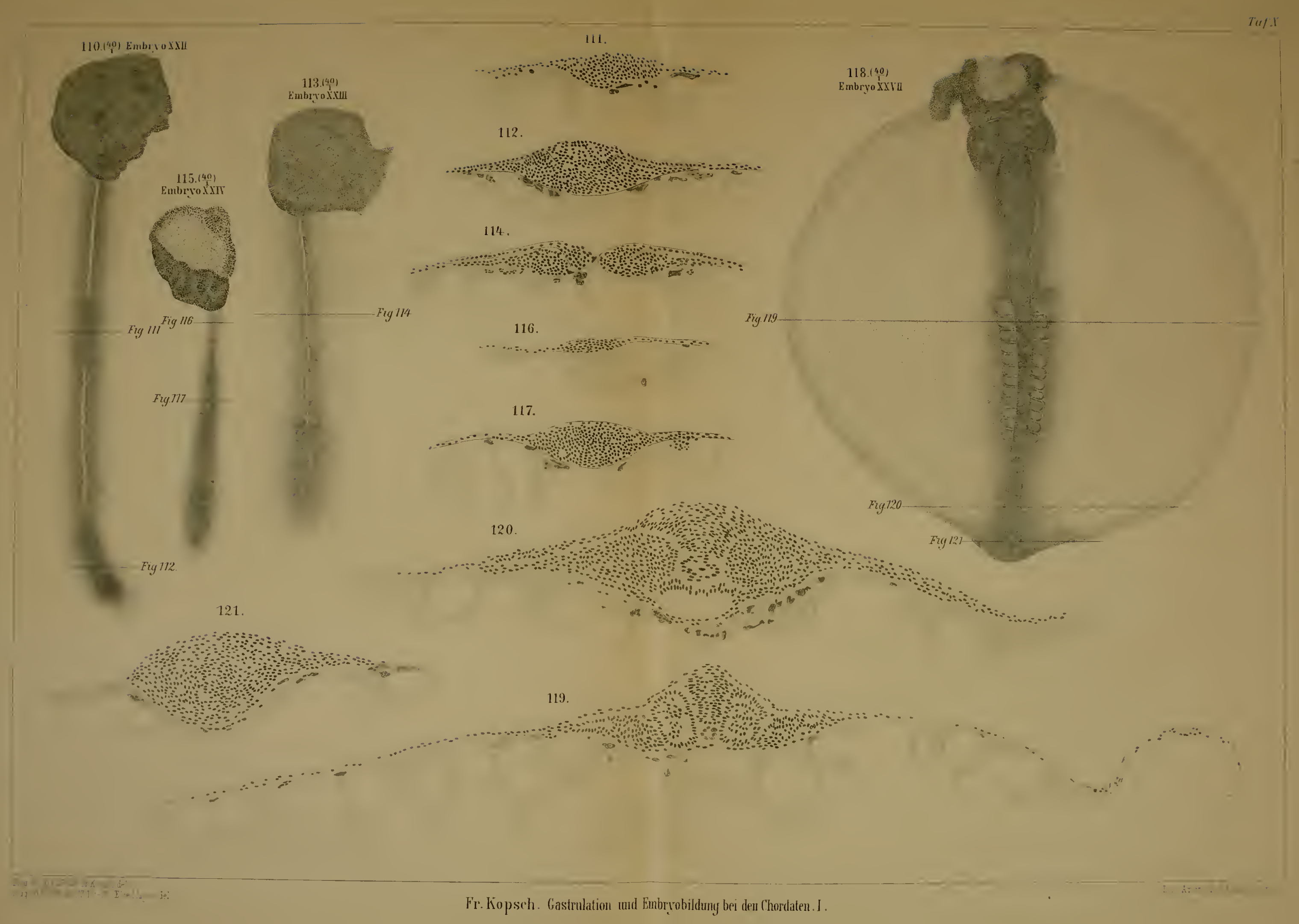




Druck von C. Grumbach in Leipzig. 



